\title{
CULTURAL CAPITAL AND STUDENT ENGAGEMENT IN EXTRACURRICULAR ACTIVITIES AT A MALAYSIAN UNIVERSITY
}

\begin{abstract}
ANITA JIMMIE
A thesis submitted to the Victoria University of Wellington in fulfilment of the requirements for the degree of Doctor of Philosophy
\end{abstract}

Victoria University of Wellington

2013 



\begin{abstract}
How students perceive education influences their extracurricular engagement at university. In this study, I investigate how Malaysian students perceive the importance of a university education and how this influences their choices about extracurricular voluntary activities. Participants included 21 university students (aged 17-25 years old) studying at a university in East Malaysia. Data collection methods included questionnaires, visual data, semi-structured individual and focus group interviews. The findings reveal that while cultural capital plays a significant role in influencing student perceptions of educational success, other forms of capital are also highly valued in the education system. Academic excellence is emphasized, with families often investing in private tuition and other skills to achieve distinction thus giving students a perceived edge over their competitors. The results also show that social capital has a significant influence on students' involvement in extracurricular activities while at university. The social capital embedded in friendships functioned as an investment strategy and participants relied on this capital to sustain their interest in community service projects or club activities. They also relied heavily on social capital resources embedded in kinship and religious institutions to obtain information and make decisions regarding future career plans and goals.
\end{abstract}





\section{ACKNOWLEDGEMENTS}

First and foremost I would like to express my gratitude and thanks to my supervisors, Dr. Joanna Kidman and Dr. Kathryn Sutherland for their advice, encouragement and unfailing support throughout this entire journey. Your advice and feedback have been incredibly helpful. Without your guidance, I would not have been able to complete this journey successfully. It has been a great privilege to be your supervisee and to work with two extremely dedicated supervisors.

A big thank you also goes out to my participants, for engaging in the research and for taking the time to attend the interviews. This study would not be possible without you! You inspire me with your constant enthusiasm and zest for helping out in the community. It has been a great honour to work with all of you.

Also, special thanks to Dr. Bronwyn Wood for her patience and kindness to a fellow colleague. Thank you, Bron, for patiently reading through my chapters, and for sacrificing your time to help me understand Bourdieu's work. The sessions were definitely less 'painful' when we had them over a delicious cup of flat white!

To my fellow PhD colleagues, Rashidah Bolhassan and Jackie Yeoh, thank you for your endless emotional support and advice in times of need. To the Manor mates, thanks so much for the mouth watering shared lunches, cultural exchanges, and the friendships you have given me. It has made our journey to 'Permanent Head Damage' (PhD) much easier to bear!

I would also like to gratefully acknowledge Victoria University for the financial support provided through the Victoria PhD Submission Scholarship.

Last but not least, this thesis is dedicated to my family- my parents, Jimmie and Julie and brother Ben. You have given me the opportunity to achieve my dreams and for that I am eternally grateful. This has been the most challenging, but also the best experience I have had and I could not have done it without your love and support. 



\section{TABLE OF CONTENTS}

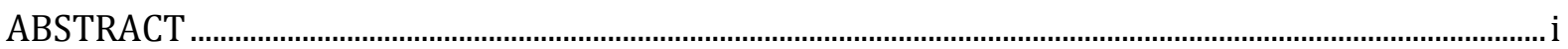

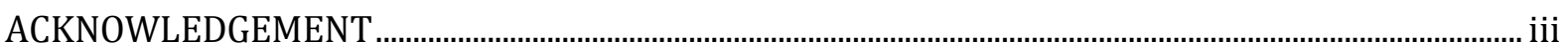

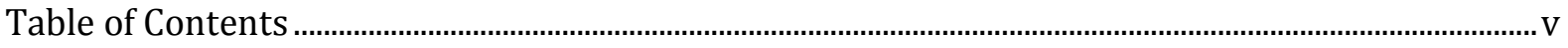

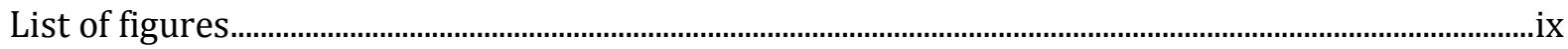

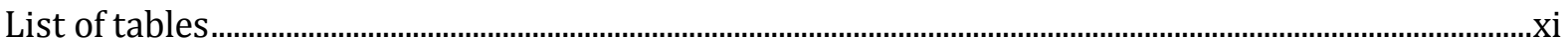

CHAPTER ONE: INTRODUCTION

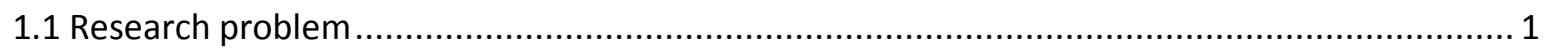

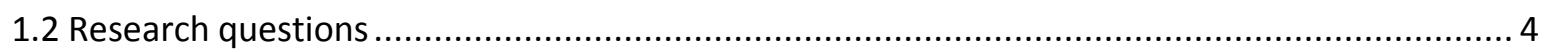

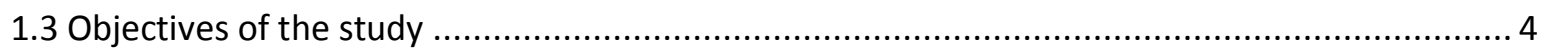

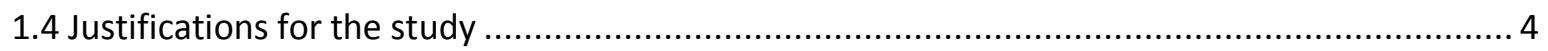

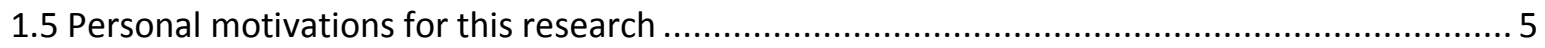

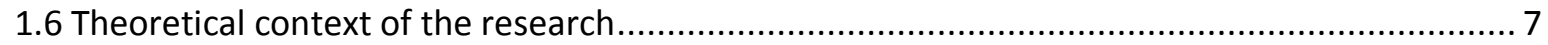

1.7 Community service in the Malaysian higher education context ........................................... 8

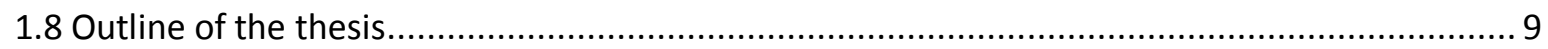

CHAPTER TWO : CONTEXTUAL BACKGROUND ……...................................................................................11

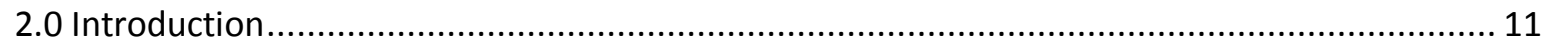

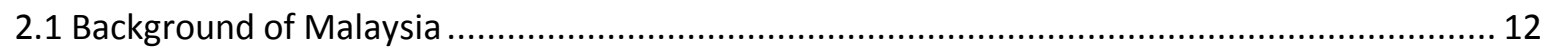

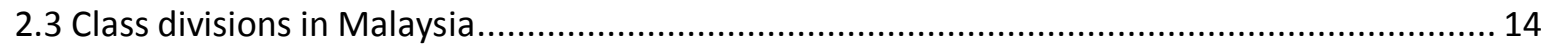

2.4 Malaysia's New Economic Policy and the emergence of the multi-ethnic middle class ........... 15

2.5 Socio-economic status and educational attainment in Malaysia........................................... 17

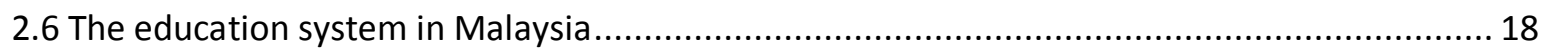

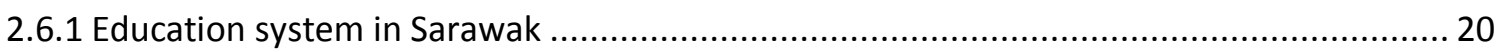

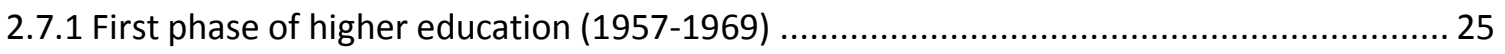

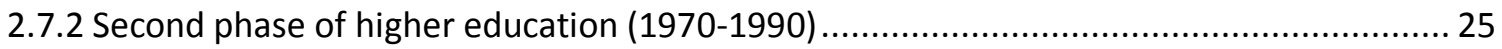

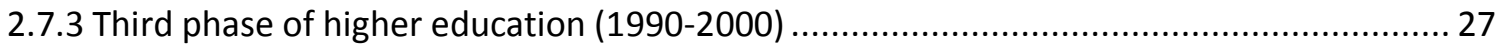

2.7.4 Fourth phase of higher education (post 2000 onwards) ............................................... 30

2.8 Civic participation and engagement in Malaysian higher education ...................................... 32 


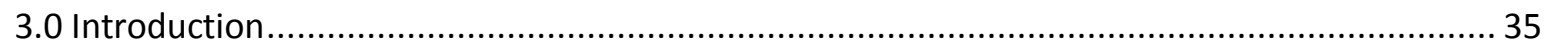

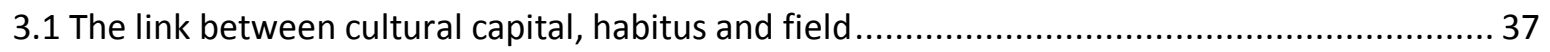

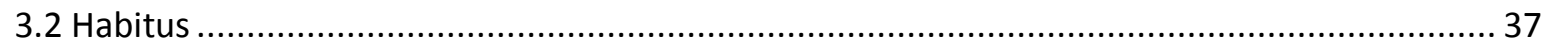

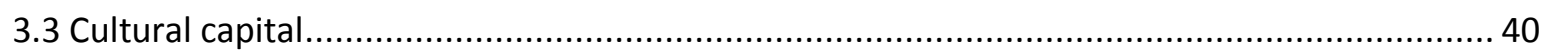

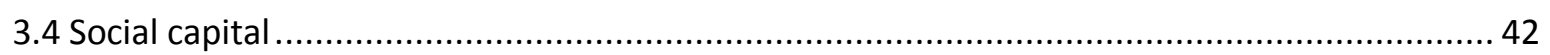

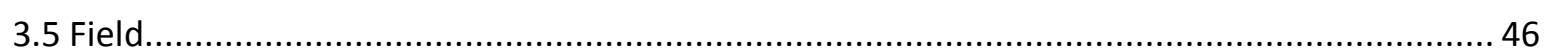

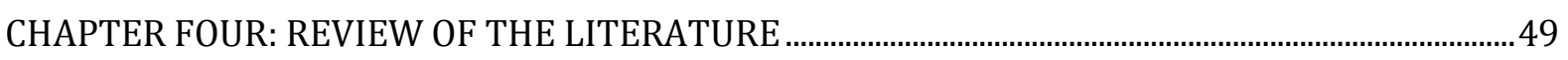

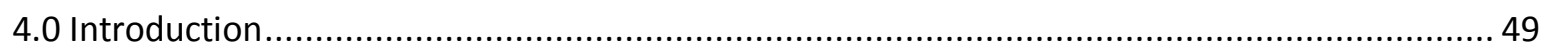

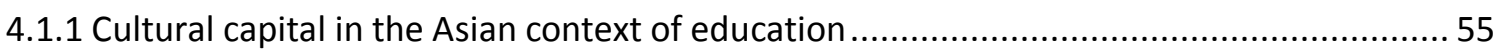

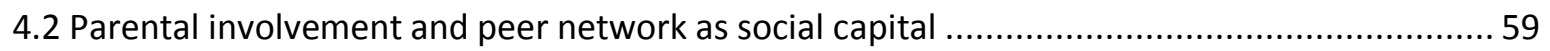

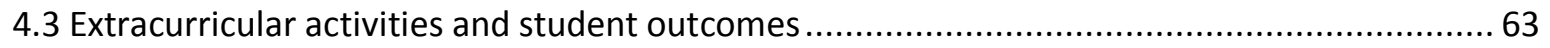

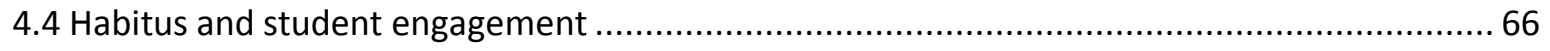

4.5 Perception and purpose of university education from Malaysian students' perspectives........ 70

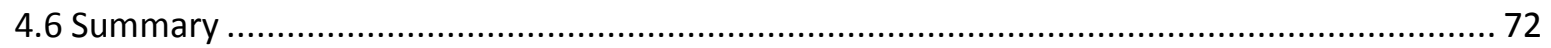

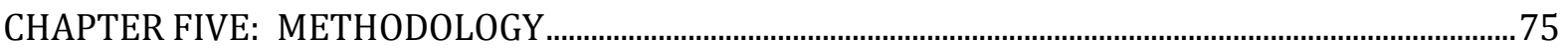

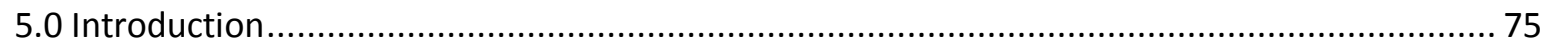

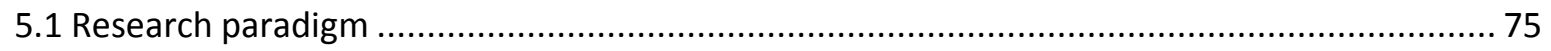

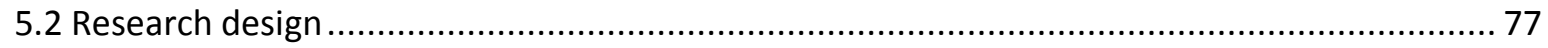

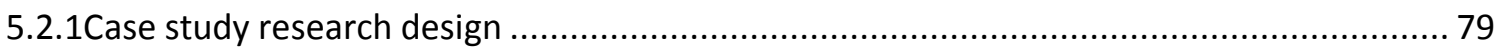

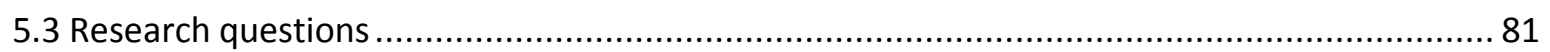

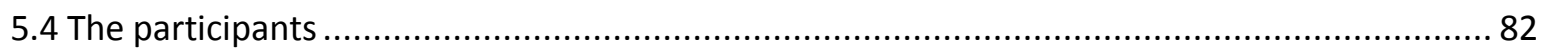

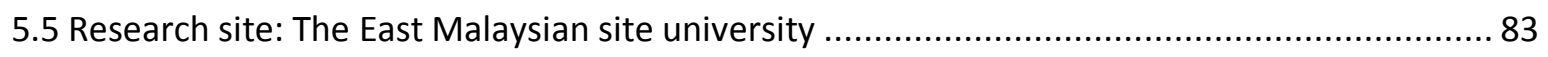

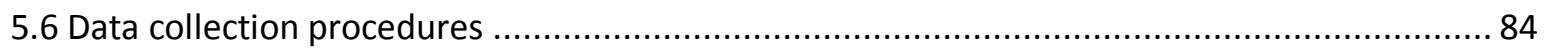

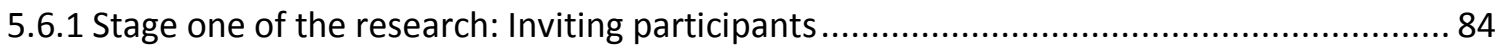

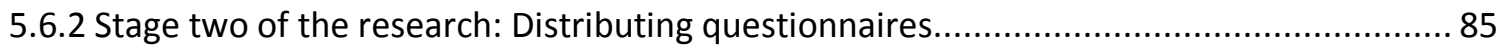

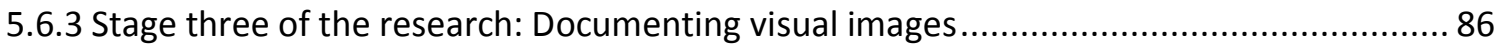

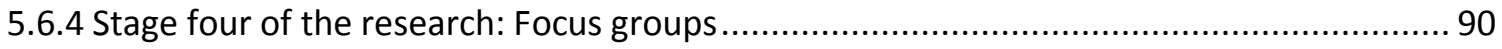

5.6.5 Stage five of the research: Follow up interviews ........................................................... 92

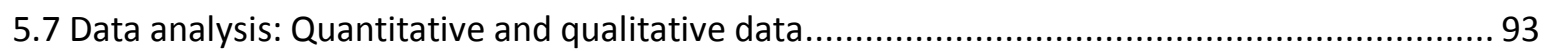

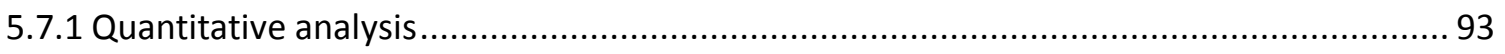

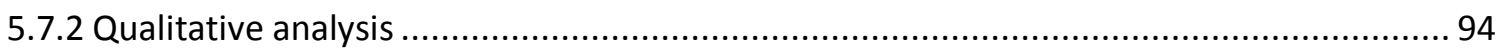




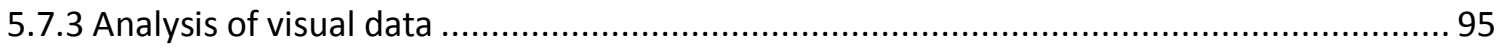

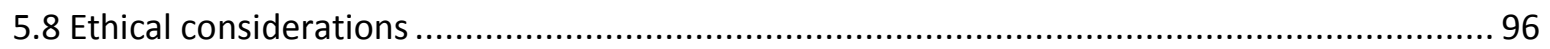

CHAPTER SIX: STUDENTS' PERCEPTIONS OF TERTIARY EDUCATION ……..........................................99

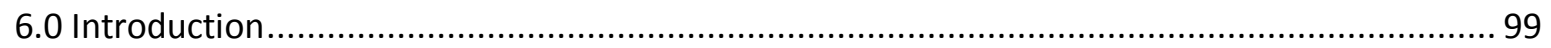

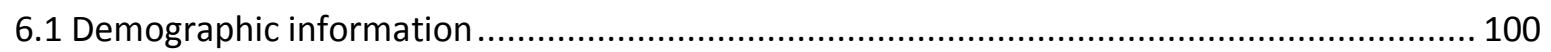

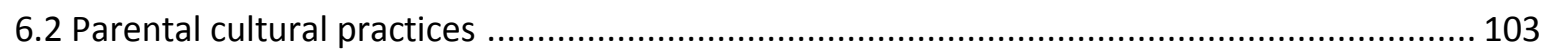

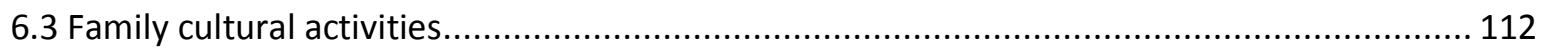

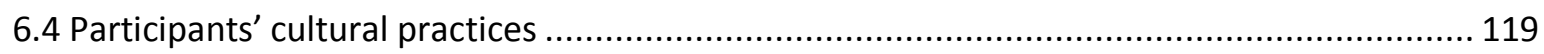

6.5 Students' perception of the purpose of university education ............................................ 133

6.5.1 University education enhances future career prospects ............................................ 134

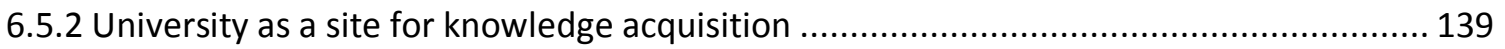

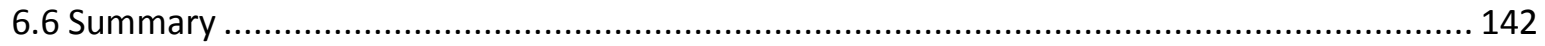

CHAPTER SEVEN: THE NATURE OF STUDENTS' ENGAGEMENT IN UNIVERSITY ACTIVITIES.145

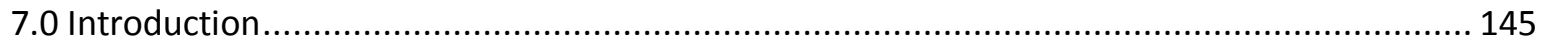

7.1.1 The role of social capital as an investment strategy .................................................... 146

7.1.2 How extracurricular activities shaped the participants' dispositions .............................. 150

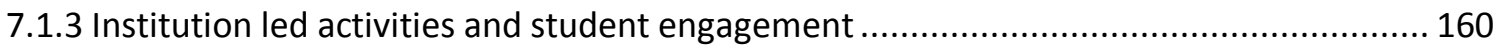

7.1.4 The role of religion and religious capital in promoting volunteerism .............................. 175

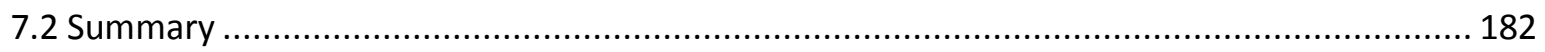

CHAPTER EIGHT: SHIFTS IN STUDENTS' PERCEPTIONS........................................................................... 185

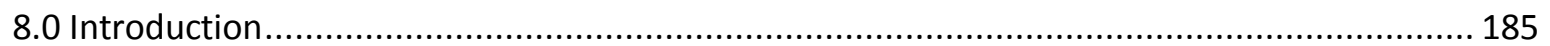

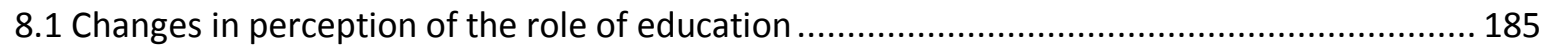

8.2 Changes in the participants' perception about volunteering................................................. 194

8.2.1Personal development and transition to a new life...................................................... 194

8.2.2 Sustainability of the project and commitment of group members ................................ 200

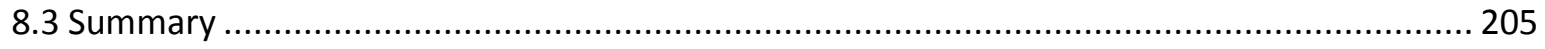

CHAPTER NINE:DISCUSSION............................................................................................................... 209

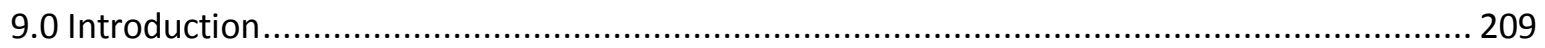

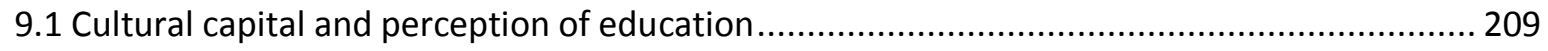

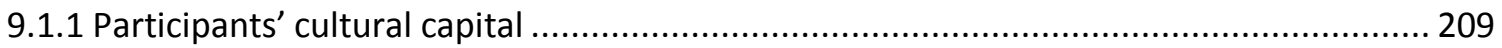

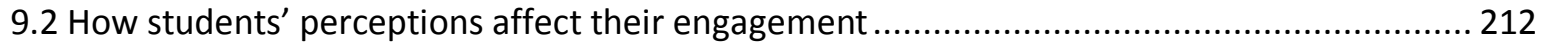

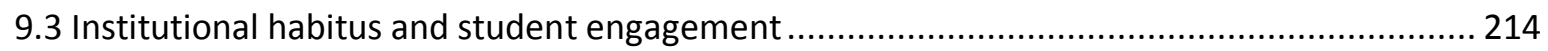


9.3.1 The university as a site for volunteerism

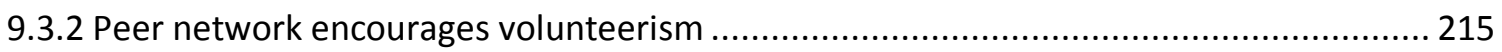

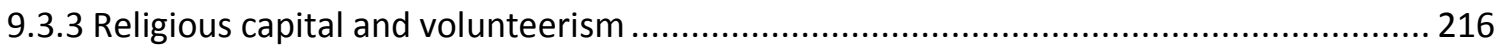

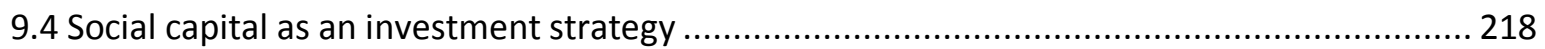

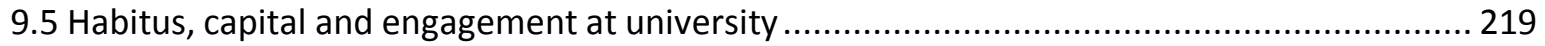

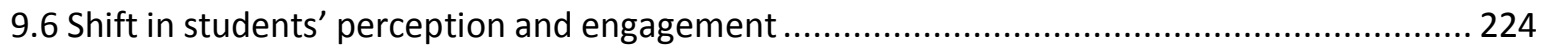

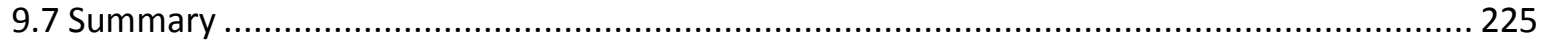

CHAPTER TEN: CONCLUSION ..................................................................................................................... 227

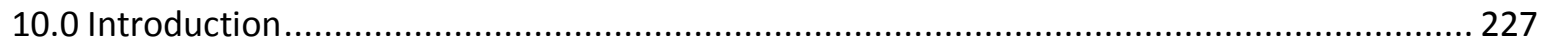

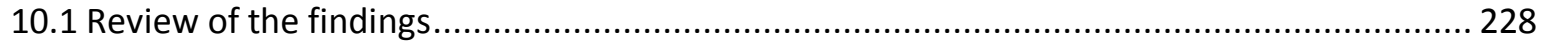

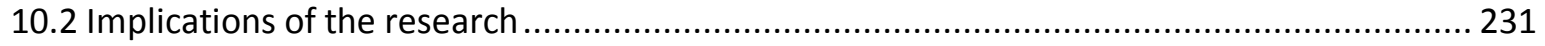

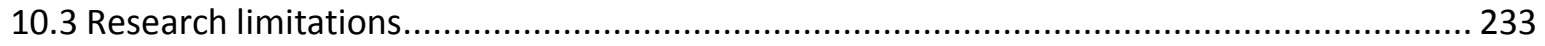

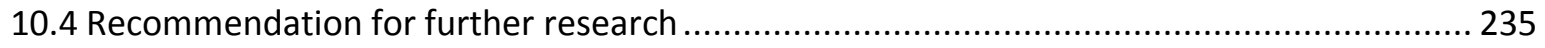

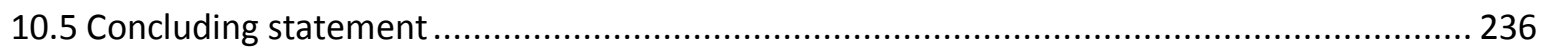

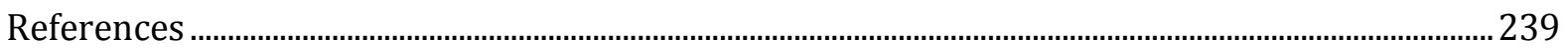

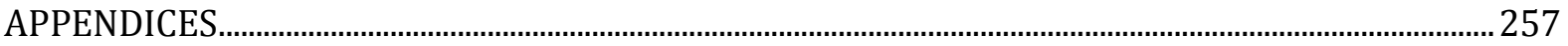

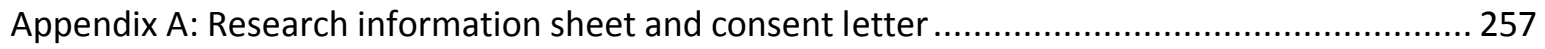

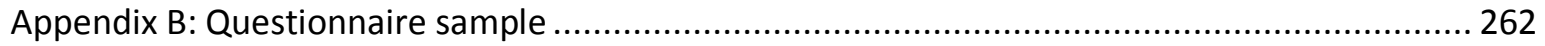

Appendix C: Structured interview questions (First year foundation students) ........................... 267

Appendix D: Structured interview questions (Third year students) ........................................... 268

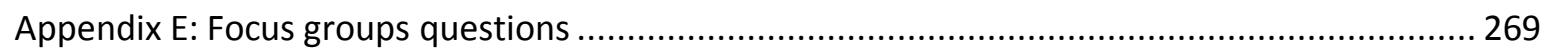

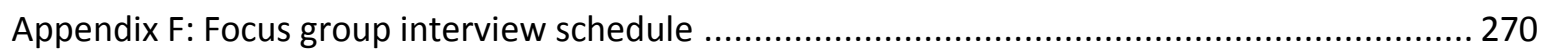

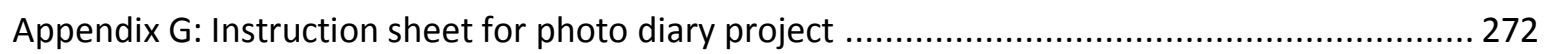




\section{LIST OF FIGURES}

Figure 1. Higher education reforms in Malaysia........................................................................................23

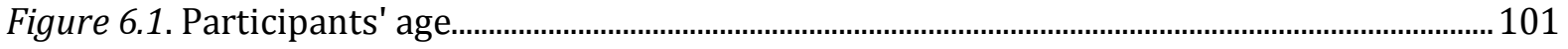

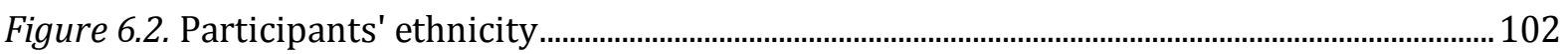

Figure 6.3. Participants' religion ......................................................................................................... 102

Figure 6.4. Accommodation arrangements while at university........................................................... 104

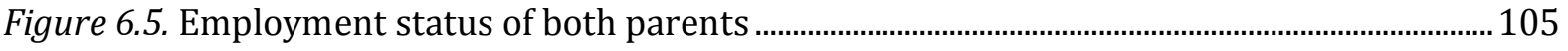

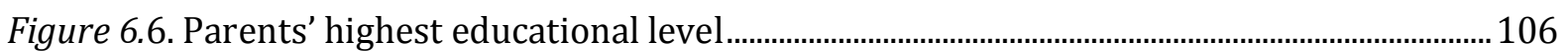

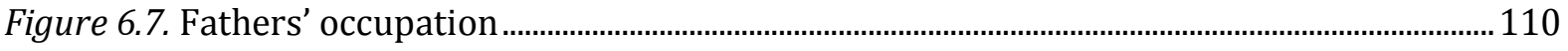

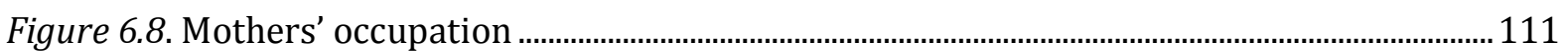

Figure 6.9. Household newspaper subscription......................................................................................... 113

Figure 6.10. Topics parents discussed at home...................................................................................... 114

Figure 6.11. Do the students' parents' engage in highbrow activities during their spare time? 115

Figure 6.12. Parents' musical preferences ................................................................................................. 116

Figure 6.13. Frequency of participation in extracurricular activities during their free time....... 121

Figure 6.14. Frequency in attending music lessons among participants ............................................122

Figure 6.15. Frequency of reading non-academic books ....................................................................123

Figure 6.16. Number of books owned by the participants...................................................................... 124

Figure 6.17. The participants' frequency in attending tuition classes.................................................126

Figure 6.18. Extra tuition classes enrolled in by subject. ............................................................................127

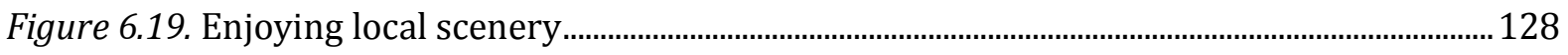

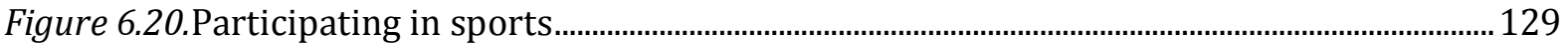


Figure 6.21. Enjoying badminton with friends 130

Figure 6.22. Friendship and building bonds.

Figure 6.23. Spending time with friends and valuing friendship. 132

Figure 6.24. Spending time with friends over a meal. 132

Figure 7.1. Creating memories and valuable experiences 148

Figure 7.2. Learning about survival training for emergencies 151

Figure 7.3. Learning new things and sharing the knowledge 152

Figure 7.4. Learning about other cultures and lifestyles 153

Figure 7.5. Learning about local indigenous culture. 154

Figure 7.6. Acquiring skills through participation in activities 156

Figure 7.7.Transferring skills to other areas of life 156

Figure 7.8. Reflecting on activities they were involved in 159

Figure 7.9. University as a site for promoting volunteerism . 162

Figure 7.10. Community service activities with the local communities 163

Figure 7.11. Leadership activities and community service. 164

Figure 7.12. Inefficient rain harvesting system. 165

Figure 7.13: Pollution affecting the main water source

Figure 7.14. Contributing back to the local community 167

Figure 7.15. Learning first aid and ambulance training 168

Figure 7.16. Environmental care and awareness promoted by the East Malaysian site university volunteers 169

Figure 7.17. Helping others as well as self 169

Figure 7.18. Learning through academic related activities. 172 
Figure 7.19. Tension arising from perceived reality 172

Figure 7.20. Religious clubs as sites for community service 176

Figure 7.21. The importance of religious clubs in building social relationships. 177

Figure 7.22. Religious institutions and cultivation of social capital. 178

Figure 7.23. Religious attendance and volunteerism... 181

Figure 8.1. Changes in perception after industrial training. 190

Figure 8.2. Orientations change to academic based extracurricular activities 191

Figure 8.3. Participating in activities related to major of study. 192

Figure 8.4 Emphasis on educational based activities. 193

\section{LIST OF TABLES}

Table 9.1 Participants' motivations and goals for volunteering 223 



\section{CHAPTER ONE}

\section{INTRODUCTION}

Unequal distribution of cultural capital benefits the children of the upper classes and disadvantages students from the lower classes. There have been many debates within the literature about the effects of cultural capital on individuals and how cultural capital rewards students from the upper classes within the education system. Drawing on the work of Pierre Bourdieu (1984), I examine the role of cultural capital and how it shapes the way students view the purpose of education. I then explore how students' perceptions of education subsequently influence their engagement in extracurricular activities at university.

In this chapter I provide a brief summary of the background of the research and I state the research problems, the research questions and the aims of conducting the research. I also explain my personal motivations for conducting the research, outline the thesis structure, and provide a brief summary at the end of the chapter.

\subsection{Research problem}

Studying and understanding university students' motivations and engagement has been a subject of interest for many educators. They seek to understand what drives university students to engage in learning and how these students derive benefit from their learning experiences. With regard to this, studies about the impact of university on students have contributed to a better understanding of what students expect from their university education and how they respond to the university setting (Sullivan, 2001; Reay, David \& Ball, 2005; Moss, 2005). To gain a better understanding of students' engagement in university, it would be beneficial to identify the value students place on education and how their perceptions of the purpose of education influence the type of learning activities they engage in while at university. However, before we can 
identify what drives engagement, we need to understand how societal and familial background influences individual perception.

According to Stanley Aronowitz (2000) with the demands of development and globalisation, students' views of education have undergone a paradigm shift. Consequently, intellectual pursuits are no longer sought for the sake of knowledge alone, but rather for primarily pragmatic reasons. As a result, students develop "instrumental orientations" (Aronowitz, 2000, p. 139) towards education. Thus, students tend to see university as a site for the acquisition of skills that can pave a way for future career or training in a field of their choosing instead of sites for intellectual development. As developing countries build their economies and cope with expanding population growth, this shift in perception has become more pronounced among university students.

Malaysian students have arguably experienced such a change in perception as the government revamped its education system over a 40 -year period. In fact the Malaysian government views university education as a catalyst for achieving the goal of becoming a developed nation (Lee, 1999; Sirat, 2010). The government has therefore steered its higher education policy in a direction that is seen as serving the country's national economic interests (Sirat, 2010). Like many other developing countries, Malaysia has sought to cater to the needs of the country by placing an increased emphasis on science, technology and commerce-based subjects in schools and universities, whilst paying less attention to arts-based subjects. Furthermore, scholarships and higher education opportunities are allocated for science students to a greater extent than those awarded to commerce or arts students.

The demand for skilled workers in the fields of education, science, engineering, medicine, accounting, statistics and other technical professions has increased in the last three decades, thus creating a need for an improved higher education system to meet the demands of these sectors (Lee, 2004). Tertiary education is often perceived by the state as an avenue for social mobility and economic growth 
(Lee, 2004). This emphasis on the importance of higher education eventually shaped the perception that having a university education would lead to upward social mobility (Lee, 1999). As a result, some students might see little importance in participating in non-academic related activities which are deemed unnecessary or not important in achieving future career aspirations (Kok \& Tan, 2011). Lim and Wai (2008) reiterate how the education scene is evolving due to the capitalist indoctrination of "manufacturing employees for contemporary labour usage" (p. 33). They equate the Malaysian education system to a manufacturing factory which threatens to ruin the state of the university today. Lim and Wai also argue the current Malaysian education system has experienced a reform from "argumentative culture" to the "indoctrination culture" (p. 33). The quest for lifelong learning and intellectual development is now threatened by the need to fill the inadequate workforce with skilled workers and continued economic regeneration and growth. This need for economic stability has caused disinterest among students in higher education institutions from taking up humanities courses which are seen as non-pragmatic and non-market driven (Lim \& Wai, 2008).

This instrumentalist approach to education portrays the image that education serves an economic purpose. Although research has been done on Malaysian students' perceptions of the role of university, there has been no research that looks at cultural capital and its relationship with engagement in university activities in the Malaysian context. A study on Malaysian students' perception of the purpose of education and its relationship with engagement in university activities can therefore provide insight into the literature on student engagement in the higher education setting. In addition, it also contributes to what we know about student engagement and the type of activities that can add to positive gains in learning in higher education contexts. 


\subsection{Research questions}

1. How does students' cultural capital shape students' perception of university education in Malaysia?

2. How do these perceptions influence the nature of their engagement in extracurricular activities at university?

3. In what ways do these perceptions of the role of education and extracurricular activities change after their studies?

\subsection{Objectives of the study}

The objectives of this study are:

1. To explore how cultural capital influences Malaysian students' perceptions of the purpose of university education.

2. To identify how students' perceptions of the purpose of a university education influence their choice of extracurricular activities they engage in while at university.

3. To investigate how students' understanding of the purpose of and engagement with extracurricular activities changes in the course of their study.

\subsection{Justifications for the study}

This study will contribute to the literature on the impact of the university on students' learning experience in four ways. First, it will extend our knowledge about how cultural capital shapes students' perceptions of the purpose of university education, particularly how this influences the way they view the role of education in their own lives.

Second, it provides a qualitative view of how students' perceptions of the purpose of education are linked to their engagement in university life, particularly in terms of civic participation and voluntary activities. Although there has been research that investigates Malaysian students' perceptions of university education, this research 
extends knowledge in this area by examining the relationship between students' perceptions and the extracurricular activities they choose to participate in while at university. This study on Malaysian students' perceptions about higher education serves to validate the findings that will be discussed in Chapter Six.

Third, this study also provides information that will help university administrators and faculty to increase the civic participation opportunities available to the students which can have a positive impact on educational outcomes. Fourth, much of the research done in the area of social class and cultural capital has focused attention predominantly on students' educational outcomes while very little attention is paid to the process through which these outcomes are formed or practiced by the students. This study will address the gap in the literature by exploring how students' practices are informed by their cultural capital and their perceptions about the role of education in determining their educational trajectories.

\subsection{Personal motivations for this research}

This research is driven by my interest and passion in understanding student engagement in university. I began working as a lecturer at the East Malaysian site university in 2004. Since I began my career as an educator, I was always interested in finding out how students perceive education and the role it plays in their lives. I wanted to investigate how this perception influences their engagement in university activities and how it affects them during their university years. I also wondered if it would be possible to tap into this area to see if there was a way to sustain this interest and motivation so their learning experience would be beneficial for them.

My learning curve began when I was asked to give a talk to a group of students for an inaugural camp held in the university. The focus of the camp was to provide motivation to students who were sitting their national exams the following year. During this camp I had the opportunity to work with a group of volunteers comprised of students from the university. I was surprised and impressed with the level of passion and commitment this group of students showed during the three days of the camp. 
There was a lot of positive energy, a high level of camaraderie and unwavering support between team members and camp members alike. This was an unexpected, but very pleasant experience, which led me to see that students could enjoy themselves and still learn without being confined to a classroom environment. In fact, they seemed to be having more fun and displayed higher levels of engagement compared with their participation in class activities.

As I started getting more involved in outreach programmes, I began working more closely with a group of extremely dedicated students whose drive and passion in community work amazed me. This group of dedicated youngsters called themselves the East Malaysian university volunteers. At the time, they were an independent student club run by individuals who were heavily involved in community service and university-related activities. They were the backbone of all the orientation sessions, and almost all the activities on campus that required student volunteers. This was a group of students who were extremely energetic, enthusiastic and positive, and working with these young people was a privilege.

From this encounter, I realised that a small minority of students could make a change in the community, if they were given an outlet and a platform to focus their energy and their enthusiasm for voluntary work. It also gave me a renewed interest in discovering why a portion of the students were heavily dedicated to the concept of volunteerism as opposed to their peers. It was then that my interest in studying students' participation in community service and civic engagement began to take shape.

At the same time I was interested in exploring why students enter tertiary institutions, what motivates them to learn and how to maintain this quest for knowledge inside and outside of the classroom. This led to a time of academic 'soul searching' where I was constantly trying to discover what kind of teacher I was and how I could best meet my students' needs in an environment where there appeared to be very little drive and motivation for some to succeed. 
Thus, I felt it would be valuable to try to understand how familial and societal influences help to form individual perceptions and the impact these factors have on an individual's decision to participate in university activities. In the context of my study I consider students' participation in clubs, and also student volunteerism as part of the university extracurricular activities. By looking at student engagement through the lens of cultural capital, and by considering the role of extracurricular activities as an aspect to examine this engagement, this study offers a unique view of student experience in the university beyond the traditional classroom environment. It also allows us a view of how socioeconomic status impacts educational achievement in higher education.

\subsection{Theoretical context of the research}

This thesis draws upon Bourdieu's theory of social reproduction, which has been a subject of much research on education, family and social class (Bourdieu, 1977). Bourdieu argues that parents endow their children with cultural capital which is the knowledge, disposition and the 'know how' essential for academic success and the lack of cultural capital can create inequalities in educational achievement. Bourdieu's concept of habitus illustrates how individual dispositions and perceptions are formed, as a result of the individual's interaction with the people around them and the exposure to their family's beliefs, values and practices (their cultural capital). I also employ Bourdieu's concept of field, to explain how individual action is structured and reproduced in order to maintain their position within the society. In the context of this research, I propose that students' perceptions influence how they view the nature of education and the purpose of a university education. I also argue that the student's perception then affects the choice of activities they engage in while at university.

By examining the role of cultural capital, and habitus, I investigate the relationship between students' cultural capital and their perception of the purpose of university education. Then I derive a link between these perceptions and the activities they choose to engage with while at university. I propose the link between cultural capital, habitus and student engagement in the discussion chapter (Chapter Nine). In Chapter Nine I present a table (refer to Table 1) to explain how students' habitus 
influences their engagement in voluntary work. We can observe how participation in extracurricular activities enhances their cultural and social capital, thus cementing their position in the field.

\subsection{Community service in the Malaysian higher education context}

Community service and voluntary work in Malaysian universities is not a new initiative. According to Shahabudin (2007), "Service to the community is part of the social contract whereby the university has a moral obligation to be accountable and socially responsible in return for the public funding spent on its up keeping" (p. 2). Many universities throughout Malaysia mirror this idea by having community-related programmes that run throughout the academic year. Many educators believe that working with the community offers an environment rich with learning opportunities that allow students to acquire interpersonal, communication, organisational and problem-solving skills. In essence, community services make learning more interesting by going beyond the traditional classroom and allowing students to interact with people from the local community. The idea that lies behind the community service initiative is the notion that community service produces responsible, civic-minded individuals who contribute both to society and their local community.

In the past, the initiative of getting students involved in community service was dependent on the university's administration or student-run clubs that veered towards more community-related programmes. Each university or higher education institution was responsible for determining the type and frequency of activities they ran during the academic year and the success of the activities depended on the number of recruits they were able to bring in. This however, began to change when the Ministry of Education caught on to the benefits the community could reap from such an exchange and began to take steps to address this interaction (refer to Chapter Two, section 2.9). 


\subsection{Outline of the thesis}

The following is a brief outline of the chapters in this thesis. In Chapter Two I provide contextual information about the Malaysian education system. This chapter sets the scene for understanding the growth of the education system in Malaysia.

In Chapter Three, I discuss Bourdieu's concept of cultural capital, habitus and field (Bourdieu, 1977, 1990). Bourdieu's theoretical framework will be outlined and related to the literature on student attitudes and perceptions. The theories give some insights into their educational decision-making processes and their perceptions about university education and their own learning experiences.

In Chapter Four of the thesis, I draw upon the literature on cultural capital in both Western and Asian contexts of education, and discuss how cultural capital is defined in these studies. I also explain why I consider parental involvement and peer network as measures of social capital in my study. In this chapter, I also focus on how extracurricular activities impact on students' experience at university and I explore studies that examine how students' habitus influences their engagement at university. Finally, I discuss students' perceptions of education from Malaysian students' perspectives.

Chapter Five provides an outline of my data collection methods. Firstly, I discuss the questionnaire that aimed to identify aspects of the participating students' cultural capital. In this chapter, I also explain how I devised a visual methods approach to data collection. I provide an in-depth explanation about the use of focus group interviews and follow-up interviews. The methods and approaches to data analysis are also explained in this chapter. In addition, the limitations and ethical considerations of the research are discussed.

In Chapters Six, Seven and Eight I report on and analyse the findings from the research. In Chapter Six I discuss how the participating students' cultural capital 
influences their perceptions about the purpose of university education. I also give a more detailed analysis of the relationship between familial and societal roles in shaping their perceptions. In Chapter Seven I examine how students' cultural capital subsequently informs the type of extracurricular activities they decide to engage in at university. I also examine how they utilise their cultural capital to navigate their way around the education system. Finally, in Chapter Eight, I explore how the participants' perceptions changed after they had been through the experience of connecting with their peers and the community. I draw on students' personal narratives to illustrate how their perceptions changed over time.

In Chapter Nine, I discuss the themes and patterns that emerged from the findings. In this chapter I examine how students exploit their cultural capital to develop strategies and practices that shape their future career trajectories. I propose that the students are aware of the types of practices that support their future career aspirations. One of the strategies they employ to stand out over other candidates is to participate in extracurricular activities. These decisions are informed by parental and societal expectations which are reinforced through 'institutional habituses' from an early stage. I conclude the thesis in Chapter Ten by reviewing the findings from this research and offering suggestions for further research in this area and stating the limitations of my study. 


\section{CHAPTER TWO}

\section{CONTEXTUAL BACKGROUND}

\subsection{Introduction}

Economic forces have shaped tertiary education policies in Malaysia from the time of British colonial rule to the present. These policies have affected the way that families and students view the value of education. In recent years, the value that middle-class Malaysian families place on tertiary education has increased exponentially, making the Malaysian education system extremely competitive. In addition, a racial quota has been implemented in the Malaysian national education system and this has created educational and social inequalities. These inequalities have had a significant impact on the growth of private higher education in the country. I discuss these matters in this chapter and link them to an accelerated expansion of international private higher education institutions in the country. Moreover, government policies over time have perpetuated unequal educational opportunities and this has created a huge market for overseas education. Consequently, this has a bearing on the decisionmaking processes of the middle-class families in Malaysia with regard to providing for their children's education.

In this chapter I give a brief history of the growth of the Malaysian higher education system. I also provide some background information for this study and discuss how the education system in Malaysia has been reshaped by the country's changing economic priorities. This has resulted in many changes in educational policy throughout the years.

First I provide a brief historical background of Malaysia prior to independence. The purpose of this discussion is to establish a context for understanding the expansion of higher education in Malaysia. Next, I present an overview of the class divisions and the variations that exist between different social classes that have emerged as a result of the economic policies that were introduced by the government in 1971. Then I explain how socio-economic status relates to educational attainment among the different ethnic groups in Malaysia. The subsequent 
sections then deal with the structure of the education system in Malaysia. I detail the expansion and growth of higher education and how this growth has led to the privatisation of higher education in order to meet the nation's economic priorities. The final section examines the role of civic participation and engagement in the Malaysian higher education system and the role played by the Ministry of Higher Education in promoting active citizenship in tertiary institutions.

\subsection{Background of Malaysia}

Malaysia is a country located in Southeast Asia, which is comprised of the Malay Peninsular, and the states of Sabah and Sarawak in the northern part of the island of Borneo. The official religion in Malaysia is Islam, and the official language is Bahasa Melayu. Bahasa Melayu is also the medium of instruction in all national schools, except in Chinese or Tamil vernacular schools. Malaysia's population stood at about 28.3 million people in 2010 (Department of Statistics, 2010). Officially, people are categorized as bumiputera or indigenous people, and nonbumiputera or non-indigenous people. The Malays, who make up the bulk of the aboriginal groups in Peninsular Malaysia, are classified as bumiputeras. In addition to this, native peoples in the states of Sabah and Sarawak are also considered bumiputera, but are known as bumiputera Sarawak or bumiputera Sabah. The bumiputeras from Peninsular Malaysia, Sabah and Sarawak account for 67.4 percent of the population while the remaining 32.6 percent of the population consists of Chinese (24.6 percent), Indians (7.3 percent) and others (0.7 percent).

By constitutional definition, all Malays are Muslims; the Chinese are predominantly Buddhists or Taoists; and the Indians are mostly Hindus, with smaller numbers of Muslim and Sikhs. The ethnic groups from Sabah and Sarawak are primarily Christians (World Directory of Minorities and Indigenous Peoples, 2005). There are about 27 different ethnic groups in Sarawak (Chang, 1999), while Sabah has approximately 12 different ethnic groups that make up the majority of the population. More than half of Sarawak's residents and about two-thirds of Sabah's are from indigenous groups. 


\subsection{Historical background}

The British colonial era: Divide and rule

Malaysia was subject to British colonial rule between 1786 and 1957. The British colonials were focused on economic imperialism, and this governed their attitudes towards education. The objective of education during this period was for children to receive basic education in their own language, which would then prepare them for their allotted role in the colonial scheme (Joseph, 2008). In this worldview, Europeans governed and administered the colony; the Chinese were assigned to labour in the mining and commercial industries; while Indians were largely assigned to working in the rubber plantation sector. Meanwhile, the Malays were responsible for providing rice and agricultural products to feed the country. At the time, higher education beyond primary level was exclusively for elite groups who managed to gain entry to English schools. These schools were seen as a means for social mobility and advanced entry into prestigious positions with the government or European organizations (Joseph, 2008). However, upon gaining independence in 1957, the unequal rates of urbanization throughout the country resulted in uneven rates of educational attainment and income among the three ethnic groups (the Malays, the Chinese and the Indians). Instead of creating an equal foothold among the three ethic groups and breaking down ethnic barriers, the modernisation process led to further differences and social inequalities amongst the ethnic groups (Joseph, 2008; Singh, 2010).

Malaysia became ethnically stratified largely due to the colonial government's policy of unrestricted immigration, divide and rule policy and the maintenance of separate educational systems for the country's three main ethnic groups. Singh (2010) explains that the divide and rule policy "presupposes a domestic balance of power with the imperial power acting as an intervening variable on either side of the communal balance" [emphasis in original] (p. 46). In Malaysia, the colonial power sided with the Malay community because of the amicable relationship that developed between the British and the Malay leaders (Singh, 2010). Singh also explains that the British also "adopted preferential and protectionist" (p. 47) policies that favoured the Malay community, especially where education was concerned. As the three groups experienced marked differentiation along social, economic and educational spheres, the creation of social inequalities between the groups began to widen. However, due to capital accumulation among the Chinese and the strong financial backing from the Chinese community, the Chinese vernacular schools began to gain a strong foothold. This left the Chinese community in a much 
better condition compared with the Malay village schools and Tamil schools across the country (Joseph, 2008).

\subsection{Class divisions in Malaysia}

The economic and social imbalance amongst the ethnic groups in Malaysia is in part a byproduct of the legacy of British colonial rule, which began in 1786. During the colonial period, which ended in 1957, Malay society was transformed when the colonial government of Malaya adopted an open immigration policy (Singh \& Mukherjee, 1993). This policy was implemented to encourage foreign labour to participate in commerce and trade. Attracted by the work opportunities, and the prospect of a more stable political climate, peasants and merchants from Southern China began to migrate in large numbers to work as merchants or tin miners. Indian labourers were also imported as field hands to work in the rubber industry and plantations (Pong, 1995). As a result, the country began to transform into a culturally diverse society comprising of Malays, Chinese and Indians as the three main ethnic groups in the west peninsula of the country.

The local Malay population, for various political, cultural and economic reasons, was prevented from fully participating in the economy. Instead, opportunities were given to Chinese and Indian labourers who were seen as cheaper and better suited to fulfill the needs of the rapidly expanding economy (Selvaratnam, 1988). The policy practiced by the colonial rule also caused the three groups to diverge markedly in their geographical, occupational and economic activities. Until recently, the majority of Malays would live in rural areas while the Chinese population was concentrated in city areas. The Malays were represented in all major agricultural sectors: farming, working in paddy and rubber farms and fishing. The Indians were mainly involved in agriculture but most were in the rubber industry in rural areas. The Chinese performed the sales and production jobs and were mostly in professional, technical and managerial occupations. Thus, under British direct rule, the Malays, Chinese and Indians began to pursue occupations that would later come to be identified with these different ethnic groups (Pong, 1993). 
Subsequently, for the ease of administering and ruling the country, the colonial government created a broad definition to identify and distinguish the general population (Pong, 1995). The Chinese and Indians were denied citizenship and deemed to be transients, who would soon return to their home country. Others who were seen by the British as having similar cultures and religion were categorised as Malays. This included the Minangkabau, Bugis, Javanese and other immigrant groups from Indonesia. The rationale for this was based on the premise that these groups practiced the Islamic religion and spoke Malay or Indonesian, which the British administration felt possessed similar roots (Pong, 1995).

In 1963, the Federation of Malaysia was formed when Sabah and Sarawak joined Malaya. The Malaysian government at that time extended the ethnic categorisation of Malays to include the indigenous people of Sabah and Sarawak. However, when they realised that the religious, linguistic and cultural practices of the indigenous tribes differed markedly from the Malays in the peninsula, the government decided to refer to the indigenous population from the two states as bumiputera Sarawak or bumiputera Sabah, which loosely translated, means 'sons of the soil'. From 1963 onwards this category replaced the Malay category for education, employment and economic quota purposes (Pong, 1995). However, the government also chose to retain the term 'bumiputera' to include the Malays in the peninsula.

\subsection{Malaysia's New Economic Policy and the emergence of the multi-ethnic middle class}

In 1969, a race riot that took place during the General Election was the catalyst for the creation of Malaysia's New Economic Policy (NEP). The cause of the May 1969 riot was due to the inequality that existed among the different ethnic communities and the economic imbalances that existed particularly between the Malays and the Chinese (Abdul Aziz, 2012). Hundreds of people were killed in clashes between the Malays and the Chinese, the two main ethnic groups in the peninsula. Fearful of another civil unrest, Malaysia's NEP was announced in 1971 as a response to the riot, after the government had reassessed the development policies that were in place at the time.

The NEP ran for approximately 20 years, from 1971 till 1990. The objectives of the NEP were to eradicate poverty irrespective of race, and to restructure society in a way that would 
eliminate the identification of race with economic functions - a practice introduced by the British colonial rule before Malaysia's Independence. With the implementation of the NEP, it was expected that the socio-economic disparity between the different ethnic groups would be visibly reduced and thereby inter-ethnic resentments and tensions would be contained (Abdul Aziz, 2012). The NEP was also seen as a way to achieve national unity.

The initial target of the NEP was to enable the Malay community to benefit from the modernisation process and be on par with other ethnic groups. In line with this objective, the government increased the share of equity ownership and employment in the corporate sector among the bumiputeras. They also sought to improve the education and skill levels of the bumiputeras and encouraged migration from the rural areas to urban areas (Abdul Aziz, 2012). In addition to this, the government also introduced quotas for Malay employment in businesses and enrolment in universities. Central and state governments also established many public corporations to help produce more Malay entrepreneurs. Thus, the NEP functioned in part as a policy of affirmative action on behalf of the Malays and indeed there was a marked increase in Malay representation in professional vocations such as doctors, engineers, accountants, dentists, lawyers and architects (Abdul Aziz, 2012).

As a result of the NEP and the subsequent political transformation of the ethnic Malay community, an urban middle class began to emerge within the Malay community. At the same time, the role of the Malay indigenous community in agricultural labour was significantly reduced. The implementation of the NEP saw the upper middle class expand from 4.0 percent in 1957 to 15.2 percent by the year 2000. The lower middle class increased from 15.8 percent in 1957 to 28 percent by the year 2000 and the working class was reduced from 72 percent in 1957 to 60.3 percent by the year 2000 (Abdul Aziz, 2012).

In the contemporary Malaysian setting, the Malays, who make up the largest ethnic group, monopolise the public and government sector. The Chinese, meanwhile, monopolise the corporate business sector (Joseph, 2008). Indian workers are mainly in small-scale commercial sectors. Class position in Malaysia depends on a combination of political connections, specialized skills, ability in English and family money. The Malaysian elite, mostly trained in overseas 
universities, is highly cosmopolitan and continues to grow in dominance as Malaysia's middle class expands.

\subsection{Socio-economic status and educational attainment in Malaysia}

As a result of the NEP, the proportion of bumiputera students enrolled at public higher education institutions began to increase due to the implementation of an ethnic quota system. Under this system, public universities are required to reserve 60 percent of university places for bumiputeras. The remaining quota is then allotted to the best Chinese and Indian candidates based on academic merit (Joseph, 2008). The government also began to introduce various affirmative action initiatives aimed at reducing inter-ethnic differences in educational attainment. These initiatives included providing scholarships to bumiputera students. In addition, in order to accelerate greater bumiputera enrolment in science and science-related courses, local universities introduced the matriculation system, which was similar to preuniversity or foundation courses. This matriculation system provided bumiputera students with the opportunity for additional entry routes into the local universities for science-based programmes of study (Selvaratnam, 1988; Joseph, 2008). This preferential treatment towards bumiputera students within the education system is aimed at controlling access to higher education because education at tertiary level is perceived as a means to social mobility and widening access for other ethnicities would create socio-economic inequalities (Joseph, 2008).

In 1970, bumiputera students accounted for 53.7 percent of total enrolments at public higher education institutions and this increased to 65.3 percent in 1988 (Aihara, 2009). Nonbumiputera students were forced to seek education overseas when the government implemented a quota-based admission system for higher education in Malaysia. As a result of this policy, non-bumiputera students, especially those of ethnic Chinese origins began to seek opportunities to pursue their education abroad. Access to an English-medium education, coupled with an international certificate offered an opportunity to procure the education they were denied in Malaysia. It is therefore not surprising to see a large number of non-bumiputera students studying in a foreign country through their own private funding (Selvaratnam, 1988; Lee, 2004). However, with the expansion of private tertiary education in Malaysia, access to higher education for non-bumiputera students has increased significantly. 
As such, educational attainment in Malaysia is not closely tied to socio-economic status per se but rather ethnic identification. However due to a lack of public data on students' ethnicity, socio-economic status and educational attainment, it is difficult to verify the actual data on student enrolment by ethnicity. In Malaysia, public or academic discussions regarding issues to do with ethnicity, religion or government policies are seen as being 'sensitive' and are prohibited if perceived to question or challenge political stability. Consequently, there is a lack of discourse or academic research which examines ethnic and social inequalities and its relation to education and the education system.

In this section I explained how the Malaysian education system was influenced by British colonial rule. I also touched on the inequalities and the social divisions that occurred as a result of the British administration. In the next section I describe the Malaysian education system, which to a large degree, is still influenced by British colonial rule.

\subsection{The education system in Malaysia}

The Malaysian education system follows a 6-3-2 structure, which means every child has to undergo six years of primary school, three years of lower secondary school and two years of upper secondary school (Kamogawa, 2003; Sugimura, 2007). This means a child has to go through eleven years of schooling, which is largely subsidised by the government. However, this subsidization changes the moment they wish to pursue higher education as their families have to bear all education costs if they want their children to pursue higher education.

There are three types of schools in the Malaysian national education system. The mainstream schools are Malay-medium schools. In these schools, the medium of instruction is in the national language, Bahasa Melayu. Schools, which use other language mediums besides Malay, are called vernacular schools and include Chinese-medium and Tamil-medium schools. Students who graduate from Malay-medium schools gain direct entry into lower secondary school, while students from vernacular schools must go to 'remove classes' or 'transition classes' to study the Malay language for a year before they can move on to lower secondary school. They are only granted an exemption if the student passes the national language paper in the national exam which they sit in the sixth grade (Sugimura, 2007). Overall, Malaysian students have to sit four national exams throughout the course of their studies. During primary school the first 
national exam a student has to sit is the Ujian Penilaian Sekolah Rendah (UPSR), also known as the Primary School Evaluation Test. This exam is taken at the age of twelve years, when students are in the sixth grade. The scores for this test determine which school and also which class the student enters in secondary school. The second national examination, the Penilaian Menengah Rendah (PMR) is taken when students are fifteen years old. This exam is also known as the Lower Secondary Assessment Exam. The aim of this exam is to determine whether a student will enter the Science Stream and or the Arts Stream in their fourth year in secondary school. The third national exam, known as the Sijil Pelajaran Malaysia (SPM) or Malaysian Certificate of Education, is taken when the students are seventeen years old. This is normally taken at the end of Form 5, or the eleventh year of school (Kamogawa, 2003).

A standard rule of measurement is used to determine if a candidate should be admitted to a higher education institution. This measurement of a student's skills is based on their performance in their SPM examinations. After the national examination, students have two options available to pursue further education. The first option is for the SPM school leavers to apply for the matriculation courses that are offered by the public universities. Matriculation courses are pre-university courses which are compulsory for SPM school leavers and they must pass these before they can enter their first year of a degree course and gain admission to a course of their choice. Another option for some students is they can opt to attend an additional two years of upper secondary school (Lower Sixth and Upper Sixth) before they decide to pursue tertiary education. This is equivalent to a matriculation programme, which all Form 5 school leavers are required to sit if they choose not to study in Lower or Upper Sixth forms. At the end of the Upper Sixth form, students must sit a public exam called the Sijil Tinggi Pelajaran Malaysia or Malaysian Higher School Certificate (STPM), before applying for university (Secondary School Education, n. d.). The application for public university is centralized and each application goes through the Unit Pusat Universiti (UPU). Using this system, all the public universities involved are responsible for the selection of students who enter their institution. The universities are also responsible for deciding the courses the students will pursue at the institution. 


\subsubsection{Education system in Sarawak}

It is worth highlighting some of the differences between Peninsular Malaysia and East Malaysia, given the East Malaysian site university, where the data collection took place, is located in Sarawak. Family practices, in particular, are different from those on the Peninsular Malaysia as I discuss later in this chapter.

Unlike Peninsular Malaysia, Sarawak was not granted independence until 1963. Sarawak was under the rule of James Brooke, also known as the White Rajah of Sarawak. When the first Rajah, James Brooke died in 1868, his nephew Charles Brooke took over. Charles's son Vyner succeeded his father in 1917, and was Sarawak's last White Rajah, a position he kept until World War II, when the Japanese invaded the region and took control. After the Japanese occupation, the task of rebuilding Sarawak was too much for the Brooke family to bear. As a result, the Brooke family led by Vyner Brooke ceded the Sarawak to the British Crown in 1946. After the war, Sarawak was declared a British colony until its independence in 1963 (Porritt, 1997).

Under the rule of the Brooke family most of the education was left to the missionaries, and the Brook family offered the schools patronage and financial support. The first mission schools were run by the Society for the Propagation of the Gospel (SPG) in 1847 (Porritt, 1997). This was then followed by the Roman Catholic Mission. The SPG, Roman Catholic Mission, Seventh Day Adventists and Borneo Evangelical Mission were open to all ethnic groups. The mission schools were large, well built and were supported by mission funds and government aids (Saunders, 1971). The Brooke family, however, were not as concerned with Chinese education in Sarawak. Most of the Chinese education was provided by the Chinese clans and associations, with some government support. Chinese secondary education was under the care of a management board made up of influential local Chinese within the Chinese community (Porritt, 1997; Saunders, 1971). As for the Sarawak Malay community, when James Brooke first arrived, the formal education was limited to religious teachings on the Koran in Arabic, and teaching of Malay in Jawi script which is based on Arabic script. However, this privilege was restricted to the Malay chieftains and members of their family (Saunders, 1971). Gradually the other Malays in the community started attending district schools built by the government. 
In 1957, a headmaster scheme was inaugurated and four teachers from Australia, New Zealand and Canada were supplied to aid in the education in Sarawak. Sarawak had no graduate teachers at this stage and the first graduate staff were supplied by New Zealand under the Colombo Plan. Thus in Sarawak, English remained the medium of instruction until the late 1970s and most leaders in Sarawak had a vested interest in retaining English as the language of instruction. English remains a language they can speak fluently (Saunders, 1971). However when Sarawak joined the Federation of Malaya, these leaders were under intense pressure to comply with using Malay as the medium of instruction and follow the practices of the Peninsular (Saunders, 1971).

The education system in Sarawak is relatively similar to the one on the Peninsular, with a few small differences. First of all, there are more mission schools in Sarawak compared with the peninsular. This may be partly due to the fact that Sarawak remained a part of the British colony until 1963, unlike our peninsula counterparts who achieved independence in 1957. Due to the strong foundation of mission schools in Sarawak, Christianity has become the most popular religion in Sarawak. Major Christian denominations in Sarawak are the Roman Catholics, Anglicans, Methodists, Borneo Evangelical Church or Sidang Injil Borneo (S.I.B.) and Baptists. However, due to federalization of the education system, most of these missionary schools have been converted into government national schools. To date, it is estimated that there are 235 mission schools in Sarawak and Sabah (Raslan, 2012) out of an estimated 10, 083 primary and secondary government run schools in Malaysia (Ministry of Education, 2010).

Second, in Sarawak, there are no Tamil vernacular schools, because there is only a small Indian population in Borneo. Most of the Indian community is concentrated in bigger towns such as Kuching and Miri, with very small numbers in other divisions throughout Sarawak.

Third, Sarawakian parents, especially Chinese parents, commonly send their children to New Zealand to continue their secondary school education, with Christchurch being the most popular destination. There is also quite a substantial alumnus from the University of Canterbury in the state capital, Kuching, and in Sibu. Young people from Sibu have been pursuing tertiary education in Canterbury for more than 30 years ("Mayor's Visit Strengthens", 2002). This could 
be due to past education links between Malaysia and New Zealand under the Colombo Plan (Porritt, 1997) which saw a number of Malaysians being given the opportunity to study at the University of Canterbury in Christchurch.

Fourth, due to the multi-ethnic population in Sarawak, a majority of the people normally converse in English or Bahasa Melayu, while the more common language used by most indigenous people from different ethnic groups is a local dialect, the Bahasa Sarawak (loosely translated to mean Sarawak language). Most Sarawakians are multi-lingual, and often speak more than four languages. Thus English might constitute a fourth or fifth language for some Sarawakians. 


\subsection{The growth of higher education in Malaysia}

The notion that higher education institutions are regarded as major sources of knowledge led successive post-Independence governments to take an interest in setting up more institutions of higher education. Essentially, the expansion of higher education in Malaysia can be divided into three distinct post independence periods, which mirror the economic development of the country. The different stages of educational development are illustrated below:

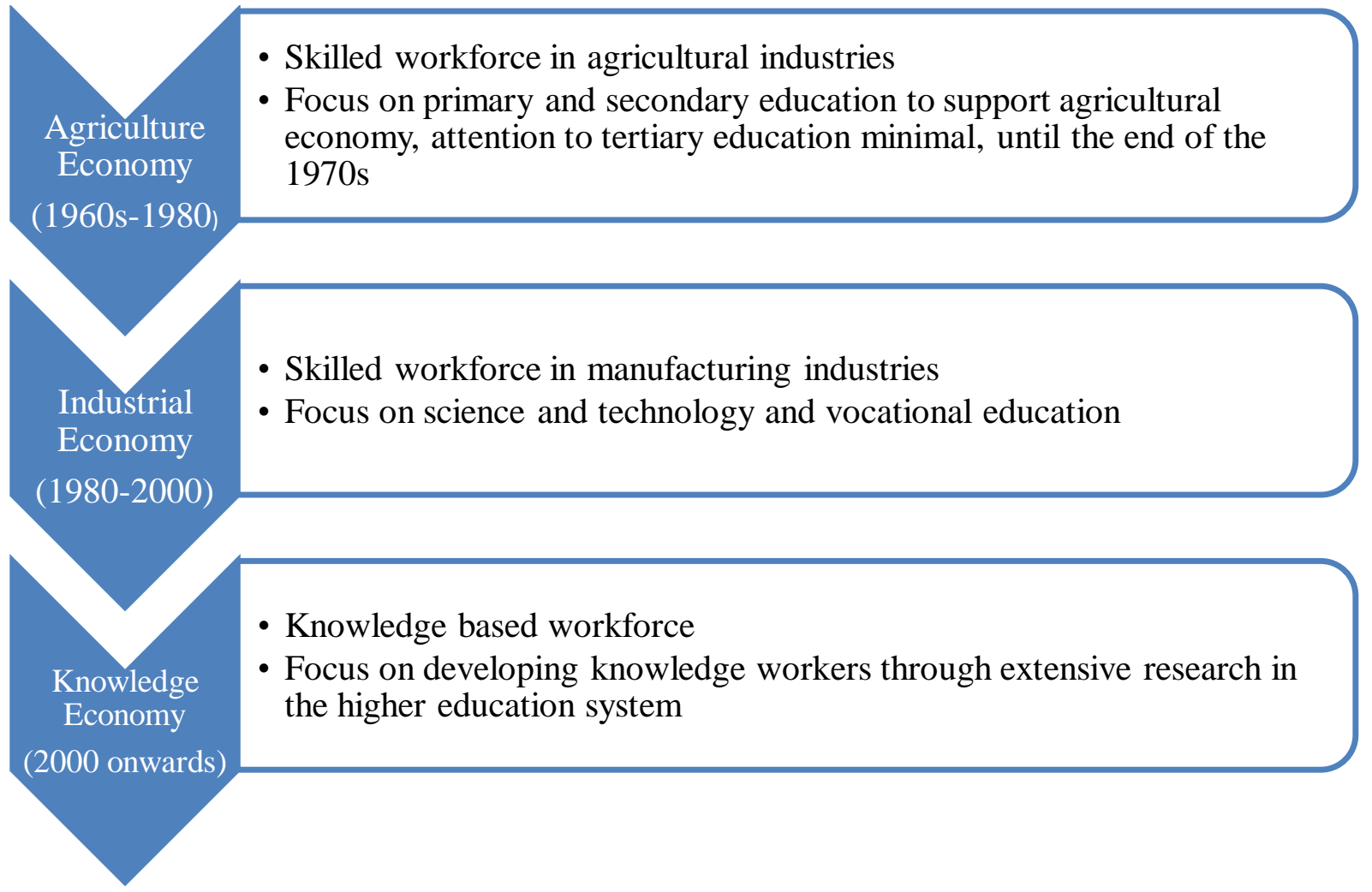

Figure 1. Higher education reforms in Malaysia (adapted from Singh, Schapper \& Mayson, 2010)

The impetus for higher education system reform in Malaysia stems from economic growth and development. The transition from an agriculturally-based economy to a knowledgebased economy has prompted the change and also shifted the focus to the role of education in fuelling the country's advancement and development. Initially, in the 1970s, Malaysia's economy was based on agricultural activities and the focus of education was primarily on delivering 
primary and secondary school education, which were sufficient to meet the economic needs of that era.

Later, the emphasis on an agricultural economy shifted as global financial trends began to change in the 1980s. The country refocused attention on an industrial, productivity-based economy to sustain the nation's growth (Singh, Schapper \& Mayson, 2010). The need for skilled workers provided the impetus for reform as this signalled that higher education was necessary to provide for the shortage of a skilled workforce. Realizing the importance of higher education, the Malaysian government then concentrated its efforts on reshaping its education system to facilitate the expanding need of the country and meet the demands of the workforce. The government then decided to launch a series of five-year National Development Plans to address the issue of primary, secondary and tertiary education in Malaysia (Singh et al., 2010).

The first three National Development Plans (agricultural economy period) were focused on developing a skilled workforce in agricultural industries. There was little, or minimal, attention paid to higher education, but instead primary and secondary education was the primary focus for the government. During the industrial economy period, the government began to intensify its efforts on creating a more skilled workforce to generate economic growth. The higher education sector was corporatized and more private institutions of higher education were established. The emphasis of the education system turned to science and technology, and vocational studies also began to receive more attention.

Eventually, the Malaysian government began to shift its attention from an industrialised economy to a knowledge-based economy. Globalisation also played an important role in the move towards a 'knowledge- based economy'. Thus, from the year 2000 onwards, the focus on education shifted from training skilled workers to creating knowledge workers who could rebuild the economy and contribute to a more developed and progressive nation, in line with the country's vision (Singh et al. 2010). In short, the reform of higher education in Malaysia has been shaped by the economy. 
In sum, the growth of the Malaysian higher education system was linked to ideas about the country's economic growth. The development of higher education was also closely tied to the economic conditions experienced in the country. The next section of this chapter outlines the changes that have taken place since the 1960s till the present time.

\subsubsection{First phase of higher education (1957-1969)}

In 1957, after Malaysia gained independence from British rule, the opportunities for higher education in Malaysia were limited. Higher education was not considered a priority as the economy was focused on labour-intensive activities (agriculture, coal mining and construction) and demand for unskilled labour was essential for the country's growth (Sivalingam, 2006). There was, however, concern that all those of school-going age should receive at least 11 years of free education, excluding university education.

University education has never been compulsory for all its citizens. In 1962, five years after independence, the first university in Malaysia, the University of Malaya was established. The medium of instruction at the university was English and its graduates were mainly absorbed into the Malaysian Civil Service. The University of Malaya was of "colonial vintage" (Sivalingam, 2006, p. 7) and graduates of the university were considered to be the elite of the society. As the country's economy shifted from an agricultural economy to an industrially-based economy, higher education was rapidly transformed. The government addressed the shortage of professionals in the workforce, in fields such as medicine, science, engineering, dentistry and also in technical and managerial fields. In order to meet the needs of the shifting economy, new policies were drawn up and universities that offered scientific and technical programmes were created.

\subsubsection{Second phase of higher education (1970-1990)}

Under the Third Malaysian Plan drawn up for the period of 1976-1980, education in Malaysia developed rapidly. The government believed that in order to build a strong, well balanced and integrated society, the education system had to focus on producing skilled and semi-skilled professionals to enter the workforce and start contributing towards economic growth (Sharom, 1980). To achieve the objective of national development and unity, a long-term 
plan for the development of higher education was set in motion. Steps were taken to ensure the development of higher education was consistent with the socio-economic objectives of the country. Under this major change, development plans and policies were formulated to address the issue of economic growth. With this in mind, the Higher Education Committee (HEC) was set up with the aim to improve and revamp higher education in Malaysia.

The Committee's other concern was to address the issue of technical education as there was an acute need for engineers and technologists to fulfil the needs of the growing economy (Sharom, 1980). The Committee's recommendations resulted in the establishment of four universities in rapid succession. In 1969, the second university in Malaysia, The Science University of Malaysia, was set up in Penang. A year later, the National University of Malaysia was set up. The Malaysian University of Technology, formerly a Technical College, was upgraded and awarded university status in 1971. The University of Agriculture, now known as University Putra Malaysia, was established in 1972. It was the intention of the government that the universities address the industrial and agricultural needs as the country was geared towards transforming the economy by participating in science, technology and industrialization (Sharom, 1980).

With the establishment of these universities, the citizens were also presented with more opportunities to participate in higher education. Education then was seen as a catalyst for achieving the goal of becoming a developed nation (Lee, 1999; Sirat, 2010). At the same time, the government were adamant about upholding the idea of education as "an instrument for promoting and strengthening national integration by inculcating a common and shared destiny among different ethnic groups, removing racial prejudices and encouraging cultural tolerance" (Lee, 1999, p. 87). The aim was also to provide equal educational opportunities to economicallydisadvantaged groups. 


\subsubsection{Third phase of higher education (1990-2000)}

Since access to higher education was linked in the public imagination to upward social mobility, the government made a decision to implement a "racial quota policy whereby the ethnic composition of the student population in the universities should be a reflection of the ethnic composition of the country" (Lee, 1999, p. 90). The government expanded the number of existing universities and built other institutions of higher learning to accommodate the growing number of students who were ready to participate in higher education. By 2002, there were 11 public universities, 5 university colleges, 6 polytechnics, 27 teacher training colleges and plans for community colleges to be set up in the 193 parliamentary constituencies around the country (Lee, 2004).

The implementation of the racial quota policy, the rising cost of overseas education and the 1997 Asian economic crisis, brought about a new set of problems with regards to higher education (Lee, 2004). The universities were unable to supply places for the growing number of students who wished to enrol in higher education programmes. This facilitated the privatisation of higher education in an effort to address the lack of supply of public higher education institutions to meet the growing demands of its citizens. The Malaysian government was eager for the private sector to play a part in providing higher education for its citizens, particularly in the fields of technical and vocational education.

Four legislative acts were consequently passed that opened the way to the restructuring of the higher education system in Malaysia (Lee, 2004). The legislative acts, which framed the policies of higher education in Malaysia, are the National Council on Higher Education Act 1996, the Universities and University College Act 1995, the Private Higher Education Act 1996 and the National Accreditation Act 1996. This legislation gave the state the power to regulate the framework for the development and monitoring of higher education in Malaysia (Sirat, 2010).

Firstly, the National Council on Higher Education Act 1996 was passed to enable the government to set up a single governing body to monitor and guide the direction of higher education in Malaysia (Lee, 2004). This body was responsible for formulating and devising national policies and strategies for the development of higher education in the country, and 
ensuring that the public and private higher education sectors were coordinated. It was also responsible for encouraging private higher education institutions to offer vocational and technical programmes to the students. The National Council on Higher Education Act has also allowed the Minister of Education to grant permission to private institutions to conduct their programmes in English (Tham, 2011). The main difference between public and private higher education institutions is that the former conducts most of its programmes in the national language, Bahasa Melayu.

The National Council on Higher Education Act 1996 was then followed by an amendment to the 1971 University and University College Act which provided guidelines for public universities to be corporatized. With the passing of this act, public universities were no longer bound by the governments' bureaucratic policies and systems, and were free to participate in business ventures and enter into partnerships that could serve as a point of revenue and investment to compensate for the operating costs of the university (Lee, 2004). Corporatization led to the restructuring of the universities as well as operations and management of the university as a whole.

In contrast, the Private Higher Educational Institutions Act 1996 (PHEI Act) outlines the government's regulatory control over all Private Higher Education Institutions (PHEIs). Under this PHEI Act, all PHEIs are required to obtain approval from the Minister of Education before setting up, or offering, programmes of study in their institutions. The Act stipulates that Bahasa Melayu must be the language of instruction in PHEIs and approval must be obtained to teach in English or Arabic. In addition, foreign universities are entitled to set up branch campuses in the country, but only upon invitation from the Minister. The PHEI Act also clearly states that Malaysian Studies, Islamic Studies and Moral Education are compulsory subjects and must be taught in all PHEIs across the country. The PHEI Act acknowledges the government's complete autonomy over the types of PHEIs that can be set up and the kinds of programmes they can offer to the public (Lee, 2004). Finally, the National Accreditation Act or LAN (Lembaga Akreditasi Negara) monitors and standardizes the quality of the programmes offered by the PHEIs. All PHEIs must obtain approval to run courses and these courses must meet the minimum requirement set by LAN in order for their degrees to be recognized by the government (Lee, 2004). If the degrees are not recognized by the government, the graduates from the PHEIs might 
not be able to join the workforce upon graduation and their degree will not be acknowledged by certain companies in the country.

The four Acts outlined above caused PHEIs to diversify and offer a wide range of programmes in various fields. It also forced PHEIs to come up with a multitude of programmes, which would suit the needs and choices of their clients, which also led to the establishment of newer, more marketable programmes of study made available to the public. Since PHEIs were not allowed to confer degrees, they were forced to collaborate with foreign universities throughout the world to offer degrees under twinning programmes. It also allowed certain PHEIs to carve out a reputation in specialized fields, for example, Lim Kok Wing is well known for its arts and design programme, INTI College for its business and management programmes, and so on.

As a part of the Ministry of Education's (MOE) attempts to build Malaysia's reputation as a centre of excellence for education, the government envisioned a plan to enhance the development of higher education in the country. This included the licensing of public institutions of higher education to confer degrees and conduct courses in collaboration with foreign universities as a means towards achieving the goals set by the MOE (Md Sidin, Husin \& Tan, 2003).

Due to the budget constraints and massification of higher education (Lee, 2004), the expansion of higher education institutions became a matter of concern for the government. This led to the decision to corporatize public universities to sustain the maintenance and management of funds allocated for each of the universities. On the 1 January 1998, the oldest university in Malaysia, the University of Malaya, became the first university to be corporatized. Subsequently, the Science University of Malaysia, the National University of Malaysia, University Putra Malaysia and the Malaysian Technology University, proceeded with corporatization. 


\subsubsection{Fourth phase of higher education (post 2000 onwards)}

The National Higher Education Strategic Plan 2020 and the National Higher Education Action Plan 2007-2010, launched in August 2007, clearly outlines seven main thrusts of higher education in Malaysia. The seven thrusts are: widening access and enhancing quality; improving the quality of teaching and learning; enhancing research and innovation; strengthening institutions of higher education; intensifying internationalisation; enculturation of lifelong learning; and, reinforcing the MOE delivery system (Ministry of Higher Education, 2009). The underlying idea of the plan is to transform the higher education system in the country so that Malaysia's higher education system is in sync with the changes occurring in the global higher education landscape (Sirat, 2010). Consequently, the government adopted a policy of expanding the role of the private sector as a provider for higher education in the country (Sivalingam, 2006). This was in order to meet the needs of higher education, and to encourage more parents to send their children to local institutions. The government began encouraging the establishment of private institutions to provide training and education to the masses.

Taking up the call, private sectors then began to offer twinning programmes and preparatory courses for students who were interested in pursuing higher education, but at a relatively affordable rate. These are also known as joint programmes, which allow students to do their degree locally in their first year and their subsequent years at the mother campus overseas and franchised degree programmes through partnerships with Malaysian colleges and universities (Ministry of Higher Education, 2010). Either way, students would be graduating with a certificate from a foreign university, which of course was a popular choice amongst middle-class parents (Sivalingam, 2006). At the same time, the private institutions started to become more specialised, and began offering specific courses that reflected the changing trends in education. Private institutions began to target 'popular' courses such as medicine, biotechnology, computing and accounting, and began to diversify their engineering courses that were deemed more valuable in the working field. Universities were ranked based on the range of courses that they have to offer that reflects this 'value'.

Furthermore, as public universities were slow to respond to the challenge of producing skilled workers, private higher education institutions began to play a more active role in addressing the labour shortage experienced by the country (Sato, 2005). In response to this 
situation, six private universities, Malaysia Multimedia University (MMU), Universiti Tenaga Nasional (UNITEN), Universiti Teknologi Petronas (UTP), Universiti Tun Abdul Razak (UNITAR), International Medical University (IMU), and Universiti Industri Selangor (UNISEL) began offering degree level courses in various subjects such as engineering, business, medicine and multimedia (Kamogawa, 2003). Since that time the number of private universities has expanded and as mentioned earlier, foreign universities began to set up branch campuses and offshore campuses to provide widening access to higher education in Malaysia (Sato, 2005). In addition, more private higher institutions were set up across the country and conglomerates such as Tenaga Nasional Berhad (the largest electric utility company in Malaysia), Telekom Malaysia (the largest telecommunication company in Malaysia) and PETRONAS (the Malaysian owned oil and gas company) have jumped on the bandwagon to try to seek opportunities within the educational scene in the country.

There are basically two categories of private higher education institutions, namely private colleges and private universities. Private colleges are institutions without the degree conferment status of Universities or University Colleges. On the other hand, institutions that have been conferred university or university college status are referred to as private universities (Wilkison \& Yusoff, 2005). In this case, only institutions with the University or University College status are allowed to confer degrees. Most private colleges provide technical training and education (accounting, business, management, information technology, fashion design, computer studies and so on) to cater for the needs of various industries. The colleges, however, are able to offer degree courses only through arrangement with overseas or local public universities. Under these programmes, the colleges can conduct courses leading to bachelor degrees through twinning programmes offered by institutions which carry university status (Wilkinson \& Yusoff, 2005).

To date, there are currently 20 public universities, 30 polytechnics, 72 public community colleges, 23 private universities, 5 foreign university branch campuses and about 452 private colleges in the country. There are also various other higher educational institutions from the UK, the US, Australia, Canada, France, Germany and New Zealand which offer twinning programmes. Since 2010, the role of higher education institutions has undergone a rapid change. The existing universities in Malaysia are now categorized into three main groups: Research, Focused and Comprehensive. Focused universities offer technical, educational, management and defence 
programmes, while the Comprehensive Universities offer a variety of different courses in a range of fields (Ministry of Higher Education, 2010). Universities are often ranked on the range of courses they are able to offer. The university with the most valuable course will likely target a larger portion of the country's population.

The preceding sections set out the background of the Malaysian education system and how the developing economy spurred the growth of higher education in Malaysia. The next section explores recent developments of community service and civic participation practices in Malaysian higher education institutions.

\subsection{Civic participation and engagement in Malaysian higher education}

In December 2010, the Higher Education Minister, Datuk Seri Mohamad Khaled Nordin, announced that universities with the best outreach programmes would receive recognition and grants from the government, awarded by the Ministry of Higher Education (MOHE) for outstanding outreach programmes organized by universities across the nation ("Varsities with best outreach", 2010). The aim of the grant was to encourage universities to be more proactive in engaging with the community, whilst cultivating the spirit of volunteerism in campuses nationwide. The Minister of the MOHE called for more active participation from the universities in an effort to encourage more students and staff to contribute to society and create significant social impact in the surrounding community. Datuk Seri Mohamed Khaled Nordin also stressed that universities should not just function as 'ivory towers' but give back to the society in various programmes (Tan, 2011). He emphasized that although the universities' core business was to spread knowledge and information, their societal role cannot be neglected or ignored. Ten months later, in September 2011, the MOHE was looking into the possibility of awarding credits to university students as a method to encourage volunteerism (Tan, 2011). The Deputy Higher Education Minister, Datuk Saifuddin Abdullah, said the MOHE was looking into the possibility of awarding credits to university students to motivate them and award them for their time and commitment in helping those in need. Since some universities had already initiated similar measures to acknowledge participation in community projects, Saifuddin felt that awarding credits to count towards their studies was a positive way to motivate the students to participate in more community-related activities. 
The MOHE also encouraged the idea of community service in various universities in the nation by allocating grants for outreach programmes. To address this issue, in December 2010, the then minister of MOHE, Datuk Seri Mohamed Khaled Nordin, announced that universities would "receive recognition and be financially rewarded" for the best outreach programmes ("Varsities With Best Outreach", 2010, para. 2). The idea that lay behind this initiative was to encourage a larger spectrum of universities to participate in community-based projects which would inculcate the spirit of volunteerism in various campuses. This initiative was seen as a way to reward universities that created or promoted community related activities or programmes which would leave the most significant social impact on the surrounding community. In September 2011, the MOHE proposed the idea of awarding credits to students who volunteer in community work (Tan, 2011). The Deputy Minister of MOHE mentioned the possibility of awarding credits to students for active contribution to voluntary work. The effort to acknowledge the importance of civic education and civic participation in higher education is a new initiative. However, to date there have not been any news release or reports, which state whether the grants have been given out. There is also no news on the effectiveness of this initiative at the present time. 



\section{CHAPTER THREE}

\section{THEORETICAL FRAMEWORK}

\subsection{Introduction}

The social world is accumulated history and if it is not to be reduced to a discontinuous series of instantaneous mechanical equilibria between agents who are treated as interchangeable particles, one must reintroduce into it the notion of capital and with it, accumulation and all its effects. (Bourdieu, 1986, p. 46)

In this study I employ Bourdieu's three main conceptual tools, cultural capital, habitus and field to understand how students' perceptions develop and how this perception subsequently drives their engagement with extracurricular activities at university. My study is concerned with the social world - the way individuals form perceptions, manage social relationships and interact with people within their community. As mentioned in Chapter One (section 1.5), my research interest lies in investigating why students pursue tertiary education and how they form their perceptions about the role of education. Taking this into account, my study draws on Pierre Bourdieu's theory (1977) of cultural capital as a framework to understand the "relation between culture, social structure and action" (Swartz, 1997, p. 6). Bourdieu provides strong "thinking tools" (Grenfell, 2008, p. 2), which can be used to explain the social process involved in understanding individual practices and action.

One of Bourdieu's primary areas of interest was "[w]hat motivates human action?" (Swartz, 2008, p. 8). He explained how social structures affect individual action and practices by introducing the concept of habitus, another notion that I used to guide my study. Bourdieu's notion of habitus is particularly useful in my study because it underpins my response to my second research question, namely: 'How do 
students' perceptions influence the nature of their engagement in university activities while at university?'. Bourdieu's (1977) explanation of habitus shows how individual action in the social world is structured by people's perceptions and understandings of their world. As Bourdieu (1977) explains, the habitus "functions at every moment as a matrix of perceptions, appreciations and actions" (pp. 82-83) that structure how the individual responds to people within their social sphere (Horvat \& Antonio, 1999). Habitus also helps us to understand the nature of student engagement at university by providing explanations of how students position themselves in a specific field or social space (in this case - the university).

Another powerful thinking tool developed by Bourdieu is the concept of field"structured spaces" (Swartz, 1997, p. 117) or social spaces where individuals struggle and compete for recognition and 'distinction' (Bourdieu, 1984). I employ Bourdieu's (1984) concept to describe how my participants make use of a combination of their educational capital and involvement in extracurricular activities to achieve 'distinction' in the educational field and the work field. By utilising Bourdieu's concept of field I am able to illustrate how individuals use different forms of capital to compete with their peers to achieve distinction. Given all of these, I chose to employ Bourdieu's conceptual tools as my theoretical framework because "it incorporates sociocultural factors and individual agency to explain the reproduction of existing social structures" (Walpole, 2003, p. 49).

Taking these arguments together, I utilise a Bourdieusian framework to frame my study on student engagement in university extracurricular activities. Bourdieu's concept of cultural capital, habitus, field and social capital are particularly useful in this study as they explain how family socialization and social networks influence individual disposition and perceptions. This in turn helps us to form an understanding of the ways that individuals engage in university activities. Few studies link these concepts together, and my study addresses the gaps in literature by providing insight into how individuals are influenced by their cultural capital in their choice of university activities. I also investigate if cultural capital has any bearing on their decisions to participate in extracurricular activities. I draw on the concept of habitus and social 
capital to investigate whether these two variables have an impact on students' decisions to join in these activities.

\subsection{The link between cultural capital, habitus and field}

Before discussing the theoretical concepts introduced by Bourdieu, I shall establish the relationship between the various ideas discussed in this chapter thus far. I begin by discussing the key concepts of Bourdieu's work that are of relevance to this study. These concepts are habitus, field and capital. In Distinction, Bourdieu maps out a formula that explains how the social world is structured and shows how this motivates peoples' action. According to Bourdieu:

[(habitus) (capital)] plus field = practice. (Bourdieu, 1984, p. 101)

As Reay, (2004, p. 435) proposes, "It is through the workings of habitus, cultural capital and field that the logic of practice is generated". Maton (2008) summarises the relationship when he explains that "practice [results] from relations between one's dispositions (habitus) and one's position in a field (capital), within the current state of play of that social arena (field)." (p.51)

I discuss each of these concepts in turn in the following section and explain how they can be applied to this study of the influence of students' perceptions of education and their engagement in extracurricular activities university.

\subsection{Habitus}

In Outline of a Theory of Practice (1977), Bourdieu defines habitus as:

The structures constitutive of a particular type of environment ... produce habitus, systems of durable, transposable dispositions, structured structures predisposed to function as structuring structures, that is, as principles of the 
generation and structuring of practices and representations ... [T] he practices produced by the habitus [are] the strategy-generating principle enabling agents to cope with unforeseen and ever-changing situations. (p. 72)

The notion of habitus refers to the way culture is embodied within an individual (Harker, 1984, p. 118), thus establishing the way the individual is disposed to view the world. A person's individual history constitutes their habitus, but so does their whole collective history of the family and class that member belongs to. In other words, people who live similar lifestyles due to common levels of access to capital, generally share similar worldviews. This shared worldview is a result of common experiences and interaction, and constitutes a person's habitus (Swartz, 1997). For instance, Nash (1990) postulates that the way families view education plays a vital role in influencing how their children perceive education and the school culture. The family sets the "scholastic expectations" (Nash, 1990 p. 438), which are transmitted and institutionalised in the children's upbringing and interaction. This naturally shapes the perceptions, beliefs and value they place on education and learning. Thus, habitus explains how a person's perception and worldview is shaped by family and class structure, which is an important focus of this study.

Dumais (2002) explains that habitus is formed when an individual internalises their social structure and their place within the social sphere. Through this process of internalisation, the individual formulates aspirations and practices that enable them to evaluate their potential and future endeavours within their social field (Bourdieu, 1983, p. 352). Thus, these "internalised experiences" (Dumais, 2002, p. 46) and the volume of cultural capital gained by an individual as a result of habitus, play an integral part in student achievement and success in university, as habitus orients action (Swartz, 1997). Harker, Mahar and Wilkes (1990) extend this argument by stating that the existing conditions in our "environment [have] a structuring effect on the family socialisation process thus forming our practice" (p. 121) (what people do and what they think they are doing). The practices that have been formed are reproduced and reinforced in positive conditions or adjusted to suit externally changing social circumstances (DiMaggio, 1979; Harker, 1984). Habitus describes how an individual's perception structures their actions and practices, another important aspect of my 
study. It underpins students' perceptions about the nature of their engagement in university life.

Essentially, a person's disposition and ability to competently manage their capital often results in success within various fields. Bourdieu (1983) argues that the position an individual holds within a social space is defined by the position he or she occupies within different fields. He stressed that in order for a social class to maintain its successful practices for reproduction, it is vital that the agents defend or improve their positions within the field of interaction (Bourdieu, 1977). Individual habitus structures the way people act, think and how they perceive their surroundings thus helping the individual to position themselves in a given field. This in turn helps them to navigate their way around as they compete with other individuals for power and dominance within a field. In the context of this study, the students' habitus helps them to assess and determine their practices in the university (field) and the choice of activities they pursue while in university. In this case, their decision to engage in extracurricular activities is partly driven by their struggle to excel in a different field in the future, in this instance the workforce. In my study, the concept of habitus and field provides an analytical lens (Maton, 2008) to explain the variations in student engagement at university, as the students compete for merit in the education system.

In addition, through the workings of habitus I am able to describe the "rational calculations" (Maton, 2008, p. 54) and 'logic of practice' that frames my participants' action when making decisions about studies, participation in extracurricular activities and future career plans. Habitus represents a person's values, attitudes and belief system inherited from their families which, when combined with their capital (economic, cultural and social) results in academic success. Capital refers to the resources at their disposal, which are valuable to achieve success in the school system. In the following section I explain why Bourdieu (1977) argues that cultural capital is important for educational success. 


\subsection{Cultural capital}

Pierre Bourdieu's theory of social reproduction is an attempt to explain how power and inequality operate in society. He was particularly interested in investigating how cultural transmission functions across all social classes as a strategic process of family based intergenerational reproduction (Nash, 1990, p. 432). Bourdieu and Passeron (1977) were the first to document the idea of cultural capital in their research on university students in France, and how their university experience contributed to the reproduction and perpetuation of French elite status. It was within this context that Bourdieu and Passeron (1977) developed the concept of cultural capital, to explain the persistent inequalities in educational stratification existing in France.

Bourdieu (1977) defined cultural capital as "instruments for the appropriation of symbolic wealth socially designed as worthy of being sought and possessed" (p. 448). He claims that cultural capital exists in three forms: in embodied state, for example in the form of dispositions, attitude, taste or preferences; in objectified state, for example in the form of cultural goods such as books, paintings and instruments; and in institutionalised state, in the form of educational qualifications (Bourdieu, 1986, p. 47). Thus, Dumais (2002) sums up cultural capital as being "comprised of linguistic and cultural competence and a broad knowledge of the practices that belong to the members of the upper classes" (p. 44).

According to Bourdieu (1986), each social class possesses cultural capitals which children 'inherit' from their parents in the form of cultural knowledge (DiMaggio \& Mohr, 1985; Lamont \& Lareau, 1988), preferences, attitudes, goods, credentials and values (Lamont \& Lareau, 1988) which are then invested for social profits. Bourdieu (1977) states:

The accumulation of cultural capital in the embodied state, i.e. in the form of what is called culture, cultivation, Bildung, presupposes a process of embodiment, incorporation, which insofar as it implies a labour of inculcation 
and assimilation, costs time, time which must be invested personally by the investor. (p.48)

Essentially, Bourdieu sees social reproduction as a result of the relationship between education, family and social class. He argues that education aids the reproduction of social inequality when the education system rewards those who possess elite cultural capital and penalises those who don't. Children learn to convert this cultural capital into educational credentials, thereby reproducing social structures and maintaining the social status of the family (Bourdieu \& Passeron, 1977). As Bourdieu (1977) puts it;

By doing away with giving explicitly to everyone what it implicitly demands of everyone, the educational system demands of everyone alike that they have what it does not give. This consists mainly of linguistic and cultural competence and that relationship of familiarity with culture which can only be produced by family upbringing when it transmits the dominant culture. (p. 494)

In addition, he contends that social inequality is perpetuated by elitist social standards, which favour upper- and middle-class children (Sullivan, 2002, p. 145), thus facilitating the exclusion of others (Bourdieu, 1986). He argues that individuals who have the most access to capital resources in various combinations constitute the dominant social class in a society (Bourdieu, 1977a). The upper classes use their resources to expand, or "maintain their class position and [legitimate] the dominant position" (Sullivan, 2002, p. 146). According to Bourdieu, children who possess the knowledge and competence in 'highbrow' or elite culture - defined as cultural appreciation and taste for cultural goods (Lamont \& Lareau, 1988, p. 156) - are conferred with 'distinction' (Bourdieu, 1984). In other words, children from higher social classes are rewarded in schools because they demonstrate an understanding of elite culture. I concur with Walpole (2003) who proposes that we employ Bourdieu's concept of cultural capital to theorise individual actions. She argues in favour of this 
theory because it helps to explain how "individuals incorporate sociocultural factors and individual agency to reproduce an existing social structure" (Walpole, 2003, p. 49).

Bourdieu (1977) hypothesises that the culture of the dominant class is mirrored in the educational system and students who possess the appropriate cultural capital are rewarded by the educational system. Thus, the core hypothesis of this theory is that cultural capital functions as a resource that equips individuals with knowledge and skills to cope within the educational system. Furthermore, Bourdieu (1986) argues that when society confers institutional recognition to the cultural capital of a given agent, this makes it possible for the person to convert his or her cultural capital into economic resources. Grenfell (2009) gives an example of this form of conversion of capital in illustrating how certain educational attributes (cultural capital) allow an individual to 'buy' financially rewarding jobs (economic gains). I utilise cultural capital theory in my study because this concept sheds light on how families transmit knowledge and skills to their children. In addition, the theory illustrates how familial practices facilitate social reproduction within society.

\subsection{Social capital}

The central thesis of Social Capital Theory lies in the inherent nature of human relationships (Coleman, 1998). Social networks are perceived as valuable assets because the interaction between the individuals in the community can be exploited to meet individual goals and actions. The three proponents of social capital often cited in research on social capital are Pierre Bourdieu (1986), James Coleman (1988; 1990) and Robert Putnam (1993). The findings of my study (refer to Chapter Eight) show that social ties and networks play a role in influencing the nature of student engagement in university. Thus, my study draws on the works of Bourdieu, Coleman and Putnam to describe how social ties and social networks influence students' engagement in extracurricular activities in university. 
Firstly, I begin with Bourdieu's interpretation of social capital. Bourdieu's belief comes from within a Marxist framework. In line with this, he began by identifying and distinguishing between three forms of capital: economic, cultural and social (Bourdieu, 1986). He defines social capital as "the aggregate of the actual or potential resources which are linked to the possession of a durable network of more or less institutionalised relationships of mutual acquaintance and recognition" (Bourdieu, 1986, p. 248). Nash (1990) explains Bourdieu's concept more clearly when he describes social capital as the integration within a network of social connections or social ties, which one can mobilise for their own advantage. In contrast to cultural capital, which is concerned with knowledge and culture, social capital is concerned with relationships within the family, school and the community (Dika \& Singh, 2002). Bourdieu (1986) argues that the network of relationships is the product of investment strategies, which are consciously or unconsciously used to form social relationships that can be useful for individuals in the long or short term. He proposes that the volume of a person's social capital is dependent upon two factors. One factor is the size of their network or connection that a person can utilise, and the second, the volume of the capital possessed by the person to whom he or she is connected. Bourdieu (1986) explains:

The volume of the social capital possessed by a given agent thus depends on the size of the network of connections he can effectively mobilise and on the volume of the capital (economic, cultural, symbolic) possessed in his own right by each of those to whom he is connected. (p. 51)

He further claims social capital can be converted to economic resources under certain conditions, as it is made up of connections and obligations within the wider network of the community (Dika \& Singh, 2002). Ultimately, social capital can be used as a resource to advance one's position within a given field, if the individual uses the appropriate strategies and their accumulated capital to their advantage (Portes, 1998). This is because social capital, similar to cultural capital, is a resource, which can be invested to gain profits (Bourdieu, 1986). Bourdieu's (1986) arguments about the quantity and the quality of a person's personal relationships help to explain how and why my participants were able to effectively recruit friends to help out in voluntary 
projects, and how they use the strength of their capital to their advantage, be it to gain information or to get connected with industry representatives for future work opportunities (refer to Chapter Seven).

James Coleman's contribution to the development of Bourdieu's idea of social capital was to explain how people utilise social capital for their benefit. Coleman's (1990; 1988) definition of social capital differs from Bourdieu's in that he sees social capital as a structured body driven by the relationships that exist between people in a given community. His definition of social capital is:

a variety of entities with two elements in common: they all consist of some aspect of social structures, and they facilitate certain actions of actors whether persons or corporate actors - within the structure. Like other forms of capital, social capital is productive, making possible the achievement of certain ends that in its absence would not be possible. (Coleman, 1988, p. S98)

A further difference between Coleman's (1998) interpretation of social capital and Bourdieu's (1986) is that Coleman views social capital as existing in intangible forms such as "[levels] of trust, or information channels among members of the community" (Dika \& Singh, 2002, p. 34). He also claims that social capital encompasses the norms that promote common good above self interest among members in the society (Lin, 1999).

Coleman's uses measures such as: family structure; parent and child discussions; parent's school involvement; parent's expectation; intergenerational closure and religious participations as indicators of family and community social capital (Dika \& Singh, 2002). He asserts that the family is responsible for adopting strategies to advance their children's life success through their social networks (Dika \& Singh, 2002). Rob Strathdee (2003) explains that "social networks can be considered to be a form of social capital that resides within families and the communities they live in when, like other forms of capital, they facilitate productive activity" (p.312). He 
provides a clear case of how social networks operate when he explains how "social networks, for example, are productive when they provide trustworthy advice to individuals about the quality and the availability of particular forms of employment" (Strathdee, 2001, p. 312). Thus, networking and social relationships play an important role in facilitating a person's success, especially if the person has the 'right' connections. Besides the role of social networks, Coleman (1988) also focuses his attention on how the roles of family and kinship, networks, and religious institutions are crucial in developing social capital. Lawrence Saha illustrates how social capital plays an important role in educational attainment. In his view, social capital "consists of patterns of behaviour that [support] and [reinforce] the goals of education" (Saha, 2003 , p. 62). He uses the example of parents who are actively involved in their children's education as an important resource of social capital to their children. More importantly, he asserts that social capital not only presents itself in the interactions between parents and children, but also exists in "friendships and even through school networks" (Saha, 2003, p. 60). I make use of Saha and Coleman's interpretations of parent-child interaction in this study to explain three areas of interest; 1) how my participants use their social capital as recruitment strategies to enlist their friends for voluntary activities, 2) how my participants utilise the connection they have with friends to learn new things and 3) how Malaysian parents' involve themselves in their children's education.

Another proponent of the social capital theory, Robert Putnam (1993) has a slightly different view of social capital. He argues that social capital is a valuable resource to combat the declining state of civic responsibility and social ills happening in modern societies. He defines social capital as "features of social organizations, such as networks, norms and trust, which facilitates action and cooperation for mutual benefit" (Putnam, 1993, p. 35). Putnam perceives social capital as a collective process of involvement and participatory behaviour that exists within a community. For example, he argues that people are more likely to participate in clubs and community activities that are personally and socially rewarding if there is a "climate of trust" that exists among each member of that club (Helliwell \& Putnam, 2007, p. 5). Unlike Coleman, Putnam (1993) conceptualises social capital in terms of social bonding, linking and bridging within and between groups and networks in the community. He argues that the social network functions similarly to a conduit, in that it allows 
members of the community to convey vital information for the collective good. Putnam's (1993) views have influenced my work especially when I explore how social capital acts as a catalyst, which influences the nature of engagement in voluntary activities among my participants. As discussed in the findings chapter when the students' enlist in religious clubs, and other volunteer based clubs their perception changed and this influences their desire to give back to the local community (refer to Chapter Eight, section 8.2).

In this section I discuss the importance of social capital to achieve individual and collective actions, and also how social networks form important links between social groups and the local community. In the next section I explain why the different forms of capitals are important resources for people as they struggle to achieve success within their social space.

\subsection{Field}

In order to understand how individuals map their positions in a particular field, it is important for us to first understand what Bourdieu means when he talks about this concept. Bourdieu defines 'field' as the social space in which interactions and events occur (Thomson, 2008). Social settings range from daily spaces we encounter, such as school or a workplace or extend to broader and more abstract range of spaces such as the field of politics, culture, science or even the field of literature (Tzanakis, 2011). Swartz (1997, p. 117) describes Bourdieu's field as "arenas of production, circulation, and appropriation of goods, services, knowledge, or status, and the competitive positions held by actors in their struggle to accumulate and monopolise these different kinds of capital".

Bourdieu uses the metaphor of 'game' to represent our lives, and his conceptualisation of capital, habitus and field is an extended metaphor to explain his notion of how individuals play out their lives (Smith, 2001; Swartz, 1997). If a person's habitus represents the individual's disposition that reflects his or her 'feel for the game' (Bourdieu, 1990), then field represents the social world where an individual plays a 
particular game. He believes that capital, whether social, economic or cultural, represents three sources that an individual possesses which are valuable resources in the game. Bourdieu (1983) claims the game that occurs within these social spaces or fields is competitive. Each social agent uses different strategies to maintain or improve their standing in the game (Weininger, 2005; Thomson, 2008). Take for example, the education field. Students are the 'players' whose goal is to meet the standards and expectations of educators in the school system in order to succeed in the game. In order to meet these expectations and to achieve success, these students must employ the capital they have received from their families and communities or prior experience (Aschaffenburg \& Maas, 1997). Proper use of their capital results in success if the 'player' receives recognition from educators. This success is what Bourdieu (1984) refers to as 'distinction' where the player's capital is acknowledged and rewarded.

Similar to games of any kind, the players in the game may win or lose, with the winners accumulating more capital to be used as resources in future games. All players begin on unequal playing grounds (Swartz, 1997) and the possession of particular forms of capital may be more valuable depending on the field they are in (Smith, 2001). Those players who have an advantage due to their capital proceed to accumulate more capital, which they use to advance further in the game (DiMaggio, 1979; Aschaffenburg \& Maas, 1997; Thomson, 2008). Thus, capital becomes legitimised when it is recognised in a specific field. Therefore, this means that capital carries value when it is recognised, credited and legitimised by others (Swartz, 1997). Thus the search for capital is in essence, a search for recognition, which 'buys' positions in the field (Grenfell, 2009).

To sum up the relationship between capital and field, Michael Grenfell (2009) aptly explains: "Capital belongs to the field and it is the field that sets its value, but it is the individual who [possesses] it. Although open to all, its distribution is by definition unequal-it would not perform its functional logic if it were not" (emphasis in original, p. 20). If the individual possesses adequate knowledge and competence in how to exploit their capital in a particular field, they advance their position and assert their dominance in that field. This also entails that this individual will be able to successfully convert his or her capital within the field. Bourdieu's concept of field explains how 
"purposeful, reasoning, self-interested actors contribute in pursuing their own subjective ends" (DiMaggio, 1979, p. 1461) within their social spaces. With respect to DiMaggio's justification, I employ the concept of field in this study to explain the nature of student engagement at a Malaysian university.

This study draws on the links between capital, habitus and field to explain how students in a Malaysian university navigate their way in the education system, and devise strategies to compete in the education field by investing in various forms of extracurricular activities so they will be awarded with distinction when they enter the work field. 


\section{CHAPTER FOUR}

\section{REVIEW OF THE LITERATURE}

\subsection{Introduction}

This study utilises Pierre Bourdieu's (1977) theory of cultural capital, habitus and field and builds on research on cultural capital in the education system. Studies of these ideas have shown that inequalities in the education system are perpetuated partly because of the kinds of cultural capital held by students from different backgrounds; and also because of the kinds of cultural capital they acquire from both curricular and extracurricular activities. As students' perceptions and experiences structure their practices in university, the main focus of this study is how students' perceptions of education are formed and how these influence the choice of activities they engage in at university. I also investigate what students gain from participation in various extracurricular activities.

In this chapter I outline the various measurements used to define cultural capital in a Western and Asian context. Based on the literature I determine the variables to include in my study. Next I explain the two divergent views of social capital normally found in the literature. This allows me to establish the definitions of social capital used in my study, as I explain further in section 4.2. In section 4.3, I discuss how extracurricular activities enhance cultural and social capital by providing students with cognitive and non-cognitive skills needed to succeed in the education system and how students use their participation in extracurricular activities as a way to boost their resume. The literature supports the findings in my study, which will be discussed further in Chapter Six. I also include a section on habitus and student engagement (refer to section 4.4) to illustrate how students' perceptions of education are shaped and how this influences their engagement in university. Finally in section 4.5 I provide studies, which focus on Malaysian students' perceptions of education. The results from these studies are in line with the findings in my studies as I discuss in detail in Chapter Six. 


\subsection{Measuring cultural capital}

Bourdieu's theory of social reproduction has been applied in various fields of educational research. According to cultural capital theory, family background exerts a powerful influence on student's achievement because the home and the family are primary areas of socialisation for children (Bourdieu \& Passeron, 1977; Katsillis \& Rubinson, 1990). One of the strengths of Bourdieu's (1977) concept of cultural capital is that it "has enabled researchers to view culture as a resource - one that provides access to scarce rewards, is subject to monopolization, and, under certain conditions, may be transmitted from one generation to the next" (Lareau \& Weininger, 2003, p. 567). As Bourdieu argues, schools function as the main locus for the reproduction and legitimation of class structure by rewarding students who are familiar with the dominant culture in society (DiMaggio, 1979). Thus many subsequent studies have tested cultural capital theory to determine if it has a positive effect on educational success (DiMaggio, 1982; DiMaggio \& Mohr, 1985; De Graaf, 1986; De Graaf, De Graaf \& Kraaykamp, 2000; Dumais, 2002, Sullivan, 2001). The results of these studies have helped to inform our understanding of the importance of cultural capital in education amongst students from different social classes.

One of the strengths of the cultural capital theory is the broad and flexible nature of the term. This flexible nature allows researchers to explore a range of variables, which explain how cultural capital works in the educational process. The following studies demonstrate how this concept is defined and measured. The earliest definition of cultural capital provided by Bourdieu (1977) is related to 'highbrow' cultural practices practiced within family. He contends that participation in, and appreciation of, 'highbrow' cultures sets people of higher social classes apart from those of lower classes. Bourdieu further argues that a person who demonstrates knowledge and competence of 'highbrow' culture gains 'distinction' from members of the society. Although Bourdieu makes references to 'highbrow' culture, he does not clearly define the term. He does however; provide measurements of cultural capital, which include museum visits, reading habits, theatre attendance and appreciation of classical music and works of art. Various researchers have employed these indicators in their studies. Thereafter, most studies focus on cultural consumption as measurements of cultural capital, and they often study how participation in 'highbrow' culture is linked to educational success. For example, DiMaggio and Mohr (1985), De 
Graaf (1986), Katsillis and Rubinson (1990), Aschaffenburg and Maas (1997) and Noble and Davies (2009) all interpret participation in 'highbrow' activities, such as visits to the museum, attendance in plays or theatres, appreciation of classical music or works of art as indicators of cultural capital.

This conceptualisation of cultural capital is largely due to Bourdieu's (1977) claims that socialisation in highbrow activities, for example interest in classical music, appreciation for art or museum attendance ensures students' success in the education system. One particularly important aspect of the role of family background on education is to provide children with the necessary skills and knowledge needed to succeed in schools. This is because the mastery of skills, styles and habits by children from families of higher social class allows them to achieve academic success in the education system, as teachers reward these skills (Bourdieu, 1997; DeGraaf, DeGraaf \& Kraaykamp, 2000). These different interpretations have resulted in a large pool of research on the effects of cultural capital on students' achievement, educational aspirations and school success.

Paul DiMaggio was amongst the first to test the theory that socialisation in highbrow culture leads to academic success in schools. DiMaggio (1982) studied the effects of participation in highbrow activities on 3,000 high school students' grades across the United States. He discovered that cultural capital, measured by students' self-reported involvement in art, music and literature showed a positive effect on their grades. DiMaggio and Mohr (1985) further investigated the impact of cultural capital on educational achievement, affirming the positive effects of cultural capital on students' grades. DiMaggio's (1982) interpretation remains as the “dominant interpretation" (Lareau \& Weininger, 2003, p. 569) because he was among the first to replicate Bourdieu's theory that socialisation in highbrow culture enhances students' chances for success in the school system (Lareau \& Weininger, 2003, p. 574). However, De Graaf, De Graaf and Kraaykamp (2000) criticise the measurement of cultural capital used in DiMaggio and colleagues' earlier work. In both studies cultural capital was conceptualised through students' self-reported cultural interest but did not consider parental cultural interests. As both studies did not take into account parental practices, 
De Graaf et al. (2000) argue that it is not clear if the "measured cultural resources of students are to be interpreted as causally prior to outcomes in schooling" (p. 93).

As such, DeGraaf (1986) proposes a different approach to measuring cultural capital, by looking at parents' "cultural tastes and preferences" (DeGraaf, DeGraaf \& Kraaykamp, 2000, p. 93). The literature reveals that a number of studies have taken this approach to measuring cultural capital (Aschaffenburg \& Maas, 1997; Sullivan, 2001; Noble \& Davies, 2009). These studies report positive effects of parental cultural capital on student achievement in schools. For example, Sullivan (2001) included measures of both child and parental cultural capital in her study about cultural capital and educational achievement among English students in their final year of schooling. Her results reveal that parental cultural activities affect their children's educational performance by improving both language skills and their breadth of knowledge at home. However, another study on parental practices, yields different results (De Graaf, De Graaf \& Kraaykamp, 2000). In their study on parental cultural capital and educational attainment in the Netherlands, De Graaf, De Graaf and Kraaykamp discovered that parental reading behaviour, rather than parental participation in highbrow culture has a greater influence on students' achievement in schools. They give two explanations for this result. First, parents who read, provide their children with "a stimulating environment at home and [act] as examples for their children" (p. 107). Parents who read frequently are able to provide reading resources, which can aid in their children's learning. In addition, the parents' reading habits closely mirror the school climate where reading is encouraged and emphasised (De Graaf, De Graaf \& Kraaykamp, 2000). Second, parents who read frequently have well-developed "linguistic and cognitive skills" (p. 107), and these are important educational skills that they can pass on to their children to increase success in schools.

In a similar vein, Aschaffenburg and Maas (1997) studied how parental cultural practices, measured by parent's "education and training in various art forms" (p. 577) (arts, painting, dance classes and so on) affects students' school success. Their study reveals that parental involvement in cultural practices has a strong effect on their children's early education experience. Aschaffenburg and Maas (1997) affirm that early exposure to activities such as listening to classical music, attending the opera or live 
performances had positive effects on student achievement. Taken together, this indicates that parental practices play a central role in children's success in the education system. I concur with Aschaffenburg and Maas's (1997) argument that "the dynamics of cultural capital can be more effectively assessed when both parental cultural capital and children's own cultural capital are included in the same model" (p. 574). There are two reasons for this; one without taking into account parents' cultural capital, it is difficult to determine if the students' instances of cultural capital are due to "prior outcomes in schooling” (De Graaf, De Graaf \& Kraaykamp, 2000, p. 93). Two, parental cultural capital is a stronger measure of cultural capital because "parental cultural capital is not likely to be affected by their children's educational success" (De Graaf, De Graaf \& Kraaykamp, 2000, p. 94). Therefore, in this study, I include parental practices, which I measure through participation in highbrow culture and parental reading habits to investigate if these practices influence my participants' perceptions of education.

A third interpretation of cultural capital emerged where studies began to examine the role of parental education and parental occupation to measure this concept. In other words, some researchers (Katsilis \& Rubinson, 1990; Noble \& Davies, 2009; Albrecht \& Albrecht, 2010) have begun to study the impact of students' socioeconomic background on educational success. For instance, Albrecht and Albrecht (2010) explore the links between social status, adolescent behaviour and educational attainment in a study conducted in the United States. In this paper, they identify three main areas for investigation: 1) the relationship between social advantage and adolescent educational achievement; 2) the relationship between social advantage and educational attainment; and 3) the extent to which children from disadvantaged backgrounds are able to overcome low grades in high school. A major contribution of this research is that both researchers employ the concept of socioeconomic status and family structure to establish whether there is a link between the two. Their results show that people from economically advantaged backgrounds have higher high school educational achievement and attainment compared with peers from economically disadvantaged backgrounds. They claim "[s]ocially advantaged adolescents [tend] to earn better higher school grades, [score] higher on the cognitive tests, [...] compared to their socially disadvantaged counterparts" (Albrecht \& Albrecht, 2010, p. 132). In addition, individuals who come from two-parent families demonstrate 
more educational advantages compared with children from single parent families. They argued that parental education levels also had a significant impact on educational achievement and attainment. Educated parents possess the knowledge and familiarity needed to effectively interact with teachers and school material (Albrecht \& Albrecht, 2010). Similarly, in their study, De Graaf, De Graaf and Kraaykamp (2000) also include parental education to measure students' cultural capital. Their findings point to the importance of parental education as a "powerful predictor of children's success in schools" (p. 103). Taken together, this suggests that participation in highbrow culture is not the only determinant of educational success among children of different social classes. In fact, as the studies above prove, parental practices, parental education and parental occupation also play a role in student achievement in the education system.

One common criticism about Bourdieu's theory of cultural capital resides in the different ways in which cultural capital has been measured and defined (Sullivan, 2002; Lareau \& Weininger, 2003). Previous research on cultural capital shows that cultural capital is conceptualized in very different ways and this has resulted in a range of interpretations of the idea (Lareau \& Weininger, 2003). In fact, a review of the literature reveals that in recent years there has been a change in the way researchers have employed Bourdieu's theory of cultural capital. Different interpretations of cultural capital have emerged as researchers begin to take different approaches to understanding the notion of cultural capital. Various measures of cultural capital have included students' reading habits for example, visits to the library, number of books at home, reading of fiction and non-fiction books (De Graaf, De Graaf \& Kraaykamp, 2000; Sullivan, 2001), participation in cultural classes (Dumais, 2002), involvement in extracurricular activities (Covay \& Carbonaro, 2010; Jaeger, 2011), frequent discussions of cultural issues between parents and their children (Jaeger, 2009) and attitudes towards knowledge and culture (Mohr \& DiMaggio, 1995).

Taking these various approaches into account, the decision on how to measure my students' cultural capital has been guided by the studies I have reviewed in this chapter. As such, I include items that measure both students' and their parents' participation in highbrow culture, parental occupation and education level and parents' 
cultural practices to explore if these variables have an impact on students' perceptions of the purpose of university education (refer to Research Question One, p. 3).

In this study, I have measured cultural capital based on parental occupational background (Noble \& Davies, 2009), unskilled or semi-skilled, skilled and professional and managerial categories; parental education level, which is measured by the highest education level achieved by both parents (De Graaf et al., 2000; Sullivan, 2001), and family cultural practices. Parental cultural practices refers to the parents' habits and behaviour in their daily lives that shape a particular cultural environment for their children and which help them to develop strong educational aspirations ( $\mathrm{Wu}, 2008)$. I have identified these cultural practices through activities that are carried out at home, such as the family's reading habits; their participation in cultural activities such as attendance in concerts, museum visits, and participation in highbrow activities; participation in religious activities and issues discussed with family members at home such as politics, religion, current issues, music and science (Aschaffenburg \& Maas, 1996; Jaeger, 2009; Sullivan, 2001). In addition I also look at the role of institutional habitus, which refers to the beliefs and practices in the community at the tertiary institution (Reay, David \& Ball, 2001; Serow \& Dreyden, 1990). Using these variables I explore Malaysian students' cultural capital. From this data, I then explain how the students' cultural capital influences their engagement in university activities.

\subsubsection{Cultural capital in the Asian context of education}

There has been a growing interest in investigating how Bourdieu's theory of cultural capital applies in the Asian context of education. However, as we will see from the studies discussed below, cultural capital in an Asian context does not necessarily involve participation in, or appreciation of, highbrow culture as in the French context of Bourdieu's study. Instead, families in East Asian contexts tend to express aspects of cultural capital through practices such as investing in extra tuition for their children, overseas education and more importantly, parental involvement in their children's education to ensure that their children are given the best opportunities in education. This is perhaps due to the fact that in many Asian societies, such as China, Taiwan and Japan, traditional and cultural practices guide their daily practices (Saha, 2003). As 
such, Saha (2003) argues that knowledge of such practices constitute a form of capital which can be converted into other forms of capital.

One example of such practice can be seen in a study done by Johanna Waters (2006), who investigated the educational practices of middle-class families in Hong Kong. She argues that many middle-class Chinese families choose to send their children to Western universities abroad as a strategy for maintaining their social and economic status. These middle-class families place a high value on professional occupations and consequently, the acquisition of formal academic credentials is essential in social reproduction. In this case, an overseas education is seen as a form of cultural capital accumulation that is valued by many middle-class families in Hong Kong. These families believe that the experiences and training provided by Western universities are a form of capital that will be more highly valued by employers. These traits are considered to be conducive to professional success in the Asian workforce (Waters, 2006). Marios Vryonides (2007) defines this accumulation of cultural capital as "the nature of parental knowledge required for successfully engaging with various educational processes and assessing various options and opportunities for progressing to higher education" (p. 868). As my research will show these strategies and perceptions are similar to those of middle-class families in Malaysia who view Western higher education countries as being more valuable and thus highly sought after by local companies and institutions. Increasing competition from working-class families and widening access to higher education in Malaysia has led these middle-class families to find alternative strategies to maintain their status by sending their children abroad to gain international credentials and skills which are required to obtain high paying jobs.

Yoko Yamamoto and Mary Brinton's (2010) study about cultural capital in the Japanese educational system shows that many Japanese parents engage in direct forms of investment in their children's cultural capital by sending their children to "shadow education" (p. 68), which includes private academic tutoring services, correspondence courses and after-school lessons outside formal schooling. These activities are designed to improve the children's chances of successfully moving forward in their studies as it helps to boost their mastery in test taking skills in basic subjects such as maths, science and languages. This practice of shadow education is particularly salient 
in countries, such as Taiwan and South Korea that rely on a practice of student assessment through stringent examinations and merit-based education systems (Yamamoto \& Brinton, 2010). It appears that the practice of sending children to extra classes and providing extra help beyond what the classroom can provide, is a common practice among parents who wish to ensure that their children get the best possible opportunity to excel in examinations and thus gain the edge over their 'competitors'. This practice of providing extra help to boost educational capital supports the Bourdieusian framework that points to the argument over how families from higher social classes reproduce their existing social structures by investing in practices that can maintain their social status.

Similar practices have been reported among Malaysian families, with regard to additional capital accumulation beyond what the educational system can offer. In a study on Malaysian students' cultural capital, Sin (2009), tracks the views of 10 Malaysian students studying in a university in the United Kingdom. She found that the students were sent for private tuition from an early age. Their parents saw this as a way to accumulate cultural capital in an attempt to provide "the opportunity to race up the higher and more exclusive" (Sin, 2009, p. 292) rungs of the educational ladder. The accumulation of the participants' cultural capital included an emphasis on the importance of education and the value of obtaining good grades in school. Their parents often took extra trouble to ensure their children achieved academic success by sending them to private tuition classes or special classes to cover areas that schools could not, or did not manage to cover. In addition, the parents capitalised on their knowledge that a degree from an international institution of higher education would provide higher recognition and better job prospects compared with a degree from a local Malaysian institution ( $\operatorname{Sin}, 2009$ ). Sin also found that educational success is closely related to familial obligations and responsibilities and that the accumulation of wealth, status and the ability to attain middle-class or upper middle-class lifestyles was seen as a way of 'returning the favour' for the sacrifices their parents have made by sending them abroad for their studies. 
Byun Soo Young, Evan Schofer and Kyung Keun Kim's (2012) study about the role of cultural capital in East Asian education systems found a relationship between family socioeconomic status, cultural capital and children's academic achievement. They argue that parental cultural capital in Korea has a positive effect on children's academic achievement. They also found that given Korea's intensive system of test preparation both inside and outside the school combined with the highly competitive education system and a strong emphasis on shadow education and the accumulation of academic capital, students have little time to participate in highbrow (defined as possession of cultural goods and participation in cultural activities) cultural activities. Byun et al. (2012) argue that participation in high culture activities leaves less time for test preparation, which may have adverse effects on academic performance. It is common for Asian families to try and increase capital by trying to help their children to achieve success in schools by getting involved in their children's education. It should be noted that parents who possess higher educational levels and who come from higher socioeconomic backgrounds are predisposed to engage heavily in supervising their children's education (Aschaffenburg \& Maas, 1997; Albrecht \& Albrecht, 2010). As the educational system becomes more globalised and educational competition intensifies these parents have to strategise and adapt the 'rules of the game' by providing extra help for their children (Bourdieu, 1986).

It is undeniable that cultural capital plays a crucial role in shaping parental perception and guiding their decisions when it comes to matters that concern their children's education, as evidenced by the studies included in this section. However, most research focuses on the importance of cultural capital in explaining students' success in the school system, while neglecting the fact that other forms of capital may also contribute to the explanation. The key studies I discussed in the literature on cultural capital in the Asian context describe how Asian parents invest in private tutoring to enhance their children's educational success. In addition, investments in overseas education are also a method for parents to ensure that their children have a better chance at obtaining a job upon graduation from university. 
Much of the research in cultural capital has dealt with educational outcomes instead of focusing on the process by which students mobilise their cultural capital to achieve success. Similarly, although most of the research on cultural capital agrees that cultural capital helps students to navigate their way around the educational system, very little touches on how students use this capital to decide what type of activities can help them to gain educational advantage or to build on other forms of capital that are equally useful for them. Also, little attention has been given to understanding how students act in systematic and rational ways to shape their educational and career trajectories and how these decisions are shaped by individual habitus. This study addresses these gaps in the literature from a Malaysian perspective.

\subsection{Parental involvement and peer network as social capital}

Studies on social capital in education tend to focus on two different aspects: one, how individuals exploit social resources embedded in social capital for personal benefit; and two, how group membership is used to enhance collective goals (Son \& Lin, 2007). This divergent view is a result of the different definitions popularised by Bourdieu (1986) and James Coleman (1988; 1990). Bourdieu (1986) argues that a person's social capital is dependent on the quantity and quality of his or her social relationships. He proposes that those who have more power also have more access to social capital. In contrast, Coleman $(1988 ; 1990)$ proposes that social capital "is created within families through the relations between youth and parents and is partially dependent on the time they spend together" (White \& Gager, 2007, p. 77). Coleman (1988; 1990) argues that social capital is reliant on the strength of relationships between the family and their community. A review of the literature suggests that Coleman's definition of social capital is a more popular measurement of social capital compared to Bourdieu's. According to Coleman, there are two ways in which social capital contributes to students' success at school. One involves "the amount and quality of interest, support and encouragement, and knowledge that other family members have about education" (Majoribanks, 2003, p. 45) and two, the degree to which social capital is transmitted during interaction with family members. 
Most of the studies in the area of social capital in education characterize social capital in terms of levels of parental involvement. There is a large body of literature on the role of parents and their involvement in their children's education that show either a positive impact or no impact on student's education (Lareau, 1989; McNeal, 1999; Croll, 2004; Helliwell \& Putnam, 2007; Majoribanks, 2002). For example, Anette Lareau (1989) found that parents from an upper middle-class school appeared to be more involved in their children's educational lives compared with parents from a working class school. She argued that the parents of upper middle-class students are more likely to be available which then provides more advantage to the children from these families. This is because the teachers were more likely to favour students whose parents showed interest in their children's education.

Similarly, Suresh Vellymalay (2011) carried out a study in Malaysia on the relationship between Malaysian Indian parents' educational level and their involvement in their children's education. This study revealed a strong relationship between parents' education and their involvement in their children's education. Parents with higher levels of educational qualification may be more able to practice the strategies that would enable their children to perform better in schools. These strategies include communicating with their children about schoolwork, monitoring homework and their children's progress in school and identifying their children's academic problems. Vellymalay also argued that the higher the level of the parents' education, the higher the likelihood that their children will develop aspirations for advanced education (Vellymalay, 2011). David Baker and David Stevenson (1986) contend that parental involvement is vital in school success because "parents manage the school careers of their children by expanding resources, applying their knowledge of how school works and by making decisions about educational options, and stressing the value of schooling" (p. 157). As Bourdieu (1986) argues, social capital may be used as a means for obtaining greater educational qualification among higher social classes as they emphasize on educational investment among their children. I take this view on board as I examine if students' social class has an influence on the nature of their engagement in university. 
In addition, communication between parents and their children is also an important component of social capital. Practices such as frequently talking, or discussing, with children about homework, and important issues are used as indicators of greater social capital and are often associated with better academic achievement (Pong, Hao \& Gardner, 2005; McNeal, 1999). Indeed, most research has suggested that greater parental involvement and more frequent communication between parents and their children are often associated with positive achievement and positive behaviour outcomes (McNeal, 1999). Paul Croll (2004) found that familial support; family socioeconomic background; and parents' involvement in their children's education has a positive impact on school success. According to Croll (2004), direct forms of parental involvement, for example monitoring homework, translates to favourable educational outcomes. The findings of his study revealed that families from higher socioeconomic backgrounds demonstrated higher levels of involvement in their children's education. This shows that parenting style can have a positive impact on a child's success in school.

Another study, which yielded similar results, was conducted by Pong, Hao and Gardner (2005) where they investigated the role of parenting styles and social capital in the school performance of immigrant Asian and Hispanic adolescents in the United States. They measured social capital according to the type of parental involvementparent and child communication (for example dinner with parents, social talk and school talk). They also measured social capital in terms of parental educational expectation and their trust in their children, and also intergenerational closure (the number of times parents spoke to their children's friend's parents). The findings of their study indicated that discussions about school matters had a positive, significant impact on the children's school success whereas discussions about social events did not have any significant benefit for the children involved in this study. One important finding was that parental expectation and trust appear to be the most important element in facilitating school success. The overall conclusion of the study revealed that parental involvement, especially discussions about school matters, contributes significantly to raising the students' grade point average in school (Pong, Hao \& Gardner, 2005). I highlight these studies here because I include interaction between parents and children as measures of social capital, which function as a resource for success in the education system. In my study, the students' parents also demonstrate a 
high level of involvement and participation in their children's education to ensure they are able to compete with their peers in the competitive Malaysian education system.

Studies have also found that friendship and peer networks play an important role in school success. Ricardo Stanton-Salazar $(2004 ; 2005)$ argues that peer networks and support among Latin American adolescents provide positive benefits especially in terms of developmental gains such as social skills and school achievement. In his study the importance of social capital and the influence it exerts among members of the Latino community enables its members to cope with environmental stressors (for instance family poverty, community violence and schools, that lack resources and facilities) and encourages them to stay in and complete their education. This is because the social resources based on connections and group memberships are important for information flow and trust which is crucial in achieving one's goals (Coleman, 1990). Seen in this light, the dependence on social interaction and strong bonds among members of a community is an important facet of social capital (Grenfell, 2009). Robert Ream and Russel Rumberger (2008) suggest this is because "friends act, for better or for worse, as prototypes for subsequent processes that influence educational attainment" (p. 125). Moreover, they propose that the role of peer networks can help to explain "students' action oriented participatory behaviours" in schools (Ream \& Rumberger, 2008, p. 112). These arguments point to the role of peer networks as a powerful source of influence over students' behaviour. With this in mind, in this study I examine the role of peer network and social ties and how these social relationships influence student engagement with extracurricular activities at university.

In this study, I draw on the work of Amanda White and Constance Gager (2007) and employ their definition of social capital as "resources derived from youth's social connections" (White \& Gager, 2007, p. 79). I also extend this to include parental involvement and discussion (Coleman, 1988; 1990) as part of my definition of social capital. In their study White and Gager (2007) conceptualised engagement in extracurricular activities as examples of social networks that operate "as carriers or transmitters of social capital" (p. 79). I also consider involvement in extracurricular activities as a source for transmission and accumulation of social capital in my study. 


\subsection{Extracurricular activities and student outcomes}

The literature discussed below indicates that participation in extracurricular activities has positive impacts on student outcomes. The studies included reveal how extracurricular activities build a student's cultural capital, while others relate to the role of social capital in influencing student engagement in extracurricular activities. In my study I also look at similar areas as I examine why my students choose to engage in extracurricular activities and the benefits they gained from participation in these activities. It is worthwhile to note that there is very little literature published concerning cultural capital and extracurricular activities in higher education, but based on the literature, there are several ways in which extracurricular activities can affect student outcomes.

A person's social class has a bearing on how actively they engage in civic activities. To test this idea, Muriel Egerton (2002) explored the civic participation rate among students from different social classes in the UK. She analysed the influence of social class on young people's involvement in social and civic engagement and found it higher amongst those who were enrolled in higher education than those who had not entered higher education. Her study also indicates that children of professionals may be more inclined to participate in civic activities compared with children of manual workers or managers, although she did not specify why this is the case. Similarly, Elizabeth Covay and William Carbonaro (2010) examined how socioeconomic status is related to students' participation in extracurricular activities. Their findings show that students from high socioeconomic status families are more likely to participate in extracurricular activities. Both parental education and parental occupation status have positive associations with participation in extracurricular activities. Covay and Carbonaro (2003) argue this is because students from high socioeconomic status families increase their cultural repertoire by engaging in various forms of activities, which they hope will improve non-cognitive skills in the classroom. For instance, participation in sports and dance can provide opportunities to develop other skills such as discipline, teamwork or communication skills, which may be valued in the classroom setting. Guided by these studies, I examine if factors such as parental education and occupation have an effect on my students' participation in extracurricular activities at university. 
It is clear that participation in extracurricular activities builds on students' cultural capital by providing them with skills that might be useful in the future. For instance, Stuart, Lido, Morgan, Solomon and May (2011) examined how extracurricular activities influence the experiences, outcomes and future job prospects of students from four different universities in the UK. They found that extracurricular activities such as voluntary work and university-related extracurricular activities (for example, sports team and committees) were important to help distinguish graduates in the job market (Stuart et al., 2011). For example, employers asserted that they would look at a students' involvement in extracurricular activities as it helped them to form judgments about the candidates. They also talked about cultural 'fit' and the candidates' confidence, social skills and ability to work in teams as an indicator of a candidate's employability (Stuart et al., 2011). The study discussed above, signals that students' involvement in extracurricular activities transmits important information, to prospective employers, about the students' cultural practices. Students are rewarded with job opportunities when they possess the cultural capital that matches what employers perceive to be traits of a good employee. In a similar vein, Jacqueline Stevenson and Sue Clegg (2011) carried out a study on how students orientate themselves towards the future through extracurricular activity. Stevenson and Clegg (2011) identified three different orientations of students based on their study. The first group had a well-developed orientation towards the future, and their participation in extracurricular activities was to aid in career progression, particularly in professional jobs. Most of the students in this group came from middle-class families who placed high importance on a high-level of educational achievement. The second group of students valued the extracurricular activities they participated in as they found enjoyment in socialising with peers at university. These students described their participation in extracurricular activities in terms of enjoyment- just to keep healthy and fit rather than viewing extracurricular activities as being beneficial for future plans. The final group of students engaged in extracurricular activities because they were influenced by altruistic motives. Their desire to help others was the main motivation for pursuing extracurricular activities (Stevenson \& Clegg, 2011).

In addition, research has shown that participation in extracurricular activities increases students' cultural capital by positively influencing students' achievement in schools thus increasing the probability of enrolling in college in the future. For 
example, Jason Kaufman and Jay Gabler (2004) conducted a study on the effects of specific causal roles of extracurricular activities on students' decision to enroll in college. They found that direct involvement in extracurricular activities such as music and dance; public service; interscholastic team sports; and student government organisations increased their likelihood of entering college. In addition, engagement in extracurricular activities that were unusual (for example a male student participating in a female dominated field) benefitted the students by helping them to stand out and appear unique among their peers (Kaufman \& Gabler, 2004). Their results point to the role of extracurricular activities as an investment strategy whereby the students invest in extracurricular activities in return for recognition and 'distinction' that can be exploited for college applications. This is because students' extracurricular involvement transmits information to college admission officers about students' cultural habits and practices. If the students' habits match those of the institutions, the students have higher chances of gaining admission into the institution. Alexander Astin and Linda Sax (1998) contend that engaging in community service and voluntary activities during undergraduate years will enhance a student's academic development, life-skill and development exponentially. They also argue that a stronger sense of civic responsibility will develop which helps in character building. In addition, Joseph Berger and Jeff Milem (2002) also claim that involvement in community service positively affects the cognitive development of students who participate in such civic engagements.

Research has suggested that participation in extracurricular activities increases students' social capital when they build networks and links with the university and their peers (Wollebaek \& Selle, 2002; White \& Gager, 2007). White and Gager (2007) claim that extracurricular activities are important sources of social capital because involvement in these activities, "provide youth with access to key resources, such as positive experiences with supportive adults" (p. 105). For example, Beckett Broh (2002) proposes that participation in extracurricular activities strengthens social ties between students and teachers. He suggests that the more frequent the interaction between the students and teachers, the more information the students gain on how to improve grades. He posits three ways in which friendships with members of the faculty can aid students. One, "by encouraging behaviour that conforms to school expectations and norms, which in turn helps students to succeed in schools. And two, by creating 
social bonds that motivate students to perform better for teachers with whom they have personal relationships" (p. 86). The third relates to teachers' bias as students who are well known and familiar to the teachers tend to be treated more leniently (Broh, 2002).

Engagement in extracurricular activities can also result in positive behaviour among students. Ream and Rumberger (2008) argue that adolescents who participate in extracurricular activities are "more integrated into school, tend to be friends with those who share their same activity profiles, and typically avoid problem behaviour" (p. 125). This in turn yields positive effects on educational achievement and lessens the probability of school dropouts (Ream \& Rumberger, 2008). Dag Wollebaek and Per Selle (2002) support this claim as they explain that the breadth and strength of one's network was a determinant for more active participation in extracurricular activities and voluntary activities as students had adequate trust and support from their peers, organization or institution they were affiliated to (Wollebaek \& Selle, 2002). As Frank Fustenberg (2000) has noted, there is a lack of research done on the role of extracurricular activities in accumulating social capital. With this in mind, my study extends the research on social capital in two ways. First identifying the benefits Malaysian university students accrue by investing in extracurricular activities. And second, by exploring how they invest their social capital as a resource to gain information and knowledge from their friends and peers.

\subsection{Habitus and student engagement}

Bourdieu argued that social space can be thought of as one large 'field' (Thomson, 2008, Swartz, 1997). Each social field of practice is metaphorically described as a game or "fields of struggle" (Maton, 2008, p. 54) where the objective of the game is for the social agents to maintain or improve their positions within the specific fields. It is within this framework that he employed the notion of habitus, to describe how social agents make use of their knowledge and "feel for the game" (Maton, 2008, p. 54) to dominate a field. In the context of my study, the university represents the field of struggle where students compete for academic distinction. This distinction allows them to maintain and further their dominance in the field. However, 
there is now increasing pressure for students to "supplement their educational credentials with other forms of distinction" (Brooks, 2007, p. 425). Johanna Waters (2006) argues this is due to the large number of students graduating from university, thus creating credential inflation. The workforce also becomes highly competitive as university graduates vie for jobs upon graduation. Students often have to ensure that they possess a competitive edge over their peers. In order to gain distinction and 'stand out' from the rest of their competitors, these students are forced to devise strategies to achieve this goal. This involves having a mastery or knowledge of the game, which is derived from a person's habitus (Reay, 2004). As David Swartz (1997, p. 100) claims, habitus consists of a "matrix of perceptions, appreciations, and actions" that guide one's practice and actions. Therefore, students' perceptions and expectations of higher education are shaped by their social, economic and cultural capital and their individual habitus (Reay, 2004). My participants' perceptions of the value and purpose of education are shaped by their knowledge and understanding of the competitive education system. As they attempt to navigate their way in the university and strive for distinction, they are forced to make choices on the most effective way to reach this goal.

Studies have shown that educational choices are made within the context of one's habitus (Lareau, 1987; McDonough, Antonio \& Horvart, 1996b; McDonough \& Antonio, 1996a). This is because choice is central to the concept of habitus (Reay, 1998; 2004; Swatrz, 2002) and students exercise choice by drawing on their past experiences. Phil Hodkinson and Andrew Sparkes (1997) argue that educational choices and decision-making among young people are based on pragmatic and rational perceptions of education on their part. The culture and knowledge upon which people base their decisions are a result of interaction with others and the values and norms, which the subjects have been living in (Hodkinson \& Sparkes, 1997). For instance, Patricia McDonough and Anthony Antonio (1996) proposed that students conceptualise their college experience differently, depending on how they perceive these experiences. They also argue that students often make choices based on how they can utilise their qualifications for further educational and occupational attainment. In a similar vein, Patricia McDonough, Anthony Antonio, and Erin Horvat (1996) modelled their study of students' college choice decisions on a Bourdieusian framework. They discovered that for students, college is viewed as a time to reinvest previously obtained 
capital and accumulate additional capital, which would prove useful for conversion in future educational and occupational attainment. They also contend that students continue to accumulate capital while in college, and would later convert it to economic resources upon leaving college or reinvesting it by attending graduate school. These studies provide evidence that cultural capital and habitus have a significant impact on educational aspirations, and achievements in college (Walpole, 2003; Reay, David \& Ball, 2005). The literature indicates that student engagement is linked to habitus in that the students choose to invest in various extracurricular activities to increase chances of converting the cultural capital they have gained from participation in these activities into economic resources in the future.

In addition to individual habitus, the role of familial habitus is also important in influencing engagement at university. Diane Reay, Miriam David and Stephen Ball (2005) define familial habitus as "the deeply ingrained system of perspectives, experiences and predispositions family members share" (p. 61). They contend that parental involvement in terms of encouragement, influence and investment is important in shaping students' decision making in educational matters. This is because "an important aspect of familial habitus is the complicated compilation of values, attitudes and knowledge base that families possess in relation to the field of higher education" (Reay, David \& Ball, 2005, p. 62). Gill Crozier, Diane Reay, John Clayton, Lori Colliander and Jan Grinstead (2008) give examples of ways familial habitus can influence student involvement in university - by passing on relevant knowledge on higher education; providing private tuition to enhance their children's success in schools; or even by using their social networks to help their children to gain advantages in schools. Thus I propose that a family's beliefs and attitudes towards education influence the way their children are predisposed to view the purpose of education. This in turn affects their engagement in university as they build on the knowledge from their parents and other relatives to choose suitable curricular and extracurricular activities to engage in while at university.

Besides individual habitus, Reay (1998) proposes that institutional habitus also has an impact on students' experience and engagement at university. Building on Bourdieu's work on individual habitus, she argues that each organisation also 
possesses its own set of habitus, which has a significant impact on a students' educational experience. Institutional habitus can be understood as "the impact of a cultural group or social class on an individual's behaviour as it is mediated through an organisation' (Reay, Davies, David \& Ball, 2005, p. 36). In the context of my study, the institutional habitus (in this case the members in the different clubs and organisations) affects the nature of students' engagement in campus activities in the site university. In addition, the university curriculum and policies that make volunteer work compulsory for students also affect the nature of student engagement in these activities (refer to Chapter Eight). As Nicola Ingram (2009) argues, "the individual agent's habitus is the integration of her accredited past experiences, the school's habitus is a product of its accumulated 'history and 'experiences', its past and present pupils and staff and its perpetuated traditions" (p. 424). This points to the role of the institution, and institution-led activities as catalysts for student engagement within the university. When students feel they 'fit in' and have a sense of belonging to the university community, the likelihood of engagement and sustained interest in engaging with peers, studies and university activities is enhanced, thus influencing the nature of their engagement (Nora, 2004). I concur with Ciaran Burke, Nathan Emmerich and Nicola Ingram's (2012) claims that 'individual habitus can be deepened by considering not only its relationship to the social field but also the interconnections that exist between habitus within those fields that are constituted by collective practices" (p. 166).

There is some debate on the use of institutional habitus to study individual practice and agency. Will Atkinson $(2011 ; 2013)$ disputes the use of the concept as he claims that institutional habitus is not a "corporeal or organic" (p. 337) substance. He contends that only people have the traits of being able to "perceive, experience, have assumptions or be predisposed towards anything" (p. 337), whereas inorganic objects such as schools or universities do not. He also argues that grouping together all families, schools or universities into a single unit assumes 'homogenisation' (Atkinson, 2011, p. 338) and disregards the notion that each entity has its own "differences, rifts, struggles and alliances" (Atkinson, 2011, p. 338), in the struggle for position in social spaces. Others such as Burke, Emmerich and Ingram (2013) disagree with his argument. They argue that institutional habitus can explain "how the group functions and is maintained through shared experiences and practices as well as through struggle and resistance [because] what is common to, and shared by, a collective is 
important in understanding individual members" (Burke, et al. 2013, p. 172). In fact, studies have shown that institutional habitus and familial habitus are definitive and have a significant impact on students' perceptions, and decision making in education (Reay, David \& Ball, 2001; Thomas, 2002; Crozier, Reay, Clayton, Colliander \& Grinstead, 2008; Ingram, 2009). Taking this into consideration, in this study I take into account the role of familial habitus and institutional habitus alongside individual habitus, to ascertain if these three factors influence my students' perceptions of the purpose of education and subsequently, their engagement in university activities. I argue that paying attention to this triad of habitus will elicit more nuanced and contextually based insights into the impact of institutional habitus and student practices and perceptions. My position is in keeping with Burke, Emmerich and Ingram's (2013) that institutional habitus does exist as a corporeal entity as it consists of collective attitudes and beliefs shaped and practiced by the individuals in an organization or institution. I concur with Burke, Emmerich and Ingram's (2013) contention that:

schools and other institutions can directly shape the habitus and practices of individuals through their organisational forms and collective practices. [...] The idea of an institutional habitus introduces a degree of nuance to this mediation, prompting us to consider not just relational aspects of habitus and field but also the interactions of the different habitus within a given field (p.167).

\subsection{Perception and purpose of university education from Malaysian students' perspectives}

The role of the university and educational institutions has undergone a significant shift in the last century. Traditionally, universities were viewed as sites for the acquisition and generation of knowledge. This is in accordance with what Samuel Gould (1970) observed when he defined the idea of the university as a site for intellectual stimulus. He observed that, " $[t]$ he touchstone of quality in a university is the amount of wisdom it generates in the young and out of the knowledge it imparts" (p. 38). However to cope with the rapid changes brought about by globalisation, the role of the university in Malaysia was transformed. Universities started to play the important role of producing individuals who could fill the country's workforce 
instead of focusing merely on promoting intellectual stimulus or growth. Aronowitz (2000) likens current higher education institutions to 'knowledge factories', which regularly produce graduates at an escalating rate to fulfill the demands of the workforce, instead of the more vital role the university should play.

There have been very few studies, which focus on students' perception about the role of university and the value they place on education, particularly in the Malaysian literature. Kok and Cheah (2011) claim that the role of the university has undergone a significant perception shift especially among Malaysian students. The traditional role of the university as a site for the acquisition and enhancement of knowledge has changed, shifting from knowledge-based to production-based (Vail, 2000; Aronowitz, 2000; Moss, 2003). This transformation into a corporate entity led the researchers to study Malaysian students' perceptions about the roles played by the university (Kok, Cheah \& Ang, 2011). Kok and Cheah (2011) carried out a survey at 10 universities throughout Malaysia, which generated 485 responses from undergraduate students. The results of their study show that Malaysian students are very pragmatic in nature (Kok \& Cheah, 2011). The students believe that the acquisition of knowledge is important but they link the acquisition of knowledge to practical aspects, such as future career progression. Their ultimate concern is obtaining good job prospects, which in turn will ensure financial stability and a better quality of life. Kok and Cheah (2011) tie this response to the government's role in policy-making, which promotes the production of skilled workers to fill the workforce. Results of the study also show that students believe that a university education will help them to acquire cultural formation (inculcate good values such as respect, tolerance and acceptance to others' culture and beliefs), which enables them to create a better society. They claim that this aspect is important especially for an Asian society, which is very community based.

Kok, Cheah and Ang (2011) conducted a follow up study involving 482 university students from the public universities in Malaysia. The participants were comprised of the various ethnic groups in Peninsula Malaysia. The findings from this study indicate that Malaysian students perceive the university as an important site for social networking, and a place where they can develop critical thinking skills which differs from the more passive, one directional-teaching style practiced in primary and 
secondary schools. As with the earlier research done by Kok and Cheah (2011), students still felt that the role of the university was to promote a better society by producing better citizens who are able to practice good values within the community. Overall they reported that Malaysian university students demonstrate a positive view of the university. These students perceived that education is a medium for upward social mobility among a majority of the students involved in the study.

\subsection{Summary}

In summary, although some literature exists on student engagement and involvement in community service and voluntary activities, the meanings the students attribute to these activities are not fully understood. These meanings would be able to provide an important lens through which we can examine the nature of participation in such activities in higher education. As discussed in the literature, there has been extensive research, which employs Bourdieu's theory of cultural capital with regards to educational achievement and educational aspirations. Despite mixed findings, a large percentage of the literature indicates that cultural capital has a strong positive relation with educational aspiration and success, particularly from middle-class families. In the literature, the idea of cultural capital has also been investigated from a South East Asian perspective, in an attempt to determine how Asian families negotiate and accumulate capital in an attempt to maintain and reproduce their social status. These studies show that Bourdieu's theory is supported and in fact, replicated among Asian families with some differences in the strategies employed to ensure educational success among Asian children, particularly in countries which practice a strong examination-based culture such as Japan, Taiwan, South Korea and Malaysia.

In contrast, there exists a relatively small body of literature focusing specifically on the role of cultural capital on student's decisions to participate in community service and voluntary activities. Most of the research in the area related to extracurricular activities focuses more on the positive impact of community service, club participation and voluntary activities on students' learning and the positive impact of such activities in university life and experience. 
Finally, I included a section on Malaysian students' perception on the purpose of university education. The studies conducted by Kok and Phaik (2010) and Kok and Tan (2011) report that Malaysian students perceive university as a site for the production of skilled workers to enter the workforce. Malaysian students are a practical group, often choosing to enter university because they realise that education enables social mobility, stable career prospects and stability. It is evident that they enter university to accumulate as much capital as they can to convert to economic resources after graduation. Students also report the accumulation of social capital which they feel makes them better people and better citizens. Based on the literature discussed above, research on how cultural capital affects involvement in community service, clubs and voluntary service, is needed to provide new understanding and contribute to research on the cumulative effects of social class on educational experiences in the higher education setting.

In this chapter I have established the context and discussed the key literature relating to cultural capital in education. In addition, I examined the research on cultural capital in the Asian context. I also considered the literature on parental involvement and peer networks as measures of social capital. Finally I included a section about Malaysian students' perceptions about the purpose of university as a way of establishing the context for examining how these students' perceptions affect their engagement in university activities. This issue will be discussed further in Chapter Eight of the thesis. 



\section{CHAPTER FIVE}

\section{METHODOLOGY}

\subsection{Introduction}

In the previous chapter I presented a review of the literature, and explained how a person's cultural capital, habitus and field influences their perceptions and guides their decisions with regard to their engagement in university. In this chapter I discuss the research design and methodology I used to obtain data and answer my research questions.

First I begin by situating my research within a philosophical context. I then describe my research design and the rationale for using a mixed method approach research design for this study. I also discuss the rationale for using a case study approach to answer my research questions. This is followed by a description of the research site and the characteristics of the research participants, before I explain the stages involved in my data collection process. I will also explain how I will analyse and interpret my data, before concluding the chapter with a discussion on the ethical considerations involved in my research.

\subsection{Research paradigm}

I take an interpretive stance in my study as I attempt to understand meaning that is socially constructed by individuals and their interactions with their world (Merriam, 2002; Denzin \& Lincoln, 2000). According to Sharan Merriam (2002) this is where most qualitative research is located. I also seek to understand the meaning individuals give to particular aspects of their world and how they make sense of their experience (Creswell \& Miller, 2010). In this regard, the existence of multiple realities or interpretations of these experiences are an integral component of this research. 
In this study, the qualitative paradigm assumes that reality is socially constructed and based on participants' beliefs and perceptions about their world. The aim of my research is to investigate participants' perceptions of the importance of higher education and how this translates into their engagement in university activities. As such, the nature of the study takes a qualitative, interpretive stance as I attempt to discover the participants' multiple understandings of their lives at university and how they form practices based on these worldviews and experiences.

Norman Denzin and Yvonna Lincoln (2000) contend that an interpretive or constructivist paradigm "assumes a relativist ontology, a subjectivist epistemology and a naturalistic set of methodological procedures" (p. 24) and these attributes are mirrored in this research. In other words, they argue that an interpretive paradigm takes the view that truth is relative to particular frames of reference, such as language or culture. There is no absolute way of explaining why a social phenomenon happens because it is always dependent on the context, culture and experiences of the subjects involved in a study. The nature of my research lends itself to an interpretive or constructive approach as I set out to study my participants in their natural settings, while attempting to make sense of their perspectives and the meanings they ascribe to their beliefs. I aim to establish how my participants use their knowledge to cope with the demands and competitive nature of education which allows me to establish whether there is a link between their cultural capital, their perceptions of education and their engagement while at university.

In addition, an interpretive or constructivist approach also identifies with contextualized perspectives towards reality (Creswell \& Miller, 2010), and this is an important aspect of this research. In other words, knowledge is constructed around personal experiences and hypotheses of the environment, and each person has a different interpretation and construction of the knowledge process. Barbara Grant and Lynne Giddings (2002) sum it up aptly when they explain that a researcher focuses "on an individual's actions or descriptions of experiences and their explanations of them. The relationship is intersubjective with the researcher acting as a listener and interpreter of the data 'given' by the participant" (p. 17) As I am exploring the similarity or diversity of students' interpretations, I provide new insight into how 
cultural capital, habitus and social capital function in the context of higher education in Malaysia. Furthermore, as I describe and interpret the events and experiences, I will construct knowledge using my participants' perspectives, another key criterion in an interpretive approach to research (Merriam, 2002). As the theoretical framework is based on Pierre Bourdieu's theory of cultural capital (as discussed in Chapter Three), the findings drawn from a Malaysian context and viewpoint will be distinctly dissimilar and diverse compared with a Western perspective.

The interpretive perspective taken in this study fits my worldview and conception of reality (Creswell \& Plano-Clark, 2007). Living and working in a multicultural country, and having a multi-cultural background has influenced my views and perspectives about cultural practice and social values in Malaysian society. The insider knowledge I have about the culture; the value placed on education in Malaysia; and the way that many students struggle to steer their way in and around the education system adds insight to the field. I explain and describe this belief system through thick, descriptive data obtained through qualitative means. In addition the use of visual data, obtained from my participants, contributes to the interpretive nature of qualitative research. However, I acknowledge that my view and perspectives may be biased in nature and the challenge for any qualitative researcher is to reduce such bias. I will address this issue in the later part of this chapter.

\subsection{Research design}

My research investigates the relationship between Malaysian students' cultural capital and their perceptions of university education. I then examine how these perceptions influence their engagement with academic life with particular reference to the community services, clubs and voluntary work they engage in. My study is predominantly qualitative but draws on questionnaire data for "baseline information" (Johnson, Onwuegbuzie \& Turner, 2007, p. 115). In the qualitative phase of the study, visual data, focus group interviews and follow up interviews were conducted. The qualitative aspects of the methodology form the core component of the research as I explore the complex interplay between the participants' worldview and the meaning they place on the role of education in their lives. In this study I aim to discover how 
they engage in certain activities based on their perceived understandings of the world around them. In this case, the use of quantitative and qualitative data serves to complement each other (Greene, Caracelli \& Graham, 1989). Jennifer Greene, Valerie Caracelli \& Wendy Graham (1989, p. 258) contend that in a "complementarily mixed method study, qualitative and quantitative methods are used to measure overlapping but also different facets of a phenomenon, yielding an enriched, elaborated understanding of the phenomenon".

Meanwhile, the quantitative aspect of the research allowed me to validate the findings about the participants' cultural and socio-economic backgrounds, which support the qualitative data that I obtained later in the study. Through conducting a questionnaire, I was able to gather demographic data about the students' and the cultural activities that both they, and their parents, engage in at home, or outside the home environment. This data provided information about students' cultural capital in ways that spoke directly to the qualitative findings. The use of mixed methods also allows for cross checking between the data derived from one specific technique to ensure the validity and reliability of findings (Morse \& Niehaus, 2009; Hesse-Biber, 2010). The two measures assess different levels and aspects of the research and this will be discussed further in the findings chapter.

My rationale for the use of mixed methods is drawn from Johnson and Onwuegbuzie's (2004) view that mixed methods research "is an attempt to legitimate the use of multiple approaches in answering questions, rather than restricting or constraining researcher's choices" (p. 17). In other words, mixed methodologies allow researchers to structure their research questions in various ways in order to trigger different levels of participation and responses from the participants (Johnson \& Christensen, 2008).

John Creswell and Vicki Plano Clark (2007) suggest that the use of mixed methods allows researchers to gain a better understanding of a research area compared with using a single dataset. The use of mixed methods approaches allows a 
researcher to "form a more complete picture of the problem then they do when standing alone" (Creswell \& Plano Clark, 2007, p. 7; Johnson, Onwuegbuzie \& Turner, 2007; Morse \& Niehaus, 2009). Furthermore, using mixed methods in research provides additional support and strength that can offset the weaknesses of both quantitative and qualitative data. It allows for the voices of the participants to be heard while at the same time, reducing the bias created by personal interpretations of the case being studied (Creswell \& Plano Clark, 2007; Hesse-Biber, 2010). The use of qualitative methods has facilitated a more dynamic interaction between me, as the researcher and the participants, thus enabling a level of trust to be established.

Furthermore, using mixed methods in research provides additional support and strength that can offset the weaknesses of both quantitative and qualitative data. It allows for the voices of the participants to be heard while at the same time, reducing the bias created by personal interpretations of the case being studied (Creswell \& Plano Clark, 2007; Hesse-Biber, 2010).

\subsubsection{Case study research design}

A case study design was used in this study to understand students' experience in extracurricular activities. Case studies are strategies of inquiry whereby the researcher is able to derive theories of "a process, action or interaction grounded in the views of the participants" (Creswell, 2009, p. 13), using multiple stages of data collection, as demonstrated in my study. In adopting a case study approach, my study uses multiples sources to collect data from the participants.

In this study I have developed two sets of case studies. One set focuses on a cohort group of first year, pre-university students while the other set concentrates on a cohort group of third year degree students. Both cohorts consisted of students enrolled at the East Malaysian site university. A case study was conducted on these cohorts to gain an understanding of how their perceptions influence their choice of civic participation while at university, and also to track if there were significant changes in 
their perception and engagement in community service and voluntary activities after a period of time.

The main reason for using a case study approach was because I hoped to gain a holistic understanding of each specific case. Case studies are particularly useful for providing rich, descriptive explanations (Stake, 2008) about the phenomenon being studied (Yin, 2003). These case studies allowed me to understand how my students' cultural capital shaped their perception of the purpose of university education and why they chose to engage in extracurricular activities in university as a strategy for building and accumulating capital. Using case studies, I am able to give an in-depth account of my participants' decision-making process in the choice of extracurricular activities.

Furthermore, case studies are a good way of investigating complex social phenomena within a real life context (Yin, 2003). Case studies are particularly important when a researcher wants to find out how or why a phenomenon is happening. Case study research designs provide vivid and complex accounts of a study in comparison to quantitative approaches (Cohen, Manion \& Morrison, 2007). In my research, the use of case studies provides information on what is unique and important in the case, so I can develop better understanding of the values and practices which drive student engagement amongst Malaysian university students. Case studies allow for vivid descriptions of the behaviour of "social agents who [are] dynamically constructing their strategies for achieving social distinction" (Robbins, 2005, p. 25). In other words, I am able to gather the interpretations from the people who have the most knowledge about the situation and elicit in-depth responses of their experiences (Gilham, 2000; Cohen, Manion \& Morrison, 2007).

Another reason for using case studies was due to the nature of the research and the questions being explored. Case studies offer a means of investigating the complex social interactions involved in the study. My aim was not to establish a representative sample (Merriam, 2002) but to focus my attention on specific factors in the research setting (for example socioeconomic background, cultural capital and perceptions) that 
could have an impact on student engagement in university. The investigation of a specific case allows researchers to explore context-bound factors that may have an influence on the phenomenon being studied (Yin, 2003). My study takes into account multiple variables, and the interplay between these variables are abstract and difficult to measure. Understanding the contextual factors may lead to a better understanding of how students who come in with different amounts of cultural capital cope in the university system.

\subsection{Research questions}

The following questions are the guiding research questions for my study:

1. How does students' cultural capital shape students' perception of university education in Malaysia?

2. How do these perceptions influence the nature of their engagement in extracurricular activities at university?

3. In what ways do these perceptions of the role of education and extracurricular activities change after their studies?

In order to answer my research questions, I canvassed the views of a group of first year pre-university and third year degree students from the East Malaysian site university in Sarawak. My participants were asked to answer a questionnaire, which provided a measure of their cultural capital. They were then asked to keep a Photo Diary, where they recorded digital images of the extracurricular activities they participated in over the course of two semesters. After that, they were asked to attend a focus group discussion. Finally, follow up interviews were conducted to elicit further information from the participants. Data gathered from these methods were then analysed and interpreted. 


\subsection{The participants}

A total of 21 participants were involved in this study, including:

i) Thirteen third year degree students from the School of Business ( $n=6)$ and the School of Engineering $(n=7)$.

ii) Eight students from the School of Foundation and Continuing Studies. Seven students from Foundation Engineering and one from Foundation Commerce.

The rationale for choosing the two different cohort groups was to capture the views of students at different stages of their academic studies. The pre-university students were new to the university and gave a fresh view of the nature of their engagement in university activities. In addition, having just finished their secondary school education and having recently made the transition to university they provided an interesting and unique perspective compared with the older cohort group who were in their third year of their university studies.

The purpose of selecting the third year cohort group was to elicit the views of students who had at least two years of experience at the university. My expectation here was after having been in the university system for a few semesters their perceptions and views may have changed over the course of their studies. My intention in selecting these two student cohorts was to provide a snapshot of how students' views might have changed during the course of academic study. In addition, I wanted to capture any similarities or differences in their perceptions in order to better understand this process of change and its relationship to their habitus and capital.

It is important to note that some of my participants' voices come out more strongly than others, because these participants were more engaged in contributing to this research project. These participants were also the ones who constantly maintained contact with me during the research process, asked questions, and sought more information on how they could continue contributing to the research. 


\subsection{Research site: The East Malaysian site university}

The East Malaysian site university is an offshore campus of an Australian university located in Western Australia. The main campus, located in Australia, has had an educational relationship with Sarawak since 1998. University representatives at the main campus in Australia and the Sarawak State Government signed a Memorandum of Understanding for the development of academic cooperation, which led to the establishment of the East Malaysian site university in Sarawak. Courses at the East Malaysian site university range from pre-university (also known as foundation) programmes through to undergraduate degrees in commerce, media studies, information technology, science and engineering. It also offers courses at preuniversity level that feed directly into its undergraduate programmes. Currently, the East Malaysian site university has approximately 3,000 students from over 40 countries studying in an international and cross-cultural environment.

The university is classified as one of Malaysia's Private Higher Education Institutions (PHEIs) and is bound by the Private Higher Educational Institutions Act 1996 and also by the National Accreditation Act because this university operates as a semi-private institution as it is partially owned by the state government. The state provided the land and funding for the campus to be built.

This university was chosen as the research site because of its multi-cultural environment. The different cultural backgrounds of the participants offer additional insights into the way individuals from middle-class families perceive education and the nature of their engagement in the university environment, as well as the potential for unique findings on cultural capital. Furthermore, the site university is one of the two private universities in Sarawak and I was interested to investigate the trends and practices in my home state. My role as a lecturer working in this university for seven years enabled me to establish rapport and locate myself in an unobtrusive manner within the research site. Through my close rapport with the students, I was able to obtain vivid and powerful data that contributes to the understanding of how they view the world and community around them. 


\subsection{Data collection procedures}

\subsubsection{Stage one of the research: Inviting participants}

After I obtained ethics approval from Victoria University of Wellington, I sought ethics approval from the East Malaysian site university to conduct research with the students. When ethics approval was secured I contacted the Student Services Manager to obtain permission to access a copy of the student list. Emails were sent out to every ninth person on the list, inviting them to participate in the research. In the email, details of the research were explained so the participants were fully informed of what they were being invited to do, and the estimated duration of the research. Consent forms were also attached to the email (refer to Appendix A for research information sheet and consent forms).

I encountered an unforeseen difficulty in the first phase of my research, as the invited survey participants did not respond to the invitation. After approximately one month of waiting, the responses from the participants were not encouraging. I emailed the potential participants a second time, and reminded them about the study. After waiting about three weeks with minimal response, I consulted with my supervisors on the next course of action. We discussed what I could do to recruit more participants and decided to enlist help from my colleagues and students. It was clear that the email approach was not an appropriate way of contacting participants so the sampling method was modified to include snowball sampling, and I managed to gather volunteers through my participants' networks. Snowball sampling refers to a form of sampling in which respondents initially chosen for a study are used as informants to locate other suitable participants as part of the sample (Penrod, Preston, Cain \& Starks, 2003). Snowball sampling has the advantage of a wider coverage because the respondents are reached through social networks (Heckathorn, 1997). This means that the respondents are selected not from a sampling frame, but from the social network of existing members within the sample (Salganik \&Heckathorn, 2004; Marpasat \& Razafindratsima, 2010).

In this phase of the research, I used a virtual snowball sampling method to see if I could recruit interested volunteers. To achieve this, I made use of the social 
networking service (SNS), Facebook, as my part of my data collection method. Fabiola Baltar and Ignasi Brunet (2012) advocate the use of Facebook as they believe that it helps to improve the efficacy of the snowball sampling and collection of data. They contend that Facebook enables personalised contact strategies that allow researchers to maximise the time-cost factor and increased sample size. Melinda Villagran (2011) argues that by using technology as a tool for data collection, it allows participants to engage in the research process as they are empowered to provide evidence for a specific study.

This method was the most successful, as I obtained immediate responses from several interested participants. Through Facebook, these volunteers also started promoting the research to their friends, and as a result I was able to get a larger pool of participants who were willing to commit to the research. The effectiveness of this social tool as a source of information will be explained further in this chapter. Christine Brickman-Bhutta (2011) adds that the value of Facebook as a sampling frame lies in the quick, accessible and diffuse manner in which information can be communicated and disseminated amongst its users.

I arranged for a face-to-face meeting with my participants and obtained consent from them to participate in the research (refer to Appendix A). I gave a briefing on the Photo Diary project and outlined some of the ethical issues involved in the second phase of the research. For example, my participants were reminded not to capture images in which individuals were easily identified. They were asked not to take pictures of children and to ensure that all the pictures taken would adhere to the ethics approval I obtained from the Ethics Committee of both universities (these issues will be discussed further, later in this chapter).

\subsubsection{Stage two of the research: Distributing questionnaires}

In the second stage of the research, I distributed questionnaires to my research participants. The questionnaire was adapted from John Noble and Peter Davies' (2009) study. The purpose of the questionnaire was to provide me with a general measure of 
students' cultural capital (Noble \& Davies, 2009). Bryman (2008) advocates the use of questionnaires as it allows for collection of structured data for the transmission of more useful, informative data that can be used to frame interview questions for further study. The data also provided information about their cultural capital, familial background and family practices. Items in the questionnaire included questions about participants' parental occupation, parental education, reading habits, participants and their parents' activities in their spare time, and the things their parents' discuss (for example, current events, religion and music) at home (refer to Appendix B). The questionnaire also included items on students' reading habits other than materials assigned as part of their coursework, students' participation in cultural activities, family structure, parents' educational level, parental occupation, parents' participation in cultural activities, parental reading habits and also topics of conversation at home (for example, politics, current affairs, religion and books) in the hope of eliciting as much information as possible about the practices within their household. I adapted John Noble and Peter Davies (2009) original questionnaire and added items to ask the students if they had previously attended private tuition classes after school and if so, what subjects they took up tuition for. This was to identify if the students' families placed strong emphasis on academic excellence. I also added questions about musical preference and attendance in music lessons to identify the students' cultural practices during their free time. Questionnaires were distributed during the briefing session and also during the focus group interview sessions for convenience and ease of collecting the responses from the students.

\subsubsection{Stage three of the research: Documenting visual images}

In the third phase of the research, I asked my participants to become 'research photographers'. To this end, they created a Photo Diary containing photographs to illustrate, document and reflect upon the extracurricular university activities they participated in. The Photo Diary project served as a powerful tool to capture parts of my participants' engagement in activities they perceived as being meaningful and fulfilling. The Photo Diary project is influenced by the work of Caroline Wang's (1999) Photovoice research. The notion of getting the participants involved in the study and give 'voice' to their experiences, perspectives and situations they capture in their photographs provided me with valuable data (Mitchell, 2008; Strack, Magill \& 
McDonagh, 2004; Hergenrather, Rhodes \& Bardoshi, 2009). The approach provides a better understanding about the values and importance the participants attach to their world (Berg, 2004).

Besides that, visual images are strong representations of the mechanisms of the participants' social contexts. The image content contains its "internal narrative" or the story that lies behind the human actions that frame the social context (Pink, 2003, p. 186). Gillian Rose (2000, p. 556) contends that photographs serve as a "cultural document' to record memories, knowledge, incidents of importance and images that are valued and important to the photographer. In addition, she believes that these cultural documents embody evidence of historical, cultural and socially specific ways in which the photographer views their world. The visual image also reflects the social context that produced the image and the social interactions in which the image is rooted and practiced (Pink, 2003).

Furthermore, photographs allow the diarists to express elements of their shared culture and their positions within it and also allow them to share their 'situated knowledge' with their audience (Holliday, 2004). Rose (2000, p. 553) contends "the production, circulation and consumption of photographs produce and reproduce the imagined geographies of the social group or institutions for which they were made". The production of cultural practices, social interactions and shared beliefs within the university are valuable sources, which informs this study on the participants' experience at university. In this case, visual methodologies play a central role in the sharing of the students' cultures. In this context, the diarists are sharing their cultural capital and situated knowledge, which formed the basis of my reflections during the data analysis phase of the study.

In addition, the inclusion of visual data in the research is guided by my belief that words are often inadequate to reflect the complex dimensions of social structure, culture and social interaction (Collier, 1967). The visual dimension of this research gives a glimpse into the construction of a range of cultural practices as they are taking 
place. In this respect, the visual data method, alongside the participants' narratives, is a powerful tool for conveying messages about personal and cultural beliefs (Collier, 1967; Rose, 2000; Pink, 2007). In light of this, Elizabeth Chaplin (2004) argues that a photograph is almost never viewed in isolation. She claims, "a photograph is never viewed purely as 'a photograph'; we tend to focus on the content of the image, and 'what it means' seems to vary according to the context in which it is viewed" (p. 36). This in turn produces more meaningful interaction with the diarist and their world as they 'speak' to us through their social interactions (Banks, 2001).

Marcus Banks (2001) argues that visual methodologies serve as powerful tools to capture social knowledge. As this knowledge is something which is seen as contextdependent and constantly fashioned and refashioned by individuals, collaboration between the research subjects becomes important and researchers need to fully acknowledge the subjects as active creators and shapers of data. By allowing their 'voice' to be heard through verbal and visual images, I am able to provide 'inner' narratives that speak to the participants' perceptions about how their experience is shaped by the community service activities they participate in. To strengthen these narratives and also to allow for the inclusion of more active voice in the research, I also include my participant's descriptions and explanations of the images they have taken (Banks 2001; Chaplin, 2004).

One appealing aspect of Facebook, is that it allows its users to create albums, share the pictures, add their own descriptions to the pictures, and comment on pictures that have been uploaded on the site (Ellison, et al., 2007). Realizing that the volume and file size would be an issue when documenting visual images, I decided to create a group on Facebook. Overall there were 22 participants (13 male and 8 female) who joined the Facebook group page. Of those, 13 participants were in their third year and 8 were doing their foundation studies. The person who creates a group is automatically designated as the administrator of the group. The administrator has full control over the page, which means they can approve members, control group content and protect the privacy of the group. The administrator also has the right to decide whether the group is 'open', 'closed' or 'secret' and this was a valuable tool for helping me maintain ethical standards and requirements throughout the study by protecting 
both the privacy and the confidentiality of the participants involved in the study (Brickman-Bhutta, 2011). For my study I ensured that I set up privacy functions to 'closed' so the images could only be viewed by the participants. The images were not available to other Facebook users or other users on the Internet.

Creating a Facebook group was an effective means of communication for my participants who found this way of engaging with the study much easier and more convenient than the more traditional approaches I had originally envisaged (BrickmanBhutta, 2011). Some participants were active users and they visited the page frequently. These users were my main channels of communication, they helped me to 'tag' their friends in comments, which required immediate attention, or they would post up comments on their friends' 'walls' so the news would spread faster and much more efficiently (Selwyn, 2009). They were also happy with the idea of posting up pictures in the albums as it then minimized the hassle of meeting up and transferring huge files using thumb drives or portable hard drives.

My participants could add descriptions of the activities in the pictures, and their friends were able to comment on the pictures they uploaded. They could have 'conversations' on the whole album, or a specific picture. It was also interesting to note some of the participants 'reminded' their friends that the visual images should not contain faces, as individuals would then be easily identified. This meant that the participants spontaneously engaged with the ethical protocols I had established and were eager to help monitor these protocols in a respectful way. Other participants asked questions about the research and their friends would respond and this helped to convey information in a collegial way. However, to protect privacy and confidentiality, if a participant felt that they were not comfortable sharing the pictures with other participants, they had the option of setting the album to private, and making it available to a specific person or group of friends only. I found this feature very useful and highly beneficial as well. 
Another useful feature was the 'Create Events' feature, which allowed me to create an event and send out invitations to all the members of the group. They would then RSVP electronically and this helped me to arrange suitable times for the focus group interviews. I was able to get immediate feedback and responses from the participants. It was also helpful that the participants could leave messages on the 'wall' of the created event, thus making it possible for us to coordinate and find suitable times for the focus group interview.

The social aspect of Facebook was a very popular form of communication for the participants. Even now, they visit the site frequently and exchange news and information via status updates, private emails and messaging functions, which are readily available within the site. Facebook also allows users to create groups and events, upload pictures and also connect to a large number of people with a single click. Given these characteristics, the emergence of social networking services (SNS) has transformed the Internet into an efficient tool for snowball sampling (BrickmanBhutta, 2011; Villagran, 2011; Baltar \& Brunet, 2012). Kevin Lewis, Jason Kaufman, Marco Gonzales, Andreas Wimmer and Nicholas Christakis (2008) and Nicole Ellison, Charles Steinfield and Cliff Lempe (2007) support this view arguing that SNSs are ideally suited for data collection and analysis with the wealth of features it offers for eresearch opportunities.

\subsubsection{Stage four of the research: Focus groups}

Focus groups can be particularly beneficial "in order to maximize the ability to produce situated knowledge about the processes and experiences outside or inside a research site" (Mason, 2002, p. 64). At the end of the semester, with this in mind, I arranged focus group interviews with the two different cohort groups. The objective of the focus group interviews was to get an in-depth view of the participants' experience regarding their involvement with various activities throughout their studies. The focus groups also provided a platform for my participants to interact and talk to each other about their experiences, and to see the similarities and differences in their thinking (Steward, Shamdasani \& Rook, 2007). It also provided an interactive space for them to share their values with other individuals who shared similar interests while bringing in 
several different perspectives as each participant negotiated and explained their views (Ary, Jacobs, Razavieh \& Sorensen, 2006: Barbour, 2007; Mason, 2002).

The nature of focus groups is that discussion is discursive and sociallyconstructed. This allows the participants to lower their inhibitions and contribute in supportive or critical ways, which consequently lead to "richer, deeper, more honest and incisive" data compared with a single interview session (Wilkinson \& Birmingham, 2003, p. 92).

Instead of recording the interview, however, I decided to ask my participants to write down their thoughts and views during the interview sessions. There were a few reasons for this, one, because the participants were reluctant to speak because they were conscious of the recording device I had placed on the table. Two, getting them to write out their thoughts allowed my participants time to think and get as much information as they wanted without the pressure of having their interaction recorded. Third, I was able to keep a written record of their personal thoughts and observations regarding their involvement and experience while doing community work and voluntary activities. To reduce the risk of 'group thinking' the students were allowed to discuss with a partner or work individually (if they wished to) on A4 paper and post-it notes. They then glued their post-it notes to a large paper where the group could then read their peers' thoughts. This generated some valuable responses as the group then discussed some of the issues their friends had raised.

I had two separate sessions for the different cohort groups. The first session comprised of all the senior students. There were 11 students (five female and six male) involved in the focus group. There were eight students in the second focus group. This was comprised of six male and two female foundation students. The focus group questions for the first year foundation students and the third year students can be found in Appendix E. In Appendix F I include details of how I conducted my focus group (as the students were reluctant to be audio recorded). 
Essentially, stages one and two of the study focused on my participants' experiences and perspectives on community service and voluntary activities. Throughout stages three and four of the research I gained insight into their decisionmaking processes, and came to an understanding of the values they placed on engaging in extracurricular activities.

\subsubsection{Stage five of the research: Follow up interviews}

Stage five of the research involved follow-up, one-to-one interviews with selected participants. I did follow up interviews because according to Ary et al (2006) they are a useful way of collecting structured data that gives insight to the complexities, depth and nuances of the participants' social worlds (Ary et.al, 2006; Mason, 2002). Cohen, Manion and Morrison (2007) contend that interviews allow participants to discuss their interpretation of the world and how they regard their situation from their point of view within the research context.

In this research, I used semi-structured interviews as they gave me a degree of flexibility about the participants' perceptions and experience (Burns, 2000). In the semi-structured interviews, I formulated questions around the research topic, but exercised a level of flexibility in modifying the format of the questions during the interview process when participants raised issues that I thought needed to be pursued (Ary et al. 2006). In addition, using semi-structured interviews provided the added advantage of reflecting on my participant's views on a subject, rather than having my views imposed on the outcomes of the research (refer to Appendices C and D). There are two different sets of interview questions for the different cohort group. For the third year students I focus on asking them about their changes in perception after having completed two years in the site university and also about their involvement with extracurricular activities during their years in university. For the first year foundation students I try to elicit information on why they chose their current course of study and their initial experience of attending university. 
Overall, eight individuals were selected for this interview. Four participants (three male and one female student) were from the School of Foundation and Continuing Studies, two (both male students) from the School of Business and the remaining two (two female students) from the School of Engineering. These participants were selected because they were actively involved in community work and outreach activities, and they highlighted some interesting points during the focus group interview which I wanted to follow up on. All the interviews were recorded and transcribed. As some participants used a mix of English and a local language, I did some translation when transcribing the interviews.

\subsection{Data analysis: Quantitative and qualitative data}

Cresswell's (2003) work on analytical tools and procedures was appropriate for analyzing my data. His procedures involve a process of "preparing for analysis, conducting different analyses, moving deeper and deeper into the understanding of the data, representing the data and making an interpretation of the larger meaning of the data" (Creswell, 2003, p. 190). Cresswell (2003) argues this analytic procedure provides a systematic and holistic method of data analysis, which engages the researcher in the study.

\subsubsection{Quantitative analysis}

I carried out analysis on the quantitative data by tabulating the relevant information such as demographic data, and the responses I obtained from the questionnaires. The findings from the questionnaires are presented in the form of graphs, charts or percentages for ease of understanding. In my study, the quantitative data was not analysed statistically, because the population sample was not randomly generated and because the main aim of the survey was to get a general picture of the participants' cultural capital and family practices. In addition, the questionnaire served to generate information for the follow-up interviews. I also referred to the data obtained from the questionnaire to provide explanations for the findings from the visual data phase and the follow-up interviews. 


\subsubsection{Qualitative analysis}

I transcribed the interviews and translated phrases from Bahasa Melayu to English where required. It is important to note that English is not the first language for many of the participants and I transcribed the interviews in English in verbatim and did not make any editorial changes. Plus, I did not make changes or correct the students' grammar except in cases where it would affect comprehension. In the initial stages of data analysis, I made notes about any interesting issues that cropped up during the interview. During the transcribing process, I also made notes of unexpected findings or responses recorded during the interview. The notes were revisited during the coding process.

A preliminary analysis was done after I had completed the transcriptions. To this end, I started the process by reading through the transcripts in order to build a set of initial codes. The initial codes were assigned based on line-by-line coding, and this allowed me to form a general idea of the possible codes that could be formed. Subsequently, other codes were added as I read through each paragraph in the transcript. As patterns began to emerge, I started to add other codes to the transcripts, and began to code the transcripts by larger chunks.

The transcripts were uploaded to NVivo9, and at that point I began to reanalyse and rebuild the codes and themes. The role of NVivo in this phase of analysis was to help to manage the codes efficiently. I was able to list all the initial codes and take a closer look at codes which seemed to overlap. From that point, I was able to merge individual chunks of data from different interviews and look for similarities or differences and analyse the information accordingly. In addition, using NVivo, I was able to formulate a more detailed and precise analysis of the codes as I analysed chunks of data from the interviews in a single file.

After coming up with the initial codes I began to sort them out and merge overlapping data. I examined the chunks of information under each node, to see if they fitted into the appropriate node. I drew out individual chunks of data, which I deemed 
interesting and in need of further analysis, and compiled them in a Word file. After revisiting the transcripts and re-reading them again, I merged the two levels of codes into higher thematic codes, thus reducing them to more manageable clusters of themes based on the research questions. At this point, the research questions helped to frame and guide the conception of themes as I tried to refine the themes and attempt to answer the research questions.

\subsubsection{Analysis of visual data}

The analysis of the visual data was guided by Caroline Wang, Jennifer Cash and Lisa Powell's (2000) framework, which involves three important stages: selecting the relevant photographs; contextualising the photographs; and coding the emerging themes and issues. Thus, guided by this framework, I organised the analysis into three stages. In the first stage, I asked the participants to either identify the photographs they felt accurately represented their involvement in community service, clubs or voluntary activities, or to select the activities to which they attached the most importance. I took this approach in an effort to address the large volume of visual images produced by some of the participants.

In the second stage, my participants began to develop the context of the stories. Each participant was encouraged to provide details about the photographs and the reasons why they felt the activity was most beneficial, or had the most impact on them on Facebook. In this case, they provided the 'voice' (Berg, 2004), giving me a narration of their journey throughout the two semesters. As my participants explained the site in which they experience community service, voluntary work and academic activities, they included a narration of their space and how they function within their field to get a feel of the game. In this case, my participants provided the research with unique perceptions that they brought with them to the study. In addition, the visual images were used as a justification for the data that emerged from the focus group and individual interviews, to identify if there was a match between data from the focus group and interviews and those reflected by the visual images. 
Finally, I identified the themes which emerged from the contextualising and narrating of the photographs. This was studied alongside the focus group and follow up interview findings, so that a more complete picture can be drawn from the different sets of data (Collier, 2001). As I examined the data from the focus group interview and follow up interviews, I looked at the descriptions provided by the students about the photographs. I also examined recurrent images or descriptions to identify if the data obtained from the photographs matched those obtained from the focus group and follow up interviews. This was to search for corresponding patterns and explore if these patterns carry any meaning or significance, which can be attached to the themes in the study (Collier, 2001).

\subsection{Ethical considerations}

Ethical considerations were strictly observed in all aspects of the research. After obtaining Ethics Approval from Victoria University of Wellington, I sought, and was granted, Ethics Approval from the site university to carry out research on students enrolled at the university. I called a brief meeting where I distributed information sheets to the participants who had volunteered to be part of the project (refer to Appendix A). The consent forms were included in the information sheet. After I explained the objectives of the research and briefed the participants on the ethical guidelines for the Photo Diary project, I asked the students if they were willing to consent to participate in the questionnaire, Photo Diary project, focus group interviews and follow-up interviews.

I was aware of the ethical issues involved when documenting visual images. One aspect that had to be taken into serious consideration was the problem of confidentiality. I had to ensure that the individuals involved in the project could not be easily identified. To manage this challenge, during the briefing, I distributed a handout on ethical guidelines for the Photo Diary to my participants (refer to Appendix G). This handout contained detailed guidelines about the Photo Diary project and the constraints involved when taking pictures during any given activity and important information so participants were well informed of the ethical concerns involved when capturing visual images for research purposes. My participants were asked to exercise 
caution and not to include identifiable images of their friends or peers or anyone involved in the activity. They were encouraged to be as creative and inventive as possible when taking any images.

Using Facebook as a data collection method carried potential ethical risks. To mitigate these, in setting up the Facebook group page I ensured that the setting was made private. Only my participants could view the page and only invited individuals could access or view the page. My participants were able to invite their friends to the page, but it would have to be approved by the administrator, which in this case was me, before they could view or participate or interact with anyone on the page. Participants' identities could also be kept confidential as individuals who were not 'friends' on Facebook could not view any information or profiles that were set on private (Light \& McGrath, 2010). The only information that they could share were the invitations to the event or the comments posted up by the participants on the group wall. Although all participants could view and comment on the pictures posted on the page, again, each participant had the option of setting the view as private, friends only or just for selected people. This function was available for all pictures and albums that are created on Facebook. In this way, the rights and privacy of each of the participants were fully protected unless they decided to make their posts and updates available to the public (which in this case is limited to participants on the page only). Issues of ethics with regards to privacy in SNSs are thus addressed and adequate measures are taken to maximize privacy and confidentiality (Light \& McGrath, 2010). The limitations of using Facebook as a data collection method is discussed further in Chapter Ten (section 10.5).

My participants were made aware that they could withdraw from participating at any point in time during the research without any repercussions. They were also assured that information they provided during the research would be kept strictly private and confidential. 
In this chapter I have discussed the research paradigms that have guided my research design. I also explained the research design and the rationale for using a mixed method approach for data collection. Next, I gave an overview of the research participants and the research site. After that, I discussed the stages I went through to collect data. Then, I explained how I analysed my data. In the next three chapters, I will present the findings, together with the analysis of the data I obtained from the questionnaires, the focus group interviews, the visual data provided on Facebook, and the follow up interviews conducted with the participants. 


\section{CHAPTER SIX}

\section{STUDENTS' PERCEPTIONS OF TERTIARY EDUCATION}

\subsection{Introduction}

The only reason why I chose to pursue tertiary education is because in the society, higher education offers graduates better job opportunities compared to those who don't have it at all. Besides, having higher education [guarantees] a higher pay that [can] improve our quality of life, [where] we [can] have better economic stability and security instead of depending on [our] parents or the government in the future. (E, third year engineering student, interview session)

The interview extract above reflects a perception of education that is commonly held by the participants in this study. It is also a way of thinking about the purpose of a university education that is shared amongst students in most tertiary institutions (Kok \& Cheah, 2011; Kok, Cheah \& Ang, 2011). Indeed, it is this instrumentalist view of education that led to my interest in understanding the significance of the impact of cultural capital, and to explore whether cultural capital plays a part in influencing an individual's perception of tertiary education.

In recent years, there has been a growing interest in the role of cultural capital and its effects on educational achievement and future jobs. In this chapter, I discuss how students' cultural capital influences their perception of the purpose of university education and I explore the relationship between familial and societal roles in shaping students' perceptions. Thus, this chapter presents findings on the cultural capital students bring with them to university and explores how this cultural capital has helped to shape their perceptions and understandings of the nature of university education. 
I also aim in this chapter to establish whether the participants' cultural capital influenced their understanding and engagement with university activities. In order to do so, I draw on the data derived from questionnaires and interviews to illustrate the changes in the way they perceived their university experience. The first of my research questions that I address in this chapter is how does the students' cultural capital influence their perception of university education? I have broken down the research question into two main parts in order to provide information about the participants' cultural capital. Part one discusses the participants' demographic information, their cultural practices and cultural capital. For the second part of the research question about the participants' perceptions of the purpose of university education, I explore the links between students' cultural capital and their understandings of the purpose of a university education.

The findings are presented as follows: first in section 6.1, I present some demographic information about the participants involved in this study including details about the participants' family backgrounds. In 6.3, I discuss three indicators of cultural capital including parents' occupational backgrounds (Noble \& Davies, 2009), parental education levels (De Graaf et al., 2000; Sullivan, 2001; Croll, 2004) and the families' cultural practices (Aschaffenburg \& Maas, 1996; Jaeger, 2009; Sullivan, 2001). In section 6.4, I discuss the cultural activities practised within the students' family environments. From these activities, I am able to draw conclusions about the participants' cultural capital. Section 6.5 examines the participants' beliefs about the purpose of university education. In summing up the chapter, I discuss the link between cultural capital and how it influences the participants' beliefs about tertiary education.

\subsection{Demographic information}

Throughout this chapter, I draw my findings using tables and charts, participants' quotes or photographs to present my findings. The data types are all aligned based on the themes that emerged from the study. I employ the use of graphs and charts to present data I obtained from my questionnaires and used the quotes from the focus groups and follow up interviews to support the findings that I gathered from the questionnaires. The photographs and students' explanations obtained from 
Facebook are used to illustrate their experience engaging with extracurricular activities and support findings gathered from the other two data sources. All names used are pseudonyms.

A total number of 21 participants were involved in this research with all questionnaires completed and returned at the end of the study.

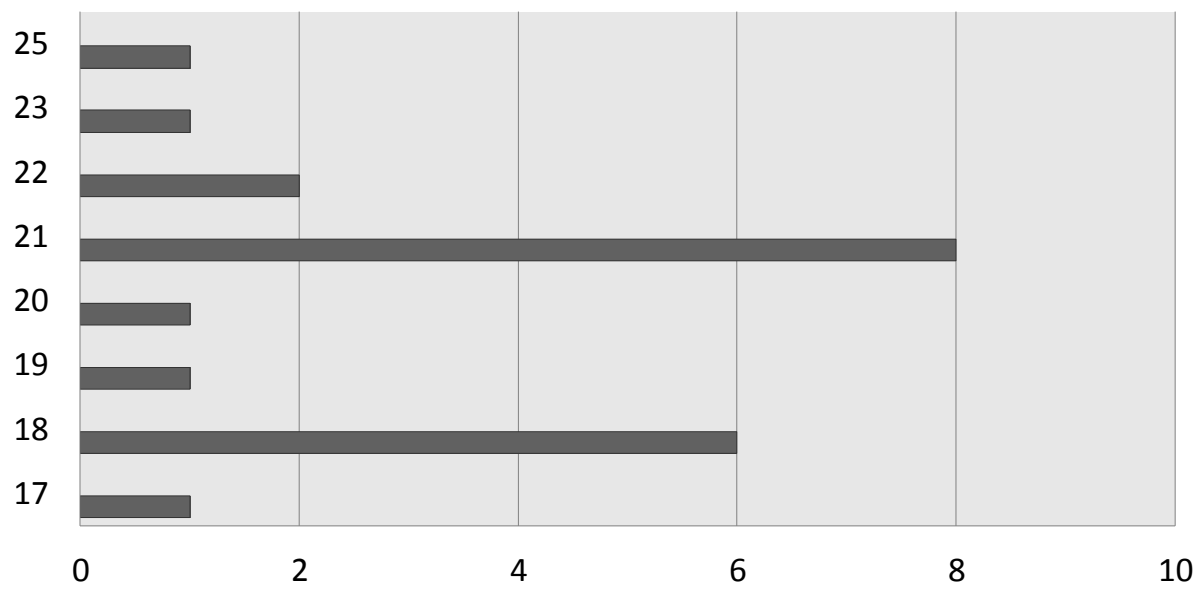

Figure 6.1. Participants' age

The participants' $(n=21)$ age ranged between 17 to 25 years. Eight participants had just finished their secondary school and were in their first semester of the foundation programme at the university. The remaining thirteen participants were third year degree students (Figure 6.1). Six of the third year students were doing their degree in business while seven were engineering students. 


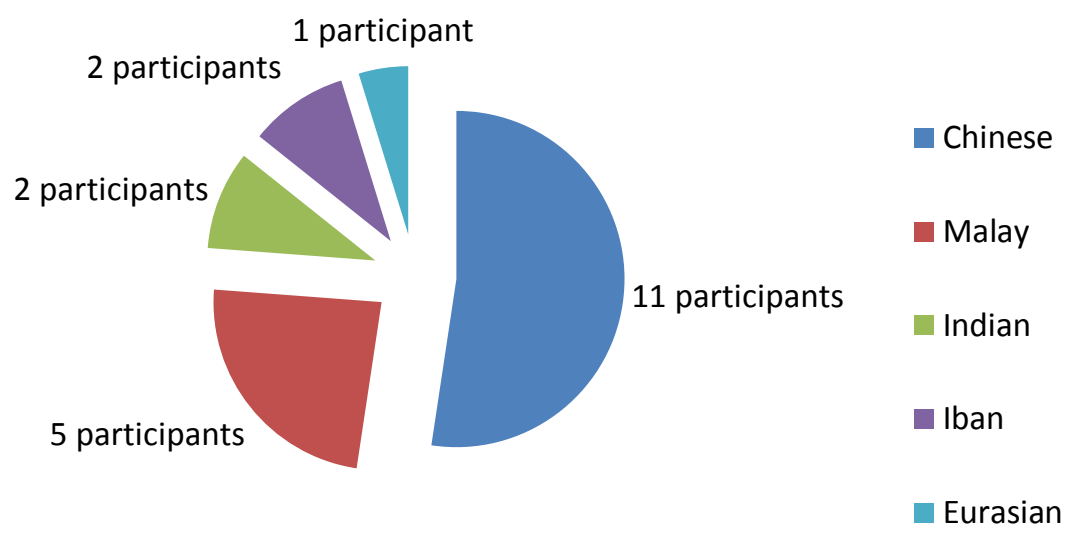

Figure 6.2. Participants' ethnicity

The majority of my participants were Chinese students ( $n=11)$, with five Malay, two Indian, two Iban (the indigenous people in the Sarawak area) participants, and one Eurasian participant in this group (see Figure 6.2). Thirteen female and eight male participants were involved in this study.

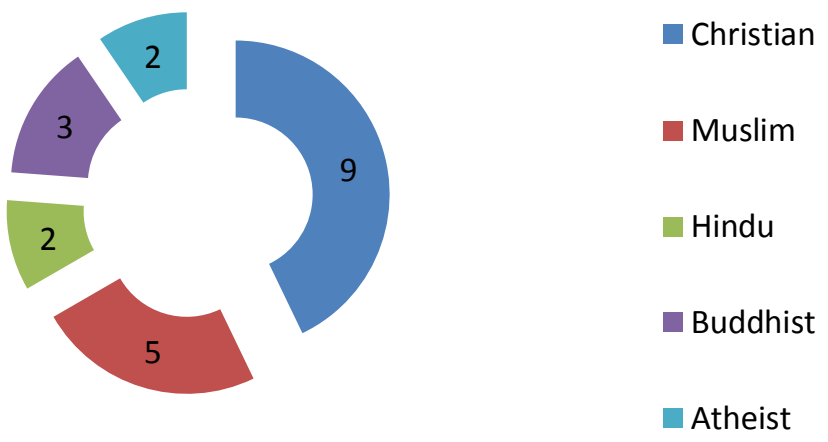

Figure 6.3. Participants' religion

Christianity makes up the largest group in the sample $(n=9)$ as we can see from Figure 6.3. There were five Muslim participants, three participants who followed the Buddhist faith, while two were followers of the Hindu faith. Two participants were atheists (as shown in Figure 6.3). 


\subsection{Parental cultural practices}

I begin my discussion by establishing the participants' family backgrounds. This includes information on parental education level and occupation. The participants were asked to provide information about their parents' educational levels and occupation in order to shed light on their socioeconomic backgrounds. This allowed me to draw a link between the participants' socioeconomic status and their cultural practices. In addition, items investigating the participants' familial activities and parents' cultural practices are also discussed in this chapter.

Contrary to the findings reported in Andolina, Jenkins, Zukin and Keeter's (2003) study where they argue that parents act as role models who drive children to participate in voluntary activities, the participants in this study reported that most of their parents do not foster any volunteering habits at home. There is also little evidence in my study to suggest that parents directly encourage their children to get involved in any sort of community service or voluntary activities. The visual data provided by the participants also do not show any evidence of parental involvement in inculcating volunteerism amongst the participants involved in this study. For example during the follow up interview, when I asked one participant if her involvement was inspired by her parents she replied:

Um, my parents.. Nah, they don't do any community work. Even in the normal neighbourhood when they are actually asked [by] all the neighbours to come to help out for the gotong royong ${ }^{1}$, only me and my brothers would go. My parents stay at home. We just go on behalf of our parents. (EL, female, third year engineering student)

Another student gave a similar answer when he was asked if his parents contributed to his interest in community work.

\footnotetext{
${ }^{1}$ Activities where people in the neighbourhood gather to help out in communal activities such as cleaning the mosque, helping out during a wedding, host an open house during festivals, and so on.
} 
Anita: Are your parents involved in community work in any way? Has that in any way influenced your decision to participate in community work here?

TK: Not really. Mostly it's from my friends and from what I actually experience. Because the more people there are, in a committee, [your combined efforts] will make it more successful. No matter what that committees [you are a part of]. (TK, male, first year foundation student)

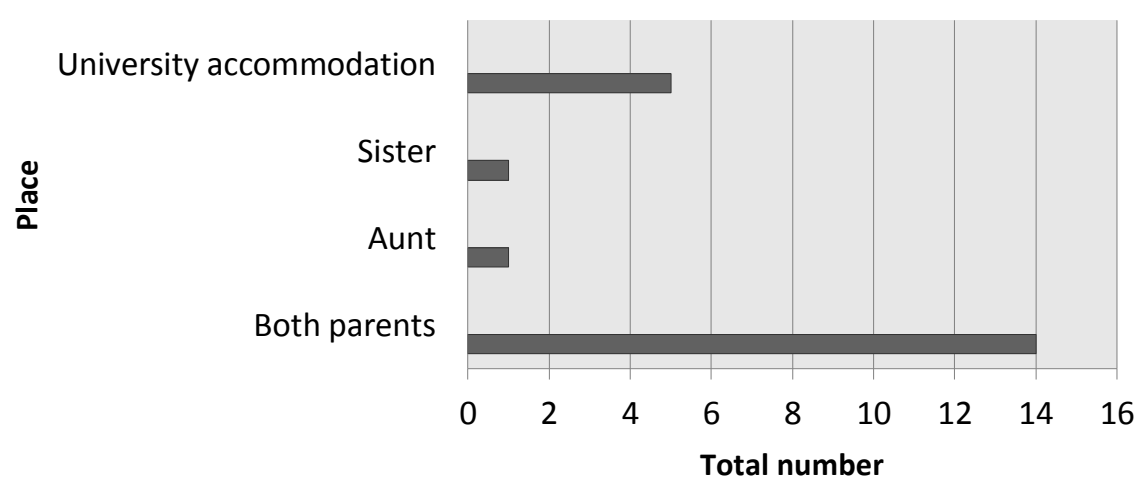

Figure 6.4. Accommodation arrangements while at university

The questionnaire findings confirm that most of the participants $(n=14)$ live with both parents although one participant was living with a sibling and another with a relative (refer to Figure 6.4). Five participants lived in university accommodation. My findings show that contrary to Coleman's (1988) theory of social capital where he argues that parental involvement and support influences children's choice of activities, the participants in this study did not mention that their parents had any part to play in supporting or motivating them to engage in community service or voluntary activities. Although most of my participants resided with their parents none of them attributed their interest in community service to their parents. In fact based on the questionnaire data and also data from the follow-up interviews, none of my participants reported having parents who were involved or interested in community service or voluntary work in any way. 


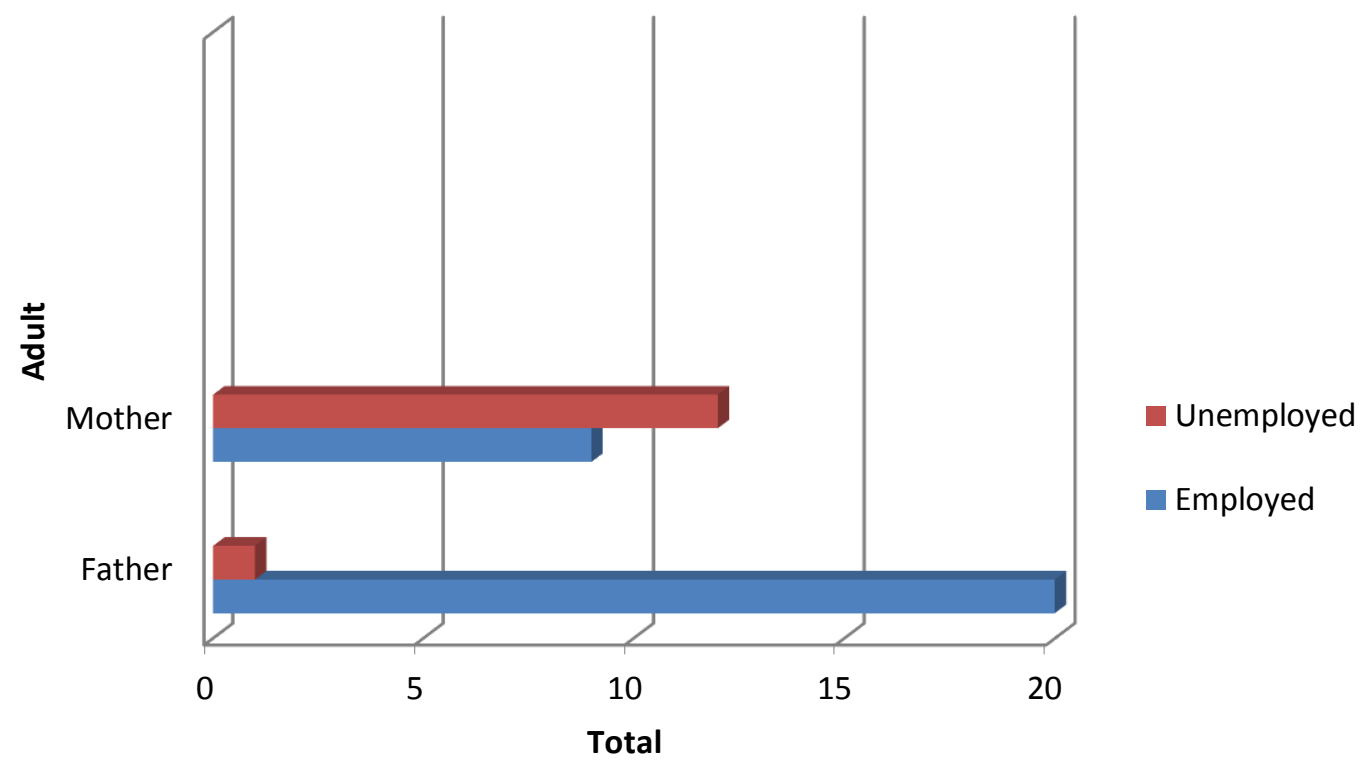

Figure 6.5. Employment status of both parents

Twenty of the participants reported that their fathers were employed and one participant reported that his father was retired (refer to Figure 6.5). In contrast to the job status of the father, only nine of the participants had mothers who were employed outside the home. The remaining twelve participants reported that their mothers were housewives. 


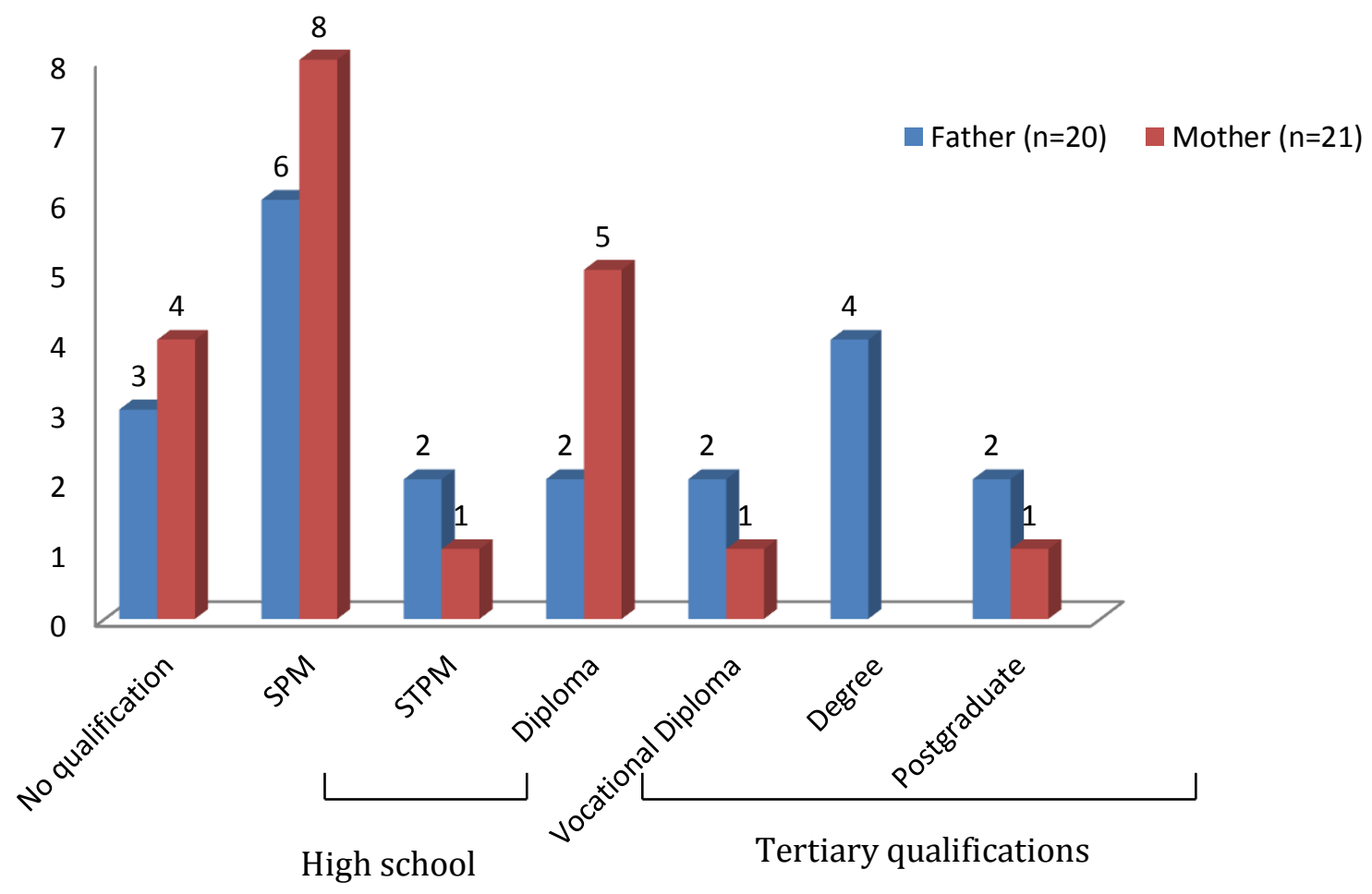

Figure 6.6. Parents' highest educational level

Based on Figure 6.6, a sixth of the parents do not have secondary school qualifications, and more than half of the parents do not have tertiary level qualifications. Fourteen parents possessed a SPM or Malaysian Certificate of Education which is equivalent to New Zealand's NCEA or National Certificate of Educational Achievement (refer to Chapter Two, section 2.6 for an explanation of SPM and STPM qualifications in Malaysia). Two fathers had achieved the STPM (Malaysian Higher School Certificate) which is roughly equivalent to the New Zealand University Bursary (refer to Figure 6.6). Two of the fathers had a Diploma while another two had a Vocational Diploma. Only four of the participants' fathers possessed a university degree. Overall, based on the findings, more mothers than fathers possessed a Diploma. Five of the participants had mothers who had a Diploma and one participant's mother had a Vocational Diploma. Only two of the participants had fathers who possessed a postgraduate degree and only one participant had a mother who held a postgraduate degree (refer to Figure 6.6). Parental education level has a significant impact on their children's perception and decision-making process. For example, during the interview session, when I asked one participant why she decided to participate in extracurricular activities at university, her reply was: 
I'm not those studious type so I remember my mum told me once that because my results are not great, my results are not like 80,90 , they're just 60,70 so my mum said if you want to, you know, balance so that people would still look at you, why don't you take up something else to back it up? So I chose sports, outside activities like that. Yeah... I hope it's gonna help me in the future. (AZI, female, third year engineering student)

In AZI's case, her mother is drawing on her capital based on her experience and transmitting this knowledge to her children by showing them what strategies to employ to accumulate capital at university. This process describes how a parent transmits her cultural capital to her child by explaining how the child can achieve success in other aspects of life besides academic success. My findings support studies on maternal education qualifications and the subsequent educational outcomes of their children that state that mothers actively manage their child's education in ways that have a flow-on effect on educational success (Barker \& Stevenson, 1986; Eccles, 1993; Sullivan, 2001; Reay, David \& Ball, 2005; Chow \& Ho, 2007; Albrecht \& Albrecht, 2010). Coleman (1990) asserts that children internalize their parents' goals and gain the most benefit if they have parents who are involved in their children's education. This finding also supports Bourdieu's (1977) theory of cultural capital insofar as parents transmit their knowledge about the education system to their children in order for them to succeed at school. The findings also support Bourdieu's argument that parents 'insider knowledge' of a field ensures that children gain educational advantage.

During the interview, I asked the students to explain what influenced their perceptions about the role of education. In the main, I found that the students' beliefs about the role of higher education came from their families, which includes their parents and other relatives. A number of the students $(n=7)$ said that their parents had influenced their perceptions about the purpose and importance of university education. For example, EL explained: 
My parents, since they too are being brought up in a family that believes pursuing tertiary education could promise better life and future for the family and it is proven to us children. (EL, female, third year engineering student)

In contrast, other participants were influenced by their parents' lack of educational experience, and they sought to break with family tradition by being the first in their family to graduate from university. For some of the participants, this indicated a strong desire to enhance their social mobility and to attain an educational goal that had eluded their parents. These participants also possess a strong sense of obligation and duty to repay their parents for the sacrifice they have made in ensuring their children achieve educational success. For example, IZ explains:

Due to the fact that both my parents [had] never been to university before, it has made me become more appreciative of the chance that I have obtained to study in university. (IZ, male, third year engineering student)

When I asked another participant, AZI, why she chose to exploit her extracurricular work to supplement her academic qualification, she explained:

AZI [...] my aim is still to [get a good job] because I promised my mum already that I would bring her to Machu Pichu.

Anita: so is she the driving factor behind your goal [to be financially secure]?

AZI: yeah, in a way. And $\mathrm{Haji}^{2}{ }^{2}$ I promised my dad that I will bring them and my siblings together because they are getting old I know that I have to work soon, earn a lot of money in order to bring them there. Yeah.

\footnotetext{
${ }^{2}$ The Haji or haj pilgrimage is one of the five pillars of Islam which means this is a religious duty carried out by every able bodied Muslim who can afford to do so at least once in his or her lifetime. The Haj is a demonstration of the Muslim people's submission to God.
} 
Sin (2009) argues that the perception of "success tends to be framed around ideas of familial duties and responsibilities" (p. 293), with most Asian children striving to excel in their studies as part of their duty towards their family. Chow and Ho (2007) also argue that academic achievement is considered as the best repayment from Chinese children to their parents. This is a common belief amongst many Asian cultures. The influence of other immediate family members also played an important role in shaping the participants' views about the role of university education. The experiences shared between members of the family can help to shape aspirations of pursuing higher education. Reay, David and Ball (2005) call these types of students 'contingent choosers' who receive high emotional support and a high level of encouragement within the family to gain academic credentials.

In addition, familial influence has an effect on the participants' view of the purpose of education. For instance, the participants' showed that they valued the advice they received from relatives and immediate members of the family. They also gained confidence in pursuing their aspirations as they had obtained this information through channels and sources they trusted. In this case, the participants drew on the strength of their family's collective culture in order to make informed decisions on whether to pursue higher education. This supports Coleman's (1990) claims that social capital exists through a network of information and trust which is present among the members.

I have a few cousins and uncles who graduated [with] either a masters or a degree in Otago and Australia. They have told me to study more and study hard so I'm able to graduate from university then working will be a bit easier as I will have $80 \%$ knowledge in the field I choose. (TK, male, first year foundation student)

Reay, David and Ball (2005) describe this kind of student as an 'embedded chooser' whose motivation to enter university is often linked to career trajectories and entry into prestigious professions. These students normally have parents, relatives or close friends who attended university and who provide a lot of guidance and advice on 
possible career options or educational pathways. In cases such as these, parents play a major role in shaping and influencing educational trajectories. 'Grapevine knowledge' (Reay, David \& Ball, 2005, p. 152) refers to knowledge gained from family members and friends who possess information about career and educational prospects and play an important role in influencing students' perceptions.

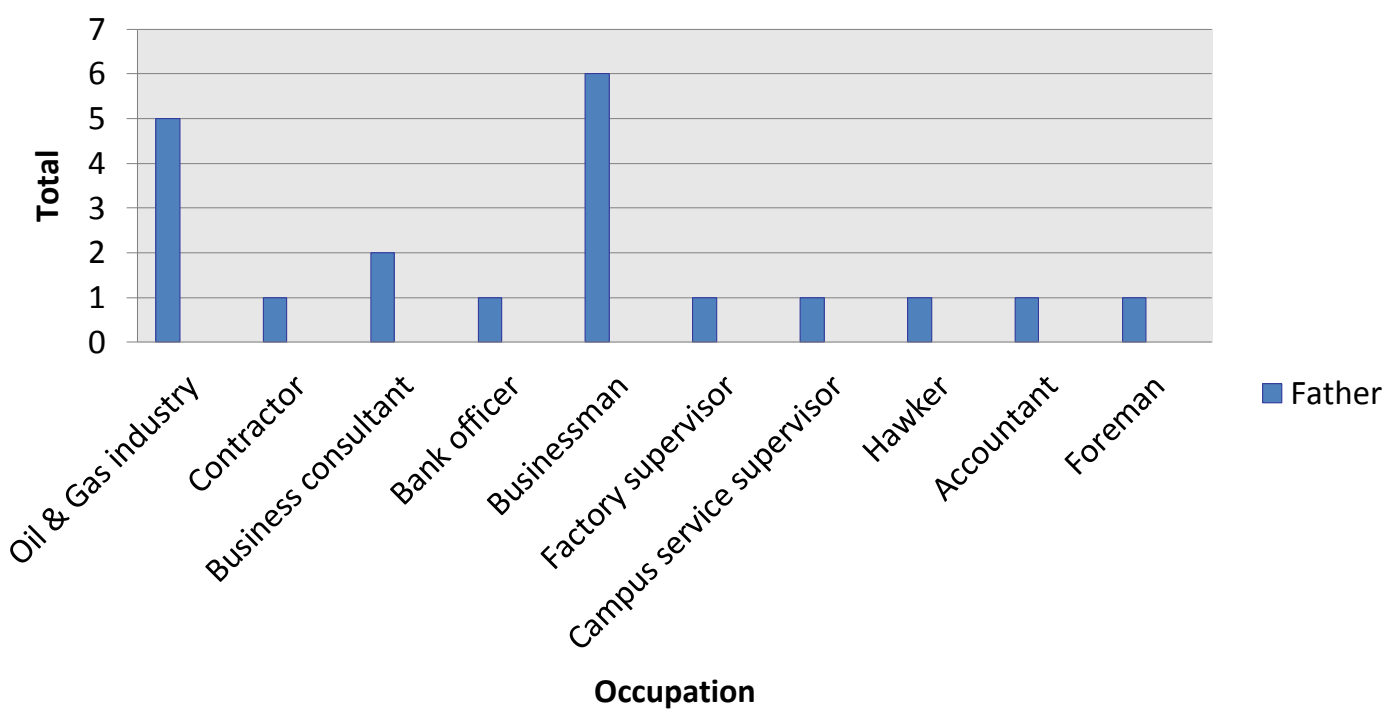

Figure 6.7. Fathers' occupation

From the questionnaire data, I found that a majority of the participants had fathers who were in the business world. Six of the participants reported their fathers had their own business, which ranged from selling engineering parts to other sundry items (refer to Figure 6.7). In addition, five participants had fathers who were in the oil and gas industry: working as engineers; in human resources; and as occupational health and safety consultants. The research site was based in a region where the oil and gas industry is a major source of income for the community therefore most of the employment opportunities for the local population are related to these activities. The site is also located at the border to a wealthy oil and gas country, which means the commerce and trade are also a popular and highly lucrative option. Overall, most of the participants' fathers worked in professional or managerial positions and in commerce and trade, which indicates that a significant proportion of the respondents $(n=11)$ were from relatively affluent families. Another indicator of their affluence is that the parents 
had the financial means to send their children to the site university for this study. Tuition fees at the site university are at least three times higher than the enrolment fees normally paid at Malaysian public universities. I have classified the participants in this study as having middle-class to upper middle-class origins and I have based this conclusion on information they gave me in the questionnaires and during the interviews about their parents' occupations, employment statuses, educational qualification and more importantly, their economic behaviour. Hughes and Woldekian (1994) define economic behaviour as the "consumption, saving, production and investments" habits practiced by the families in ASEAN countries. According to Hughes and Woldekidan (1994) in most ASEAN countries, "middle classes are not synonymous with middle income groups." (p. 139). Furthermore they contend that "middle class families in these countries have incomes well above the median. " (p. 139). As we can see the Malaysian middle class does not 'fit' the Western idea of middle class groups in the sense that Malaysian middle class families "have incomes well above poverty line, which are characterised by those able to afford only minimal standards of nutrition, clothing, housing and education. " (p. 141). The families involved in my study reflect these practices and economic behaviour.

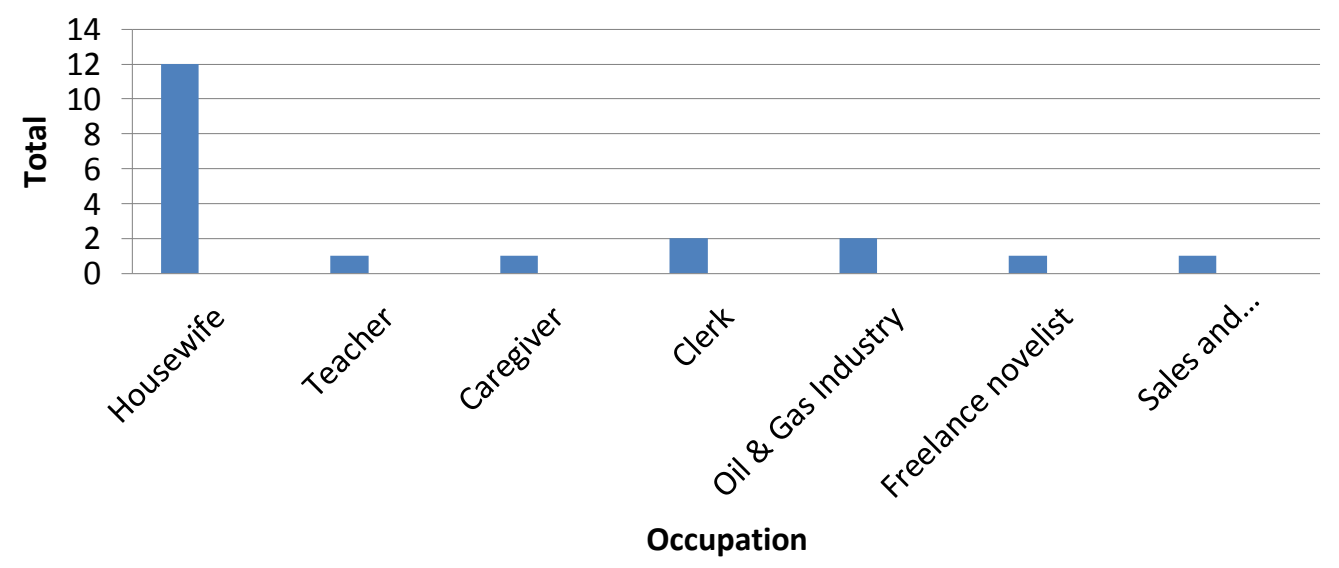

Figure 6.8. Mothers' occupation

Based on the findings from the questionnaire, a large number $(n=12)$ of the participants' described their mothers as housewives (see Figure 6.8). A significant number of these participants' mothers possessed a Diploma $(n=6)$ however, which is 
more than the number of the fathers who possessed a diploma $(n=4)$. Most of these mothers had opted to stay at home and take care of their families. This is another indicator of the participants' family affluence as this suggests that these households were supported, in the main, by the participants' fathers. In addition, Figure 6.8 shows that three of the mothers working outside the home were employed in professional roles in the oil and gas industry and also in sales and management.

\subsection{Family cultural activities}

The findings from the questionnaire revealed that the students' parents were active subscribers to local newspapers, with more than one household subscribing to at least two different newspapers. Nineteen of the participants had active newspaper subscriptions while only two participants reported their parents did not subscribe to any newspapers. Four of the parents subscribed to two different daily papers (both English and Chinese) while one parent subscribed to three different papers (all Chinese daily newspapers). Two sets of parents held four subscriptions to four different papers (in two different languages). The chart below (Figure 6.9) provides further detail about the types of newspapers the parents subscribed to. In an article published by The Star, the Deputy Prime Minister Tan Sri Muhyiddin Yassin lamented about the Malaysian population's poor reading habits. Malaysians are inclined to read light material such as newspapers and magazines, as evidenced in this study. Zainol Abidin, Pour Mohammadi and Ooi (2011) explain that this is because reading material such as magazines and newspapers are perceived as avenues for entertainment and current updates and do not constitute 'heavy' material. This can explain why most of the families involved in this study prefer to read newspapers as it does not take much time and it offers local and global news as well as news on sports and entertainment, which appeal more to the participants and their parents. 


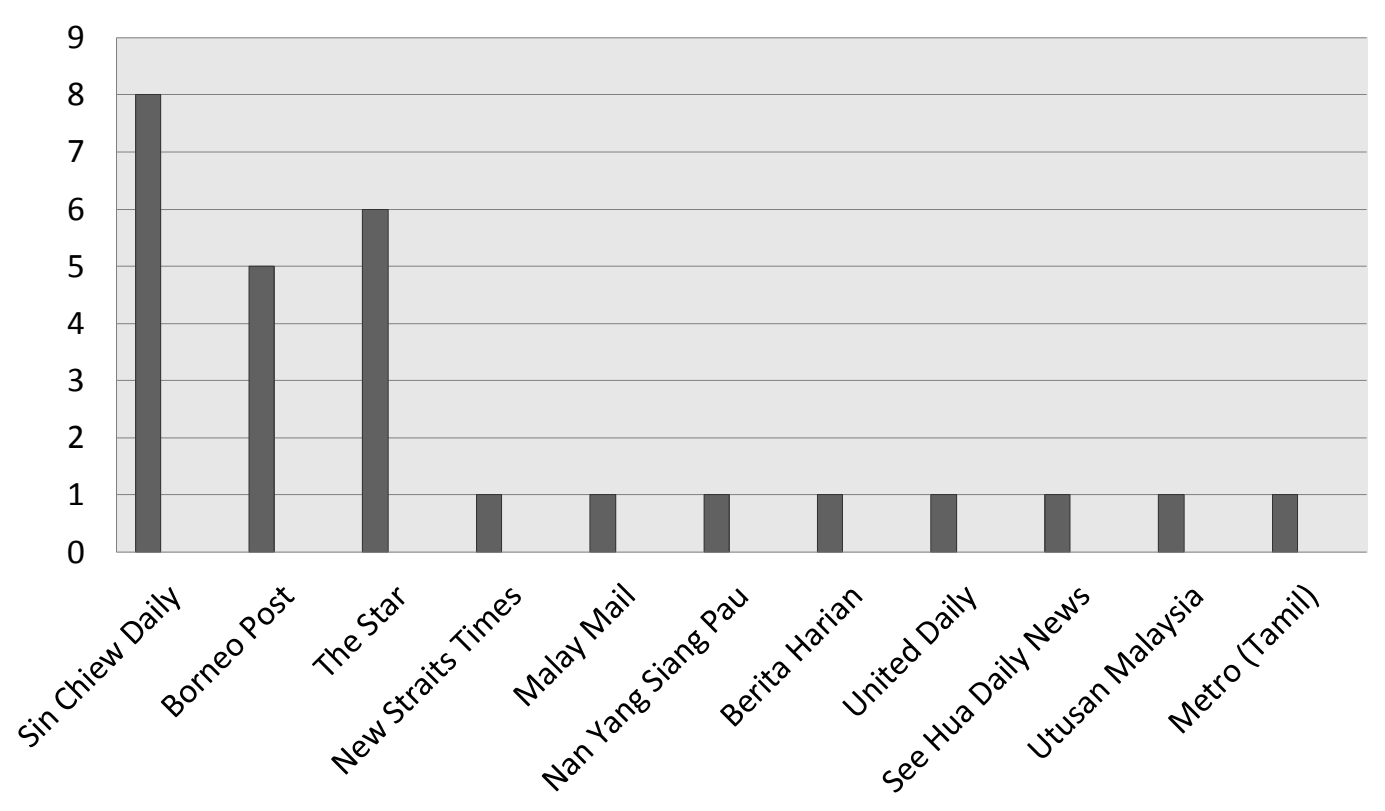

Figure 6.9. Household newspaper subscription

The questionnaire results show that eight of the parents subscribed to the $\operatorname{Sin}$ Chiew Daily which is a Chinese newspaper. Five read The Borneo Post Daily (an Anglophone newspaper), six read The Star (an Anglophone newspaper). One reason as to why the parents prefer Chinese newspapers is because these papers usually provide updates about activities in the Chinese community. They sometimes also cover political affairs that are not reported in the Anglophone newspapers (such as The Star or The New Straits Times), or Bahasa Malaysia newspapers (Berita Harian and Utusan Malaysia). Zainol Abidin, Pour-Mohammadi and Ooi (2011) offer another reason as to why Chinese people prefer to read in the Chinese language. They argue this is because they are very protective of their culture and language and an example of this practice can be seen in this study, with all the Chinese households subscribing to at least one Chinese newspaper. 


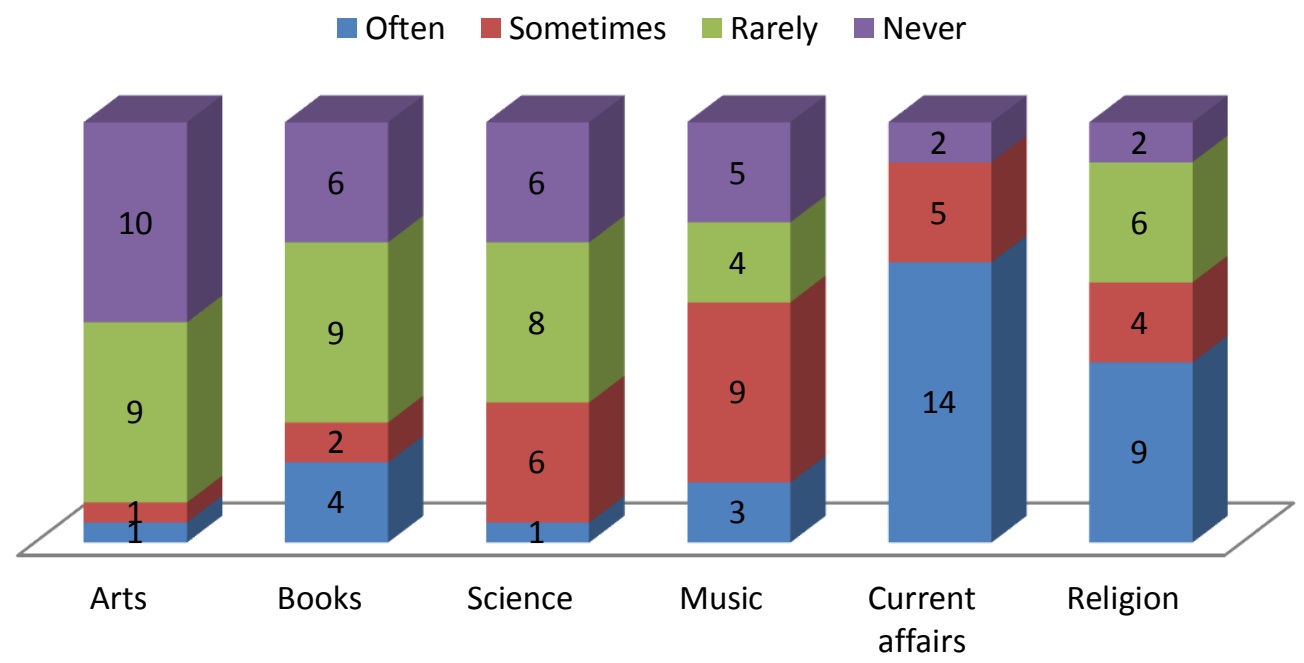

Figure 6.10. Topics parents discussed at home

Given the strong interest in newspapers, it is perhaps unsurprising that the most popular topics discussed at home were related to current affairs, suggesting that the participants' parents were aware of these sorts of issues and valued the importance of being aware of them (Figure 6.10). Other topics that were frequently discussed related to religion, with nine participants stating their parents often discussed religion at home. The topics least discussed were the arts and science. This suggests that the parents were more interested in issues which have a direct impact on their lives or on the society around them, while topics such as the arts, science and music were seen as having less immediate impact on their lives. As we can see from the findings, my participants' parents do not discuss or share topics such as literature or classical music with their children. This suggests that again, contrary to Bourdieu's claims, parents with the economic resources to send their children to private universities do not, in the Malaysian context, consider discussion about 'highbrow' activities to be of importance to their daily lives. 


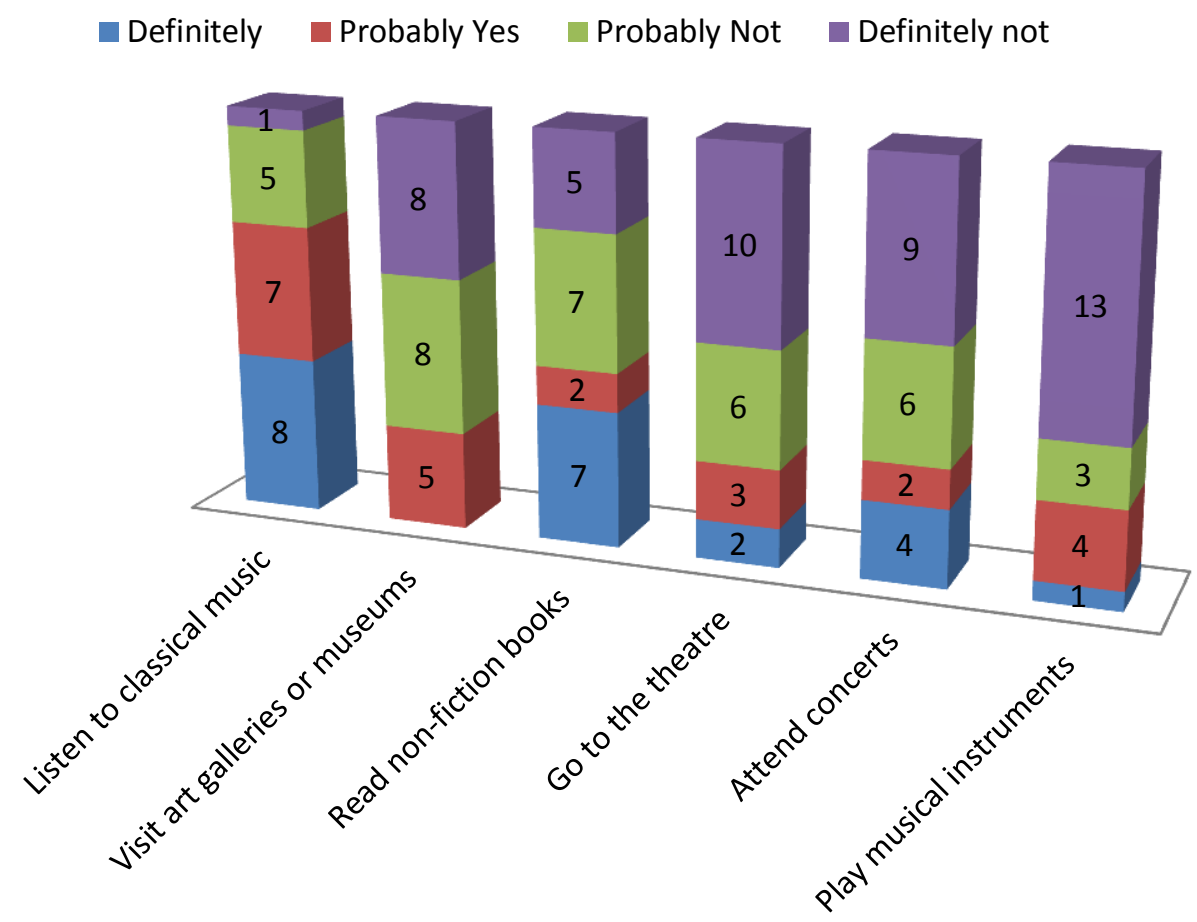

Figure 6.11. Do the students' parents engage in highbrow activities during their spare time?

Contrary to Bourdieu's belief that cultural capital is indicated by 'highbrow' activities practised within the family, the relatively affluent middle-class families who were part of the study did not appear to participate in any form of cultural activity which denote 'highbrow' culture in Western European terms. On the questionnaire, the participants reported low levels of parental interest in visiting art galleries or museums, attending the theatre or playing a musical instrument (refer to figure 6.11). Despite Bourdieu's claims that members of the French upper classes enjoyed participating in these activities, the results from the study, which focus on affluent middle-class families in the Malaysian context, indicate otherwise. In fact it would seem that the middle-class families who figured in my investigation, despite the growing forces of globalisation and trans-national migration within and around Malaysia, do not seem to value the same kinds of cultural practices as elite families in Western Europe. Van Eijck (1999) and van Eijck and Knulst (2005) argue that the interest in 'highbrow' activities is largely determined by socialisation, through parents and education. As the Malaysian education system does not build on appreciation of such activities there is a 
lack of exposure to these activities. This in turn entails that Malaysian society tends not to favour participating in 'highbrow' activities.

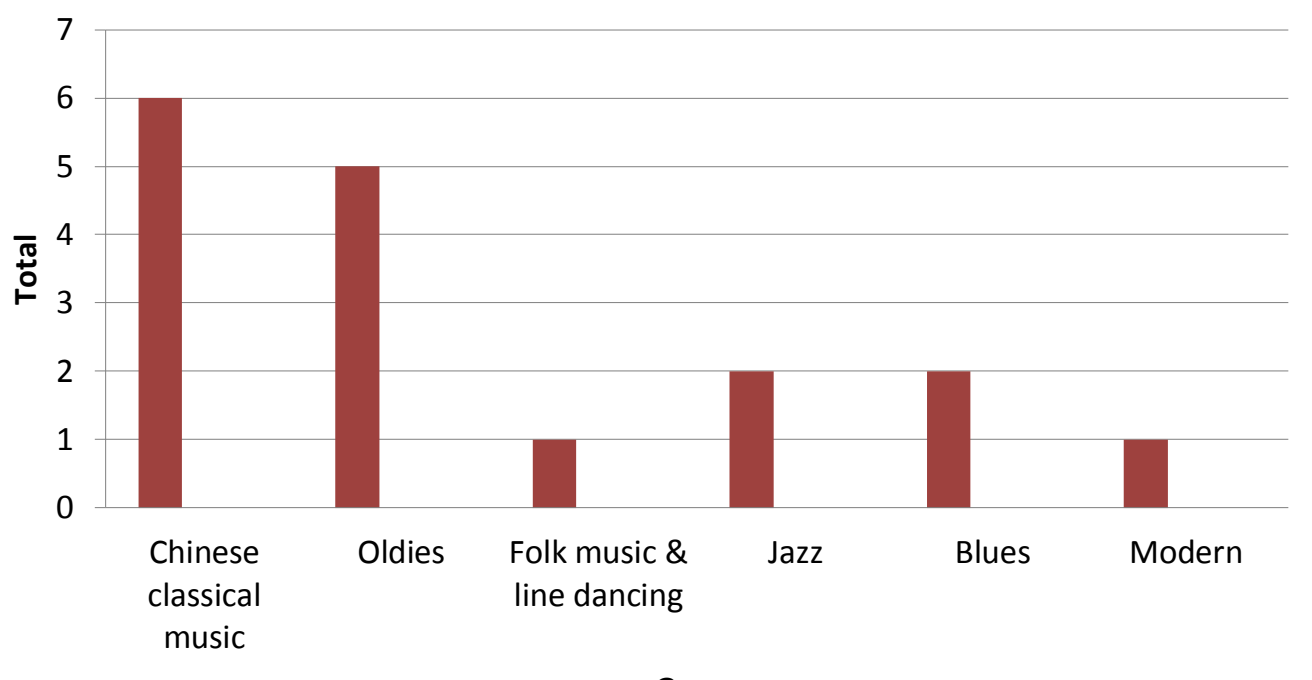

Genre

Figure 6.12. Parents' musical preferences

The only similarity to Bourdieu's notion of 'highbrow' activity is reflected by the parents' taste in music. Eight participants reported that their parents prefer to listen to Chinese classical music and seven feel that their parents probably prefer listening to classical music compared with other genres (refer to Figure 6.12). The preference for Chinese classical music shows an appreciation of cultural songs and practices. Following Bourdieu, I argue here that this inclination resembles the preferences of those in a higher class in Western European culture. The parents were also fond of listening to 'Oldies' (i.e. Elvis Presley, The Beatles as well as Chinese singers from the 1970s or 1980s) (refer to Figure 6.12). Other genres they like include Jazz and Blues music, followed by Folk music and line dancing music, which is not a common choice of music amongst Malaysian listeners. Koen Van Eijck and Wim Knulst (2005) describe these genres of music (folk and pop) as 'lowbrow' musical genres. As we can see from Figure 6.12, the parents tastes seem to vary, signalling that the parents are 'cultural omnivores' (van Eijck, 1999; van Eijck \& Knulst, 2005) for both highbrow and lowbrow musical genres. They define cultural omnivores as "cultural consumers who enjoy both highbrow and popular culture" (van Eijck \& Knuslt, 2005, p. 526). One reason for this 'omnivorous' taste in musical preference could be attributed to the fact that "knowledge of a broad range of musical styles is probably more helpful than being 
a highbrow initiate for getting ahead and taking part in the heterogeneous social networks typical of the new middle class in today's globalised world" (van Eijck \& Knulst, 2005, p. 516).

Van Eijck (1999) argues that because of social mobility, there is a change in patterns of cultural consumption within the different social groups in society. Van Eijck and Knulst (2005) contend that the increase in social mobility has lessened the pressure to engage in highbrow culture in order to 'fit in'. This is because as social climbers enter higher classes, they participate less in 'highbrow' culture compared with those who had been socialised from childhood (van Eijck, 1999). Consequently, these social climbers may also overlook the need to socialise their children in highbrow cultural activities as well (van Eijck \& Knulst, 2005). Given that some of the parents involved in my study have succeeded in entering into a higher social class based on their education level and current employment (refer to Figure 6.6), this lends support to van Eijck and Knulst's (2005) hypothesis on social mobility and the emergence of 'cultural omnivores'.

In sum, the results of this study show that the Malaysian families place a high value on educational capital and that education and educational qualifications are highly regarded. For instance, the fact that these families send their children to a private, foreign institution of higher education signals that the parents place high value on their children gaining an international qualification. The capital that is accorded the greatest 'distinction' (Bourdieu, 1984) in the 'field' of Malaysian higher education is educational attainment. This is closely linked to economic gains and perceived employment success. According to Pyvis and Chapman (2007) the reasons for seeking international education are perceived as a strategy by Malaysian students who aspire to employment with Western multinational corporations operating in Malaysia. The students studied in Pyvis and Chapman's (2007) research believed that the term 'international' was favourably associated with Western education and Western qualifications, which would translate to better employment opportunities. Moreover, the students shared anecdotes about university seniors or friends who had been employed by a large petroleum company, which reinforced their perception about the value of an international educational qualification. Sin (2009) argues that Malaysian 
parents in the United Kingdom instill values about the importance of education from an early age. She (2009) further argued that getting a British education meant securing a good job and gaining recognition and respect from family, friends and members of the community. The findings of my study reveal that parents had invested a lot in their children's education. The findings also indicate that the families involved in this study are adept at identifying the types, and sites, of valuable cultural capitals (Waters, 2008) and they seek the kind of capital that has international recognition and the perceived values of the family.

The findings in my study demonstrate that the families involved do not place as much emphasis on objectified cultural capital. This is evidenced by the lack of books in each household. Furthermore, there was no indication or reports during the interviews or through visual data of any appreciation of the arts (such as museum visits, for example) among the families, although they do appreciate music. The parents enjoyed listening to classical music (refer to Figure 6.12) and they sent their children for music lessons (refer to Figure 6.14).

Another finding was that the participants' parents were concerned with current affairs as indicated by the topics they often discussed at home. As each household subscribes to at least two different newspapers this indicates that the parents stay up to date with current news both within the local community and globally. Knowledge about current events could also be a source of information, which they use to guide or advise their children on issues concerning education. In addition, the religious capital of the families was also a significant factor. The church and the religious community within the university proved to be key sites for accumulation of social capital and triggers for volunteer practices for the families of several of the participants. This will be discussed further in Chapter Seven, section 7.14.

While this may seem self-evident, it is worth bearing in mind that while Bourdieusian theory has much to offer in the theoretical analysis of culture, not all his ideas travel well across different cultural contexts and in this study I argue that this 
Western theory does not always speak to the socio-cultural practices of South East Asian culture. My findings have shown that the middle-class families involved in this study do not practice highbrow culture in a Western European sense nor do they signal any appreciation of Western ideas about 'highbrow' culture in their daily lives. Furthermore, there is no evidence of discussions or consumption of 'highbrow' culture in their lives, except for their appreciation of classical music and the practice of sending their children for music lessons. As my participants revealed, cultural practices including visits to museums and art galleries, and listening to the opera and classical music, are reflections of Western culture.

\subsection{Participants' cultural practices}

Reflecting on their parents' behaviour, students in my study did not demonstrate involvement in Bourdieu's (1984) 'highbrow' activities. A majority of my participants $(n=13)$ rarely visited art galleries or museums, while six reported they never visit art galleries or museums during their spare time (refer to Figure 6.13). They demonstrated only a slight interest in visiting museums or art galleries and they are not specifically interested in listening to classical music or participating in arts-related activities. When questioned during the follow-up interview, one participant remarked that activities such as visits to museums, art galleries or listening to classical music "for some funny reason, it reminds me of stiff upper class British practices. When I think of highbrow, I think of those people in the Tatler magazine" (MAY, female, third year engineering student). Another participant equated highbrow activities with "gambling at high end casinos" (BRI, male, third year commerce student). One participant perceived highbrow activities as wanting "to show off intellectually though it doesn't seem real most of the time" (LNL, female, third year commerce student). It is clear from these conversations that participation in highbrow activities is restricted to people who come from a certain social class, in this case this applies to those who possess large amounts of economic resources. With respect to this, the participants clearly equate participation in highbrow activities with distinct people in the society. Only two of the participants I interviewed admitted that they enjoy going to museums, art galleries or the theatre. However, one of the participants mentioned, 
I do attend the theatre and go to museums when I travel. I believe that it is one of the many ways I could enjoy a place's culture. Unfortunately I do not listen to opera or classical music mainly because I think it doesn't appeal to my liking. Perhaps it's also because I wasn't introduced or exposed to it until I started eating at hotels where they play it while eating your meal. But I mean, the way I think, people where I am being brought up, I don't think anybody really listens to opera or classical music. (AZI, female, third year commerce student)

Another participant (AY, female, first year pre-university student) echoed AZI's sentiment when she explained that museums, art galleries and listening to classical music were important in European cultures but not part of Malaysian culture. Supporting evidence for this point of view came from the findings, where my participants indicated that they $(n=9)$ rarely listen to classical music in their spare time (refer to Figure 6.13). Only three participants said that they often listened to classical music in their spare time (refer to Figure 6.13). In addition, AZI also explained that museums in Malaysia focus more on showcasing historical items, which are all included in the school syllabus. That is one reason why she feels going to the museum is unnecessary. Another reason for lack of participation in these highbrow activities is due to the location of such institutions. For example, one participant cited geographical location as the main reason why he does not attend museums or art galleries. He explained that he does not have the opportunity to visit such places as the national museum, art galleries and the National Philharmonic Orchestra, which are located in the capital city, Kuala Lumpur (BRI, male, third year commerce student). 


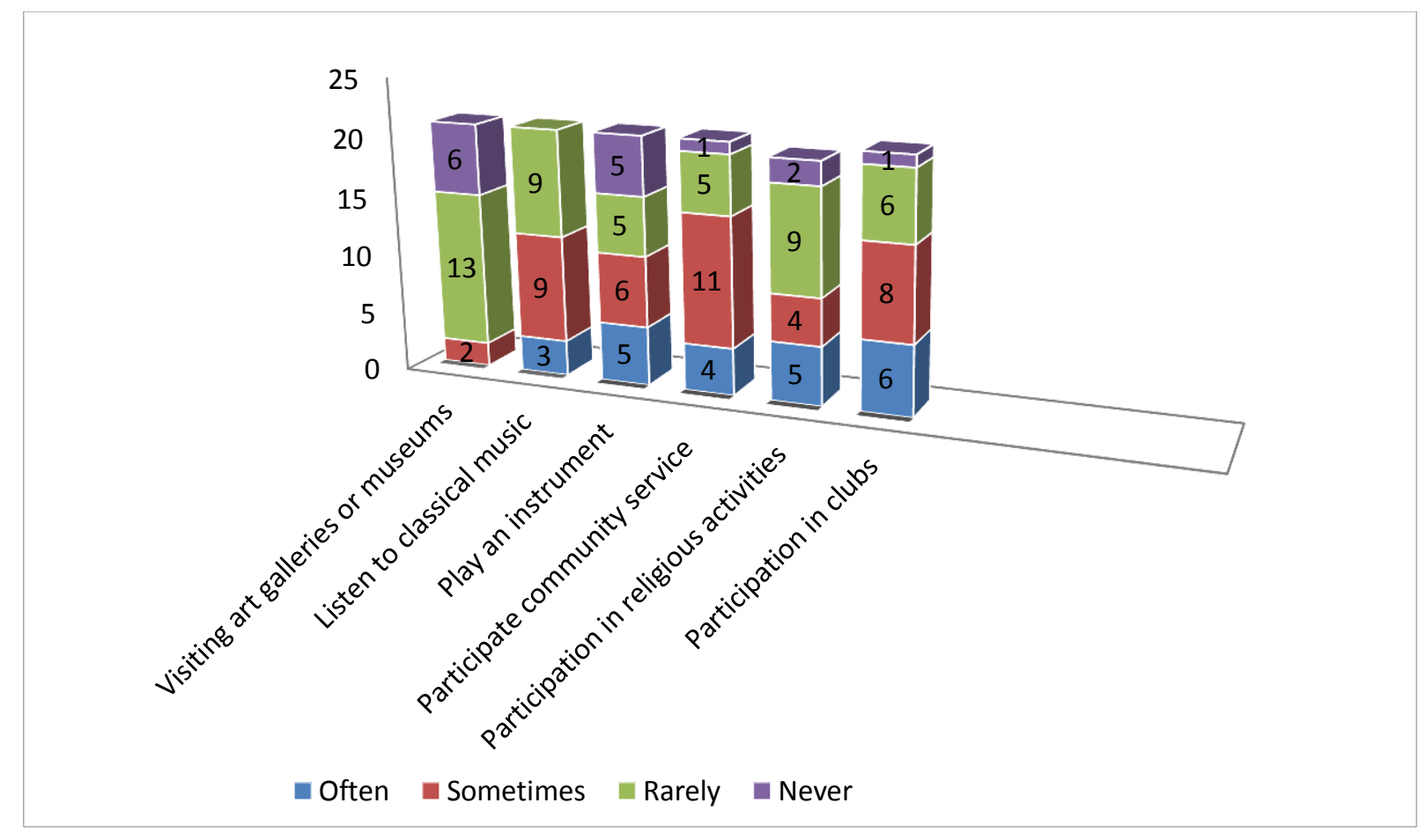

Figure 6.13. Frequency of participation in extracurricular activities during their free time

Based on Figure 6.13, a large number of the participants spent their spare time participating in community service, although the participation rate varies. Eleven participants stated that they sometimes engaged in community service. Six participants revealed they were active in participating in club activities.

The only indication of interest in any 'highbrow' activity as defined by Bourdieu (1984), is that several of the participants play musical instruments. Quite a substantial amount of spare time was spent playing a musical instrument. Five participants reported that they often played a musical instrument while six said that they sometimes played an instrument in their spare time. The participants also attended music classes to improve their skills during their free time (refer to Figure 6.14). One of the items in my questionnaire asked how often my participants attended music lessons. This item was included to determine if my participants demonstrated any indications of engaging in highbrow activities (Bourdieu, 1984). 


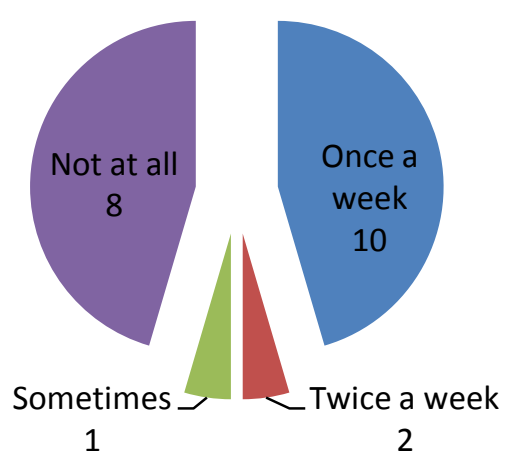

Figure 6.14. Frequency in attending music lessons among participants

A majority of my participants attended regular music classes with ten participants attending music classes once a week; with two attending classes twice a week. Eight sometimes attended music lessons while another eight do not take any music lessons at all. My findings revealed that the participants $(n=10)$ enjoyed playing the piano. The piano was the preferred choice of instrument followed by the guitar, violin, drums and a Veena (an Indian plucked string instrument). This signified that parents wished to provide their children with additional cultural capital, although not one which they can necessarily exploit directly for academic purposes. A possible explanation for why some parents sent their children to music classes includes the desire to provide their children with a well-rounded education where they can excel in both academic and non-academic skills (Leong, 2008). Another explanation is that the parents may want their children to enjoy playing a musical instrument or to nurture their musical ability (Leong, 2008). Arguably, sending children for music could constitute a strategy in which these children can accumulate a different kind of cultural capital - one that will award them distinction in the higher education field. This form of capital could be 'capitalised' when applying for admission to tertiary institutions of other institutions of higher learning. These forms of coping strategies can be used to gain a 'competitive edge' over other candidates when applying for university. 


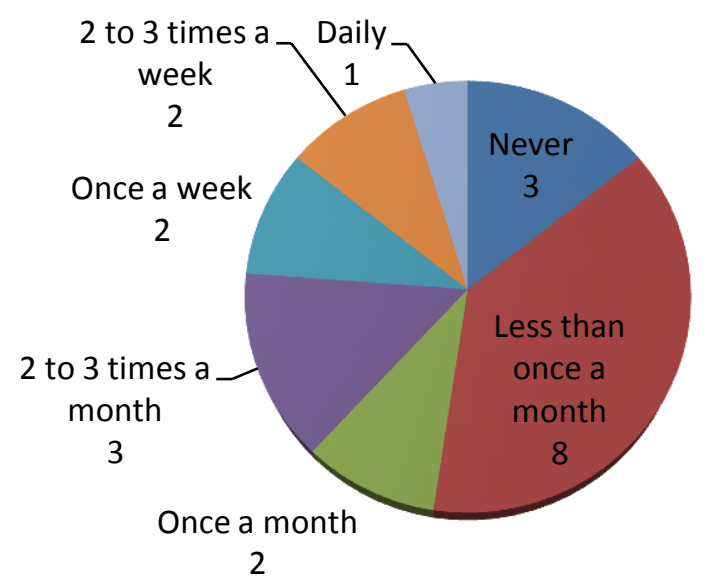

Figure 6.15. Frequency of reading non-academic books

As we can see from Figure 6.15, eight participants reported that they rarely read non-academic books. They said that they read books not connected to schoolwork less than once a month. Only two participants reported reading non-academic books regularly (2-3 times a week) and only one participant read non-academic related books on a daily basis. Participants were not generally interested in reading non-academic related material and, instead, mostly read materials for academic purposes instead of for knowledge or reading pleasure. This supports Ambigapathy Pandian's $(1997 ; 2000)$ research which found that 80 percent of the Malaysian population are 'reluctant readers'. He contends that students read only to pass exams and were reluctant to read for information or for pleasure. Other factors which caused this lack of interest in reading were attributed to the absence of encouragement from parents, expensive books and lack of interest in reading serious material (Pandian, 1997). A survey conducted by the Malaysian National Library (2006) also showed that the literacy rate for Malaysians aged under 25 years old was low. The study attributed this to the absence of a reading culture and few role models to inculcate the reading habit. Furthermore, this survey also revealed that even if Malaysians did read, about 80 percent of the reading material was in the form of newspapers and magazines. Another significant finding, revealed by the survey, indicated that the role of electronic media was challenging the reading habits in the society by shifting young people's attention to computers and television (Malaysian National Library, 2006). My study also revealed that the participants demonstrated a lack of interest in reading. For example, one of the items asked in the questionnaire was the number of books the participants had at home (Figure 6.16). 
The participants reported that they did not own large amounts of books at home. Exactly 6 participants owned approximately 25 books; 5 had a collection of approximately 26-100 books; 6 had between 101-300; 3 had between 301-600; and only 1 participant had more than 600 books at home.

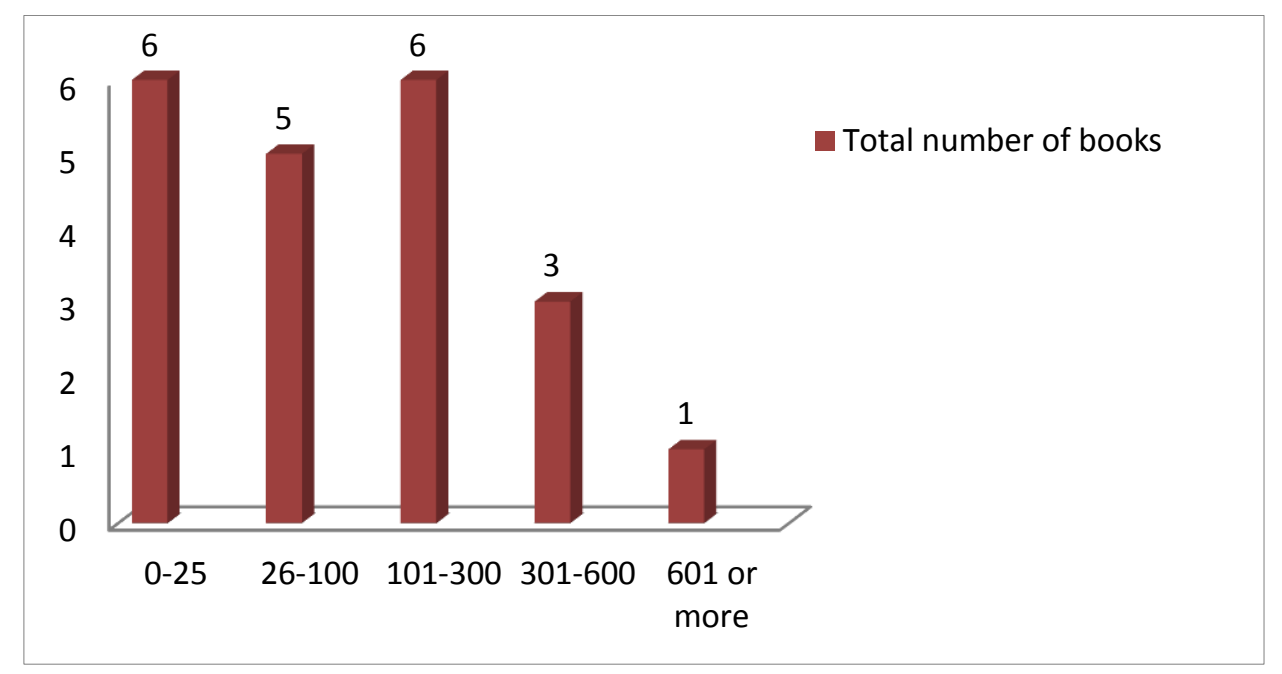

Figure 6.16. Number of books owned by the participants

When the participants were asked if their parents read non-fiction books at home, a majority $(n=15)$ reported that their parents did not read books during their spare time. As for the participants themselves, when they did engage in non-academic reading, a majority of them $(\mathrm{n}=11)$ preferred reading English and Chinese fiction novels. Others reported reading religious books, as well as novels by Dan Brown, J.K. Rowling, Jodi Picoult and other modern authors. None reported a preference for poetry, drama, or classical literature, such as works produced by Shakespeare, Austen or Dickens. One explanation for this behaviour was made in a study conducted amongst undergraduate students in two colleges in Malaysia. Abdul Karim and Hasan (2007) reported that the amount of time spent on reading by university students is higher compared with the average individuals surveyed in the past. This group of people read more because the nature of their study requires them to read. This also explained why students tend to read materials that are more academic in nature. Another explanation for the lack of books owned by students could also be attributed to the emergence of the Internet and Internet-based reference materials. According to Nor Shariza Abdul 
Karim and Amelia Hasan (2007), the undergraduate students involved in their study reported a high rate of reading Internet-based resources, in addition to reading academic books and newspapers. This may be an explanation for why Malaysian students were found to read for academic purposes only and not for general knowledge or pleasure as indicated by other studies. The trend of reading may have shifted to digital reading as technology has changed the way we approach reading and learning. Overall, the participants did not seem to demonstrate any reading practices related to Bourdieu's notion of 'highbrow' activities. These participants were not avid readers nor did they possess large amounts of books or non-academic reading material at home. In contrast with Bourdieu's participants, my participants' parents do not come from academic, scholarly or artistic backgrounds and are therefore not attempting to inculcate their children with similar cultural capital. Amongst the participants, their parents are professionals who had not necessarily had the same opportunities for tertiary education as their children now have, and thus they use their economic resources (in large part generated by jobs in the oil and gas industries) to fund the accumulation of academic capital by their children rather than replicating their own form of cultural capital.

There was a lack of interest in enrolling in arts-related subjects, as only one participant attended art lessons once a week. One explanation for this can be attributed to the fact that Malaysian students focus more attention on other core or compulsory subjects, which are tested in the national exams. For example, Abang Abdullah, Mohd Ali and Mokhtar (1994) explain how the government sees engineering as an essential component for the continued development of the country's economy. Due to this view, more universities are putting a strong emphasis on engineering to the extent that engineering is now seen as a status marker for local universities, along with other subjects such as medicine, law and accountancy. Without any of these disciplines, a university is seen as lacking the prestige often associated with a university education (Abang Abdullah, Mohd Ali \& Mokhtar, 1994). This is highlighted by a sizeable amount of scholarships and loans provided by various bodies (state government, corporate bodies, or foreign institutions). They are limited to science, technology and commerce subjects, resulting in less interest in other subjects, which are perceived to be less important (Lee, 2006). 


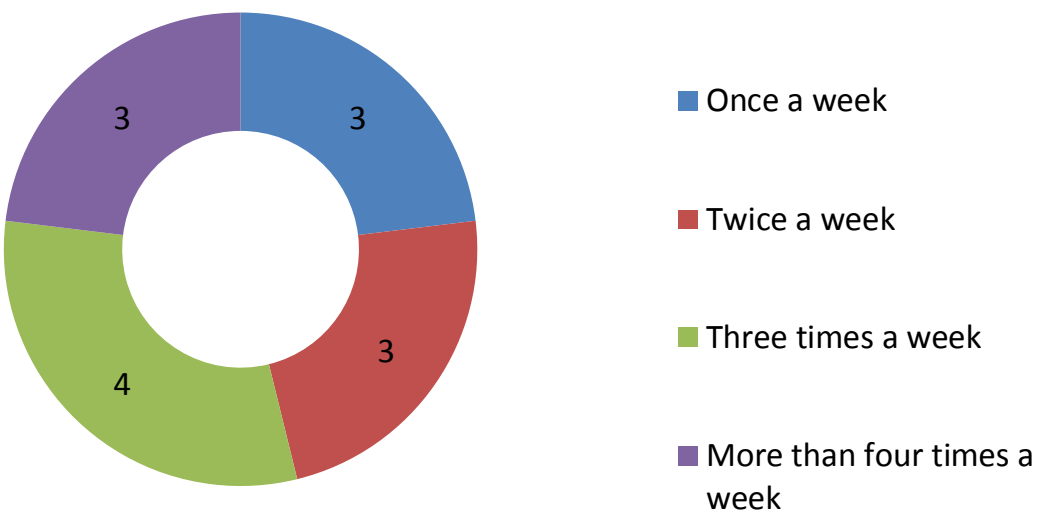

Figure 6.17. The participants' frequency in attending tuition classes

One further illustration of the degree to which students favoured academic related pursuits was their attendance in extra tuition classes. It is common practice for Malaysian students to attend tuition classes as a 'supplement' to the learning received in schools. It is also an accepted practice for children as young as seven or eight to begin tuition classes and receive extra help to cope with studies in primary school. This is due to the competitive nature of the Malaysian education system, which is based on high stakes testing and is heavily exam-oriented. According to Sin (2009) one of the ways Malaysian parents ensure their children's academic success is to send them to private tuition or special classes to cover areas not provided at school. She argues that this is a strategy employed by middle-class parents to help their children to "race up to higher and more exclusive rungs of the educational ladder" (p. 292). Yoko Yamomoto and Mary Brinton (2010), and Byun and Park (2012) also report similar practices amongst East Asian parents to ensure that their children get the best education and additional advantage over the rest of their peers in the education system. Some of my participants $(n=3)$ attended tuition classes at least three times a week (refer to Figure 6.17). Three participants attended tuition classes more than four times a week, three attended classes twice a week and three participants attended tuition classes only once a week. However, seven other participants did not provide a response as to whether they had to attend tuition classes (refer to Figure 6.17). 


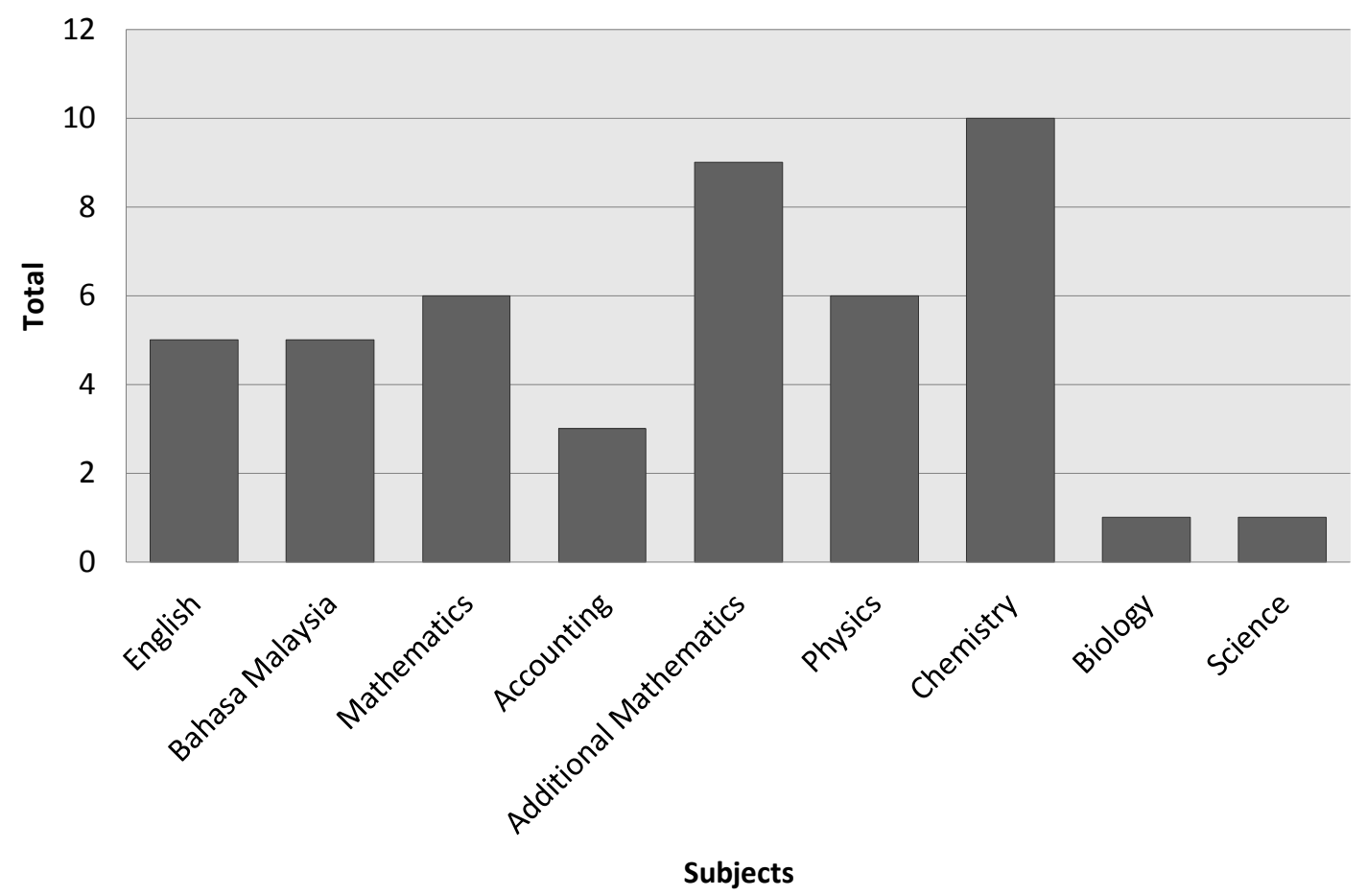

Figure 6.18. Extra tuition classes enrolled in by subject.

Given the high stakes testing and exam-oriented nature of the Malaysian education system, the practice of attending tuition is a norm within the country. Out of the 21 participants, five of the participants reported that they attended English tuition classes. Five participants took up tuition class during secondary school for Bahasa Malaysia, six participants enrolled for tuition classes in Mathematics; three enrolled for Accounting classes while nine enrolled for extra tuition for Additional Mathematics. Six participants enrolled for an extra Physics class and ten enrolled for their Chemistry subject. Only one participant enrolled for tuition for Biology and one participant enrolled for in Science. From the graph above (Figure 6.18), it is clear that the science subjects are the subjects which receive the most attention from the students. The only two non-science subjects for which most students enrolled for were English and Bahasa Malaysia (which is the national language). It is common for middle-class Malaysian students to take extra classes to help them to pass their Bahasa Malaysia paper as a failure in Bahasa Malaysia would cause a student to receive a Fail for their national exam. A failure in the Bahasa Malaysia exam would affect their chances of obtaining a place at one of Malaysia's public universities. It is also generally recognised 
that students should pass the English paper as it is an important pre-requisite for secondary school students' entrance to the country's public universities.

I did not ask the students directly during the interviews about the activities they preferred doing during their free time, but the Photo Diary data revealed various ways in which they occupy their free time. Based on the Facebook data, my participants preferred to spend this time with friends. Several students also talked about sports and food and the Facebook findings show my participants enjoying a range of activities with their friends, for example: bowling; eating; attending campus-based events; enjoying nature and the local scenery; or participating in sports. The photograph below (Figure 6.19) shows one of the popular beaches located in the area.
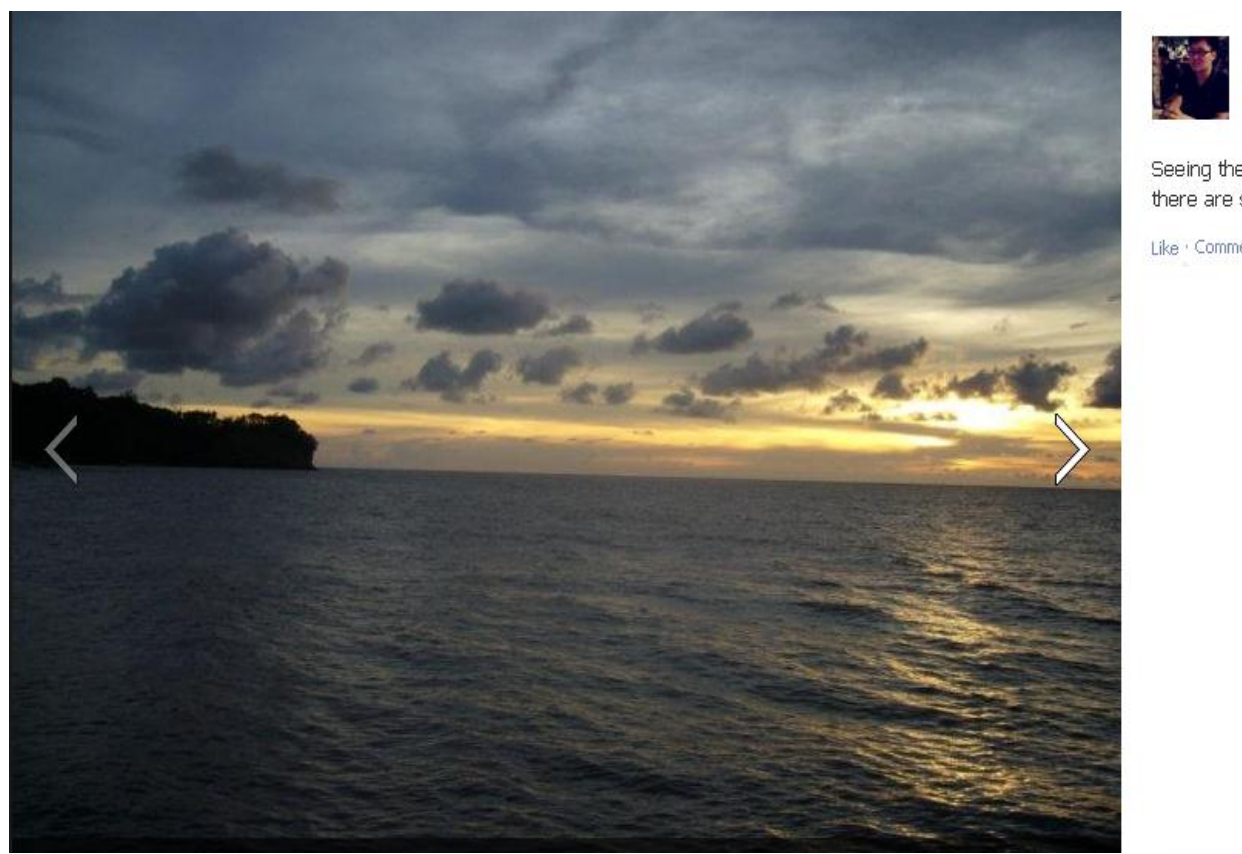

Figure 6.19. Enjoying local scenery

Caption: Seeing the sunset is beautiful, it remind[s] me that there are still beautiful things in life.

Photographer: TK, male, first year pre-university student 
Another photograph (Figure 6.20) provided by one of the participants was not captioned but shows images of students' participation in sport during their free time. Other participants also uploaded images indicating their involvement in sporting activities (refer to Figure 6.20 and Figure 6.21), which shows that this activity is a popular choice among the participants. During the individual interviews, two participants (BRI, male, third year commerce student and AZI, female, third year engineering student) also mentioned their preference for sporting activities to fill their free time.

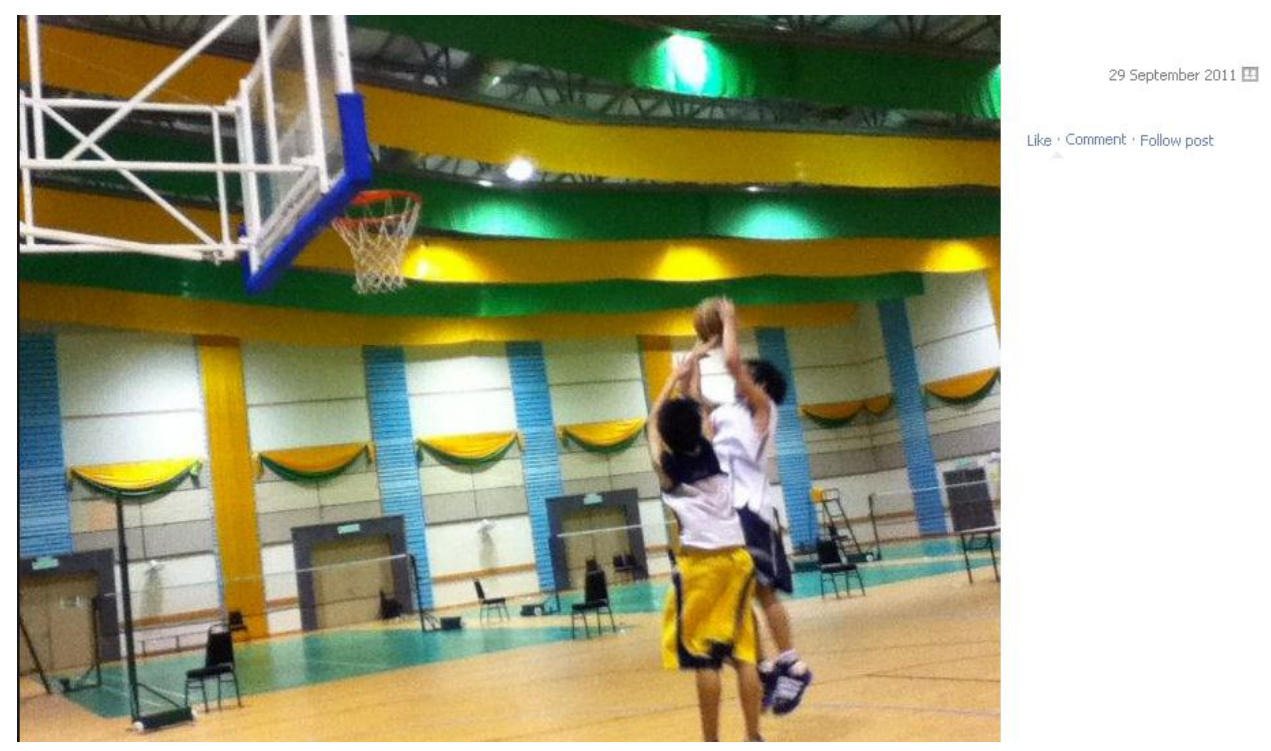

Figure 6.20. Participating in sports

Photographer: TER, male, first year pre-university student 


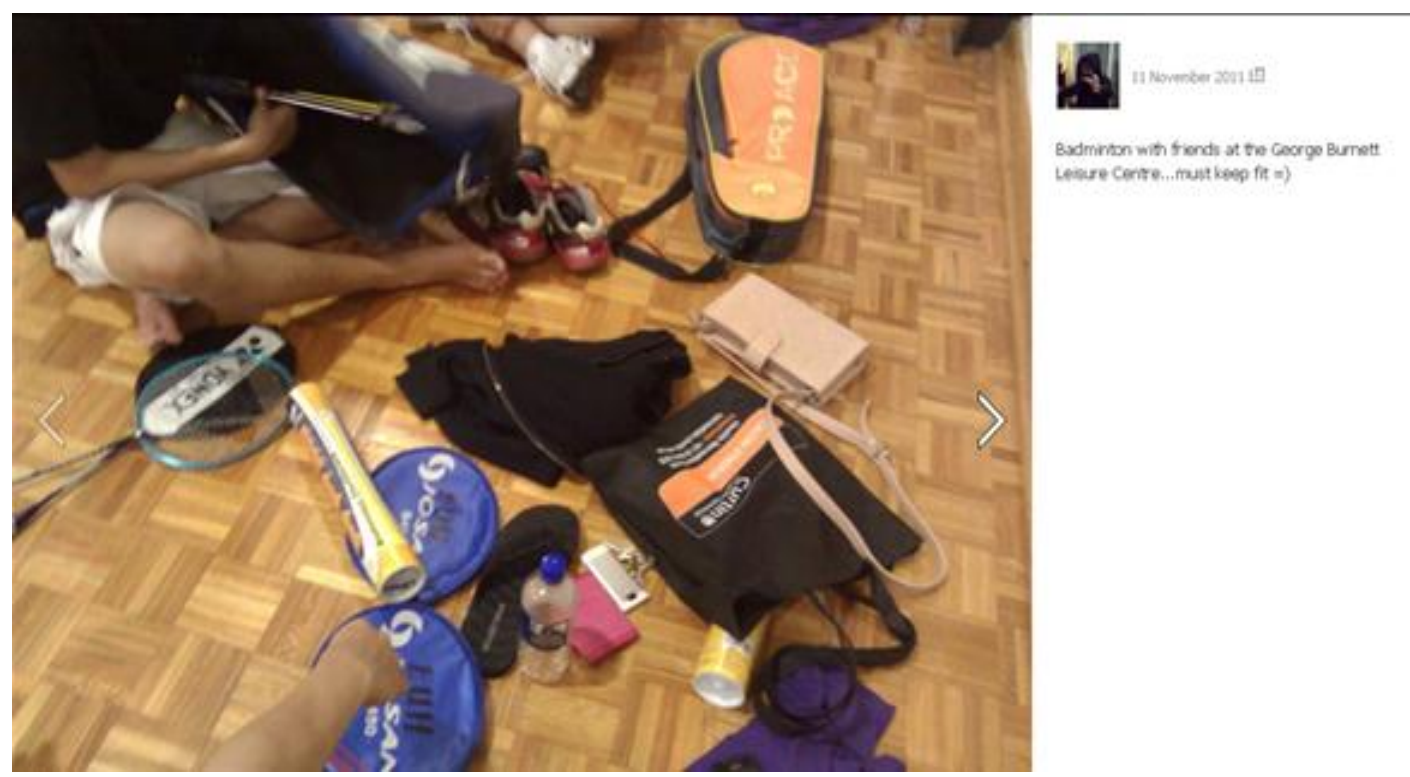

Figure 6.21. Enjoying badminton with friends

Caption: Badminton with friends at the [site university's] Leisure Centre. Must keep fit

Photographer: MAY, female, third year engineering student

In addition, my participants attached a high value to friendship as shown in the many photographic images they provided on the Facebook page. Most of these participants describe their friendships in very positive terms. The participants viewed friendship as more than just bonding with peers. In both captions (refer to Figure 6.22 and Figure 6.23) whenever they talk about friendship the participants also discuss the love they share amongst their friends. They saw friendship as a very important part of student life and the photos below demonstrate how important friendship is to them. Even though the participants placed a high value on academic success, a commitment to friendship was also significant as we can see from the caption given for the images below (see Figure 6.22, Figure 6.23 and Figure 6.24). 
As the Malaysian government emphasises the creation of human capital to generate economic growth (refer to Chapter Two, section 2.8) the neoliberal education system shapes Malaysian students to be academically driven in order to participate in the highly competitive education system, so these friendship findings are somewhat unexpected. Based on the findings, the value the participants placed on friendship challenges the prevailing perception of Malaysian students as entirely academically focused. One resounding theme that came through from the focus group interviews and individual interviews was related to how building relationships with peers made the university experience more enjoyable and fulfilling for my participants.

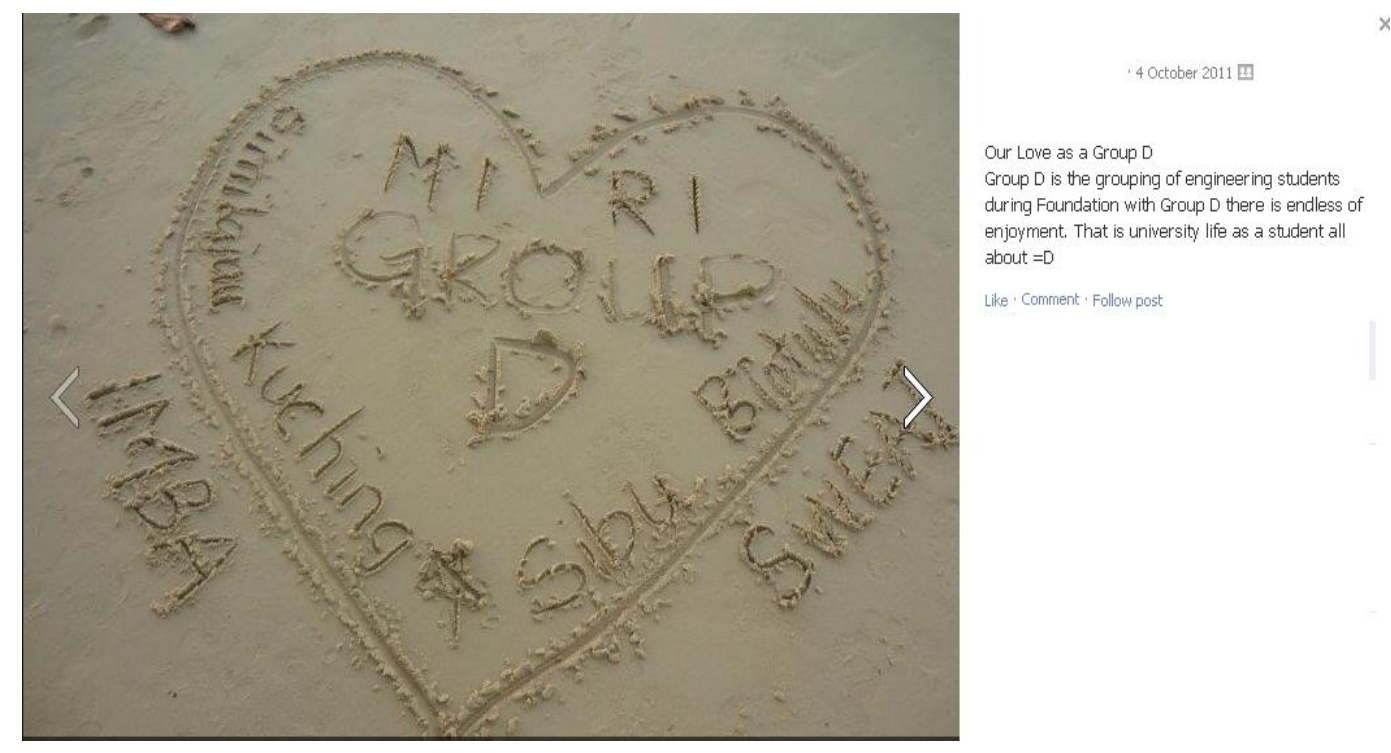

Figure 6.22. Friendship and building bonds

Caption: Our Love as a Group D. Group D is [a group] of engineering students during Foundation. [W]ith Group D there is endless enjoyment. That is [what] university life [is all about for] students $=D$

Photographer: TL, male, third year engineering student 


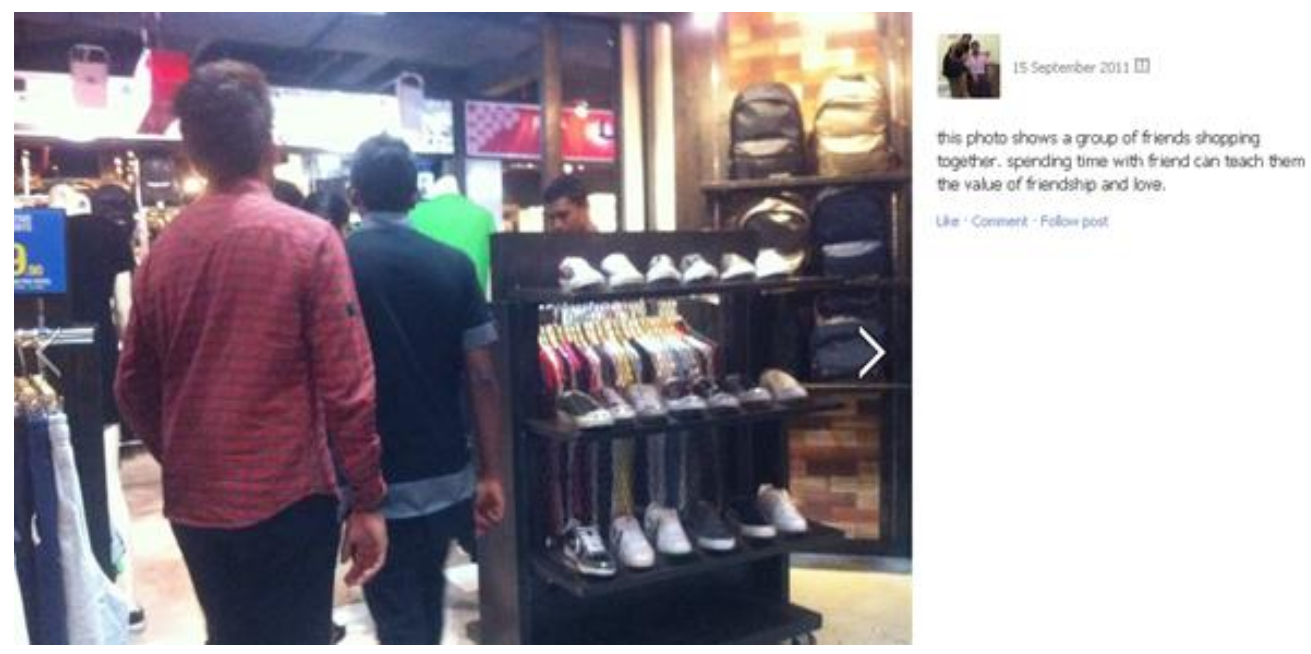

Figure 6.23. Spending time with friends and valuing friendship

Caption: The photo shows a group of friends shopping together, spending time with friend[s] can teach them the value of friendship and love

Photographer: GHI, female, first year pre-university student

My participants also showed that they enjoy spending time with their friends and trying out the local cuisine or just enjoying spending time with their friends over a meal. One example is given below (Figure 6.24):
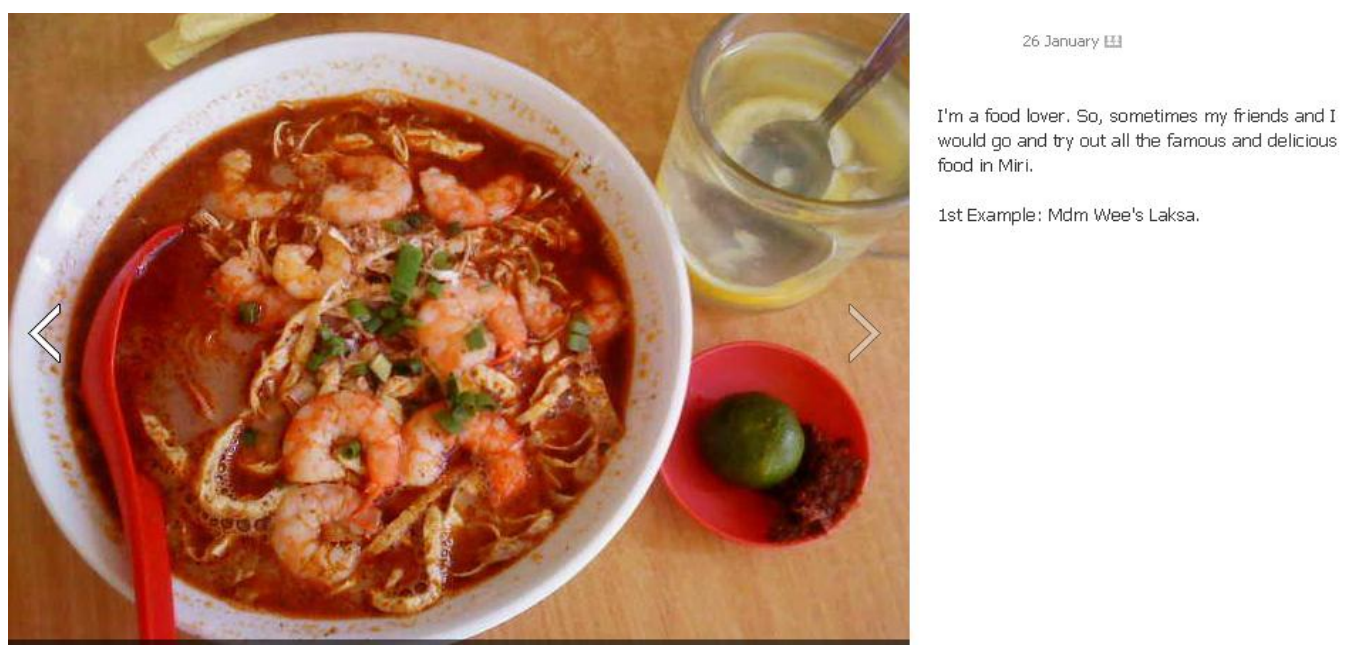

Figure 6.24. Spending time with friends over a meal

Caption: I'm a food lover. So, sometimes my friends and I would go and try out all the famous and delicious food in Miri. 1't Example: Mdm. Wee's Laksa.

Photographer: ANGEL, female, third year commerce student 
During the focus group interview, some participants (RAY, male, third year commerce student; MAY, female, third year engineering student; BRI, male, third year commerce student; and BW, male, first year pre university student) explained that they had formed strong bonds with their peers and cited forging friendships and building networks as main factors in their decision to engage in extracurricular university activities. My participants often mentioned that they would definitely participate in extracurricular activities or volunteer for a project if their friends were participating as well. Most would also choose to join future activities because of the bond they had built with their peers during the activities. One participant summed up his thoughts on friendship succinctly when he explained why he decided to engage in extracurricular activities. He explaned, "I guess it is friendship and also networking. To be honest, I was a shy person but getting involved [in] community service actively really made a difference." (ASF, male, third year engineering student).

Having a strong support group, which consists of like-minded individuals, facilitates volunteerism as young people are motivated to volunteer when they have peer support and encouragement. The findings also echo Putnam's (1993) belief that social capital exists in a collective setting, where members of a community work together to achieve a collective good. Putnam strongly emphasized the role of social bonding in producing individuals who have a strong sense of civic responsibility. Besides that, although a small number of the participants $(n=5)$ participated in religious activities their participation in these activities had a significant impact on their desire to engage in voluntary activities. The link between their religious participation and decisions to volunteer in community service and voluntary work projects will be explored further in Chapter Seven, with data taken from the interviews with the participants and their Facebook posts.

\subsection{Students' perception of the purpose of university education}

In the preceding sections, I provided background information about the participants' cultural capital and the extracurricular activities they chose to participate in during their free time. Furthermore, key information pertaining to employment status, educational level and family cultural practices, valued by Malaysian middle- 
class families was discussed. The next part of this chapter extends my analysis of the findings that I discussed in the first half of this chapter. In particular, I explore the participants' beliefs about the purpose of a university education. The results discussed in the following section speak to my first research question, which is, how does cultural capital influence students' beliefs about the purpose of a university education? The findings from this section are taken from the focus group conducted with 15 participants who volunteered for the focus group.

\subsubsection{University education enhances future career prospects}

The purpose of the focus group was to explore participants' beliefs about the purpose of university education. Findings from the interviews that were carried out revealed that a large number of the students $(n=9)$ believed that the primary purpose of a university education is to prepare them for their future careers. In this respect, the participants' ideas about tertiary education are closely linked to their long-term professional and economic aspirations. With this in mind, the participants entered university with clear expectations about the future and also with very specific goals in mind. They were acutely aware of the role education plays in providing better career prospects after graduation. BW remarked, "University gives a platform for me to expand my job opportunities." (BW, male, first year foundation student)

BAL explained that he had always been told that education is important as it guarantees financial stability in the future. This is a very pragmatic view of education, and a common belief held by many participants in the study. He explained, "I was always told that having university education will guarantee me a good job with a good pay that will lead me to a better life in the future." (BAL, male, first year engineering student)

JEFF described how important it is to have a university education to ensure that one is employable and can survive in the current economy. "I believe the purpose of university education is to ensure a job position in the world we live in nowadays. " (JEFF, male, first year foundation student) 
Third-year students were more inclined to believe that the purpose of university education was to prepare them for working life. This may stem from the fact that they are in the final year of their studies. Over time, their perceptions may have altered as they drew nearer to graduation and prepare to enter the workforce. RAY provided a clear explanation for this change in perception when he stated, "University education is a transition for every student so that they can prepare themselves before working with professionals in the society." (RAY, male, third year commerce student)

Eight other participants expressed the same belief during the interview. They all mentioned job opportunities, future career prospects and employment as the main reasons for pursuing university education. In this respect, their beliefs about the importance of education stemmed from their observations about their surroundings. These observations were further informed by family members or from the media (particularly the print media). The explanation provided by BR sums up most of the views held by the third-year participants:

Going through an education pathway should give some credit to students to have acquired certain skills, which might be useful in the job, [and] hence make it easier to acquire the job. Some employers might see an undergraduate as someone who had the discipline/perseverance in studying and perhaps might reflect in their working attitude, which is what employers are looking for. (BR, male, third year commerce student)

The participants also utilised this knowledge for their own benefit, demonstrating the understanding that having access to the 'right' individuals or organizations is important in order to seek opportunities which might benefit them. Their knowledge about how to use their social capital supports Bourdieu's (1986) argument that social capital is dependent on the volume and quality of networks and relationships a person is able to establish. With strong networks, it is possible to mobilize social capital as a strategy for advancing one's position within a given field. Moreover, accumulated capital can be used to one's advantage, for instance, to obtain 
information, knowledge or skills from peers within the network. BR continues and states:

Connection with [the] corporate world and peers will enable a student to know what is required out there. Hence we can still brush up on certain skills and prepare ourselves before being thrown in[to] the real world. It indirectly means you have a good head start right after you graduate compared with those who don't have such connection or knowledge or skills. (BR, male, third year commerce student)

The participants drew on the strength of their social capital and capitalised on this resource to acquire new skills and knowledge when they thought it might help them in their future lives. The participants showed their understandings about how they could utilise their relationships with peers to acquire new resources or competencies. In this study, the participants engaged in peer interactions and networking with the intention of profiting from these interactions. For Coleman (1990), this behaviour highlights the functional role of social capital. They capitalised on the ties that exist between members to achieve their goals. For instance, during the interview TK remarked:

We can also meet new friends who maybe specialise in a certain field as we can't really excel in all fields. We need to build a network of friends to socialise and also someone to refer to when we need more info on something. (TK, male, first year foundation student)

MAY provided an astute explanation for her perception about the purpose of university education. Now that she is approaching the final semester of her studies, her reflections about the role of university education were not only limited to job opportunities, she also talked about capitalising on her education as a means of enhancing her future opportunities, for example, to further her studies or to venture into other fields of knowledge: 
Initially I saw it as a compulsory stage for completing my studies before looking for a stable job in the future. I now see it as merely the stepping stone (or perhaps something that we can choose to opt out of) towards future undertakings such as postgraduate opportunities in other fields. (MAY, female, third year engineering student)

This perception may stem from the Malaysian government's policy of emphasizing education as a tool for producing more workers to boost the country's economy. According to Lee (2006) the government's decision of transforming the Malaysian education system into a knowledge-based one has resulted in the changes in policy particularly in generating more workers to fill the workforce. In addition, the government's policy of placing emphasis on higher education qualifications also reinforces the importance of educational qualifications. MAY's change in perception suggests there is a tension between the initial belief in the role of education and the expected goals after having experienced university life. The desire for obtaining higher qualifications and the idea of branching out into other fields suggests that the participant aspires to accumulate capital for future use.

When my participants were asked to explain who had influenced their beliefs about the purpose of a university education, 10 of the participants said that Malaysian 'society' has contributed the most in shaping their view that the main purpose of tertiary education is to ensure they get a good job. The distinction between the roles of parents, teachers and the community was not clear cut, but the participants attributed their beliefs to these parties. This is because they obtained information, news or advice from various sources around them, thus shaping their understanding of the importance of education. For example, V says: "[l think the influence comes from] society. In all of my childhood, parents and teachers keep stressing the importance of education to get a job, education to money, education this, that." ( $\mathrm{V}$, male, first year foundation student)

The current employment and economic climates also had a significant influence on the participants' views about the purpose of a university education. Four of the participants cited the industrial and economic forces as major influences. They 
suggested that their views are based on what they saw happening in the workforce at that time.

I see education in this way because we are living in the industry-driven world where careers and jobs are based on the demands of the industry. I was always told that having [a] university education will guarantee me a good job with a good pay that will lead me to a better life in the future. (BAL, male, first year foundation student)

From my eyes itself, the environment has influenced me. This is due to labour problems that [have] never been solved. Even fresh[ly] graduated students cannot find a job so I was putting myself in their shoes. I have to be better than them to get hired easily. (AY, female, first year foundation student)

Since [I was] young till high school, we have been taught basic knowledge that allows us to be ready for life. I believe that they are sufficient for a person to lead a good life. However, due to the change of lifestyle and cost of living, it is no longer enough. (IZ, male, third year engineering student)

One participant, BR, said that he kept up to date about economic issues that were happening around him because he believed that this would give him an 'edge' in the employment market. He was able to talk in an informed manner about the current conditions experienced in the workforce. He described how employers look for more than just academic qualifications in a job candidate.

Employers in business events always emphasize ... employing graduates who are not just into books but who can actually speak/present/lead. Going through an education pathway should give some credit to students who have acquired certain skills which might be useful in the job, hence easily ... acquir...[ing] the job. Some employers might see [the graduate] as someone who has the discipline or perseverance in studying and perhaps might reflect in their working 
attitude, which is what employers are looking for. (BR, male, third year commerce student)

Reay, David and Ball (2005) explain how individual habitus shapes people's perceptions of education. They argue that habitus helps to position individuals and assess their situations about a particular event. They draw on their mastery and knowledge of the economic climate, knowledge of employer requirements, needs of the society and social conditions in the community to map their position in the field. This knowledge determines the importance and value of university education in their lives. This habitus dictates the logic of their practice and influences how they engage in university activities as I will discuss further in the next chapter.

\subsubsection{University as a site for knowledge acquisition}

Although it would appear that the participants had set very specific goals in their pursuit of higher education, not all the students shared the same beliefs about the purpose of university education. Some chose to enrol at university because they valued knowledge for its own sake and because they believed that learning is an important component in advancing their knowledge. In this regard, not all the participants were focused on their career outcomes and were more intellectually inclined and motivated to use their university experience as a platform for learning. For example, V commented:

I'm very into science, and engineering is science..., and I'm very into knowledge and this is why I'm in tertiary [education]. I'm not in engineering because I want to work as an engineer; I'm in engineering because I want to learn. ( $\mathrm{V}$, male, first year foundation student)

Some of the participants (eight out of fifteen) also placed value on the acquisition of knowledge and skills and they attributed the attainment of such skills to the university setting. These eight participants viewed their quest for a university 
qualification as a valuable training ground for gaining skills which they could not obtain elsewhere. For example, NL described her university experience as a journey where she picks up many different skills. She also viewed the university as an important and desirable site for learning. During the interview, she explained that the university prepares its students in these ways, "[University is a place] to learn, to think more critically, to socialise, to enjoy, to solve problems critically, to explore." (NL, third year commerce student)

The university environment was also seen by these participants as a site for acquiring skills that would have potential value in their later lives. Again, making friends and building social capital was mentioned alongside the opportunity to acquire technical and soft skills which they believed would benefit them in their future working lives. JC commented:

University education provides the whole package, from learning specialised skills to getting to know a different person from different backgrounds, which is rarely found in typical Malaysian secondary education. I'm more inclined to participate in activities which have potential learning value (i.e. technical, soft skills, broadening knowledge/view, etc). I'm aware of my limited time in university and thus choosing the right activities is important. (JC, male, third year engineering student)

From my participants' points of view, a university education can also help to shape character as well as develop skills which are deemed useful for personal development. Other participants describe university education as "empowering" (JC, male, third year engineering), "promoting higher knowledge" (RAY, male, third year commerce student) and "learning knowledge and skills not formally taught in other places" (BW, male, first year foundation student). One student summed it up by describing the university as a site for the production of both academic and nonacademic knowledge, "University is there to provide the platform, environment, facilities, anything that helps to develop the skills to be the person they want to be." (IZ, male, third year engineering student) 
The findings above reflect my participants' views and beliefs about the purpose of obtaining a university education. My findings reveal that the participants' are aware of the importance of a university qualification for improving their career prospects and for accumulating the skills required to cope in the working world after graduation. However, the results also show that tensions arise after a period of time at university, as the participants start to realise that they can use their education to diversify and seek other opportunities for further studies in other knowledge fields. This change indicates that my participants used their cultural capital to make decisions about the types of activities they needed to participate in based on the experiences they had had. This also suggests that they are applying their knowledge to create opportunities for their future. One explanation for this change can be attributed to the experience they had while at university, as I will show in the next chapter in which I discuss the participant's shift in perception after participating in university activities. Their exposure to various resources have changed their perception and influenced their beliefs about the purpose of getting a university qualification. Again, this suggests that the students' perceptions are influenced by the cultural capital which they amassed at university.

Bourdieu's (1984, 1986) concept of field can be employed to explain this instrumentalist view of education and educational success. As Bourdieu (1984) explains the field is a social environment where agents struggle and compete against other agents for position within the field. The competition for 'distinction' (Bourdieu, 1984) within specific fields is what drives individual agency. For example, within the field of education in Malaysia, educational success is defined by excellent grades in the national exams, which allows entry into public and private institutes of higher education in the country. Individuals who obtain excellent results in their national exams are therefore awarded with 'distinction'. Another way to obtain 'distinction' is by supplementing educational success with other qualities (leadership skills, communication skills, and so on) perceived to be of equal importance to succeed in higher education. Thus, in order to succeed in the field of education in Malaysia, an individual must possess the 'right' educational capital alongside specific skills, which will give them a competitive edge. 
In sum, although both parental cultural capital and individual cultural capital are important resources for the participants in this study, the presence of educational capital is also a necessary form of capital valued by both the parents and the participants. Furthermore, having the 'right' friends and building on social relationships and networks also proved to be equally important alongside cultural and educational capital among students in this Malaysian university.

\subsection{Summary}

My findings point to the importance of educational capital as a primary source of motivation for both parents and students in the Malaysian education system. The drive for academic excellence is to attain economic gains to achieve social mobility and financial stability. This raises questions whether students experience a shift in perception after engaging in community service, as the results also show that students value friendships, knowledge, and other aspects of social life. The findings also indicate that the Malaysian families in my study value different forms of cultural capital than those suggested by Bourdieu (1986).

My results also indicate that the participants entered university equipped with academic capital gained from private tuition classes. This suggests that the parents held clear beliefs about the importance of education and maintaining consistently good grades that would secure a place at the tertiary institutions in the country. By sending their children to extra tuition classes, they hoped that their children would have the skills they needed to compete with their peers in the competitive Malaysian education system. Although some parents did not pursue higher education and their children were the first generation to experience university education, the parents still strongly believed in the value of education. The findings from my interviews support this argument and this was shown when the participants revealed some very pragmatic views about the purpose of university education as a pathway to a stable job and a secure financial future. These were ideas they derived in part from their family but also from strong social messages in Malaysian society. In addition, I have been able to show that parents who possess a higher level of education use this knowledge to guide their children and help them to acquire a competitive edge by engaging in specific activities 
which allowed them to 'stand out' from the rest of their peers and get noticed by employers.

In addition my findings also shed light on the manner by which students acquire and use academic capital to succeed in higher education. Given the competitive education field, and the marked oriented, utilitarian work field in Malaysia, it is critical that the students invest in extracurricular activities to achieve distinction and stand out from the rest of their peers. The manner in which they exploit their social networks and connection for gaining knowledge also highlights their need to excel in higher education, thus ensuring they have higher chances of entering the workforce. Furthermore, the parents in my study also relied on their social and economic resources to provide guidance and advice to their children while they were at university. However, the findings also reveal that other forms of capital are equally important in influencing the participants' engagement in university activities. Cultural capital helps the participants to form perceptions of the importance of education and social capital allows them to make use of their connections and social relationships during their time at university. They acquire social and academic skills at the university and they develop skills which are not formally taught in class by participating in community service activities, club activities and also voluntary work projects. Social capital is also important for the participants as they gather information about the labour market from various sources in their lives, for example the society. The participants explained that society also played an important role in influencing their perceptions as they discussed how they were informed of work opportunities, challenges and future prospects by their teachers, parents, the media and also industry representatives.

Besides that, the amount of social capital accumulated by family members and relatives is also important as an investment strategy for advancement in higher education. My findings indicate the participants were influenced by the knowledge and experience from relatives who had studied in local universities or abroad. Overall, results of my study indicate that social capital, coupled with cultural capital shaped individual perceptions and beliefs that allowed the participants to make informed decisions about their futures. Although cultural capital played an important role in 
informing the students about what is important for educational success, the role of social capital in the form of building and maintaining peer networks played a bigger part in influencing their engagement while at university due to the competitive field of higher education in Malaysia. Social capital is a powerful tool for promoting greater student engagement and enhancing student experience at university. Findings on this aspect of the study are discussed in the next chapter.

In the next chapter, I present the findings and analysis for my second research question, on how students' perceptions influence the nature of their engagement in university activities during their period of study. 


\section{CHAPTER SEVEN}

\section{THE NATURE OF STUDENTS' ENGAGEMENT IN UNIVERSITY ACTIVITIES}

\subsection{Introduction}

This chapter explores the links between the participants' beliefs about the purpose of university education and their engagement in extracurricular activities. The purpose of this chapter is to identify whether the participants' views about the purpose of education affect the choice of activities they engage in while at university. In this chapter I present the themes that emerged during the focus group interviews and the follow-up interviews with regard to the participants' involvement with extracurricular activities over a period of two semesters at the university. In addition, I include interview excerpts and other data generated in my interactions with the participants on the SNS, Facebook to illustrate participants' understandings about community work and the importance they placed on participating in these activities. I also included the explanations they provided about the images to show how their perception changed as they progressed through university. This information addresses my second research question on how do these perceptions influence the nature of their engagement in university activities during a two-semester period. 


\subsection{Students' engagement in university activities}

\subsubsection{The role of social capital as an investment strategy}

Bourdieu contends that individuals seek ways of converting their social capital into economic gains (Bourdieu, 1986). My findings support his argument as it became clear to me that the participants had actively deployed these kinds of strategies to garner social profit. For example, the social capital that the students accumulated spending time with faculty, friends and organizations was often viewed as being valuable for a letter of recommendation in the future. They also became adept at exploiting their extracurricular activities as a form of 'resume padding'; a strategy that they hoped would set them apart from their competitors when seeking a job (Handy et al., 2010). For example, during the individual interviews, one participant explained that she realised that extracurricular activities were important because her involvement in these programmes would place her in a good light and ahead of her peers when it came to employment (refer to AZI's comments on page 95).

BW talked about how he was advised to join clubs and various extracurricular activities because it would be good for his resume.

During the orientation, someone said [...] Joining clubs and extracurricular activities is good for your resume. I was like, oh cool! If you have a Cert for bachelor [bachelor's degree], any cert [certificate], only one cert, is very bad. Because employers want someone that's holistic in every field not just a nerd, or [someone who is] book smart. And I don't want to come out [to] be the person that only [has] one Cert, begging people to employ me. (BW, male, first year foundation student)

My participants also noted that their interactions with other students in groups, volunteer associations or athletic teams could furnish them with opportunities for accumulating social and cultural capital. When asked why they chose to continue being active in community work and voluntary projects, they cited "building bonds" (RAY, male, third year commerce student), "widened social network" (MAY, female, 
third year engineering student) and "having fun with friends" (BRI, male, third year commerce student) as major factors, which sustained their interest in participating in various activities at the university. Handy et al. (2010) explain that students use volunteering as a strategic route to enter the labour market. They explain that volunteering has a 'signaling role' (Handy et al., 2010) used to convey that a candidate possesses qualities that make him or her a desirable candidate in a job interview. Furthermore, because of the competitive nature of the education system and the workforce, students are pressured to devise strategies to signal what sets them apart from other competitors. Investing in extracurricular activities is one avenue to achieve this goal.

Social experiences seem to be central to the participants; in fact they are as concerned with friendship as they are about their studies. In this respect, the university setting provides the field in which they can enhance not just their knowledge and skills, but also their stock of social and cultural capital. In addition to fostering closer bonds, the social interaction between the participants and their friends provide opportunities for learning and acquiring cultural capital thus enabling them to pick up new skills and knowledge that may be beneficial for them in the future. Figure 7.1, taken from the Facebook group page that was set up for this study, shows how much these participants valued their friendships. My findings suggest they place high importance on making friends and building bonds with their peers. The following extract is from an interview with a participant, RAY, who viewed his extracurricular activities as a memorable event in his life. During the interview when I asked him what he valued most about his experience, he replied, "You get every single piece of [the] puzzle of memories so when you gather it, it's a perfect picture. You know that ok, remember last February, what did we do?" (RAY, male, third year commerce student) 


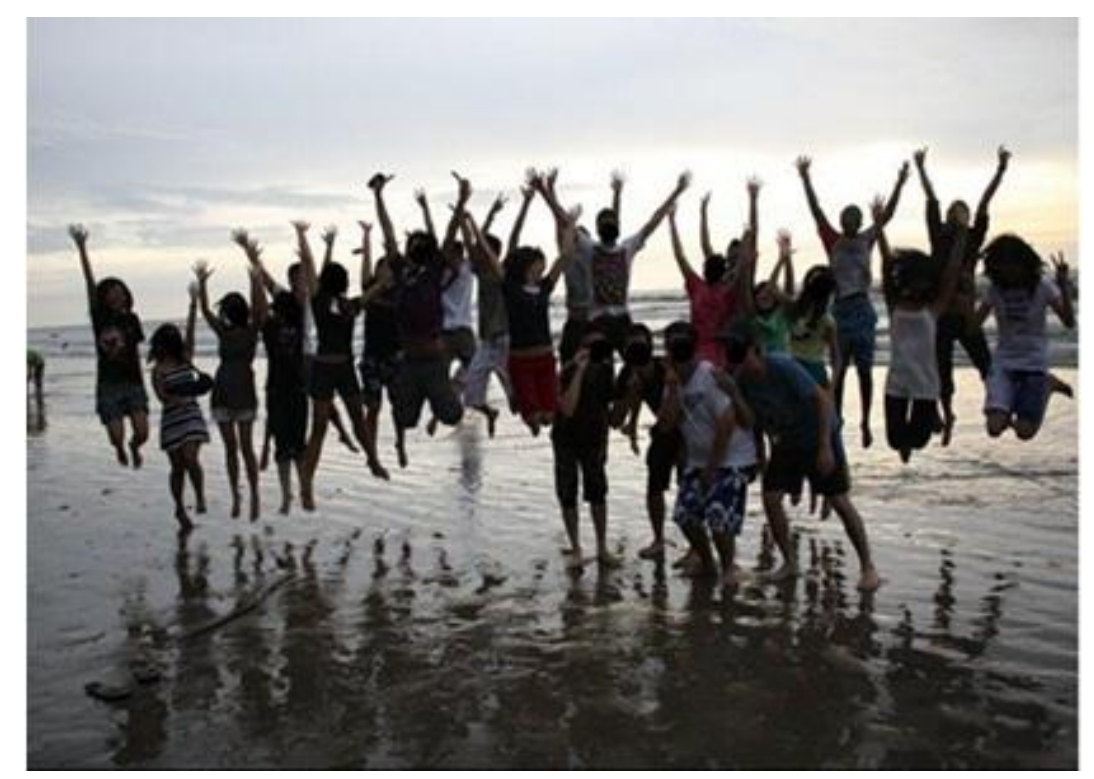

Figure 7.1. Creating memories and valuable experiences

Photographer: RAY, male, third year commerce student

My findings also show that the Malaysian middle-class participants who were involved with this study tended to invest less time in building economic gains and more on establishing social capital. ASF described his beliefs eloquently when he talked about how accumulating social capital (in this case networking with peers) could help him to achieve his goals. He claimed: "With broad networking, it's easier for me to reach my goals either in university or [the] real world. You gain success not because of what you know, but who we know." (ASF, male, third year engineering student)

This extract shows that this participant accorded a high priority to networking and establishing relationships with the 'right' kind of people in order to reach their goals. In addition, the accumulation of this kind of social capital was also seen as important in developing skills, which would serve them well in the future. One participant, BR, said that extracurricular activities had allowed him to learn a variety of skills, which are often not taught in formal learning, as follows: "The Student Orientation team, like we learn a lot of teamwork, [and] communication. I really see there's a lot of team work and everybody is really working with each other [and] working together". (BR, male, third year commerce student) 
The Student Orientation team is a student group that is responsible for helping the faculty members during the university's orientation week every semester. Their duties include providing campus tours; assisting the staff who run the orientation programme (such as helping out with group activities and briefing sessions); assisting students with registration; and, providing information aimed at easing new students' transition into university life during the first week of enrolment. MAY described her experience with a leadership programme run by the university that had helped her to develop interpersonal and intrapersonal skills. She explained how she and the other group members overcame their problems and worked together to resolve their conflict to achieve the objectives of their project.

One particular experience I had was as a team member in a group of four, and we worked for nine months with approximately twenty government agencies, NGOs, and political parties. The main difficulties were bureaucratic policies and the problem of gathering more than $80 \%$ of the representatives within the same timeframe. At the same time, we had to deal with exams and assignments as usual. If it was not for the determination of all four members (there were also squabbles and fights within the group, whenever it became too stressful), we probably wouldn't be able to continue the project. I've learned a lot about communication and administration skills. Both are equally important in a lot of activities (or group work) I'm involved in because I can contribute those skills and my previous experiences to achieve our objectives. (MAY, female, third year engineering student)

In general, the students actively utilised their cultural capital to accumulate social capital, which they believed would be valuable to them in the future. In some instances it was as simple as establishing friendship networks that helped them to develop good social skills or acquiring information from friends who they judged to be experts in a particular field. Others were more strategic, because they perceived engagement in community service, clubs or voluntary activities as a way of establishing relationships with organisations and potential employers. In addition, some of the participants also viewed engagement in these activities as a form of 'resume padding' a strategy to stand out and show potential employers that they are made up of more 
than just 'book smart' material. They believed that through being involved with these activities they could acquire the tacit skills which would indirectly help them to perform better, not just academically but also in their future working lives.

From a Bourdieusian perspective, I argue that the participants were converting the capital they had accumulated during university into the attainment of better career prospects and the ability to cope within the society. For them, this could translate into securing, high paying positions in the workforce in the future.

\subsubsection{How extracurricular activities shaped the participants' dispositions}

The participants' habituses reflected their dispositions and perceptions about the purpose of university education and the university's role in advancing their job prospects. They were able to identify which activities would aid their personal growth and development and also articulate how those activities could advance their position in the workforce after graduation.

My participants expected that higher education would promote their personal development by offering them a more concentrated exposure to diverse ideas, values and experiences that they were unlikely to encounter in secondary school or at home. For instance, LWK explained that he was able to learn about survival training during his first aid training at university. The photograph he posted on the Facebook page that was set up for this study shows a training session organised by the university's Red Crescent Club. The Red Crescent Club's main role is to promote the importance of first aid and safety amongst the students on campus. The caption reads: "Boat Handling: I've learned the basic training on how to manoeuvre a boat [and how this] is important when there is an emergency such as flood[s]." (LWK, male, third year commerce student) 


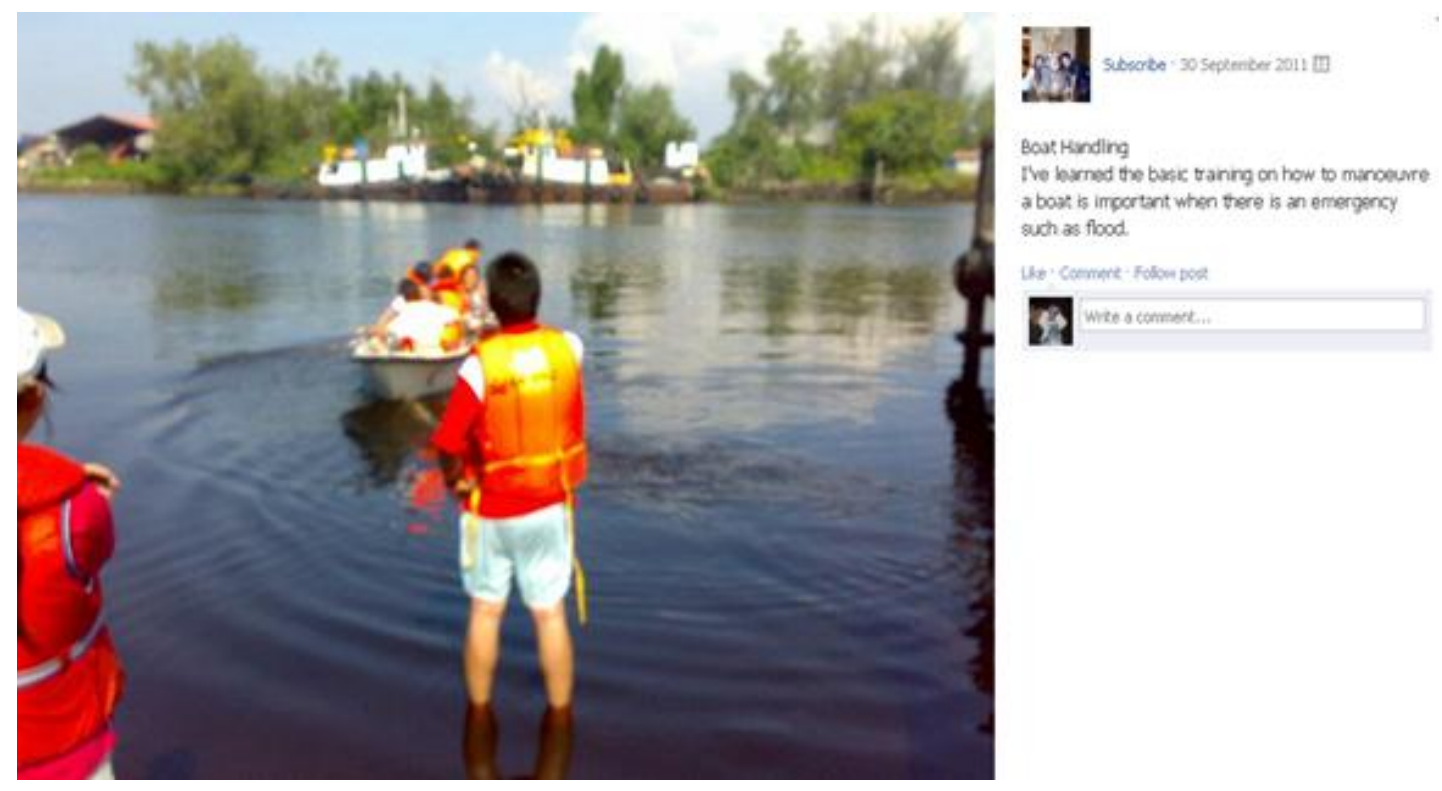

Figure 7.2. Learning about survival training for emergencies

Photographer: LWK, male, third year commerce student

In another example, BW uploaded a photograph onto the Facebook page, which shows an advertisement for a camp he had attended. He explained, "Exploring Humanitarian Law: This 3 days 2 night camp really taught and exposed me [to] the importance and application of IHL (International Humanitarian Law). Before coming for this camp, I have no idea what is IHL. The way the camp [was] arranged makes the learning of $\mathrm{IHL}$ even more interesting with tons of presentations and on-the-spot drama/sketch. I even use[d] this topic as my ECS final presentation." (BW, male, first year foundation student) 


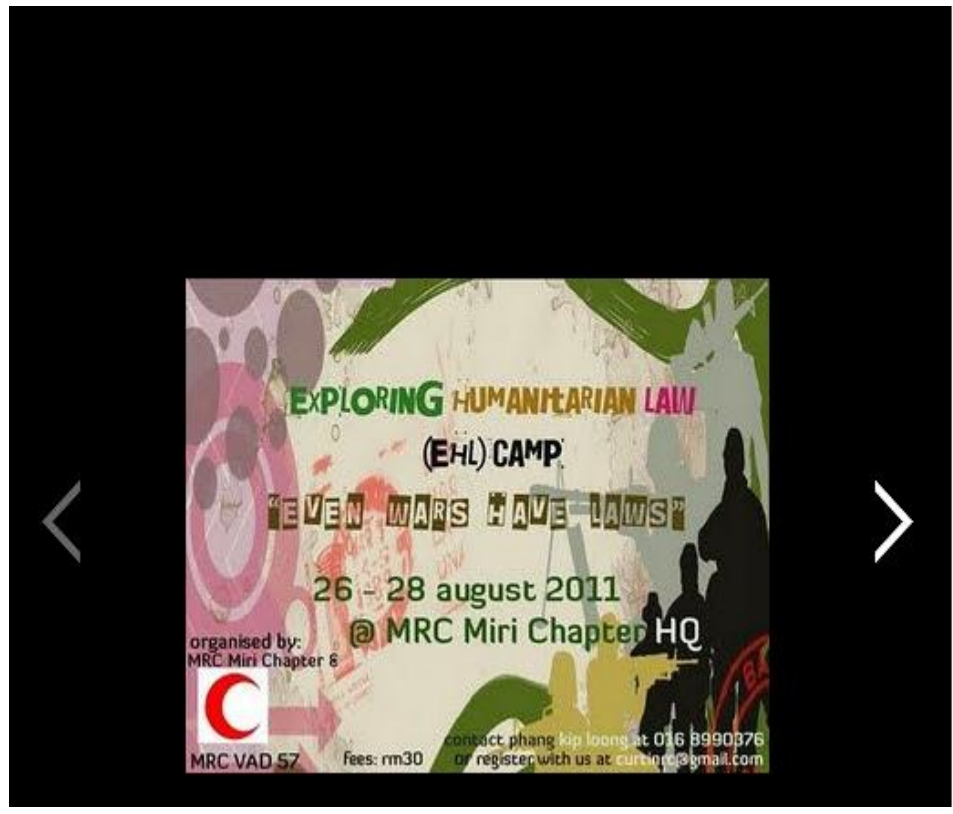

Figure 7.3. Learning new things and sharing the knowledge

Photographer: BW, male, first year foundation student

In this case, the participant even decided to share with his friends what he had learnt in his Effective Communication Skills (ECS) class as part of his assessment. As a result of his experience during the camp, he used this learning experience strategically and applied it to his academic life as well.

Other participants viewed the university as a place where their beliefs and abilities could be challenged and shaped. They explained that they looked for activities that would satisfy their desire for new experiences and self-growth. For example, during the interview $\mathrm{V}$ explained the types of activities, which appealed to him and the reasons behind his participation in these activities.

I think I [will] choose activities that are challenging to me. For example, I am currently interested in debating. I value debating because it's one of the few forms of sports where you get to beat your opponent intellectually and this is one form of sport that you need critical thinking to a very high level and this is 
something that interest[s] me deeply.[...] I'm also interested in speech. And basically anything that interests me. I think to properly describe this I need a real example. [...] I have options but generally [...] (pause) whatever it is that I feel can contribute most towards my growth, then I'll prioritize them one by one. ( $\mathrm{V}$, male, first year foundation student)

In another example, based on the data from the Facebook page (Figure 7.4), AZI described an experience she had when she went for an educational trip to the Mulu Caves. ${ }^{3}$ During this trip she went to a Penan ${ }^{4}$ (an ethnic tribe in the Sarawak region) longhouse in the Mulu district. She explained how interesting the experience was for her as she was able to learn more about a different culture during her trip.

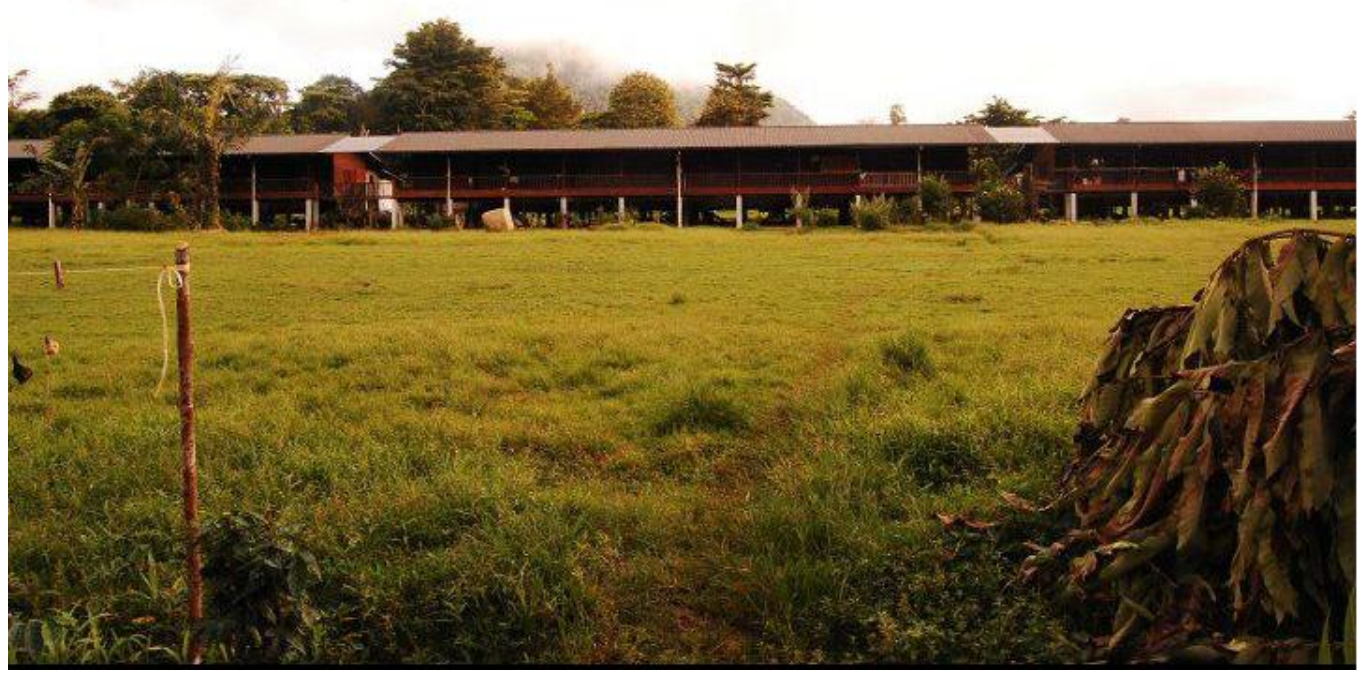

Figure 7.4. Learning about other cultures and lifestyles

Photographer: AZI, female, third year engineering student

\footnotetext{
${ }^{3}$ The Mulu Caves are a UNESCO World Heritage Site famous for its limestone karst formation.

${ }^{4}$ The Penan people live in the interior districts in Sarawak and many continue to lead traditional nomadic ways of life.
} 
During the trip, she also managed to capture a photograph of a Penan lady playing a traditional instrument called the nose flute also known as a keringut. She described how this was a valuable experience for her as it alerted her to the existence of a local indigenous culture that was very different from her own ethnic Malay culture. In this respect, the learning experience at university went beyond classroom learning and the participants considered that these activities were equally valuable to them.
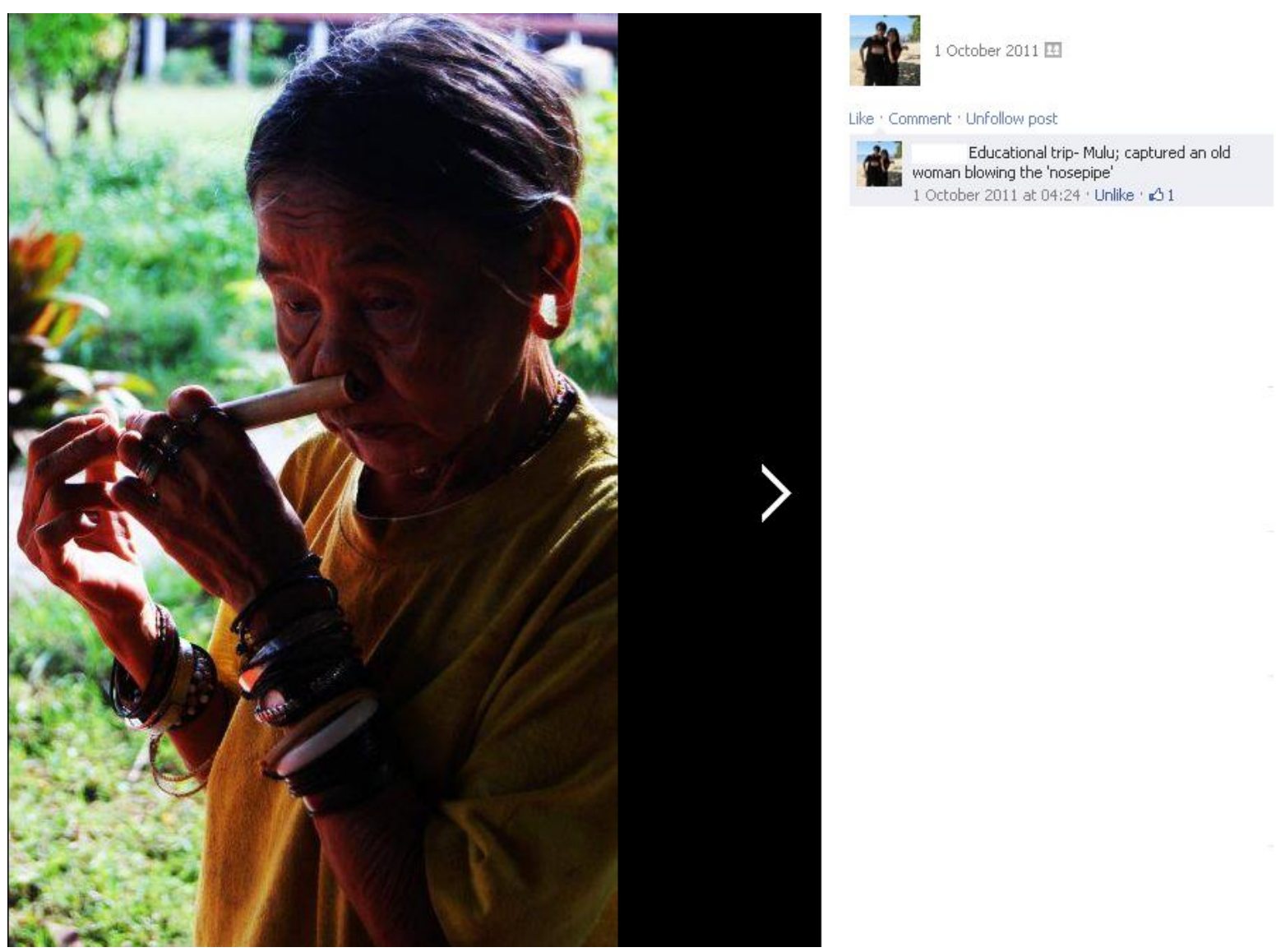

Figure 7.5. Learning about local indigenous culture

Photographer: AZI (The woman pictured gave permission for her image to be used as part of this study)

In addition, my participants highlighted the importance of the learning process, as well as the outcomes of the activities they chose to participate in. They see engagement with community service, clubs or voluntary work as a win-win situation, where they get to participate in activities for a good cause but still gain new knowledge 
while engaging in these activities. For instance during the interview, ASF explained his beliefs about his participation in community service. He states: "As long as I learn something new, I don't really mind the objective of the activities. But the important thing is that whatever activities I do must be for the good cause." (ASF, male, third year engineering student)

Another important finding obtained in my study is that the active involvement in extracurricular activities facilitated the transmission of tacit knowledge and this was the case for the participants in the study. In this context, the participants believed that their learning was not always explicit during the activities but rather, aspects of situated, authentic learning were involved. My participants mentioned teamwork, cooperation, management and conflict resolution skills that they had gained from participating in these extracurricular activities. At the same time, they often talked about: how many friends they made; how having fun made the activities more interesting; and how friendship and bonds are strengthened during each activity. They were knowledgeable about what activities they chose to participate in, but at the same time they still had a strong desire to participate in activities through which they would form relationships with peers and other adults. In this respect, they placed as much importance on the value of the activity as they did on the development of social bonds. For instance, one of the photographs uploaded on the Facebook page (Figure 7.6) came with this caption, "Student Orientation advisor team: leadership (guiding students) \& [had] fun working with different people/teamwork (different people need different styles to work with, so you need to adapt to their personality to make the best [out of the situation])." (BRI, male, third year commerce student) 


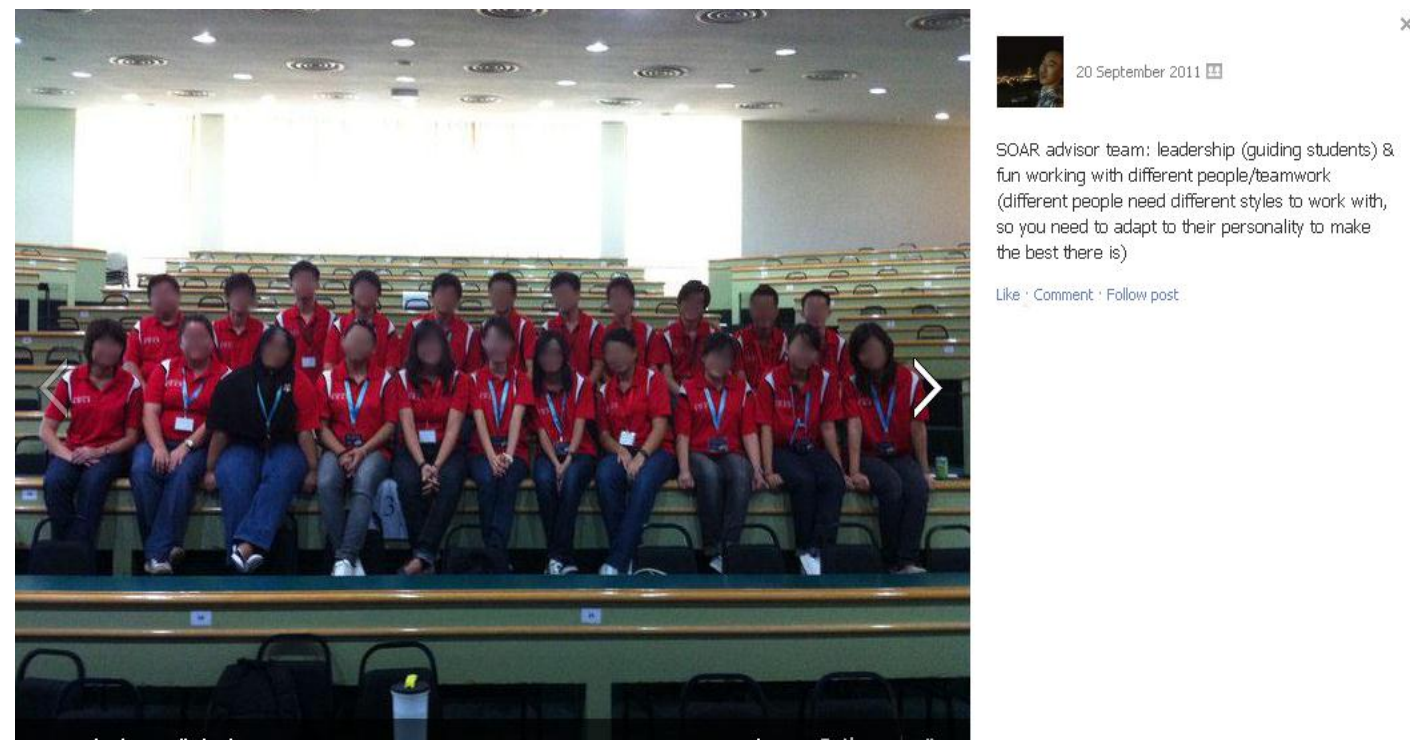

Figure 7.6. Acquiring skills through participation in activities

Photographer: BRI, male, third year commerce student

Figure 7.7, taken from the Facebook page shows how my participants acknowledge the skills they picked up and how it can be applied to other areas of their life. The caption in the photograph below reads, "Took part in a skit performance during VCF (Varsity Christian Fellowship) Camp 2011. A good opportunity to hone communication skills (with the audience) as well as bravery to perform in front [of] many people." (JC, male, third year engineering student)

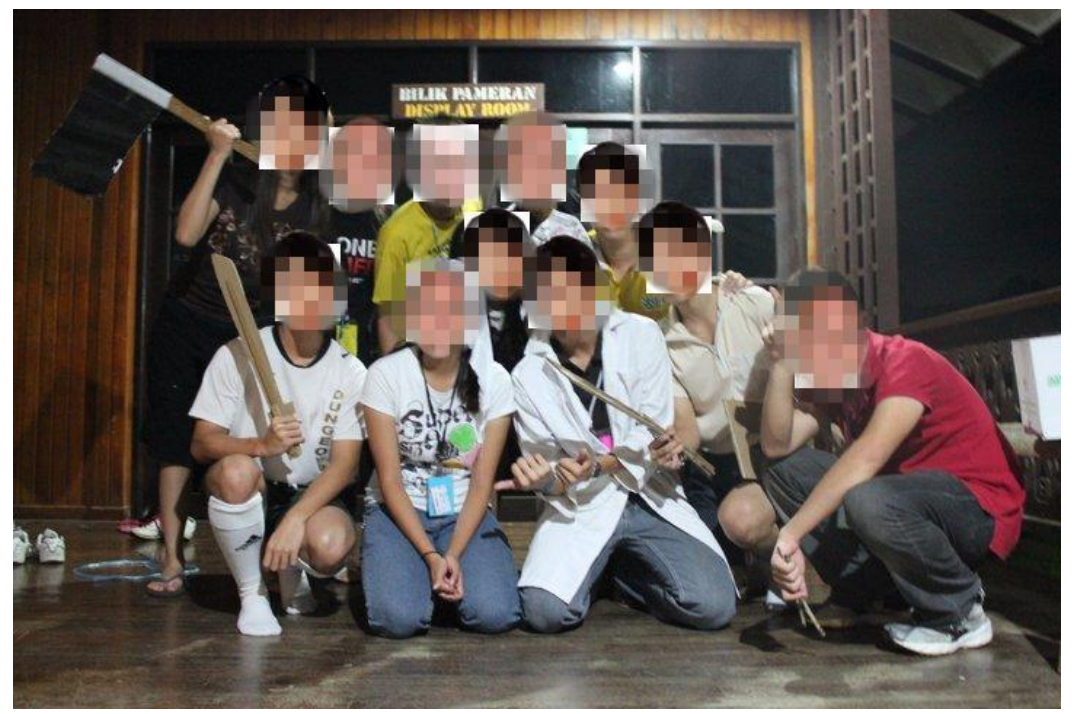

Figure 7.7. Transferring skills to other areas of life

Photographer: JC 
My participants also talked at length about how certain events had a lasting impact on them and helped them out in classroom activities. This suggests that they are aware they were picking up certain skills in an implicit manner, and that transmission of tacit knowledge was involved when they engaged in such activities. For example RAY remarked, "Yeah of course from Student Orientation advisors [in] those events I did learn because since you are doing certain events you will be assigned to different task[s]." (RAY, third year commerce student).

He went on to explain how this had helped him in his academic life, and how, during classroom activities, he applied the skills he had picked up during orientation week. He related his experience as a student orientation advisor to another aspect of his academic life where he explained how his experience could be applied in different contexts:

From there [in] every single part you get different points of view so whenever you're doing your units, let's say marketing units or management units you know how to, [relate] certain examples or experience to share to the class what are the points of view for this certain particular department, let's say management. What would [the] management team feel like whenever you have this decision, what kind of dilemma [would] you face and what are the possible solutions that you can use to solve this. So it helps in assignment it also helps in class discussion. (RAY, third year commerce student)

Participation in extracurricular activities helped my participants to develop a range of problem-solving skills. For example, when faced with challenges and problems, it appears these young people monitored their strategies in response to feedback from their peers or members of the faculty involved in a project. ASF described how he practiced self-reflection after every event. In this case, he explained how he uses the tacit knowledge he acquired during each activity and reflected on them so he can improve in future activities. In the extract below, he talks about management skills and then mentions the leadership skills involved during the process of completing an event. He also reflects on each step involved in the organization and 
implementation of the project and analyzes the strength and weaknesses of the project, which meant he was utilising his experience to improve his management and leadership style in future activities.

Extracurricular activity to me is an opportunity to get to know people more as well as myself. [At the end of every activity], l'll always make time for self reflection. The aspects that I reflect on, in this case, [for example] for cocurricular activities who were the OC [Organising Chairperson], who [was] in his or her committee, who was his or her adviser etc. Easy to say, it is how the OC or team leader organised the activities/events and who were involved with it, because all the past experience made me a better leader. (ASF, male, third year engineering student)

In addition, my participants explained that they reflected on the planning process and altered their strategies to come up with a solution to the problem. For instance EL said:

I had to prepare lots of things, back in East Malaysian Volunteers, I don't actually experience that you see. People just [assign the task to] me, just ask me to be there, everything is prepare[d]. But when I was in another volunteer club, I was given a chance to be the one thinking of how to motivate. I enjoy the planning from the very start, which includes the communication between the schools, how to communicate with the students that kind of thing. And then the one thing that I really learn[t] that time is it's not easy to teach. (EL, female, third year engineering student)

She relates her current experience to her previous involvement with another club and reflected on the differences. She then realised that she enjoyed the whole process, from planning through to the implementation of the event. She also acknowledged that it was not an easy task to educate and this experience provided her with a new perspective on teaching. Again, the experience taught her to reflect on her 
journey and changed the way she perceived her past experience. This suggests that in previous clubs, she was not given much freedom to work independently during the planning of an event and this newfound independence gave her confidence and was a new learning curve for her.

Figure 7.8, signals that the participants spend a great deal of time reflecting on an activity or event they have been involved with. The caption provided by JEFF shows that he valued the experience as it helped him to get a different perspective on his field of study. The caption reads:

Took part in a presentation for Design Project (one of the most important coursework for chemical engineering students), with presence of professional engineers from the industry. Learning to [brush] up [on] professional presentation skills [that may be] (important for future career) as well as [the] ability to handle the fear and pressure of public speaking. P.S: engineers are not only required to be technically capable, but also must be able to communicate ideas with others in an efficient manner. (JEFF, male, third year engineering student).

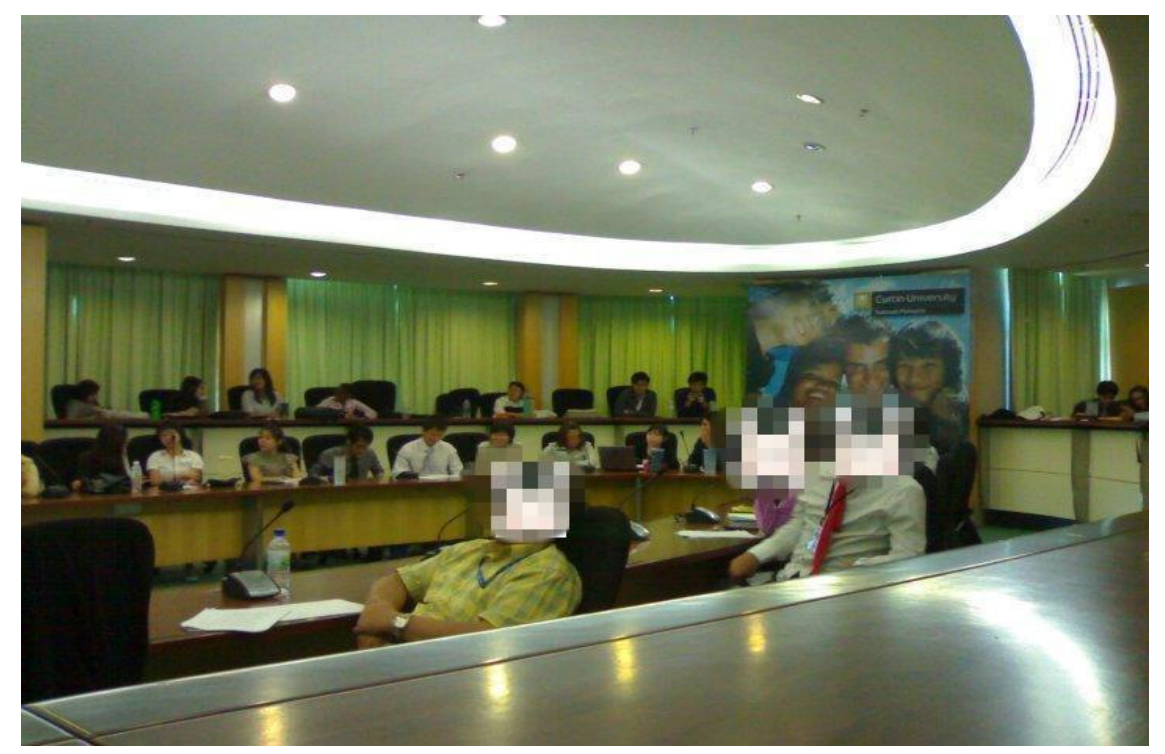

Figure 7.8. Reflecting on activities they were involved in 
This extract (Figure 7.8) suggests that the experience of interacting with professionals in the industry had a significant impact on creating a shift in the participants' thinking. He realized that presentation skills and communication skills were also important aspects of learning, which would be useful in the future.

\subsubsection{Institution led activities and student engagement}

One of the most important findings to come out of this study was the role of institution led activities in shaping the students' interest in participating in community service, clubs and voluntary work throughout their university lives. McFarland and Thomas (2006) argue that schools and local communities serve as important fields for heightened extracurricular involvement. They believe that the clubs and organizations within the school can develop civic interest amongst youth attending the institution. In my study, institution led activities influenced my participants' dispositions and perceptions towards community work and voluntary activities during their participation in these activities. For example, my participants were exposed to the concept of volunteerism and compassion from an early stage, and were often asked to participate in outreach activities, which promote volunteerism. It was also common for some secondary schools to organize activities for their students and these institution led activities appear to have had a deep impact on my participants.

The practice of organizing such activities has consequently resulted in the students being 'trained' to volunteer and practice voluntarism when they can. This shows that educational capital is valued alongside pembentukan sahsiah (character development and the inculcation of values such as compassion, empathy, tolerance and understanding) as we can see from the excerpt below. My findings also indicate that social capital is important for the participants as they are taught to help out in the community. The notion of helping out and volunteering in the community is strongly encouraged, and sometimes even made compulsory by the schools. For example, AZI explains: 
My school they usually organize during fasting month, we go to...what do you call that... rumah anak yatim? Oh, orphanage... yeah, to help out and everything. It's like we did that since we were in form 1. At first we were forced to but then we're in high school for five years and every year you do it so it sort of become[s] voluntarily. (AZI, female, third year engineering student)

The role of the educational institution is therefore an important source for encouraging volunteerism and community service among primary and secondary school students. My findings suggest that besides being equipped with educational capital, it is also important for the students to possess excellent character. They need to demonstrate that they have a good $\operatorname{sahsiah}^{5}$ and a good education to be considered successful. For example, the participants are familiar with the concept of giving, and helping out people less fortunate than themselves as these are themes that are repeated in religious classes in primary and secondary schools. Participants cited religious classes and religious lessons as influential in shaping their attitudes about volunteerism. ASF explains:

What I learn from Islamic Studies in primary school [is that] if I want to do charity work, it is better for us to do it as a company rather than individual. If we want to do it individually, we should do it anonymously. (ASF, male, third year engineering student)

From both an Islamic and Christian perspective, followers are strongly encouraged to give alms or to tithe, but the person who does this must be sincere and they are encouraged to do it anonymously and not show off or make it public. The whole concept of giving, then, is based on ideas about humility and the sincerity of the giver when doing something good (for example, almsgiving, helping out in the community, and so on).

\footnotetext{
${ }^{5}$ Character development.
} 
Besides religious classes, my participants also credited their interest in pursuing community work and voluntary activities to other non-academic activities that promote leadership and a strong sense of responsibility, commitment and dedication towards a particular cause. This signals that the students have formed a disposition towards community service as they 'bring over' their habitus for volunteerism obtained from their secondary school education into their university education. For instance, at the beginning of each semester a group of student volunteers will be asked to help out with the student orientation. The photograph below shows how the participants feel about the whole orientation programme, which they volunteered for. For example, during the interview, RAY commented:

Actually I think it's a influence from what I do in high school because [in] high school normally they don't have much voluntary work but mostly you take part in all those um.. like what people always do like prefects and so on so when you get enthusiastic in organizing stuff that's where the perception comes. (RAY, male, third year commerce student)

Furthermore the university also plays an important role in encouraging participation in community service projects. Figure 7.9 provides a clear example of how university led activities can act as a catalyst for volunteerism.
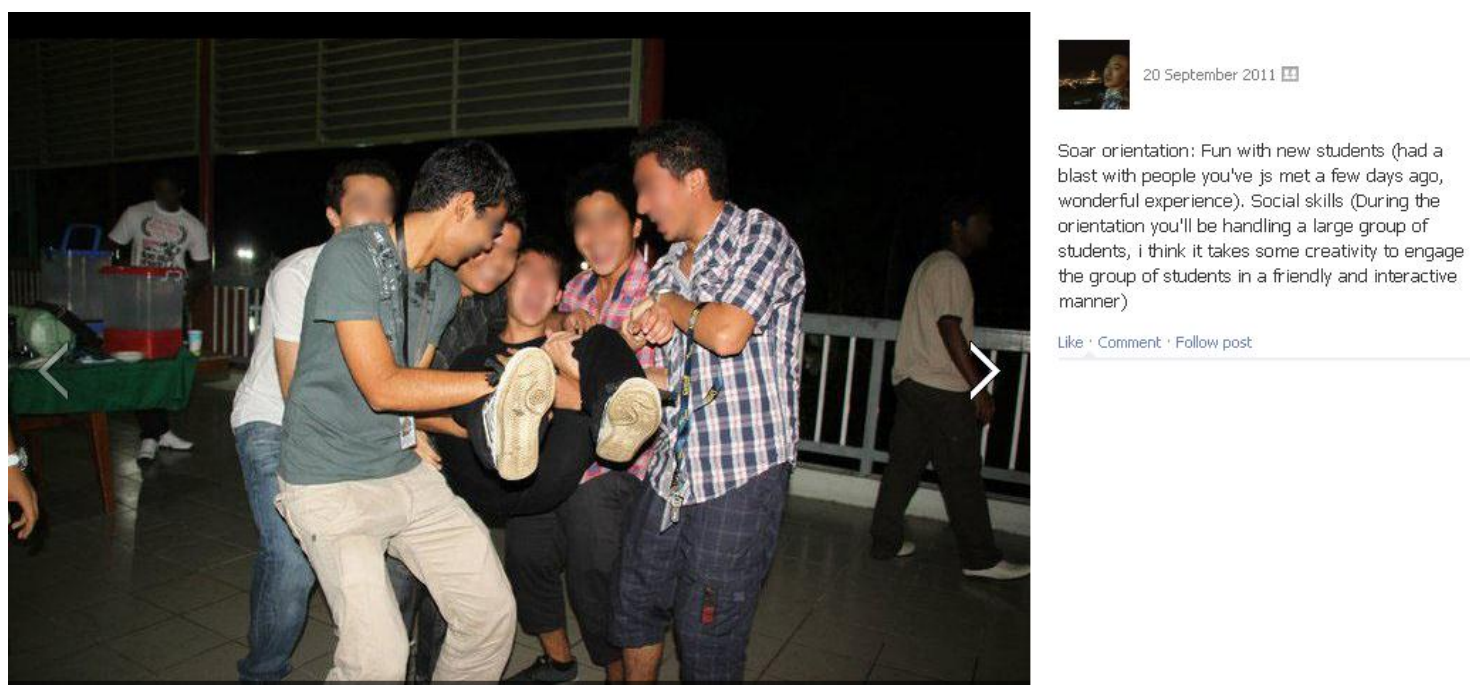

Figure 7.9. University as a site for promoting volunteerism 
The description provided by BR (refer to Figure 7.9) reads:

Student orientation: Fun with new students (had a blast with people you've just met a few days ago, wonderful experience). Social skills (During the orientation you'll be handling a large group of students, I think it takes some creativity to engage the group of students in a friendly and interactive manner)." (BR, male, third year engineering student)

The university also runs a series of projects, which aim to enrich the students' experience while at university. Annual community service projects are organized and these activities were designed to get students involved with the community within the university and the immediate geographical area. The subsequent photographs depict the activities, which the participants have joined, together with the descriptions of the activities. All the photographs and commentaries are taken from the Facebook page data.

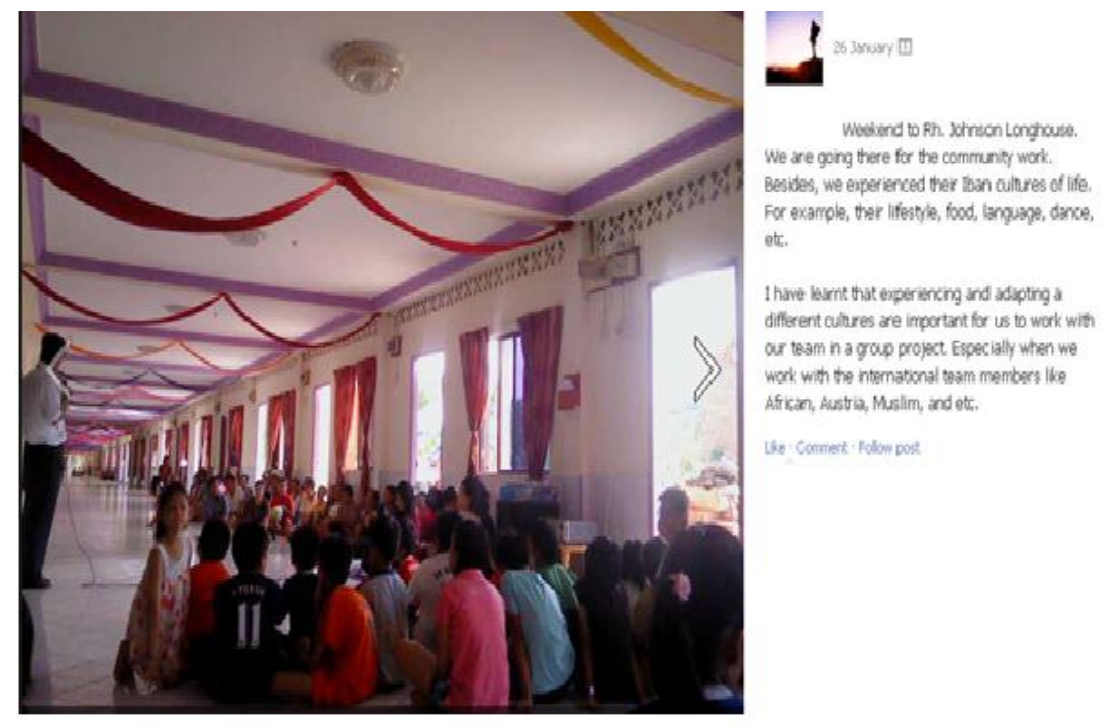

Figure 7.10. Community service activities with the local communities

The participant described Figure 7.10 as follows: Community Service Weekend in Rh. Johnson Longhouse. We [went] there for the community work. Besides, we experienced the Iban [way] of life. For example, their lifestyles, food, language, dance, etc. I have learnt that experiencing and adapting [to] different cultures are important for us to work with our team in a group project. Especially when we work with the international team members like African[s], Australian[s], and etc. (ANGEL, female, third year business student). 
ANGEL was describing her experience during the Community Service Weekend where students get the opportunity to visit the Iban longhouses in the area. During this activity, students typically spend two days living with the longhouse people and experiencing their culture, traditions and way of life. They also get the chance to help the longhouse folks should they require any help (for example, repair fences, paint the longhouse, clean the longhouse area, and so on).

In the photograph provided below, $\mathrm{V}$ explained how his experience with a leadership programme (Figure 7.11) organized by the university led to his participation in community service.

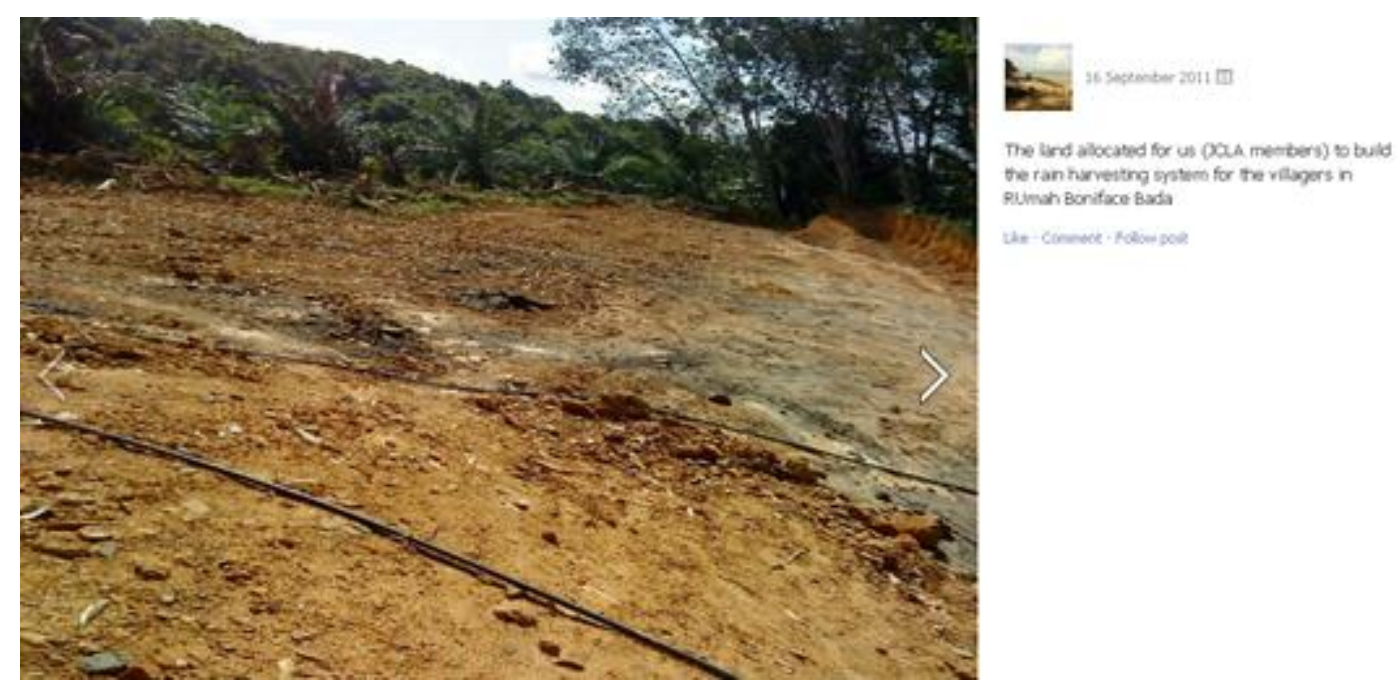

Figure 7.11. Leadership activities and community service

Description provided by the participant for the photo (Figure 7.11): "The land allocated for us (Leadership Academy members) to build the rain harvesting system for the villagers in Rumah Boniface Bada." (V, male, first year foundation student).

The participant was describing his involvement in the leadership programme. The university's student leadership programme that was developed in honour of the fourteenth prime minister of Australia with the objective of instilling his three core values of vision, leadership and community service, among students in the university. As part of V's community service project for the programme his group decided to help raise funds to build a rain harvesting system for the longhouse community as at that 
time, an ineffective system was operating which was causing water shortages during the drought season. He provided a series of photographs showing various locations of the longhouse and also gave explanations about why the longhouse people needed their own rain harvesting system (see Figure 7.12 and 7.13).

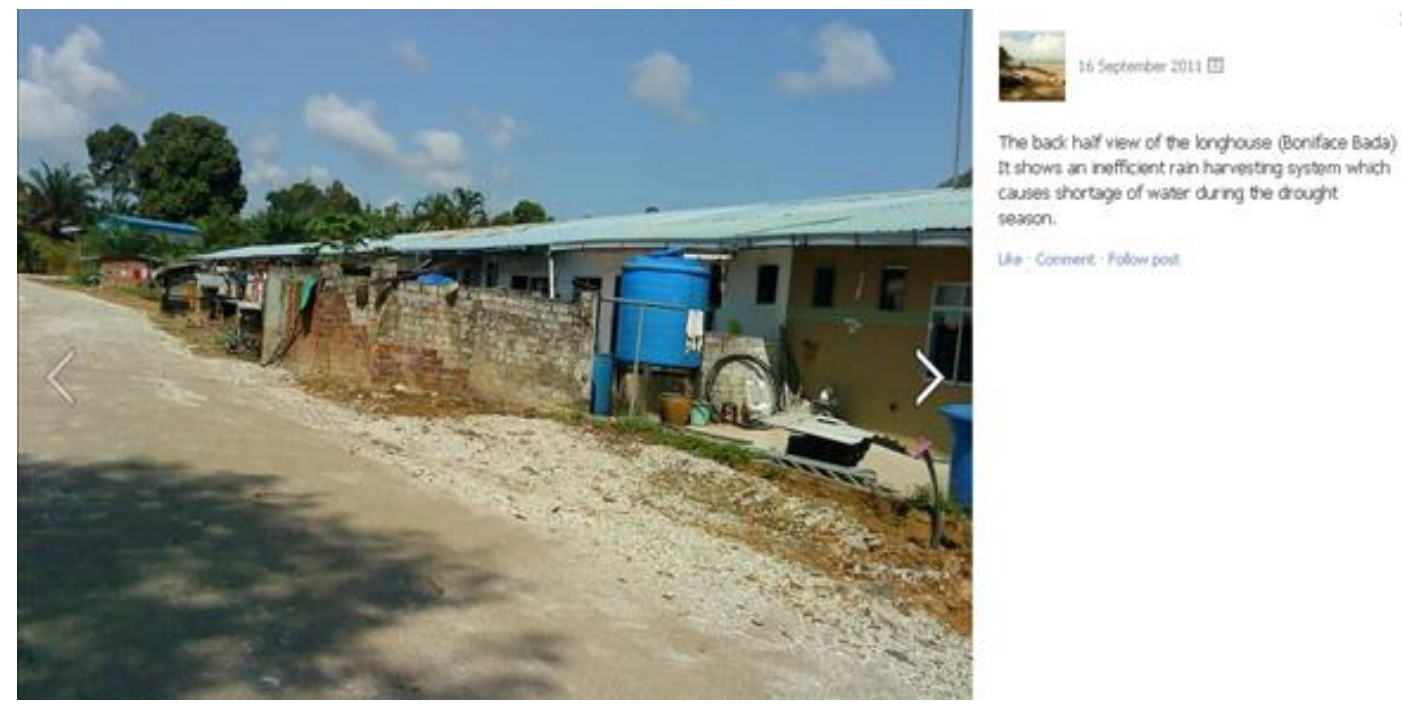

Figure 7.12. Inefficient rain harvesting system

Description provided by the participant: "The back half view of the longhouse (Boniface Bada) It shows an inefficient rain harvesting system which causes shortage of water during the drought season."
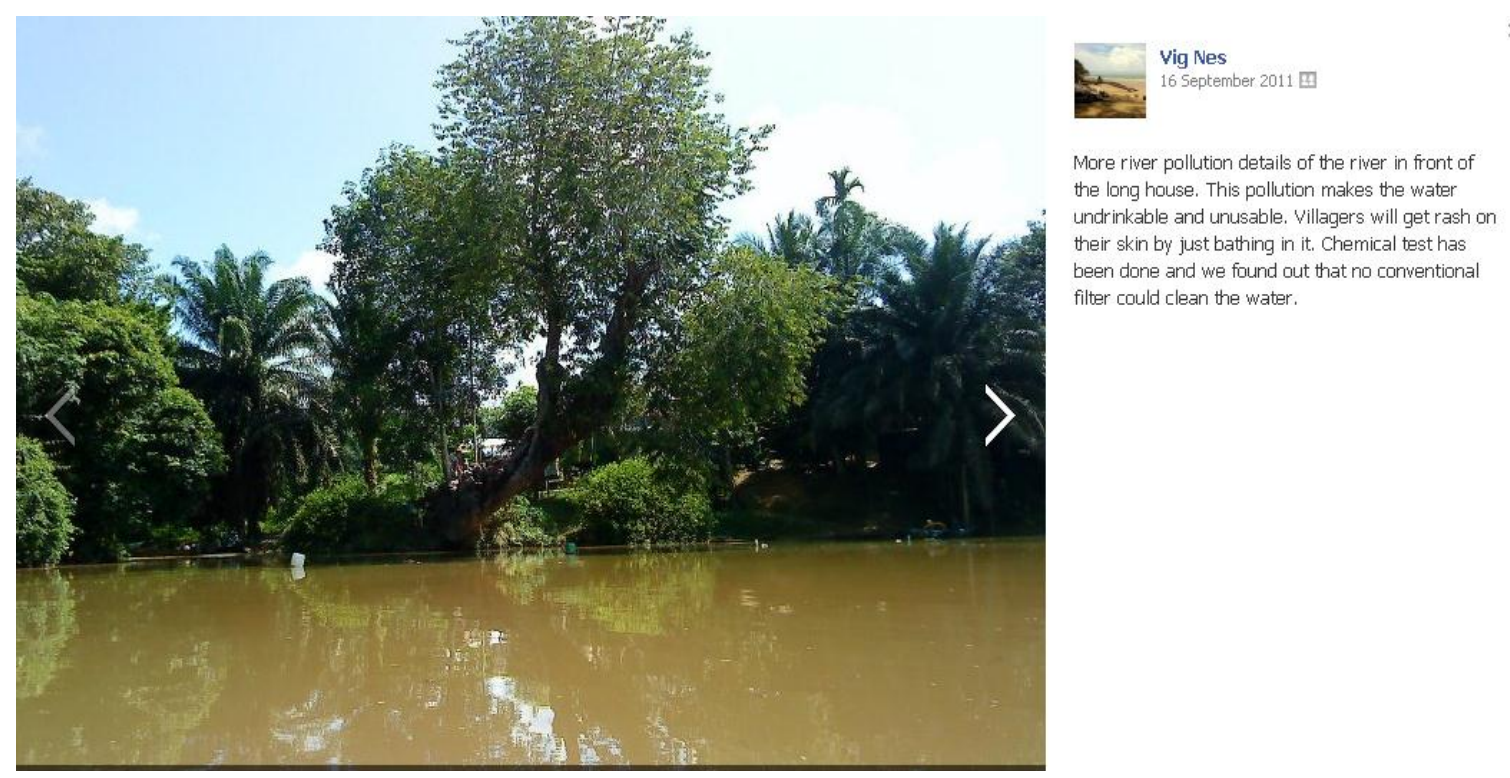

Figure 7.13. Pollution affecting the main water source 
Description provided by the participant:

A closer inspection of the river, reveals that it is heavily polluted by the palm oil industry. More river pollution details of the river in front of the long house. This pollution makes the water undrinkable and unusable. Villagers will get rash on their skin by just bathing in it. Chemical test has been done and we found out that no conventional filter could clean the water.

Photographer for all three pictures: $\mathrm{V}$

From the findings above, the role of the institution in enhancing interest in community service related projects was also an important way for students to enhance their cultural and social capital. The university offers a series of projects and programmes promoting community-related projects and the students are encouraged to practice their leadership, entrepreneurship and creativity to solve problems in the community within the geographical area. These activities also draw on the skills they have learnt from their academic lives and students are able to employ these skills when they present their proposal on the project, seek for sponsorship, organize fundraising projects and communicate with the members of the site communities.

Furthermore, the student clubs in the university are also actively involved in promoting activities, which have very strong ties to the community. These clubs have a very high orientation towards outreach projects and contributing back to the community. Figure 7.14 provided in the next page contain images of activities carried out by the student clubs at the university. 


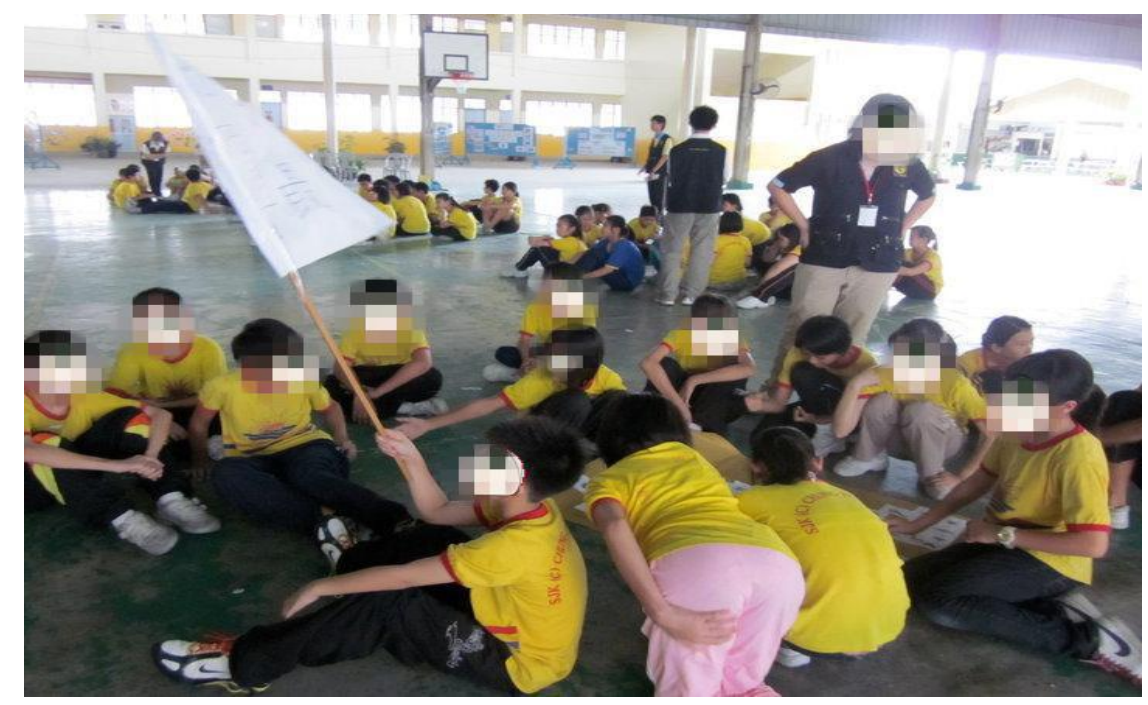

Figure 7.13. Contributing back to the local community

Photographer: ELE

The caption provided by the participant:

Volunteered in I am No 1 camp (2010) to help motivate[e] the UPSR candidates [to] not giv[e] up on studying even though they didn't do well for the mock exam and help to keep their spirit high. And most importantly, gave them the advice to do their very best in exam Not getting all 'A's is not the end of the world. (Life Moves On babe!!) (ELE, female, third year engineering student)

This image (Figure 7.14) taken from the Facebook page data shows one of the activities that the participant volunteered for as a facilitator for a camp. The objective of this camp was to motivate students who were going to sit a national exam. The student club ELE was involved in was actively involved in providing educational and motivational talks to the primary and secondary schools in the area. These student volunteers come into these environments with a high level of cultural capital, obtained from their family and through the participation in similar activities with their peers. They often organized training and talks for members of the club. Facilitators for the camps were also required to undergo training, provided by faculty members or senior members of the club. In turn, the members of this club tried to provide the same opportunity for the students in these primary schools. They also make use of the social capital - by obtaining contacts in the school from the university faculty and various organisations around the area to target the schools, which require their help. 
Figure 7.15 shows an activity organised by the Red Crescent club. Details of the activity provided: "Ambulance training: I had learnt various ambulance/paramedic related trainings like 'the triage system', the various type of oxygen supplier and how an ambulance manage to reach the destination less than 3 minutes." (BW, male first year foundation student)
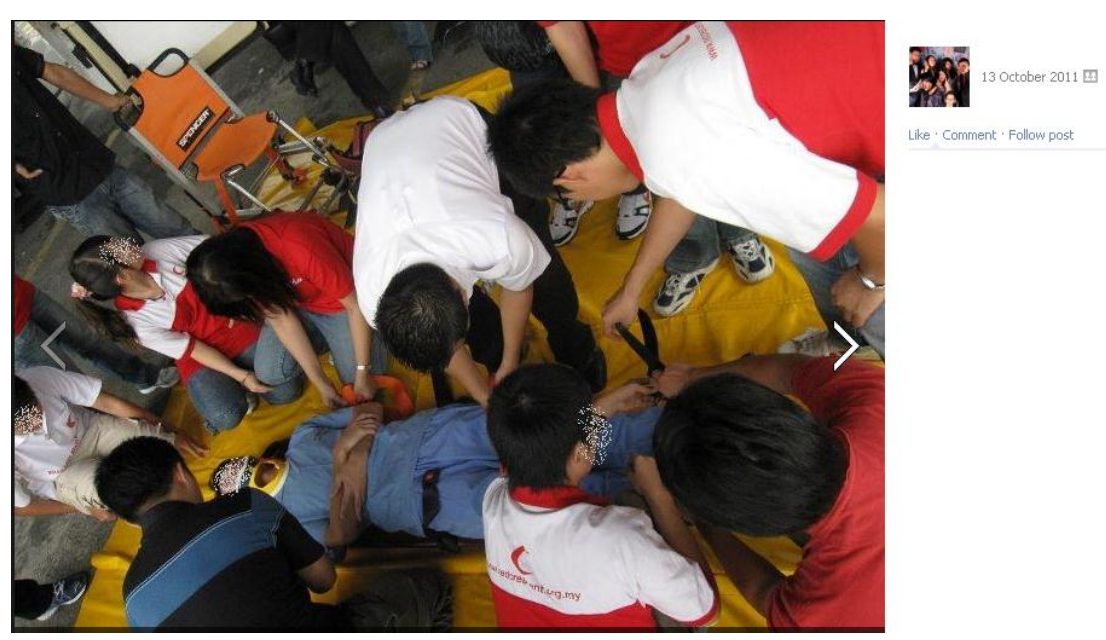

Figure 7.14. Learning first aid and ambulance training

Another photograph by the same participant is shown below. He participated in the university volunteers' beach cleaning activity in his first semester. The activities, which these clubs organize, cover a wide range of community based activities. The activities range from environmental care, awareness on issues in the society (children with cancer, AIDS, child neglect and abuse, recycling campaigns and blood donations, carried out within and also outside of the university. 


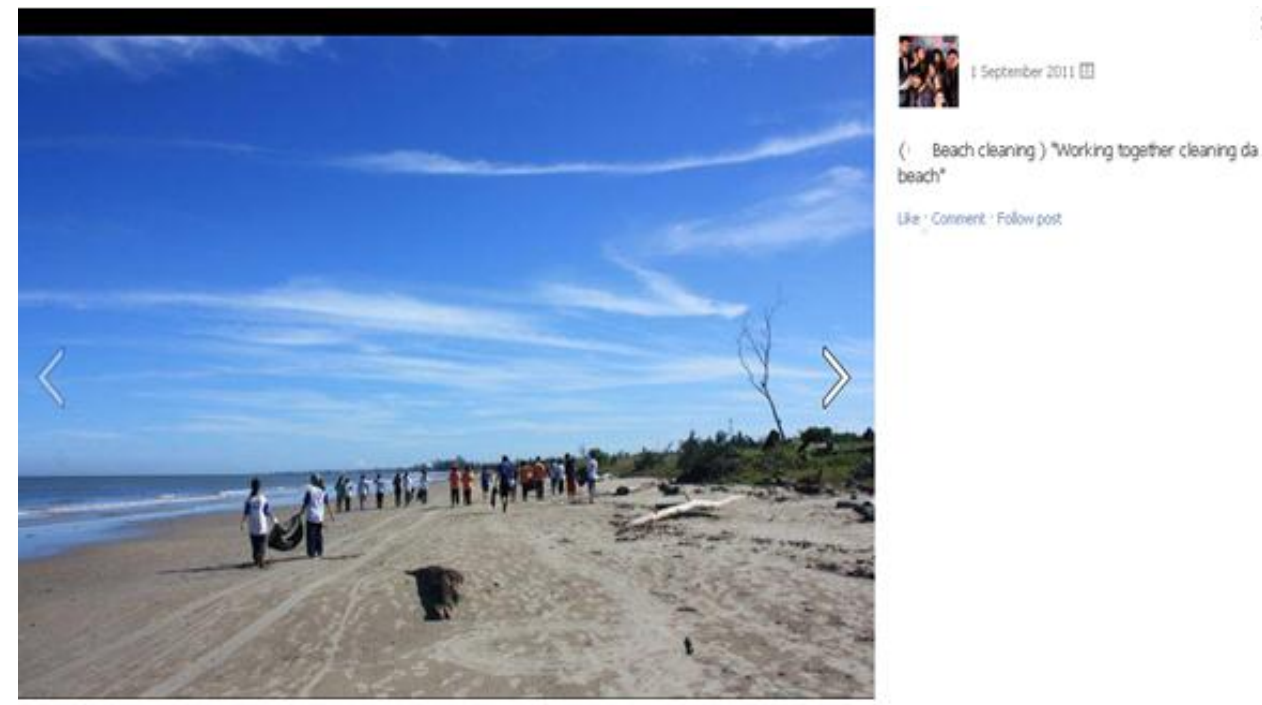

Figure 7.15. Environmental care and awareness promoted by the East Malaysian site university volunteers

Photographer: BW

Figure 7.17 shows a Blood Donation drive organised by the student club in one of the community service events held on campus. This campaign is a bi-annual campaign carried out in collaboration with the Miri Blood Bank to help replenish the stock and to provide ample supply for emergency use. The participant described the event as being personally meaningful for him as he helped others by donating blood for a good cause. Caption: "Blood donation campaign organised by EMU Volunteers! Learning to help others as well as myself." (JEFF, male, third year engineering student)

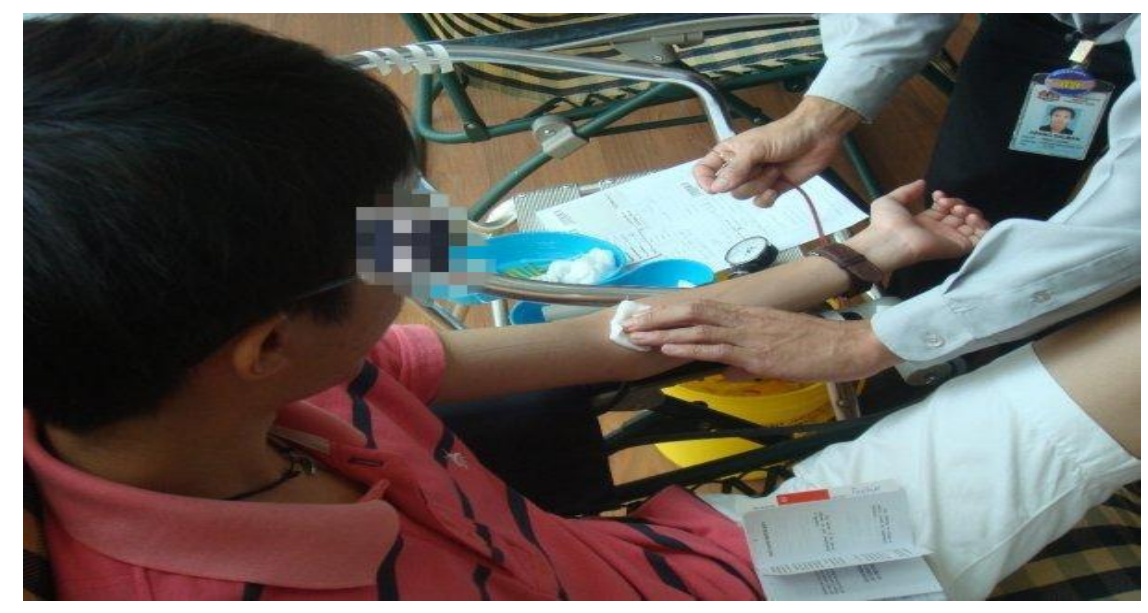

Figure 7.16. Helping others as well as self

Photographer: JEFF (male, third year engineering student) 
In sum, the findings suggest that the student clubs in the university, which also constitute part of the university culture, have an important part to play in promoting student volunteerism. The results also suggest that social capital plays an important role in recruiting volunteers and promoting engagement as participants reveal they would normally participate in events or projects if they had friends joining the activity or if they were recruited by word of mouth. For example during the follow up interview I asked the participants why they participated in university activities. RAY explained:

When I first joined [the university] I [met] the student volunteers. They are part of the ones that organize orientation. I see what they do and then all those effort they put in and I thought they were staff but when I know them they tell me that they are just a student so, I was amazed that student can actually do something this big and entertain students. Yeah, from there people [started] approaching me and they asked me whether I wanna join certain events or not. (RAY, male, third year commerce student)

Another participant, AZI, explained:

Anita: What actually motivated you to sign up as a volunteer?

Azi: I had some persuasion.

Anita: From whom?

AZI: From them. Yeah, the current members [in the club] at the time.

(AZI, female, third year engineering student)

One participant, ELE, described why she was compelled to join in a volunteer club at the university.

[...] because I was pulled by the person, by the people inside to join [the activities]. Later, I loosen my ties with them then I was actually free to go around, then I end up in another club for a while to help out because they are lack of facilitators so I joined in without interview, without anything. I just joined in as a freelance you know that kind of thing. (ELE, female, third year engineering student) 
TK also reported similar views:

Anita: Are your parents involved in community work in any way? No?

TK: umm... a little?

Anita: A little? Do they bring you along when they go for these activities? Has that in any way influenced your decision to participate in community work here in [the site university] itself?

TK: Not really. Mostly it's from my friends and from what I actually experience. Because the more people there are, in a committee, it will make it more successful. No matter what that committee is.

Overall, most of the participants attributed their interest in volunteering to their peers' support and encouragement. Findings from the interviews point towards the power of friendship in shaping the desire to volunteer.

In addition, academic-related clubs also play a significant role in encouraging students to apply the skills they have learnt to their related fields of study. For example, the Accounting club is one of the most active clubs in the institution, and club members often organise games, talks and conferences to support the Accounting students in the university. My findings show that the students' active participation in these academic and social environments allow for the integration of positive experiences and facilitate gains in learning. There are some participants who profit from such activities, for example a participant, ANGEL, who attended a leadership seminar uploaded an image on the Facebook page with this caption. "Attending a seminar about how to become a leader. Who is leader? etc.. This could enhance my leadership skill in the future. And also can gain more knowledge on these seminar topics they presented. "Today's Learner, Tomorrow's Leader." (ANGEL, female, third year business student) 


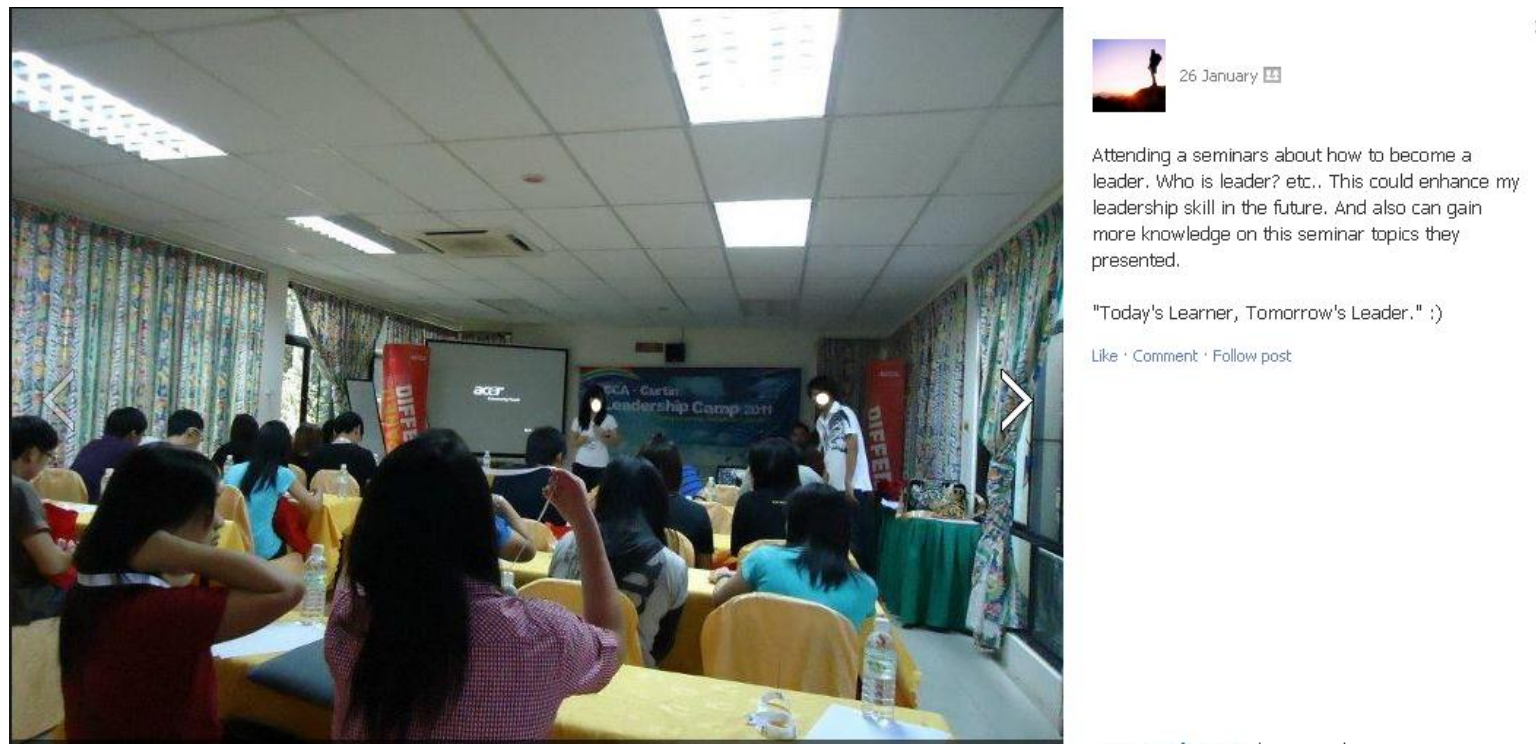

Figure 7.17. Learning through academic related activities

However, not all the participants report positive gains as a result from their engagement with club activities. Based on data taken from the Facebook page, PB described her experience of joining in the business games organised by the Accounting club. After the experience she reflected on the things she had done and realised that the degree major she was taking was probably unsuitable for her.

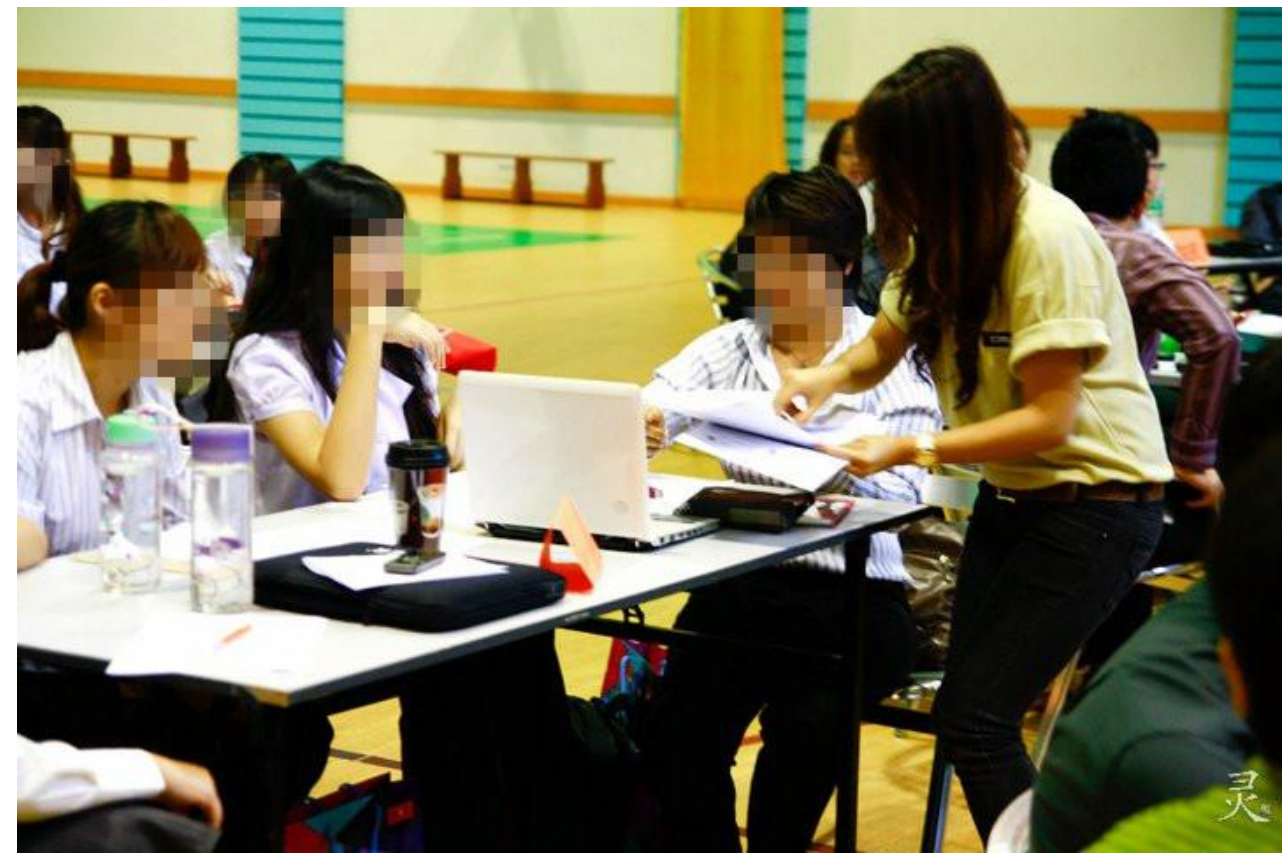

Figure 7.18. Tension arising from perceived reality 
The description provided for this photo:

These are the photos of CIMA Business Games 2011 that i have participated in [the site university]. I participated in this activity as I wanted to expose more to business activities for learning how business is operating which would be beneficial for my future employment. By taking part in this activity, I realized the aggressiveness and competitiveness among students which reflects the working environment in the real business world. However, I was not encouraged to compete with them. This situation has proved that I am not the kind of person that wants to be excellent or stand out in business area whereby business is not my interest. Or I haven't ready to compete in the real working environment. (PB, female, third year commerce student)

For this student, a tension emerged between her perception of her chosen course of study and the perceived reality of what is expected from her when she graduates. This suggests that PB was drawing on resources from her habitus and her experience in classroom activities and had tried to match her understanding to this activity. The mismatch between her expectations and her experience created conflict and clashes with her habitus thus creating doubts about her future aspirations. Besides that, the units, which the students have to enrol in during their time at university, also appear to have started a drive in volunteering, as narrated by some participants. One unique policy in private higher education institutions is the requirement for students to complete Moral Studies and Malaysian studies units, which are strongly oriented towards community work-related projects. These units are designed to promote specific values as outlined in the curriculum, such as integrity, compassion, patriotism and other core values deemed important to form a person's character. These units also serve as a platform to encourage student participation in community and voluntary work. For example during the interview, EL explained her experience with community service projects offered in a unit in her foundation programme.

During my foundation [programme], I was involved in a project where we needed to help single mothers in the community. Being a person who loves to do volunteering work since young, I definitely would say even if it is not compulsory, I would still commit myself doing so. For me, to be able to help people makes 
me happy and I would do it again when I have the time. (EL, female, third year engineering student)

Although the intent of the syllabus may be designed to instill civic responsibility amongst the students, in reality this objective may not always be achieved in the true sense of the word. While the intent of the project was undoubtedly sincere, the participant's idea that the single mothers in the community need help or assistance is placing her in a situation of power, or dominance. Her team's decision to step in and offer help implies that 'others' who possess less or who live in a condition that is unequal to theirs, suggests that the participant is viewing the people she helps through a lens of authority and power. In this respect, the person who is in the superior position assumes they are able to create a better world for others. This deficit thinking locates the other party as a remote entity whose conditions in life they have to 'improve'.

Another example of this deficit thinking involves AZI, presumably taking the same unit. During the interview she also explained her experience taking up a similar project during her pre-university studies.

In my foundation studies, I was involved in a small project where we're required to help the 'needy'. So my team and I decided on a single mother with four children, living nearby the Miri river. After meeting her, we were devastated to see her living condition- living in a shack, with no proper access to water and electricity. We then (after a month) managed to then close to RM 1,000- which in the end helped her send all her four children to school, and rent a small flat- a better living condition compared with before. I feel satisfied, that I have managed to help somebody in need, am I am indeed thankful on how privileged my life is. But I have stopped 'following up' on what the progress of her family is now. Something that I regretted doing back then as there was no support from my team. (AZI, female, third year engineering student)

In this case, the participant's perception that she has made the single mother's life 'better' and that her condition now had improved because of their help indicates 
she is positioning herself in a superior position and anyone who is leading a different 'quality' of life is in need of help and improvement. In this context, the service learning advocated by the lecturers in this unit may reinforce the students' deficit notions and reinforces the assumption that "isolated actions of caring individuals can overcome societal problems" (Butin, 2003, p. 1682). Legitimising such notions may perpetuate the dominant deficit perspectives of these individuals and affect power relations across diverse groups of people.

\subsubsection{The role of religion and religious capital in promoting volunteerism}

The findings from my interviews reveal that religion plays a role in affecting community service amongst the participants. My findings indicate that families function as institutions that promote volunteerism through the religious values that are practiced in the home. The family's religious practices had a strong impact on the participants who were encouraged to volunteer at an early age due to exposure from family members and close relatives. For example, during the interview one participant explained the reason why she participated in voluntary work at the mosque. She attributed this practice to her father who often visited the mosque and helped out whenever he could.

My dad, he brings my siblings and I to help out around the mosque, like sometimes they have like, what is it, gotong royong so it's not something that we're forced to do, it's something that you just want to do it. (AZI, female, third year engineering student)

Religious institutions can also function as a site for community service and voluntary activities. Religious institutions are heavily family-oriented (Glanville, Sikkink \& Hernandez, 2008) and perhaps for these participants, joining religious clubs and associations is a way for them to cope with being away from home. The tendency to join in with like-minded individuals plays a role in influencing their desire to join religious clubs. It could also foster a sense of belonging and camaraderie, which is very important for these young people. For example, one participant explained why she chose to join the activities organised by the Catholic Student Society. 


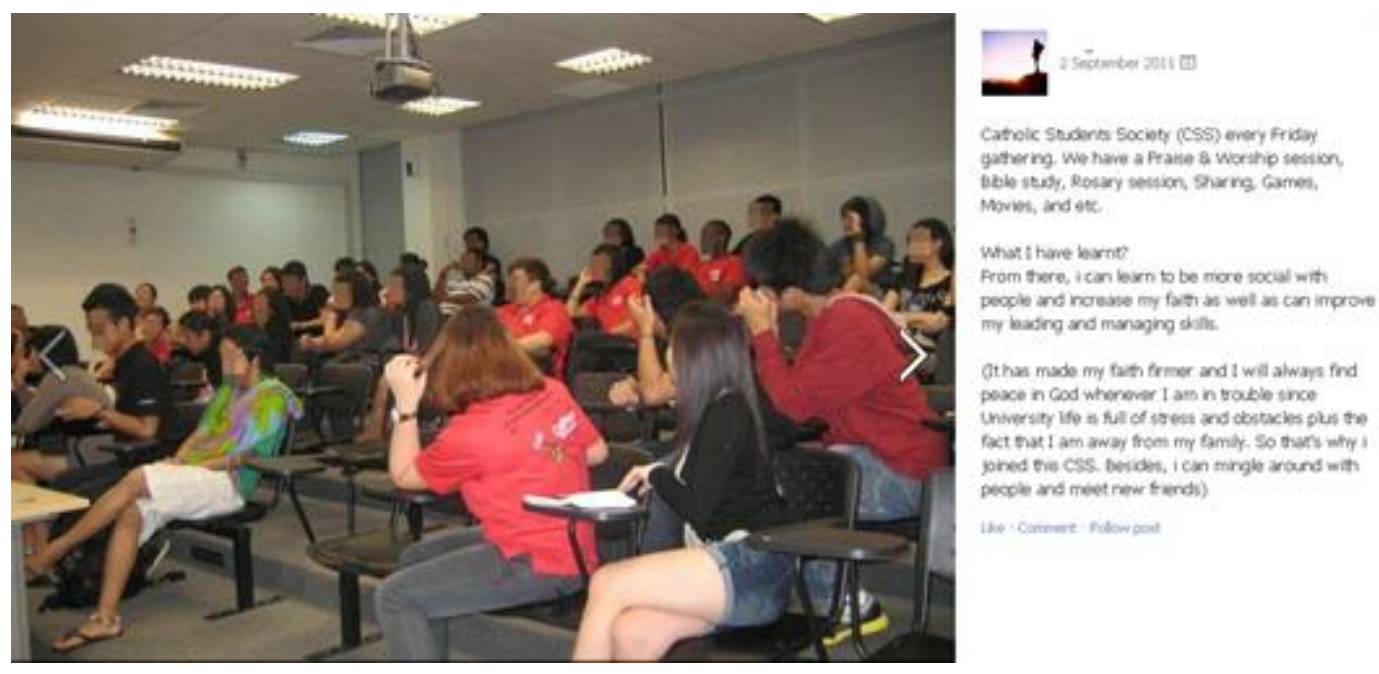

Figure 7.20. Religious clubs as sites for community service

Caption: Catholic Students Society (CSS) every Friday gathering. We have a Praise \& Worship session, Bible study, Rosary session, Sharing, Games, Movies, and etc. What I have learnt? From there, I can learn to be more social with people and increase my faith as well as can improve my leading and managing skills. (It has made my faith firmer and I will always find peace in God whenever I am in trouble since University life is full of stress and obstacles plus the fact that I am away from my family. So that's why I joined this CSS. Besides, I can mingle around with people and meet new friends.) (ANGEL, female, third year commerce student)

ANGEL is building on her social capital by joining in religious activities. Social structures such as religious clubs or faith-based organizations facilitate social interaction and provide an atmosphere, which is rich in social resources. Given that religious clubs and organisations promote a collective set of shared beliefs and norms these sites are seen as 'fertile ground' for the development of social capital. As we can see from the example given above, the participant mentions "being more social", "mingling around with people" and "meeting new friends" as major reasons why she chose to participate in activities organised by the CCS.

The image and the description below (Figure 7.21) describe how the participants make use of the social relationships they gained through associations with religious clubs when they need help. The participant involved transferred from the 
offshore campus to the main campus in Perth, Australia. She started to get actively involved in the Christian group on campus and provided some snapshots of the activities she joined in since she started getting involved in this club. The caption she provided was, "Cell group, every Friday night - preparation for worship session." (MAY, female, third year engineering student)

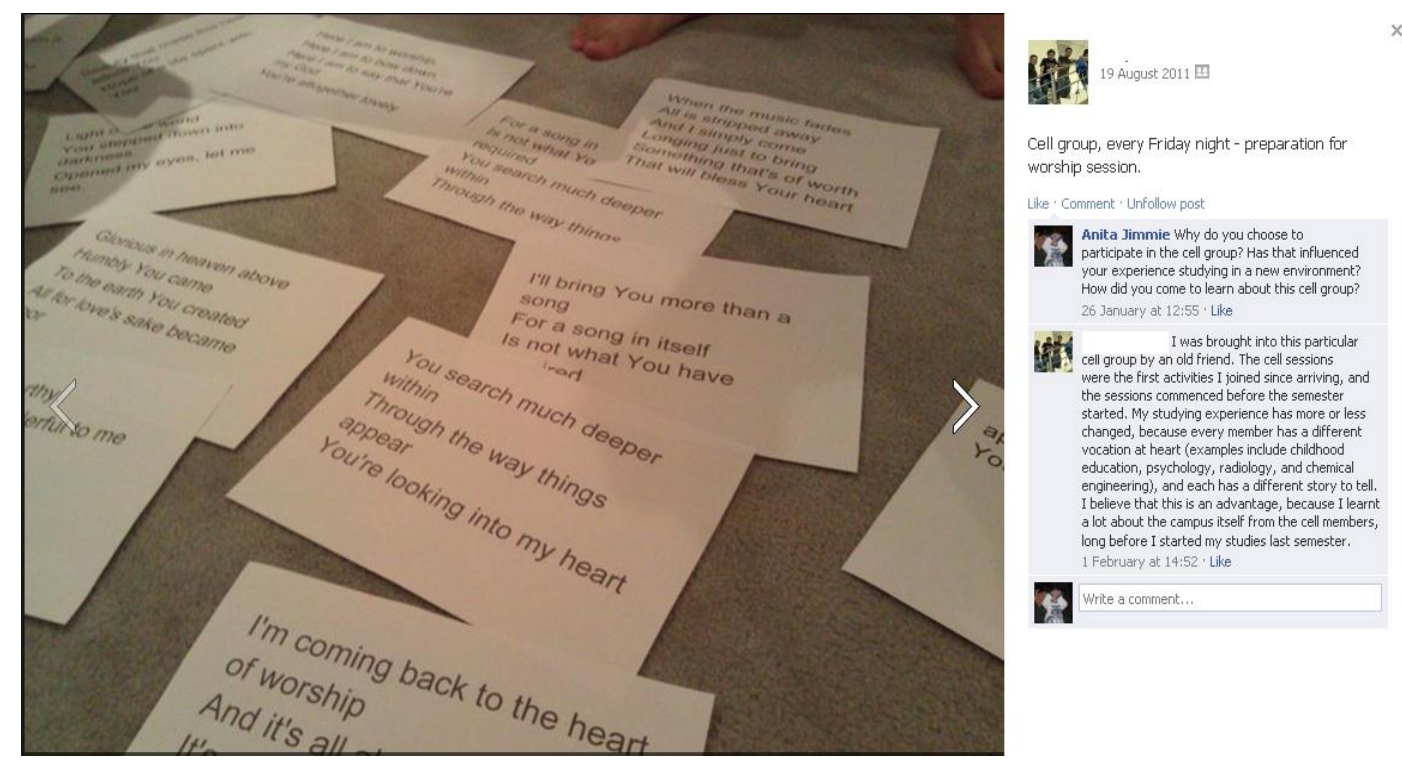

Figure 7.19. The importance of religious clubs in building social relationships

When I asked her why she chose to participate and join in the cell group meetings on a regular basis, she explained;

Anita: Why do you choose to participate in the cell group? Has that influenced your experience studying in a new environment? How did you come to learn about this cell group?

MAY: I was brought into this particular cell group by an old friend. The cell sessions were the first activities I joined since arriving, and the sessions commenced before the semester started. My studying experience has more or less changed, because every member has a different vocation at heart (examples include childhood education, psychology, radiology and chemical engineering) and each has a different story to tell. I believe that this is an advantage, because I learnt a lot about the campus itself from the cell members, long before I started my studies last semester. (Conversation taken from Facebook data) 
The findings demonstrate that the influence of religious participation can be used as a social resource that creates durable networks and these relationships can help individuals get the support they need. In this case, the participant was brought to the cell group by her friend, and this helped her adjustment period in a new and unfamiliar place. In addition, she mentions how her interaction with members of the cell group provided information about the campus, which was a valuable source of information for her even before she began her studies abroad.

Religious institutions are traditionally seen as sites for cultivation of rich social capital. Relationships formed between members of the religious congregations are seen as beneficial as they create bonding, rapport and emotional support for its members. Although these networks are beneficial for members, however, involvement in religious activities does not always carry implications of altruism or the desire to create change to help people in need. Wuthnow (2002) argues that religion embodies beliefs and moral actions, and religious institutions enact these actions in a community of believers. This does not necessarily reflect the intrinsic desire to help, but the action of helping is motivated by the desire to 'feel better about themselves' for being in a 'better' condition compared to others. For example, the images below, taken from Facebook, show how the Christian student clubs at the university encouraged participation in voluntary activities among its members.

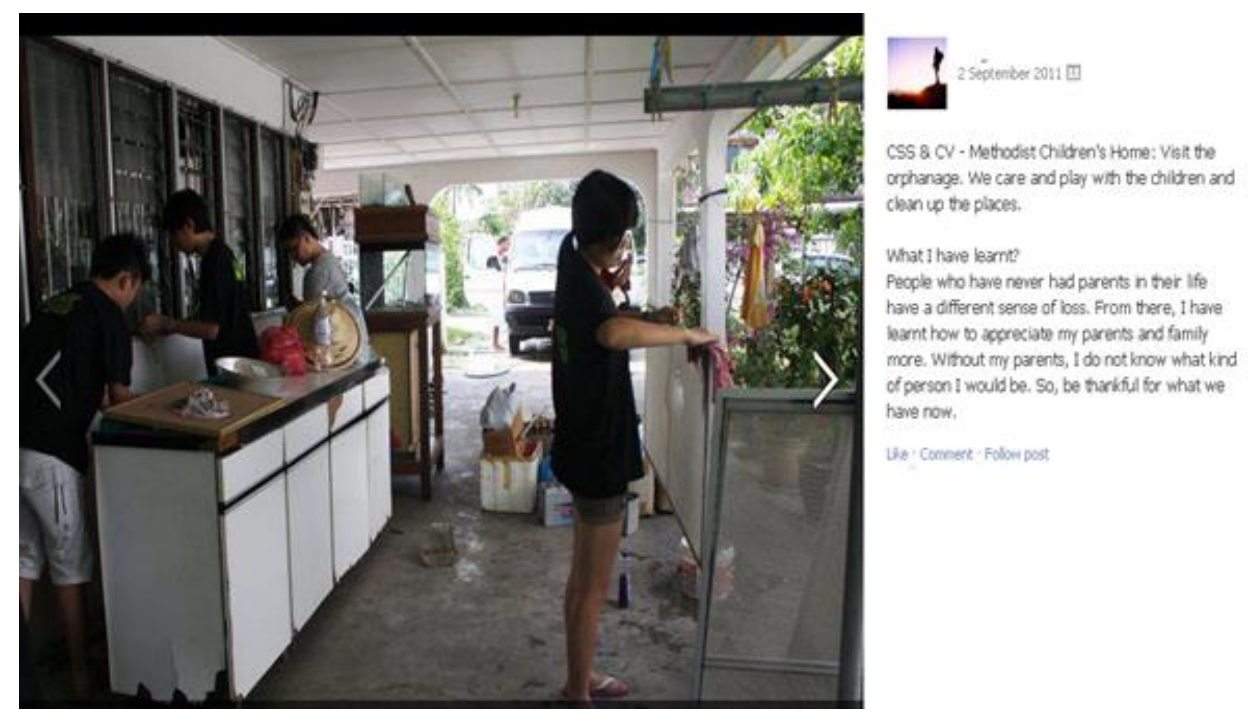

Figure 7.20. Religious institutions and cultivation of social capital

Photographer: ANGEL 
The description provided by the participant for this image:

CSS \& CV - Methodist Children's Home: Visit the orphanage. We care and play with the children and clean up the places. What I have learnt? People who have never had parents in their life have a different sense of loss. From there, I have learnt how to appreciate my parents and family more. Without my parents, I do not know what kind of person I would be. So, be thankful for what we have now. (ANGEL, female, third year commerce student)

My findings illustrate that religious practices may not in themselves increase the amount of moral orientation towards altruism or empathy, but that interaction with others in the context of supportive relationships may do so. Religious involvement may be a resource that helps them get what they want so they feel 'justified' in enjoying such privilege. This indicates the power relation that exists between those from a different social status. The action of helping others deemed less fortunate than ourselves does not allow us to 'bridge' cultural, racial and social divides because this thinking creates divisions of how people view themselves and their definitions of 'us' and 'them'.

My interview findings also reflect the same thinking, as we can see below. For example during one interview when we were discussing about the voluntary work, AZI answered:

Anita: So when they [parents] bring you along for these activities was that a voluntary thing? Did it have any impact on your decision to continue with voluntary work in [the site university] or in your school?

AZI: I was not forced to. Yeah, no... Because every time they [parents] do it, we.. my cousins, my sister, everyone in the family would want to be part of it because it is something, you help people, so why not. You're the lucky ones, right? (AZI, female, third year engineering student)

The conversation above illustrates how this participant distinguishes between 'me' and 'them' and she acknowledges that she is in a more privileged position 
compared with the 'others'. One reason why she feels compelled to join in voluntary work is because she feels that she is lucky in the sense that she belongs to a good family, she has supportive parents and she has the resources to go to a good school and university.

In another interview, TK explained that he would help out in activities, which focus on helping children. He described his desire to help out as below:

Anita: What gets you passionate about [joining] an event? Let's say for example you choose like you say, you really want to help children and you decide you want help out with children with cancer. What drives this passion?

TK: um, I think mostly pity for them. Yes, because ah, there's a difference between my life and theirs. And I'm just trying to help them... their life become more [better]. (TK, male, first year foundation student)

Again there is a distinction between 'us' and 'them'. In his opinion, since 'we' are in a better position than 'them' therefore we ought to help out and create a better life for 'them' because 'we' have the power to do so. We can see that there is a distinction made between the participant and 'Others' and how he feels he is in a position of power to help them.

My findings suggest that religious attendance is positively associated with increased social capital such as volunteering and participating in community service related activities. Faith-based organisations facilitate social interaction, which provides an atmosphere ideal for cultivating interest in community work. In addition, such organisations nurture civic engagement through the socialisation of group members to achieve collective norms. As an example, JEFF took the image below (Figure 7.24) during his internship in another state. He could have been drawn to participate in the activity as part of the social influence from members of the congregation or church leaders. 


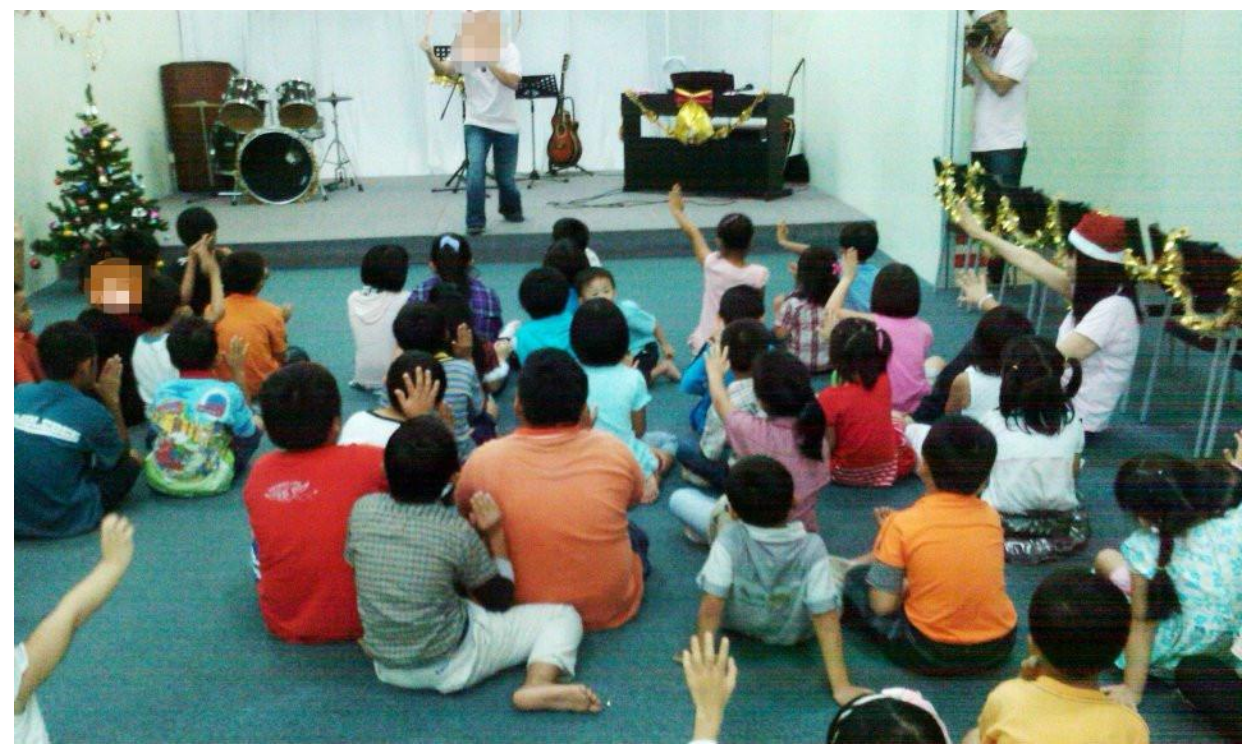

Figure 7.21. Religious attendance and volunteerism

Caption: "Helping to organize a Christmas party for children from broken or problematic family background while doing industrial training in Labuan- an effort by a local church there" (JEFF, male, third year engineering student)

Robert Wuthnow (2002) claims that religious institutions are important sources of social services for the underprivileged as they function as places for recruiting volunteers and soliciting donations. Contextual factors such as social interaction, trust and shared values influence youth social capital and they become more inclined to participate in voluntary activities as a result. Religion and religious institutions provide an effective structure in society, which can nurture civic engagement through vast social capital networks. Given that these networks are durable, its members are able to reach a large web of people; the potential to facilitate participation in community and voluntary work is also enhanced.

Overall, the findings reveal that social capital, social support and social relationships are effective resources in promoting civic responsibility amongst its members. On the other hand, one problem that arises could be that misconception occurs among the members of the congregation. The inequality, which exists among the different class factions, could be widened, especially if the members start to assert their 'moral superiority' over the people they are helping. When individuals begin to adopt 
the stance of thinking of 'us' and 'them' and attach this sense of superiority over individuals who have less social status than themselves it will affect the power relations between each class. It also asserts the idea of social dominance, where the person with higher social status has the power to influence or change the lives of the people in a lower social status or class.

\subsection{Summary}

In summary, the participants understood how to advance their future position within their field by using the accumulated social capital as an investment strategy to gain admission to the workforce. They were aware that having a resume with a list of extracurricular participation could set them apart from their 'competitors'. My participants possess the knowledge of the working world from family members, relatives and use this knowledge to create opportunities for facilitating access to the workforce and achieve their goals. They mention advice received from seniors and representatives from various organisations about attributes for successful employment, and the need for pro-social skills, which can help them to cope with the demands of the workforce. My participants also possess insider knowledge needed to advance their position within the field. The unification of cultural capital and accumulated social capital at university could create opportunities for these participations to achieve their end goal, which is employability and ability to perform in an uncertain future. They were equipping themselves to enhance the possibility of achieving the opportunities.

Moreover, the educational institution also plays an important role in encouraging student participation in community service, clubs and voluntary work. The participants acknowledge how the institutional habitus creates an impact on their perception, especially when they are exposed to community service at a young age. The role of the institution in supporting community service activities is extremely important, as these participants have revealed. In addition, if the institution has a strong view on corporate social responsibility and advocates activities, which are oriented towards serving the community, participation in such activities is greatly heightened. Many participants cite programmes run by secondary schools and the 
university as the reason for sustained interest in community service activities. Thus the educational institution functions as a site for the acquisition and continuation of outreach activities amongst its students.

However, findings also reveal that there are tensions between the participants' expectations and the actual reality they face. Although the educational institution may function as a site for enhanced civic responsibility, in some instances however, the institution also creates a social gap between its students and the community they are in. In some instances, activities designed to help out in the community actually lead to the creation of deficit thinking, where the participants view the people they help as a remote entity instead of members of the community. They discuss how their voluntary services help to improve the condition or make a better world for the 'others' who are 'less privileged' compared with themselves. In addition, this creates benevolence to these members of the community. Furthermore in some instances, participants are motivated to help out in the community not because they are truly concerned with the needs of members of the community, but because they feel they have to 'justify' their privileged position by helping out those they see as being 'less lucky' than them. Besides that, religious institutions and members in the congregation could also contribute to the view of 'us' and 'them' if the members of the institution advocate the notion of civic responsibility as a way to remind the members to be grateful or to feel blessed that they are luckier compared to the 'less fortunate'. If members of the religious institution are unable to bridge the social divide and see the people they help as equals rather than 'less lucky' or in need of 'improvement' these dominant deficit perspectives of 'others' will be perpetuated and maintained. Butin (2003, p. 1682) argues that reinforcement of this thinking allows "those in the culture of power to maintain unequal power relations under the guise of benevolent volunteerism". This will create the assumption that individual, isolated actions of those who are in a position of privilege can overcome societal problems and this legitimises the action on the behalf of the person 'bestowing' help. 
Engagement in community service is also reinforced by the family and by religious institutions. The religious capital provided by the family, in addition to the teachings received from religious institutions, increases the interest in 'helping out'. The relationships the participants build within the religious institutions help them to form a sense of religious obligation to serve the underprivileged within the community. In addition, support garnered from friends and other supportive adults can foster a stronger desire to participate in civic activities. This positive reinforcement provides the opportunity for them to shape networks with like-minded individuals who have a passion for community service. This also means the participants will potentially be recruited for future events, which encourages them to be more active participants. It is worth noting that they credit their social networks as a point of entry to participate in community service and voluntary work. It seems that this form of recruitment is more effective in engaging participants as these individuals value the friendship and camaraderie shared during a community work project.

The findings presented in this chapter lay the foundation for understanding why students' engagement with extracurricular activities varies. The different motivations and factors that influence their decision to participate in extracurricular activities are explored in relation to Bourdieu's theories to establish how cultural capital, habitus and social capital function in the educational field. The following chapter explores the final research question on the ways in which the students' perceptions changes during the course of their studies. 


\section{CHAPTER EIGHT}

\section{SHIFTS IN STUDENTS' PERCEPTIONS}

\subsection{Introduction}

In the previous chapter I discussed the way that cultural capital shapes individual beliefs, and how these beliefs influence the way education is viewed. Then, I explore how perceptions about the purpose of university education influence engagement in university activities, particularly in community services, clubs and voluntary activities. In this chapter, I address my third research question and I investigate in what way the participants' perceptions of the role of education and extracurricular activities have changed after they engaged in these activities. I also discuss the ways in which the participants invest in extracurricular activities, and some of the outcomes of their attempts to convert this form of capital, through their engagement in various organisations at the university.

In the three findings chapters I have drawn my results from data collected during focus group interviews, follow up interviews, and from images and comments that the participants posted on Facebook. Out of the 21 students who agreed to participate in the research, 18 volunteered for the focus group and Facebook phase of data collection. This chapter contains data taken from the three sources to illustrate the changes in the participants' perception about volunteering after a period of one semester.

\subsection{Changes in perception of the role of education}

My findings indicate that the participants who were in their third and final year of university had experienced a change in their volunteering practices. This transition indicates an increased awareness of their need to be more 'industry ready' and the need to be prepared to meet the demands of the workforce. Thus, their engagement in 
university activities also underwent a change, to reflect their understanding of their position in the field. This suggests that my participants were aware of their position within the field of work when they enter as new graduates, and they use the resources they have accumulated from the university to help them to improve their position in this field.

For example, IZZ explained that he stopped participating in non-academic activities because he realised that he was in his final year and he had to change his involvement to focus on attaining more educational capital for his future. During the interview, he explained that he had to shift his priorities due to two reasons; first to improve the quality of his family's life. IZZ does not come from a well-to-do family; he was on a scholarship from an oil and gas company. Second, he saw it as his duty to repay his parents for their love and sacrifice. Similar findings were reported in Thomas O'Donoghue's (1996) study on Malaysian Chinese students' perceptions of what is necessary for their academic success in Australia. The findings of his study revealed that the Chinese students regard 'respect for their parents' as a motivational source for achieving academic success. O'Donoghue (1996) argued that the motivation for students to study is affected by their strong sense of duty and obligation to their parents. Furthermore, students also attributed their sense of obligation to their parents for bearing the cost of their education. It is important to note that this perception does not only apply to the Malaysian Chinese but also the other ethnic groups in Malaysia as well as evidenced by the interview excerpt below. The participant below is a Muslim student from the Malay ethnic group.

I have to shift my priorities to other things now. My priority now is to have a job and improve the quality of life of my family. As I am the eldest son of the family, I have lots of responsibilities and high expectations by my parents. They have [to] work very hard to send me to university. It is now my time to repay [them]. (IZZ, male, third year engineering student) 
Another participant, EL, reflected on her participation in voluntary activities and commented:

When I first started, I was very active, I [joined almost all the activities]. You would see me in every picture, every activity, there's always [my picture in] there. Like there's the house painting, there's the.. rumah panjang (long house) [activity]. [I went to] the Community Service Weekend, I went for the, the fundraising, I went for the some visit somewhere, I forgot already there's too many. [Laughs] I can't name all of it, but there's too many! (EL, female, third year engineering student)

When I enquired why she started to slow down and become less active in voluntary work, she explained that it was taking up too much of her time and she had to start focusing on her future plans as she was approaching her final year. Again, O'Donoghue (1996) explained that the Malaysian Chinese students exploit their cultural characteristics of being hard workers to motivate them to achieve academic success. One important facet of this diligent behaviour is cultivating self-discipline and self responsibility when studying. The students in his study demonstrated that they were disposed to value hard work and perseverance in order to achieve academic success, as shown in the interview excerpt below with EL:

Well, [it] can't be helped. I mean I do want to join community service but the time I mean sometimes you have two, two events at the same time you see, like volunteer another one is academic based. If you ask me, when I'm in foundation, I wouldn't care about my academic thing. I would go for volunteer, volunteer, volunteer, but when I starting from second year I have that, that kind of ah, wake up call you know, that kind of thing... so I just realised that hey... I need to know something about my field, because even I was after I'm done with my first year, I was still kind of blur, what is chemical engineering is you see? That's when I feel I need to slow down with my voluntary work and try to catch up with whatever I'm doing now. (EL, female, third year engineering student) 
As we can see, this causes a tension between the participant's desire to volunteer and the awareness that she should devote more time to studying and mastering her area of study. O'Donoghue (1996) claimed that this ability to set selfimposed motivation is an ability which is characteristic of the Chinese culture and the ability to draw on this characteristic was an integral part of the Malaysian Chinese participants. The participant whose interview was quoted above was in fact a student from a mixed marriage, her mother is from the Chinese ethnicity and her father's ethnicity is Malay.

One participant in his final year of study described his current level of participation. RAY explained:

For now mostly I focus on my, my studies. I did [get] involve[d] in some of the activities [and] at the same time I did join another organization that another international (inaudible) organization which we call AISEC (Association Internationale des Étudiants en Sciences Économiques et Commerciales.) [...] But after I know AISEC it feels very [pause] it's something new because it [is] a student run organization, you have to be a student to join and then at the same time it helps people to um, to deal with global issues not only in Malaysia but in other countries as well. (RAY, male, third year engineering student)

Parental objections also added to the tension, which participants experienced. BOON described her parent's point of view on her involvement in community service, clubs or voluntary activities. During the interview she revealed that her parents discouraged active involvement in extracurricular activities, as they were worried it would affect her studies. Since she was also doing some part-time work as a tuition teacher, her priorities were no longer focused on extracurricular activities as it would take up a lot of her time. She explained: 
I was discouraged to do so due to the reason that I worry this activity will [sacrifice] much of my study time and my parents also discourage[d] me to [get] involve[d] in such activities. At the same time, I am working as a part time tutor for primary students, which has compromised some of my study time. If I were given a choice, I would forgo my part time work and engage in volunteering activities. (BOON, female, third year commerce student)

Again, the same issue was raised- these participants had to prioritise and decide what sort of activities would be more beneficial when advancing their position in a new field. Suddenly the drive towards accumulating social capital is replaced by the need to acquire as much educational capital as they can. By the third year of study, the students came under considerable pressure to acquire academic qualifications. They realized the value of academic qualifications in obtaining a good job. Consequently, they decided to participate in more academically-based activities, which would give them a better understanding of their field of study. In the case of the thirdyear participants, the findings indicate that during their third year of study, the amount of time they spent building their social capital was reduced and they began to focus their attention on attaining more educational capital to meet their future needs.

Another example, provided by ZIM during the focus group interview, reinforced the findings discussed above. When I asked why his participation in a sports club declined, he answered, "I stopped during final year because of final year project assignments in university. [l] feel like [l] want join but it is restricted by [the university's] final year project." (ZIM, male, third year engineering student) 
The industry training they are required to complete in their third year of study changes the way students view their education and the skills they need to prepare for this new stage in their life. For example, in Figure 8.1, IZZ talked about his experience as an intern for his industrial training, in an oil and gas company. He had the opportunity to go aboard an offshore platform during this experience. The industrial training could be a possible catalyst for a change in the way he thought about his future and the realisation that life in the working world may not necessarily utilise the skills he had picked up while volunteering or participating in club-related activities.

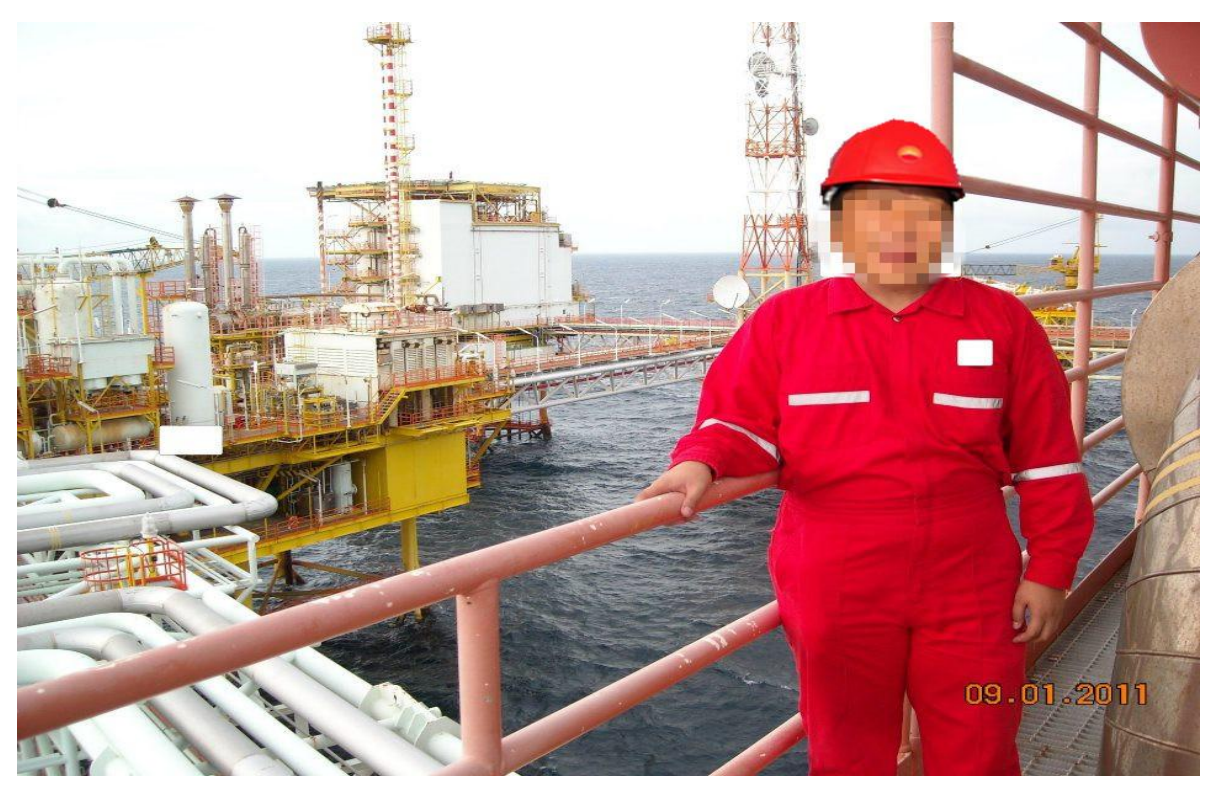

Figure 8.1. Changes in perception after industrial training

Photographer: IZZ, male, third year engineering student 
The following images taken from the Facebook page group data demonstrate this shift in perception amongst students in their final year of study. I noticed that the third-year participants started to upload more photographs of academic-based extracurricular activities in keeping with their shifting perceptions about education and community work activities. For instance, in Figure 8.2, AZI uploaded a photograph of a field mapping activity, where she had to map the local area. This activity was closely related to her studies in geology. The student had decided to join more fieldtrips related to her area of study in order to increase her knowledge about the field of geology so she would be better equipped to deal with a working environment when she graduated.

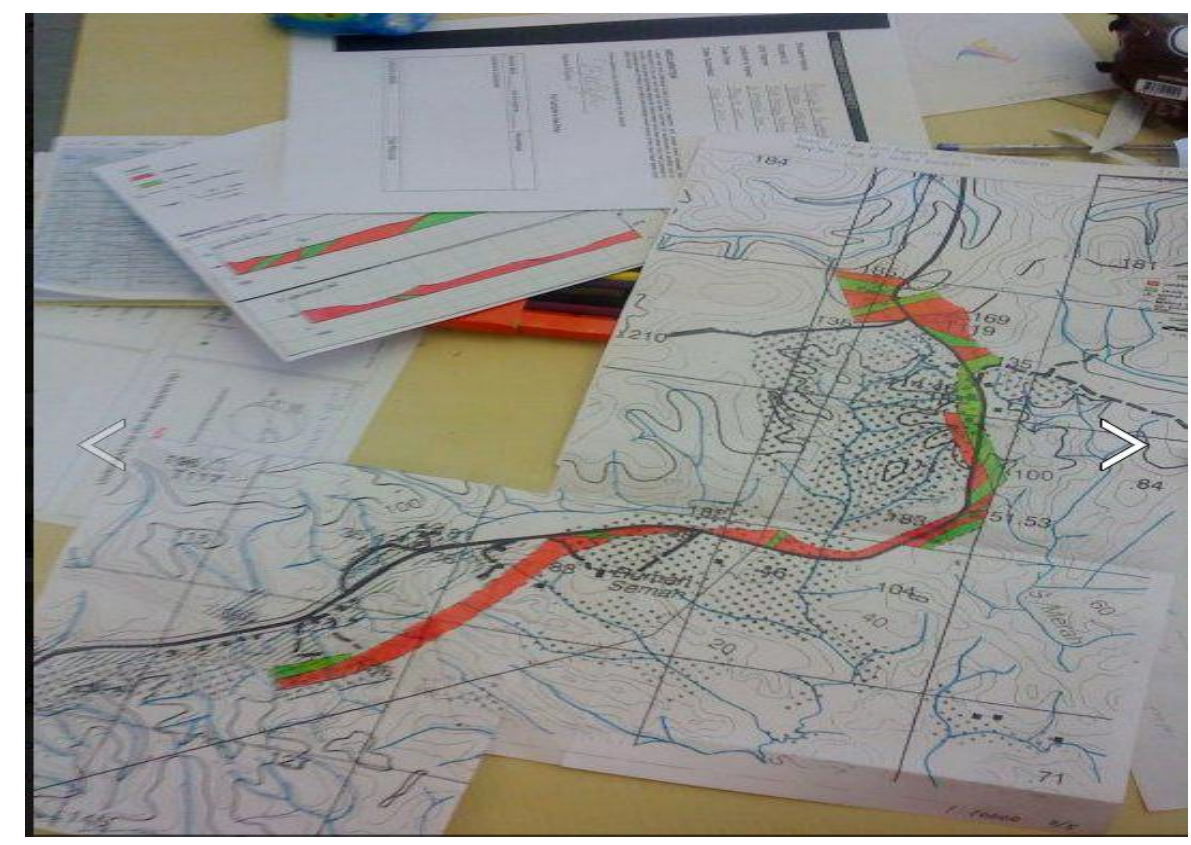

Figure 8.2. Orientations change to academic based extracurricular activities

Photographer: AZI, female, third year Geology student 
In Figure 8.3, BRI joined a talk organised by the Accounting club at the university. His choice of activity again reflects his degree major, which is Accounting and Finance. Like the other participants, he had become increasingly selective about the types of activities he joined- and by the time he participated in this study he was more focused on activities which would gear him towards his chosen field. These activities also helped to familiarise him with some of the issues he would have to deal with in his chosen path of study.

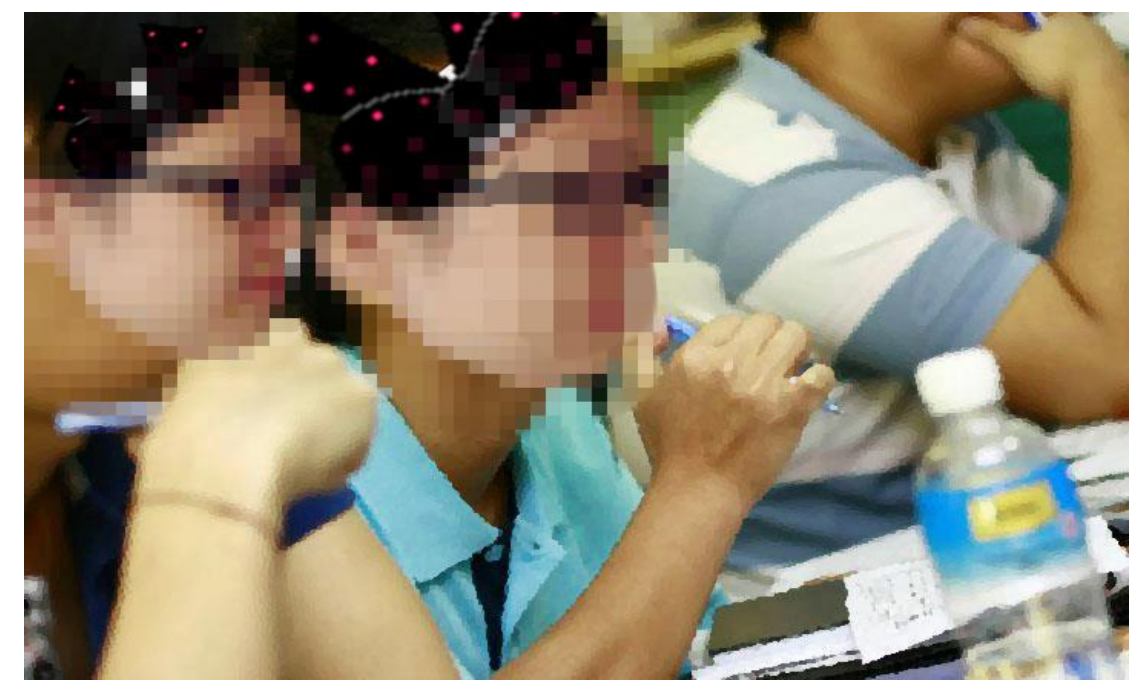

Figure 8.3. Participating in activities related to major of study

Caption: Your money \& brain talk by Jonathan Quek organized by CPASC: Investments, Personality test \& CPA.

Photographer: BRI, male, third year engineering student. 
A third-year participant, EL, uploaded an image of one activity she had participated in, which was related to communication and presentation skills. This activity emerged from a series of professional workshops designed to target the mechanical engineering students at the university. As can be seen in Figure 8.4, I noticed that the participants started to add more pictures which carried more educational value, compared with the images provided by the first-year foundation students, which were still more focused on non-academic based activities and events.
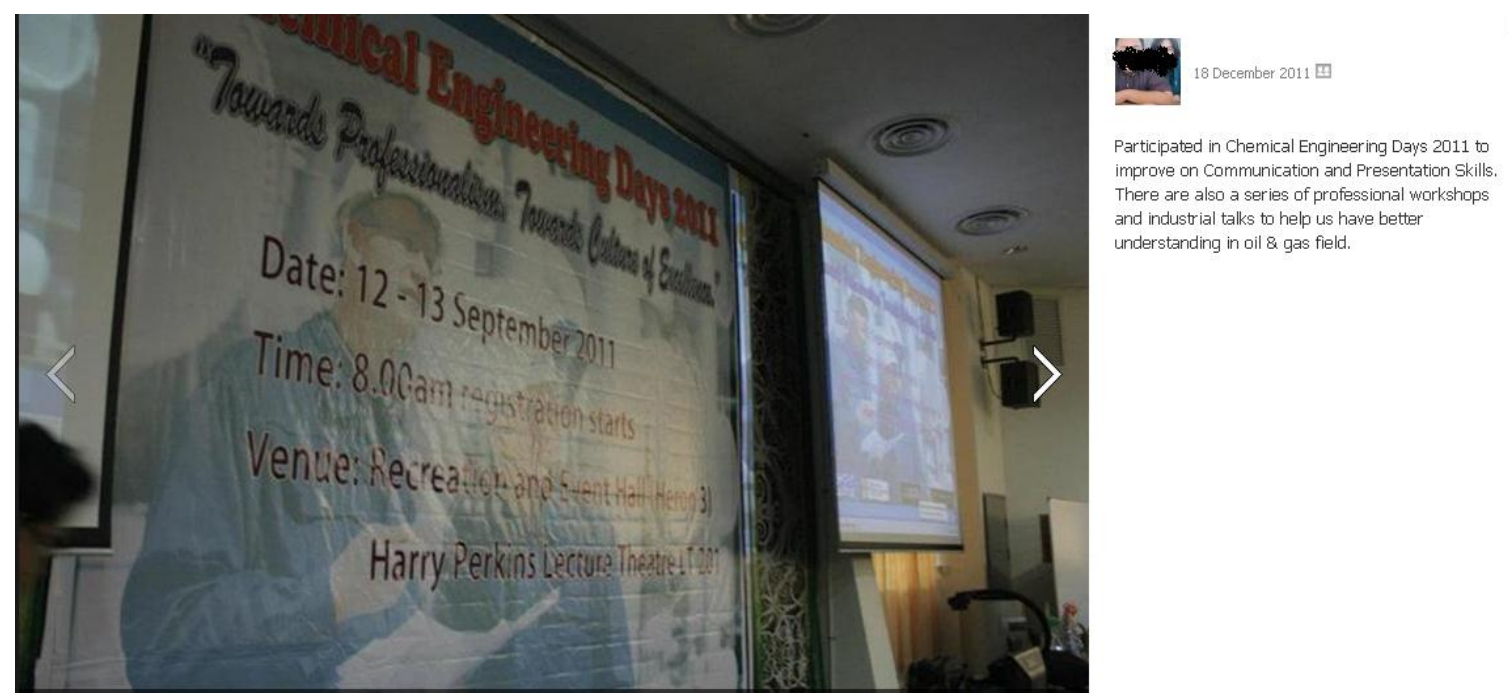

Figure 8.4. Emphasis on educational based activities

Caption: Participated in Chemical Engineering Days 2011 to improve on Communication and Presentation Skills. There are also a series of professional workshops and industrial talks to help us have better understanding in oil \& gas field.

Photographer: EL, female, third year engineering student. 


\subsection{Changes in the participants' perception about volunteering}

\subsubsection{Personal development and transition to a new life}

The participants decided to engage in community service activities, club activities and voluntary activities because they believed that the opportunities offered by these activities provided them with an opportunity to widen their horizons beyond the formal learning experiences provided in their university classrooms. Over time, the students increased their participation rate and it became routine for them to become more active in taking up such roles. The findings indicate that their positive experiences of volunteering influenced the participants' perceptions about the value of community work and voluntary activities. When the participants' cultural habitus collides and merges with their institutional habitus, these positive experiences build their enthusiasm to become involved in community service and voluntary activities. For example, during the interview EL explained why she started to get active in community service and voluntary work at university. She uses the term 'habit' to describe how her engagement in these activities became increasingly important to her and eventually created greater enthusiasm and commitment to participating in future activities.

You know like it's really become a part of me. At first it was not personal interest, but when it became a habit, it actually how to say... ah, it just.. interest me even more. (EL,female, third year engineering student)

In addition, the data shows that some of the participants saw the transition from high school to university as a fresh start, or a new phase in their lives. Thus, they wanted to explore, and also experiment with their new environment by taking up activities, which they thought would mark the starting point of this new and exciting life ahead. As they started to expand their social circle and their web of networks they then began to seek out activities, which interested them. Being in a new and unfamiliar environment within the university opened up various opportunities for them to engage in a diverse range of activities, which they may not have been able to participate in when they were in secondary school. BW said in his interview: 
I can learn something that I don't know, maybe coming to university like the thought of coming to the university, means having a new life. So it's time for me to change my perspective, change my views and start experimenting everything. So that's why I did it. I experiment almost everything. (BW, male, first year foundation student)

When I questioned why he chose to get involved in specific activities during the semester, BW explained;

Um, because we are, we are getting... we are getting sick of joining clubs because of resume. In the beginning of semester one, I was like joining every club for resume... but as time goes by l'm getting sick of making decisions based on this resume factor so I try to explore other factors. Like helping people, helping myself, learning new experience, and because last time in high school opportunities are given to elite students only. (BW, male, first year foundation student)

This indicates that some of the participants experienced a shift in worldview after participating in various club activities. However, although they might not be completely driven by the need for resume padding, there is still evidence that the participants engaged in activities, which they saw as profitable in some way to their studies or future career prospects. In this case, this participant did not have the opportunity to participate in such activities in secondary school because only elite students, selected by the teachers are given the chance to participate. In consequence, he decided that he wanted to make up for lost time by joining every event available on campus before deciding which activities he would most enjoy.

My findings also revealed that not all the transitions from secondary school to tertiary institutions were smooth ones for the participants. During the interview, BAL related some of the difficulties he encountered when he was trying to organise club activities at university. The participant had experienced frustration when his expectations about university activities turned out to be different from his experiences at secondary school. 
In my journey from secondary school to my university, I find it harder to organise activities in my university or school scale because everyone have different schedule and is less willing. I also find the university club to be more independent than school. It makes people more independent and strengthens bonds between club members. Club members are just like family, doing good deeds for the community. It actually helps us to organise better activity for charity. (BAL, male, first year foundation student)

Nevertheless the transition was still beneficial for him, as he reflected in the second half of his comments. Despite these tensions he did manage to obtain positive gains from the experience. This indicates that the students sometimes experienced problems as they adjusted to activities at university and this tension stems from the differences in schedules and also his experience of being in contact with people who are reluctant to participate in such activities.

The participants also explained that participating in clubs, community service and voluntary activities helped them to acquire knowledge. Furthermore, the educational values, which they gained from engaging in these activities were seen as bonus points in joining such activities. Data from the focus group interviews show that the participants' general impression was that their involvement in club and religious activities was positive. Some of the responses received during the interview were as follows:

I did join a religious club in university which every time there was a meeting, new information about my religion will be informed. Most of the information that I never know. So I take this as an advantage for me to learn and apply to daily life. (AY, female, first year foundation student)

In contrast some of the participants who had engaged in these activities began to question why some of the skills they had acquired in volunteering were not imparted in formal classroom contexts. Having had the experience of learning CPR and 
other life saving techniques from his involvement in the Red Crescent society, led LKW to rethink the government's role in advocating the need for first aid training in secondary schools. He commented, "I learn more about first aid. I learn CPR and this makes me wonder why not the Ministry of Education especially for secondary schools make students compulsory to attend basic CPR?" (LKW, male, third year commerce student)

My findings also indicate that the participants have positive perceptions about the role of community service, clubs and voluntary work in their lives after participating in these activities. They believe that getting involved in community work and voluntary activities creates a change in the way they think about the world and also about the surrounding community. This shows that having positive perceptions about the impact that an individual can create in their community does affect students' decision to become more active volunteers. For example, GH explains:

A change for someone as ... It's like I don't care whether it involves me or not... but it has to the impact should be a change in our thought, in the society. (GH, female, first year foundation student)

Upon further investigation, however, GH reported that she found out some disturbing information as a result of her experience with voluntary work. She said:

I got to know that orphanage did not have many sponsors to support the orphans and handicapped. I always thought that they get all kinds of sponsors and still they depend on others to survive and after charity I realised that they are sponsors to support their living but there are some people who manipulate the sponsorships they get. So this information motivated me to donate to the orphanage whenever I have the chance. $(\mathrm{GH}$, female, first year foundation student)

In this case, GH learnt that despite all the funding received by an orphanage, the institution still requires constant support and donation from the public because there was misappropriation of funds by irresponsible parties. This changed her views about 
the matter and she vowed to help out in the future after she found out that the orphanages really did need a lot of help and financial support.

Based on the literature, the concept of giving something back to society suggests a disposition towards contributing to the collective good of that society. James Younis, Jeffrey McLellan and Miranda Yates (1997) define this action as a collective agency, where the members accept that they have social responsibilities and engender a sense of the need to fight for social justice and equality. This suggests that there is a strong bond, which exists between students and members of the local community. The desire to create a change within the folds of the community shows that my participants were disposed to help out in the local community in an attempt to fulfill their social responsibility. An example by EL is given below:

There are times that you just feel like you need to help people because even if we as engineer, we are not just trying to make the world a better place that kind of thing, that sort of thing. We still need to give back to the community that's what we learn like not really that community, that community but in terms of giving a talk. When you give a talk to the younger generation, you're also in a way helping them to realise that when you all grow up you're not just a machine to work all the time. (EL, female, third year engineering student)

Other comments given by my participants also express similar notions. BAL explains:

Yes because it brings me a sense of satisfaction and joy. Contributing to the community is what I love to do and plan to continue doing it even when I work and help spread the importance and benefits of a volunteer. (BAL, male, first year foundation student)

However, not all these actions of giving back to the society are motivated by the desire to work for the collective good of the society. When I asked my participants if they would continue to participate in volunteer work in the future, BW revealed: 
Yes, but depends. If there is incentive I will go! If there is no incentive, I may not go. Sometimes it depends on my mood as well. ... most of the time my answer is yes because it is required [for] resume or work. I also go if there are free T-shirts or gifts. I also have to see if it is an important issue which is overlooked or people are not aware of. (BW, male, first year foundation student)

$\mathrm{V}$ discussed his point of view in a different light. He explained that he would only contribute if he felt passionate about an event or if it was meaningful for him.

Yes I would join that particular project if it is something that I am interested in or passionate about or something that I feel is important. When a project doesn't have much impact or when it feels like a publicity stunt than anything else [then I would refuse]. (V, male, first year foundation student)

$\mathrm{V}$ explained that he would think carefully about the events he decided to join and that included examining the purpose of the activity. He claimed that he would only choose to participate in an activity that appealed to him and which he viewed as holding importance for him. This shows that there are participants who were quite selective about the type of events they chose to volunteer for. It also indicates that they were actually quite critical of some of the events happening around campus because they had worked out which activities were sincere and which ones were publicity stunts.

The participants' perceptions and misconceptions about certain social issues often changed after a period of involvement in these activities. My data suggest that the participants learnt how to be more understanding and empathetic after the experience of doing community work. Some of the excerpts taken from the focus group interview indicate that my participants had experienced changes in their way of thinking and viewing the people they had helped during the activities. Some of the views are expressed below: 
I learnt the value of humanity and I learnt love, before this I was scared to meet disabled people because of some incident, but after this charity project, I learnt to understand them. (GH, female, first year foundation student)

It has changed the way I think and I feel more responsible after attending and completing a community service project. (TK, male, first year foundation student)

Through this university experience you know... I think I know like what it's like to be in their shoes. So you know what they need [and] you value how much support they need more than you, you're gonna give back to them. I think once you know what it's like to be in their shoes you also have the heart of giving, soyou won't be like those selfish people who are so stingy [with] their money. (BR, male, third year commerce student)

My findings indicate that several of the participants experienced a change in the way they thought about the social world. They may still display signs of 'superiority' and they may still exhibit deficit thinking, but from the responses they gave during the course of this study, this kind of thinking began to shift their viewpoints as they were exposed to these community projects. These experiences created a change in their way of viewing community service and its impact on other individuals in the society.

\subsubsection{Sustainability of the project and commitment of group members}

The findings from the study reveal that the issue of sustainability was an important one to consider when participants were discussing their perceptions about community service projects. They felt that a good community work project, one that would attract them to participate, would have to be sustainable in order for it to have any significant impact both on the participants and the people who were being helped. Unless a project met this kind of criteria they defined an activity as "meaningless" (V, male, first year foundation student) or as the case below reveals, pointless to a certain degree. When an event or activity occurs in isolation, or when there is no attempt to 
follow up with the people they have helped, these participants did not feel inclined to participate in such activities. In their opinion, if the project was a one-off event, which was not sustainable then it was a waste of resources, time and energy.

Cleaning the old folk's home doesn't have any significance in helping them. It's just cleaning outside, what's the point in that? I mean, you just go there once, clean and that's it. There's no contact after that so it's pointless for me. (BW, male, first year foundation student)

EL gave her definition of meaningful activity as one that would create awareness within the community and also to be a part of the community she is working within. Fundraising and charity events do not seem to appeal to her much as these activities were short-term activities that did not have a lasting impact on these people she was working within the community. She also believed that fundraising activities were not a personal gesture because they did not allow her to have direct contact with people in the community or provide her with the opportunity to participate in any hands-on activity which could leave a lasting impression on the lives of the people in the community.

I would say fundraising wouldn't need me as much as the one like in the rumah panjang (long house), because fundraising is just more to you know, like promote, I mean create more awareness to the people to come and help out [by] donat[ing] some money. I mean [when] you donate [or] you collect money even if I'm not there, other people could actually take over my place and ask [for donations]. I feel that I would rather go for the rumah panjang, go tolong tolong (help out), go and try to help that one is even much more meaningful to me. To be a part of the community, instead of just hey I give you money you know. (EL, female, third year engineering student)

Besides that, the issue of sustaining a project is not just limited to the duration of the project or cause, but also refers to the commitment and dedication shown by members of the organising committee. A committed team will produce committed 
members and this promotes healthy involvement from others to join in the project as well.

Like any other project, community service projects can fail (or fail to achieve objectives) if the members and leaders do not have the drive to go ahead with what they started. (MAY, female, third year engineering student)

An important aspect of doing a community services project is the commitments of the parties involved. In other words, how committed the parties involved in the project. This is due to the fact that the purpose of organising such projects is to help those who are in need and is usually requires the support of all relevant parties. The success of these projects is depended on the cooperation of everyone in it. Any parties that do not commit themselves would create a hindrance in achieving the objective of the project. (IZ, male, third year engineering student)

The findings in my study revealed that there are instances where investment in social capital fails to provide the expected returns for the participants. One such example concerns participants who were willing to sacrifice their time and energy but they did not feel welcomed by members in certain clubs at the university. GH disclosed why she stopped participating in student run clubs as she felt unwelcome by the group members in the club.

I just felt as if these clubs that conducted this kind of community services and stuff, were not very welcoming. So I... I didn't really feel very comfortable to going on and doing whatever they were doing so just kept to myself. $(\mathrm{GH}$, female, first foundation student) 
AZI expressed a similar feeling, but she attributed her lack of participation to the feeling of being left out and isolated even though she was amongst her peers. Language barriers and cultural differences can also be the basis for lack of active participation in club and voluntary activities.

I don't really join that much of [...] voluntary [pause] events [pause] work.. or the club itself because [pause]... I'm not being racist but [pause] majority of the ones in the club are Chinese so sometimes I felt isolated. And I don't mind, I like to mingle with different races but the thing is they, I feel I feel like they are the ones who isolate me because they speak in Chinese most of the time and I don't, I don't understand Chinese at all so it's not.. I decided not to join because I felt I was being left out, left alone. (AZI, female, third year engineering student)

My findings reveal that some of the participants who dropped out of voluntary work and club activities reported that they did not feel a sense of belonging, or being able to identify with their peers in the group. This feeling of isolation created a barrier between them and the rest of the group and this negative experience led them to reduce their extracurricular pursuits significantly.

Besides the issue mentioned above, another issue cropped up during the interview. Findings in my study indicate that members of certain clubs in the university were perceived as 'socially dominant' by some students. These students feel that members of this club only interact amongst themselves and form 'cliques' within the same social sphere. Other students viewed this as 'snobbish' (BAL, male, first year foundation student) and 'elitist' (BW, male, first year foundation student. During the interview, EL, who used to be a member of a prominent and active club in the university brought up a similar issue as well.

I leave the club is because erm, I [felt] that I didn't balance my timetable anymore at that time where I have lesser time for my own studies and for my own friends because when I actually joined the club I was more to club oriented, 
how to say.. ah.. "cliquish" with the people in [that club], I was.. I mean I do have better network among the members but I have to consider my study friends as well. I didn't stop just like that, I just slow down the momentum until it just stopped by its own. (EL, female, third year engineering student)

In this case, EL actually decided to break away from the club slowly as she realised that she needed to strike a balance between her 'academic' set of friends and friends she made during her volunteer work at university. Her use of the term 'cliquish' signals that she is aware of how other students perceive the club members and their social status within the university. As we can see from the three cases mentioned, the practices and social status of members in a club can be a deterrent when it comes to recruiting new members and sustaining membership in an organisation. This is an example of how my participant interpreted her cultural and social capital against that of her friends. She also acknowledges how her involvement in one particular club created a 'gap' between her and other students. This indicates she was drawing on her knowledge of her cultural capital to discern how she should behave with her friends in the club and with her 'academic' friends. Furthermore, as she maps her position within the field, she struggles to reconcile between academic priorities and non-academic activities, which she thinks will be a valuable resource that can be used in the workforce.

In addition, the issue of commitment was also brought up when my participants discussed their involvement in university clubs and associations. Again, the same topic was raised - commitment - not only amongst members of the club but more importantly the leaders, who should model such behaviour in order to attract likeminded individuals. My data suggest that the idea of establishing a commitment towards the cause and also creating an ongoing commitment amongst the members in a club or organisation play an important role in maintaining continued participation and involvement in club activities or voluntary activities. An example is given below. This quote was taken from an interview session with V. He described why he decided to set up a debating club at the university and he explained his views on recruiting members for this club. 
I get to form a team because forming... for debating it's not a solo job you need team and to get people who actually you know, go into this type of thing you need committed people. And having a club attracts committed people into it. (V, male, first year foundation student)

\subsection{Summary}

Overall, my participants demonstrated their knowledge of their cultural capital when they chose to engage in community service activities and academic club activities. They believed such engagement would give them a greater chance to obtain a good job following graduation. These participants accumulated further social capital through participation in extracurricular activities, which they perceived could be converted into economic gains in the future through the use of their social networks and through the knowledge gained from corporate representatives in the industry. My findings show that the participants were adept at utilizing their cultural and social capital to reproduce existing social and cultural structures and to gain advantage in their future fields to achieve social mobility.

However, after having experienced community work and voluntary work in university, my participants then went through a shift in the way they perceived community service and voluntary work. Some described the experience as an opportunity for personal development, which is important in the transition to a new phase of their life. They felt it was important for them to try out new things and learn from these experiences. Several participants talked about their desire to participate in activities that were ongoing and sustainable. They believed that commitment and the ability to attract committed members to help out in a project was an important factor in encouraging greater participation in community service. Without support from friends, committee members and the university, they argued that a successful community-oriented project could not be carried out. These participants talked about going through a reflective process after participating in these activities, which allowed them to perform better in future activities. 
On the other hand, tensions also arose when they engaged in these activities. Certain factors worked against the participants' desire to engage in extracurricular activities. Firstly, there is evidence to show that students' perception of their social status and their position within the university led them to distance themselves from those they term the 'snobs' or 'elite' club members in the university. They did not feel welcomed by the club members and they did not feel a sense of belonging nor could they identify with the existing members in the club. In these cases, their investment in social capital did not reveal expected returns, thus they decided that these activities were not worth their time or attention.

Secondly, another source of tension was the shift of priority, which the thirdyear participants experienced in their final year at university as they reduced their involvement in community work and they started to engage more actively in academic based clubs and organisations. Thirdly, there is evidence to suggest that the third-year participants were experiencing a change in terms of their deficit thinking as they report having a better understanding of the issues happening in the community they are helping. As discussed in the previous chapter, the educational institution plays a role in 'promoting' and reinforcing this deficit thinking but the participants also indicated that their exposure to volunteer activities have helped them to better understand the situation facing the members in their local community.

In addition, the results reveal that the participants also became more critical of the activities they would choose to engage with in the future. My findings indicate that the participants would choose to volunteer for activities, which can be sustained over a period of time. They were reluctant to participate in short-term activities where there is no attempt to follow up or create a lasting impact on the community. For example, visits to the old people's home were seen as meaningless if a group of volunteers chose to go there to clean up, interact with the old folk for a few hours and then end the journey at that point. If there were no attempt at further contact or further help then these participants would feel that the project carries no lasting value for both parties. Besides the type of activity, the objective of an activity is also a factor, which they think about before volunteering. If they feel that the project is only a marketing stunt, or an attempt at publicity they would not volunteer or offer their time or energy. 
Furthermore, they also add that their desire to continue their participation also stems from the club itself. If the members of the organisation were committed to a cause then they would be able to attract participants who were equally dedicated and willing to help out for a particular project.

In sum, my findings indicate the participants do undergo a change in their perception and engagement after having participated in extracurricular activities. In some cases there is a misinterpretation of their social position in relation to those they see as 'less fortunate' or less privileged than themselves. There is evidence to suggest that they viewed themselves as 'superior' in a sense, and that they had the power to make a better world for those who were not of a similar social standing. In addition there is also evidence that this 'superiority' was present amongst students themselves when they perceived certain clubs as being 'socially dominant' or belonging to an 'elite', based on the membership and club activities. This perception creates a social boundary between the members of said club and the rest of the students at the university. This view may be justified, but there is little evidence from the data to suggest so. This belief does serve as a hindrance because the participation rate is reduced based on this preconceived notion of 'them' and 'us'.

My data also indicates that the participants who had entered their final year of study were concentrating more on academic based activities - workshops, talks, seminars and conferences, which were targeted at enhancing the participants' knowledge of their chosen field. The participants were no longer as focused on voluntary work or community related practices and instead diverted their attention to attaining other forms of capital (academic capital), which they hope to invest in when they enter the working world. 



\section{CHAPTER NINE}

\section{DISCUSSION}

\subsection{Introduction}

In the previous chapters I discussed the students' perceptions of education and how this has shaped the nature of engagement at university. I also examine how family and individual practices influenced the way they view education and how that has contributed to the nature of their engagement, particularly in voluntary activities. In this chapter I explore the patterns of participation in extracurricular activities that emerged from the data.

This discussion chapter extends the analysis found in Chapter Six, Seven and Eight. In this chapter I present the discussion thematically, and provide a more nuanced view of the role of cultural capital in shaping students' perception of education and how this perception then drives their engagement in extracurricular activities throughout the academic year.

\subsection{Cultural capital and perception of education}

\subsubsection{Participants' cultural capital}

This study was designed to explore the nature of students' cultural capital and how this shapes their perceptions of the purpose of university education. My findings reveal that the participants came from a privileged group, with significant amounts of economic, social and cultural capital (but a different kind of cultural capital from the privileged participants in Bourdieu's French studies). The interviews demonstrated this privilege, and it was signaled in a number of ways including: the degree of parental involvement in education; parental expectations and aspirations with regard to educational achievement and success; and the emphasis put on extracurricular activities by students as a strategy to enhance future career opportunities. In addition, the emphasis on educational capital signals that this form of capital is highly valued 
among the middle-class families involved in my study. The parents and the children had been actively engaged in pursuing educational success prior to university education by investing in private tutoring. Possessing excellent grades is one way to attain distinction, thus setting them apart from their peers.

\subsubsection{Perceptions of education}

The results of this study show that there was a positive link between students' cultural capital and their perception of the purpose of university education. However contrary to prior studies (DiMaggio, 1982; DiMaggio \& Mohr, 1985; Aschaffenburg \& Maas, 1997) that have noted the importance of highbrow culture in educational attainment and academic success, the findings of this study reveal that the families valued academic capital highly. In fact, these families have inculcated the importance of achieving academic excellence by equipping their children with sufficient academic capital prior to entering university. Taking on an Asian lens to examining cultural capital, I provide an explanation for this variation in the findings below.

Many of my participants demonstrated an instrumentalist view of the role of education. This view can be explained in part by my participants' parental education level. The findings discussed in Chapter Six and Seven show that the parents with higher educational levels drew on their educational capital and social capital to provide guidance to their children. This included advice about the types of activities to join so they are able 'stand out from the crowd'. Some followed their parents' advice and capitalised on their involvement in extracurricular activities as a form of resume padding. This was so they would have an edge over their peers when seeking employment. Thus, parental education - particularly parents who possessed higher qualifications such as university degrees - played an important part in influencing the participants' perceptions of the role of university education. This is an indicator of the 'insider knowledge' (Bourdieu, 1977, 1986), which was transmitted from my participants' parents. My participants' all placed a high value on education as a path for them to obtain a good career. They saw university qualifications as a way for them to improve their lives, and the lives of their parents. This corroborates with the findings reported in Albrecht and Albrecht's (2010) and Sullivan's (2001) studies in which it 
was found that parental education had a significant impact on children's educational attainment. For example, educated parents are familiar and knowledgeable about the school system and can effectively use their knowledge to their children's advantage.

In Chapter Six, I explained that Malaysian families valued institutionalised forms of capital highly. One of the reasons why the Malaysian middle-class families value academic qualifications is due to unequal educational opportunities. As I discussed in Chapter Two, one of the greatest impacts of democratisation in education in Malaysia, is wider access to education among members of different socioeconomic backgrounds in Malaysian society. Consequently, these middle-class families no longer have exclusive ownership of the benefits provided by education. Thus, they are forced to devise strategies to maintain their status and privileges in the society. This strategic form of cultural capital serves to differentiate themselves further from families of other social classes. It is a way for the families to achieve 'distinction' (Bourdieu, 1984) and maintain their status within the society. Another possible explanation for this perception of education is related to how culture works as a field in the Malaysian context. As Malaysia is comprised of many different ethnic groups, and because of the preferential treatment given to specific ethnic groups (refer to Chapter Two, page 16), there is fierce competition to obtain places in public higher education institutions. As each ethnic group has an unequal foothold especially in the field of education, a distinct pattern to emerge among students of different ethnic groups in the higher education scene in Malaysia is to obtain exceptional grades in their national exams in order for them to be able to accumulate educational capital. Thus, there is a culture of competitiveness among the different ethnic groups to obtain 'distinction' not just for merit in the education system but in the workplace as well.

As discussed in Chapter Six, one strategy employed by my participants' families to perpetuate their social status included investing in private tuition. This was to ensure that their children were equipped with an elite form of educational capital prior to entering university. The finding in my study is corroborated by Juliana Jelani and Andrew Tan (2012) who argue that Malaysian families place a high value on education and Malaysian parents often search for alternative measures to ensure that their children do well in their studies. Sending the children for private tuition increases the 
chance of getting accepted to prestigious institutions. In this way, parental emphasis on the importance of education is passed on. As a result, dispositions towards the role of education are reproduced. The habitus of valuing education is instilled amongst the participants at an early age, as signaled by the emphasis on extra tuition to achieve academic excellence. This echoes Yamomoto and Brinton (2010) and Byun Soo Yong, Evan Schofer and Kim Kyung Keun (2012) who have conducted studies on Japanese and Korean parents' practices of investing in extra tuition to ensure that their children excel in their studies, a pre-requisite to enter prestigious universities and obtain good jobs.

In my participants' view there was a clear link between the possession of certain types of institutional capital and outcomes in the labour market. As I discussed in Chapter Seven, they frequently cited the importance of education in creating better opportunities in the labour market, and also in increasing chances for financial stability in the future. In this thesis, I argue that the parents' and students' knowledge about the labour market influences their perceptions about the role of education. These perceptions shaped the nature of their engagement in university. For example, if an individual is predisposed to view education as a method for shaping career trajectories, then their participation in university would be oriented towards academic based activities or clubs rather than focusing on voluntary or outreach activities.

\subsection{How students' perceptions affect their engagement}

One of the problems with the expansion of education, particularly in higher education, is the problem of credential inflation (Waters, 2008), which affects most countries. The excess of academic qualifications and the competition for employment is a huge challenge for middle-class families and families from all social classes. As a result these students have sought new investment strategies that set their children apart from other competitors, as my study shows. A strategy used to create 'distinction' (Bourdieu, 1984) from other competitors includes investing in extracurricular activities during university. This finding corroborates a study on middle-class families in the United Kingdom conducted by Johanna Waters and Rachel Brooks (2010) who report that: "Buoyed by their families, students are deeply concerned with acquiring 
the 'right' credentials and other embodied traits, which will be ultimately converted into social status and economic capital." (p. 218)

This explains why middle-class families develop strategies such as investing in private education and stressing the importance of extracurricular activities as useful tactics (Waters \& Brooks, 2010) to secure 'distinction' (Bourdieu, 1984) and advantage over other peers. As I mentioned in Chapter Seven, active involvement in extracurricular activities could also provide evidence that students were equipped with the extra skills and experience required by potential employers (see Kaufman \& Gabler, 2004; Stuart et al. 2011). Including one's experience with extracurricular activities in a resume was also seen as an effective means of self-marketing. Lucie Shuker (2012) defines self-marketing as a way for individuals to promote themselves to potential employers in ways that "are sensitive to the demands of the market" ( $p$. 11). She argued that an ideal self-marketer tailors their activities and draws on their experience to enhance career trajectories. This self-marketing skill is particularly important in instances where there is no monetary exchange involved. Instead, the exchange of symbolic and social investments is used to gain entry to the workforce.

My participants explained that the skills and experiences they obtained when participating in extracurricular activities would help them to cope in the workforce because they could supplement their qualifications with skills relevant to future work. My findings corroborate those found in Rachel Brooks and Glyn Everett's (2009) study on postgraduates' belief about the value of a degree. In their study, their respondents reported that participating in extracurricular activities at university was a way to consolidate their degree with relevant experiences that could help them in the job market. These participants claimed that extracurricular activities provided them with appropriate 'soft skills', which increased their marketability and gave them a competitive advantage over their peers. My findings echo those of Lehman (2009) where he found that students decided to enrol in university based on their perception that universities have a vocational value, which can enhance social mobility and chances of gaining the upper hand in the labour market. The 'ethos of vocational education' is cultivated due to the experience students have with their family's socioeconomic background. They understand the need for a university education as a 
pathway to economic security and the utilitarian concerns of employability, income and mobility (Lehman, 2009, p. 147).

In addition, student engagement at university may be influenced by their desire to consolidate their position within a field. During the follow up interview, one participant explained that her experience at university enabled her to see that she had many different options to pursue after graduation. This included continuing with a post-graduate degree or venturing into a new field of study. Brooks and Waters (2009) suggest that this is a strategy employed by middle-class families to secure their position in the society. These families pursue further learning in the form of postgraduate qualifications or other forms of educational qualification. My findings are also similar to those reported in MaryBeth Walpole's (2003) study in which she found evidence that a students' social status affects his or her engagement in university. She reported that students' ideas about converting the capital they accumulated in college into graduate school attendance and high degree aspirations displays a habitus that views graduate education as a reinvestment toward further capital accumulation. Such a reinvestment has been found in a high-status habitus (Walpole, 2003). The desire to pursue higher education also indicates a disposition for academic excellence, as a result of the family's emphasis on the value of education.

\subsection{Institutional habitus and student engagement}

\subsubsection{The university as a site for volunteerism}

Besides the students' perceptions, my findings show that several factors influenced student engagement in university. One of the factors influencing student engagement was the educational institution they were attending. The educational institution has an important role to play in facilitating and sustaining the desire to do community service and voluntary work. For example, Astin and Sax (1998) contend that participation in community service in high school predisposes students to continue with their involvement in college. My participants who were active in community service and clubs explained that they were interested to continue their involvement in university because, as one participant summed up, their participation had become a habit (Chapter Eight, section 8.31). The constant exposure to clubs and 
voluntary work during their secondary school life cultivated a habit for volunteerism, which they then carried over to university life. This finding has important implications for curriculum developers as it suggests that the school and the education system have the power to inculcate active citizenship among students at an early age.

However this data must be interpreted with caution, because my findings also suggest that the educational institutions may, at times, reinforce deficit thinking among students. As discussed in Chapter Eight, the way the students position themselves in relation to the people they are helping could reflect signs of deficit thinking. The notion is reinforced when they distance themselves from the people they are helping and place themselves in positions of privilege and power. This problem is exacerbated if members of the faculty or the organizational leaders promote the misconception when advocating their events. For example, in some of the units offered by the university, certain projects and assessments included in the syllabus evaluate students' on the community service projects they carry out during the semester. In these projects the students are urged to help out the 'less privileged members of the community' (those living in poverty, single parents in the society, and so on). This action may unintentionally create the misconception that those in a more privileged position are better suited to change the lives of others. If the students' misconceptions were to be reinforced, then the good intentions reflected in the curriculum would lose their impact. David Jefferess (2008) argues that the notion of civic responsibility can be misconstrued when a person places himself or herself in a position of power and takes on the responsibility to 'make a better world' for others. The person is "somehow endowed with the ability and inclination to 'help' the Other" (Jefferess, 2008, p. 28), which promotes deficit thinking among young people.

\subsubsection{Peer network encourages volunteerism}

The roles of friend and peer networks are essential in facilitating active engagement in university activities. For instance, almost all the participants in my study described the importance of building friendships as the main reason for participating in an activity. They also attributed active and sustained participation in university activities to their friends. Most of the participants were recruited by friends 
to volunteer for community service or voluntary activities. My participants revealed that their decision to get involved with community service was not motivated by parental practices. In this respect, their involvement in voluntary work was influenced by their friends and peers. Social capital in the form of peer relationships is important for the formation of social ties amongst young people (Broh, 2002). This is in agreement with Lin's (1999) argument where he claims that social capital is "captured from embedded resources in social networks". In this case, the embedded resource comes in the form of individual contacts used to obtain help. For example, most of the participants participated in community service and voluntary activities because their friends recruited them. In this instance, social capital helped to facilitate information flow and influenced the participants to join in because helping out was 'fun' and 'served a good cause'. Given that the single most important source of influence on an individual during university years is his or her peer group (Astin, 1977) it is not surprising that the participants also attributed most of their volunteer practices to peer influence. Jon Dalton and Anne Marie Petrie (1997) explain that peers can be instrumental in shaping civic responsibility and are rich sources of motivation in encouraging the ethos of volunteerism. This argument is supported by the interview findings presented in my study. This signals that friends are important locus points for volunteerism.

\subsubsection{Religious capital and volunteerism}

Another significant finding I discovered is the role of religious capital in forming voluntary practices. Bourdieu (1990) claimed that religion also forms a type of capital, which is embedded in social relations. Religiosity refers to how a person's behaviour and belief towards religion play an important role in shaping the desire to volunteer in community-related activities. In addition, one's religious socialisation, (one's exposure to religious values during their formative years) also influences a person's desire to volunteer in the local community. A family's religious capital and the degree of involvement with a religious institution trigger the desire to take up a more active role in volunteering across all religions (as represented in my study). Richard Caputo (2009) claims that there is a positive relationship between religious capital and civic engagement, and Frank Fustenberg (2001) argues that when families become involved in religious activities or expose their children to religious institutions, their children become socialised into the religious community. Thus, religious capital serves 
as a good indicator of my participants' motivation to engage in community oriented activities.

Furthermore, religious attendance is strongly associated with positive measures of social capital such as volunteering and participating in civic endeavours. Robert Wuthnow (2012) suggests that religious participation is an important factor in recruiting volunteers. This is because people with shared affiliations with religious groups are more likely to join groups and encourage each other to volunteer. The findings in my study echo Wuthnow's (2012) as my participants claimed that social interaction is an important reason for participating in voluntary activities associated with the religious clubs at university. On the other hand, it is important to consider that the desire to engage in voluntary activities may not necessarily be attributed to religious sensibilities of their own. Susan Jones and Kathleen Hill (2003) contend participation in community service or civic related activities are not necessarily viewed as such by individuals. Sometimes a family's tradition or way of life, such as helping out in religious institutions or even organizing dinners and activities with children from the orphanages becomes a learned habit. They use the term 'ethos of service' to describe how some families inculcate certain habits within their families (Jones and Hill, 2003). As I described in Chapter Seven, my participants reported similar experiences. They used phrases like "it has become a habit" or "we just want to join our parents and family" when describing their motivations to get involved in such activities.

In addition, the participants also claimed that the role of local religious institutions was important in getting them to participate in community-oriented services. This is one way for people to rationalise their actions and build collective identities for social action. Identifying oneself with a religious institution is also a way for the religious groups to map and construct their identities within the local community (Lichterman, 2008). These identity-mapping processes are essential for providing its members with a sense of meaning and fulfillment, which ensures continued participation in civic activities. For example, social ministry is one way for religious institutions to legitimise social actions and reforms. In some instances, the religious institutions carry out civic activities in the local community while 
simultaneously advocating social ministry among the members of the community they are helping out.

Besides social interactions linked to religious participation, the students also exploit social capital that exists in the form of kinship and peer networks as resources to obtain personal goals. This will be discussed in detail in the following section.

\subsection{Social capital as an investment strategy}

One significant finding to come through in my research was the use of social capital as a way for the families and their children to renew and develop their stock of cultural capital. In my study, familial networks and the insider knowledge of how a particular field operates was the main source of information and guidance to students about jobs and future plans (Morrow, 2001). For example, my participants cited reliance on information gained from relatives before they made decisions about pursuing higher education. Information regarding experience studying abroad, university rankings and the suitable courses to pursue were all garnered from the interaction between the participants and their relatives. Rachel Brooks and Johanna Waters (2009) contend that for young people, social networks play a crucial role in expanding their 'horizons for action'. Fustenberg (2005) argued that the connections with one's extended family provide the much-needed support and aid to increase the family's social capital. Through the interaction with kin, families rely on these direct ties to maximize their reach of information and the resources made available through those connections. Ultimately both parents and their children come to recognize and use the resources at their disposal for the family's continued success in maintaining their social position (Fustenberg, 2005).

The findings of my study also show that the participants use their social capital as sources to gain knowledge and learn new things. Coleman (1990) emphasizes that individuals use their social relationships to obtain better outcomes in individual actions, and his arguments are supported in my study. My participants discussed how they learnt different skills and obtained information from their friends. This helped 
them to gain knowledge in different areas (for instance, academic and non-academic related matters). Lin (1999) argues that individuals can be rewarded with added resources beyond the individual's personal capital by accessing his or her social ties. There is evidence in my study to suggest that the students understand how to capitalise on their social capital to obtain rewards and to achieve personal goals.

\subsection{Habitus, capital and engagement at university}

In sum, the participants had multiple, and often complex motives for getting involved in extracurricular activities while at university. These motives were shaped by the participants' dispositions and the way they perceived extracurricular activities. For the purpose of my study, I created a table (Table 9.1), which illustrates the participants' motivations and explains how the students' perception of extracurricular activities affected their engagement in these activities. This table lists the different student 'orientations' (for instance those focusing on career trajectories, social relationships and so on) and the gains in the type of capitals they perceived as important in providing them with 'distinction' (Bourdieu, 1984) in the higher education field. For example, if the participants perceived that the main reason for attending university is to obtain a good career, they possess a stronger orientation to engage in activities that fall into the category of 'career' or 'understanding'. Thus their capital is activated by their motivations to participate in extracurricular activities. It is important to note, it is not my intention to 'pigeonhole' the students to a specific typology but rather to help in understanding students' agency.

My participants' reasons for volunteering can be classified into six different categories. Gil Clary and Mark Synder (1999) argued that different people pursue different goals, although the same person may have multiple motives for volunteering. For example, some of my students were driven by social goals as well as career related goals, both of which were equally important for them when they chose to participate in university activities. As we can see from Table 9.1, students who possessed strong social motivations typically engaged in activities that were described as 'fun', or have some sort of social enrichment. Similarly, if they felt a sense of belonging or "club members are like family" then they would be more committed to join in club-related 
activities. Students who demonstrated strong social motivations reported a significant increase in social capital, as they expanded their networks of friends and experienced a more enriching social life. As a result, these students tended to derive benefits in terms of social skills, confidence and positive behaviour (Stanton-Salazar, 2004; Ream \& Rumberger, 2008). Meanwhile, students who perceived education as a path for career attainment would often participate in more academically-driven extracurricular activities. Based on my findings, some students perceived extracurricular activities as a way to "help me in the future" or would be "good for the resume". In cases such as this, students would be more concerned with investing their time and effort in activities that can help them to acquire specific sets of skills and experience, which would help them to stand out from their peers (Stuart et al., 2011).

Stevenson and Clegg (2011) suggest that there are three different types of students who participate in volunteer activities; one such type are those driven by altruistic reasons. They are motivated to volunteer because of a strong sense of civic responsibility. One of my participants described her desire to help out as being "the right thing to do". Students driven by altruistic reasons see participation in voluntary associations as being personally rewarding. This includes feeling appreciative of their life and being satisfied with their current position of privilege (Clary \& Synder, 1999). Students driven by self-interest would engage in extracurricular activities, which would lead to personal development. As discussed in Chapter Seven, some of the students reported that they would only participate in volunteer activities if it benefited them in some way, for example by leading to self-discovery or by providing them with valuable learning experiences.

In contrast, the participants who volunteered because of religion were mostly influenced by their family members; prior school experience; and religious clubs in the university. They were often driven to participate in volunteer activities because they were 'socialised' (Fustenberg, 2001; Wuthnow, 2012) into volunteer activities by church, and religious organizations (Andolina, Jenkins, Zukin \& Keeter, 2003; Ryan, 2011). Finally, my findings also reveal that knowledge acquisition plays an important role in determining student engagement. As I mentioned in Chapter Seven, 
students would join in extracurricular activities if they could "learn new things" or it provided them with beneficial learning experiences.

My study extends the knowledge on 1) how students' orientations are shaped, 2) the types of activities different students engage in at university, especially with regards to volunteer activities, 3) how students make use of extracurricular activities to achieve individual goals and 4) how students' experiences with community service shape their future engagement and involvement in these activities. 


\begin{tabular}{|c|c|c|}
\hline Motivations & Capital & Phrases used to describe motivation \\
\hline $\begin{array}{l}\text { Social } \\
\text { Motivation to volunteer is driven } \\
\text { by social relationships. }\end{array}$ & $\begin{array}{l}\text { Reported gains in social capital, } \\
\text { particularly social skills. }\end{array}$ & $\begin{array}{l}\text { "Fun" (BRI, male, third year commerce student), "club } \\
\text { members are like family" (BAL, male, first year } \\
\text { foundation student), "have a social life" (AY, female, } \\
\text { first year foundation student). }\end{array}$ \\
\hline $\begin{array}{l}\text { Career } \\
\text { Motivation for volunteering is } \\
\text { driven by the desire to obtain a } \\
\text { good job in the future. }\end{array}$ & $\begin{array}{l}\text { Accumulation of cultural capital, which } \\
\text { can set them apart from their } \\
\text { competitors. }\end{array}$ & $\begin{array}{l}\text { "Good for resume" (BW, male, first year foundation } \\
\text { student), "help me in the future" (AZI, female, third } \\
\text { year engineering student). }\end{array}$ \\
\hline $\begin{array}{l}\text { Self-interest } \\
\text { Motivation for volunteering is } \\
\text { related to personal development } \\
\text { self-esteem. }\end{array}$ & $\begin{array}{l}\text { Gains in cultural capital if they pick up } \\
\text { new skills or learn more about their } \\
\text { abilities from participation in university } \\
\text { activities. }\end{array}$ & $\begin{array}{l}\text { "Change my perspective and attitude" (JJ, male, first } \\
\text { year foundation student), "learnt the value of } \\
\text { humanity" (GH, female, first year foundation student), } \\
\text { "opening your views of the world" (V, male, first year } \\
\text { foundation student), "self discovery" (JC, male, third } \\
\text { year engineering student). }\end{array}$ \\
\hline $\begin{array}{l}\text { Altruistic } \\
\text { Motivation to volunteer serves } \\
\text { to reduce guilt over being "more } \\
\text { fortunate" than others. }\end{array}$ & $\begin{array}{l}\text { Enhances social capital especially by } \\
\text { building bonds and trust with like- } \\
\text { minded individuals. Also an important } \\
\text { locus for recruiting friends to volunteer } \\
\text { for future projects. }\end{array}$ & $\begin{array}{l}\text { "It's the right thing to do" (AZI, female, third year } \\
\text { engineering student), "appreciate my life" (JEFF, first } \\
\text { year foundation student), "be satisfied with my life" } \\
\text { (LNL, female, third year engineering student). }\end{array}$ \\
\hline
\end{tabular}




\begin{tabular}{|c|c|c|}
\hline Motivations & Capital & Phrases used to describe motivation \\
\hline $\begin{array}{l}\text { Religiousity } \\
\text { Volunteering is influenced by } \\
\text { exposure to religious teachings } \\
\text { and family practices in religious } \\
\text { institutions. }\end{array}$ & $\begin{array}{l}\text { Influenced by religious capital and } \\
\text { religious practices at home, and also } \\
\text { religious institutions to volunteer. }\end{array}$ & $\begin{array}{l}\text { "What I learn from Islamic studies" (ASF, male, third } \\
\text { year engineering student), " we are part of the } \\
\text { community in the temple" (GH, female, first year } \\
\text { foundation student), " help out around the mosque" } \\
\text { (AZI, female, third year engineering student) }\end{array}$ \\
\hline $\begin{array}{l}\text { Knowledge } \\
\text { Motivation to volunteer stems } \\
\text { from the wish to acquire } \\
\text { knowledge and experience in } \\
\text { informal learning situations } \\
\text { which may be beneficial in } \\
\text { academic or non-academic } \\
\text { related fields. }\end{array}$ & $\begin{array}{l}\text { Gains in cultural, social and academic } \\
\text { capital that can be exploited within and } \\
\text { beyond the university setting. }\end{array}$ & $\begin{array}{l}\text { "learn new things" (RAY, male, third year commerce } \\
\text { student), "teamwork and tolerance" (BRI, male, third } \\
\text { year commerce student), "learning experience" (V, } \\
\text { male, first year foundation student) }\end{array}$ \\
\hline
\end{tabular}

Table 9.1 Participants' motivations and goals for volunteering 


\subsection{Shift in students' perception and engagement}

This final discussion section examines the changes in student perception and the rate of involvement after participating in extracurricular activities. In Chapter Eight, I explain that when it comes to students' engagement in community service and voluntary activities, significant changes occurred during their studies, especially amongst the final year students. The third year participants began to demonstrate shifts in their engagement with extracurricular activities. Participation in competitions, seminars, workshops, conferences, business games and fieldtrips were associated with significant gains in learning, beneficial for future job opportunities.

The participants cited sustainability of a project and the commitment of each member in the organization or committee as important factors when it comes to committing to future projects. When they reflected on their relationship with the local community, they gained insight into their role in society. My results are in contrast with Linda Sax's (2004) where she claimed that students majoring in engineering were less likely to be "committed to social activism" (p. 75). My findings indicate otherwise, as most of the participants (12 out of 19) were engineering students. Furthermore, three of the engineering students who were in their third year mentioned that they would continue their participation with voluntary activities when they started working.

Overall, many participants' desire for continued participation was driven primarily by self-interest. The participants were motivated to volunteer out of self-interest. The volunteering offered them gains in social interaction, knowledge and the acquisition of leadership skills. This shows an awareness of the benefits they would gain from participation. The benefits, in their view, were important for continued participation. My findings support Robert Ryan, Rachel Kaplan and Robert Grese's (2001) study in which they discovered that while initial decisions to volunteer may be altruistic in nature, self-interested motivations were vital for continued involvement amongst volunteers. Ryan et al. (2001) also asserted that gaining educational experiences are important aspects that motivate participation in volunteer activities. 
One important finding also points to how individual participants interpreted the social and cultural capital of others within their field. Evidence from the study revealed that my participants considered some of the clubs and its members as 'cliquish', 'snobbish' or 'elitist'. They admitted feeling like they 'did not belong' or 'uncomfortable' and thus chose to withdraw participation. In one case, one of the members of the 'elite' club also voiced similar views and expressed her decision to focus on her study friends instead of her club friends. This ties in with Bourdieu's (1986) argument regarding social class and exclusionary strategies performed by members of that particular class. From his class perspective, Bourdieu (1984) sees this as a strategy for maintaining 'distinction' as the investment of members in the dominant class (as a group or network) engaging in mutual recognition and acknowledgement so as to maintain and reproduce group solidarity and preserve the group's dominant position. Thus, membership is exclusive and restricted. Similar actions were performed by some clubs at the university, in that they had interviews and a rigorous selection process to choose members for certain projects. Reay (1998), Horvart and Antonio (1999) and Nora (2004) also claim that a person's college experience is tied to their habitus. If students feel comfortable and they 'fit in' with the college environment, they are more likely to be engaged with both curricular and extracurricular activities.

\subsection{Summary}

My study indicates that although both academic and cultural capital are important resources, Malaysian middle-class families rely more on social capital as a tool for advancing in university and later on in life. The results signal that parental cultural capital is important as this knowledge enables parents to provide guidance for their children to succeed at university and in the working world. The parents' practice of sending their children to private tuition and music classes also shows that they are using their knowledge of capital to help their children advance in their education.

My participants' parents relied on their cultural and educational capital to help guide their children's decision making at university. The findings also indicate that parental educational capital is important in two ways; firstly, as a resource that parents mobilize to advance their children's education and secondly, as a guide to advise their children about the type of activities they should engage in while at university. 
In contrast with their parents, my participants relied heavily on cultural and social capital, especially in their first year to help them to navigate their way successfully through university. However, as demonstrated by the third years students, these students tend to rely more on their educational capital to gear them towards working life upon graduation. Both first and third year students depended on their relationships and interactions with peers to forge bonds, learn new skills, practice leadership and communication skills and develop character. They also relied on social capital as an important resource to gather information from channels they trusted, especially if they had to decide whether they wanted to participate in community service projects, club activities or voluntary activities. In addition, my participants also relied heavily on information from their relatives, teachers, industry representatives and peers to inform them about conditions in the workforce and employers' expectations. This helped them to orient themselves to the kinds of activities that they believed they should focus on while at university. Based on my findings, I argue that social capital is also an important resource for the participants while at university. The strength of their social capital allows them to decide what activities are important when it comes to career advancement. Social capital also plays an important role in attracting the participants' involvement in extracurricular activities as they valued the friendships that they had built along the way. My participants were more committed and willing to participate in future activities if they had friends who were involved in these activities. Friendships were also a determining factor in sustained interest in an activity. The more friends who had joined an activity, the more likely students were to remain active in a club or a project. Also, the participants felt that social relationships functioned as an important component for them as they gained knowledge, obtained information and worked together with their friends. This interaction proved beneficial for them both academically and nonacademically. 


\section{CHAPTER TEN}

\section{CONCLUSION}

\subsection{Introduction}

This study set out to explore whether cultural capital influences Malaysian students' perceptions about the purpose of university education. From that starting point, I examined the link between students' perceptions and their engagement in extracurricular activities, particularly in community service, club activities and voluntary work. Finally, I investigated how the nature of the students' engagement in extracurricular activities changed after they had participated in these activities.

Four data collection methods were used in this study: questionnaires, visual data, focus group interviews and follow-up interviews with some participants. The questionnaires set out to identify the participants' cultural capital and explore the kinds of activities the participants and their parents engaged in during their free time. This helped to explain the family's practices and the types of activities they value in their daily lives. Next, I incorporated visual data methods aimed at getting rich data about the various types of extracurricular activities that the participants engaged in while at university. The participants provided photographs of activities and uploaded the images on Facebook. They also provided descriptions about the photographs and explained why they chose to participate in those particular extracurricular activities.

I also collected data through a focus group. The aim of the focus group was to explore the participants' perceptions about extracurricular community work and voluntary activities at the university. This focus group was also a platform for the participants to discuss their experiences after participating in these activities. Next, I conducted follow-up interviews with selected participants to generate further data about their participation in extracurricular activities. I also explored the motivation and interest that lay behind their continued interest in participating in these activities. 


\subsection{Review of the findings}

My first research question was "how does students' cultural capital shape their perceptions of university education in Malaysia?". I found that my participants' perceptions were mainly influenced by social and environmental factors. Their definition of society included the environment, their teachers, the school system and future employers. They believed that the advice and support of members of their social networks helped them to gain an understanding of the importance of education in advancing their future careers. They also acknowledged that a university education gave them the knowledge they needed to cope in society and in the workforce. During the focus group and follow up interview discussions, the participants talked about how a university qualification can be used to gain financial stability and improve their family's quality of life (Chapter Eight). The participants also understood that having a university education allowed them to pursue different avenues, for instance, continuing postgraduate studies or branching out to a different field, in the future. This indicates that the participants were drawing on their cultural capital to make decisions about the activities they should participate in while at university.

Another result from this study concerned the role of parents' educational capital. Parental educational capital has a significant impact in influencing the types of activities the participants chose to engage in at university. This finding suggests parents have considerable influence some of which is overt, for instance by explaining why getting involved in extracurricular activities are important to supplement academic achievement. Some of the parental influence is more tacitly transmitted to their children, for example, enrolling their children in music lessons to provide them with different forms of educational capital.

My second research question explored "how do these perceptions influence the nature of their engagement in university activities?". Using my findings, I developed a table as a basis for explaining how the participants' habitus influenced their goals and desire to participate in community service, clubs and voluntary work (see Table 9.1). Using this table we can observe how individual participants perceived their position within the field and how they navigated their way based on their knowledge of the 'rules of the game' in a field. During the interviews, the participants described their perceptions about community work and the benefits they gained after participating in these activities. The visual data provided by my 
participants (Chapter Seven) shows the types of activities they chose to participate in at university.

One of the most significant findings to emerge from the study was the role of social capital among the Malaysian middle-class families involved in this research. In this study, results revealed that social capital was crucial as an investment strategy for both the participants and their parents (Chapter Seven). The participants understood the importance of having the right connections in order to advance their position in their field (refer to page 132). For example, building working relationships with representatives in the industry (engineers, human resource managers) allowed them to access specific information, such as employment criteria or job vacancies within an organization. The participants drew on resources from their relatives in order to obtain information and make decisions about their future. Participants often approached friends when they needed help especially when it came to learning something new or even sharing the knowledge they had. They were aware of the importance of building social networks as they had to rely on this bond for obtaining information.

Besides that, social capital emerged as an important determinant of participation in community service and club activities. The results of this investigation indicate that social capital was essential for continued participation in community service, club activities and voluntary work. My participants mentioned that they preferred to join in activities if they had other friends who participated as well. They enjoyed helping out more when they had friends involved as they felt this was a way to strengthen the friendship and build bonds with their friends. They also revealed that one of the major benefits they gained from participation in extracurricular studies was the ability to interact with new people and make more friends.

Another contribution of this study is the role of religious capital in promoting volunteerism in the Malaysian context. The presence of religious capital within a family has a significant impact on the desire to participate in community service and voluntary activities. Although the participants may not be completely aware that they are engaging in any sort of community service or voluntary activities, their interest was formed when they engaged in 
activities organized by the religious clubs at the university and the religious institutions (for example. mosque, temple or churches). This socialisation process indirectly influenced their perceptions and desire to help out in the local community.

Besides the role of religious capital, the education institution was also an important site for generating an interest in continued participation. The role of the education institution was vital in creating an environment where students are encouraged to pursue their interests in engaging with civic activities. During the focus group interviews, some of the participants discussed how assessments for the Moral studies and Malaysian studies units gave them the opportunity to reach out to the local community. Some of the degree units for commerce students also contained similar assessments. Indirectly these assignments created an interest in helping out, but faculty members have to be cautious to ensure that they do not promote deficit thinking among students.

The final research question addressed the issue of "in what ways do these perceptions change during the course of their studies?". My results show that the participants experienced a change in perception after participating in community service, clubs and voluntary work. In some cases, the participants revealed that they were more grateful and appreciative of their life after participating in some of the activities. They realized that they were in a position of privilege compared with others in the local community. This made them more determined to help out in future activities organized by the clubs and religious institutions. The participants also learnt to be more critical of the events and the causes of the projects. They were also more selective of the activities they chose to participate in.

The rate of participation also changed over time and this was especially apparent among the final-year students in the university. They experienced a shift in priorities the nearer they were to completing their studies. They no longer focused on volunteering but instead started to join more academic-based activities organised by the clubs in the university. Furthermore, they also started to participate in workshops, seminars and conferences that were related to their field of choice at universities. The participants understood the importance of building links with industry representatives to gain knowledge about the 
working world and their field of choice. The visual data shows that the final-year participants focused on joining activities which provided more direct links to the industry, such as site visits organised by the faculty; talks given by engineers or business representatives; and business games organised by student-run clubs.

In conclusion, I found that there were significant links between parental educational capital and students' perceptions of the purpose of university education. However, social capital proved to have a stronger role in determining the participants' rate and level of involvement in university activities. Their interest in continued participation was closely linked to their relationship with peers. In addition, the students' participation in university activities was positively associated with gains in social and educational capitals. The kinds of capital they value also determine what type of activities they engage in at university and also the participation rate in these activities. I argue that the combination of cultural capital and social capital provides a way for students to navigate their way successfully through the education system.

\subsection{Implications of the research}

The findings from my study make several contributions to the current literature. First, my findings give insight into the importance of social capital as a resource used by students to enhance their social position and generate networks of social capital for their benefit. Second, the current findings add to a growing body of literature on social capital and how students make use of their social capital to achieve individual goals. Also, the study provides insight into how students can benefit from participating in various extracurricular activities and how they can exploit their social capital to recruit other volunteers for future events.

Third, current findings also add substantially to our understanding of students' motivations to participate in extracurricular activities in the university environment. Based on the data from this study, several categories of students were identified, each driven by different habituses prior to entering university. The type of capital that the participants accumulate at university also differs in nature based on their dispositions. This finding furthers our knowledge and understanding of student motivation to engage in extracurricular 
activities and acknowledges the importance of these activities in enhancing university experience for the students.

Next, the results of this study explain the link between family practices and religion and how these factors influence students' participation in civic activities. The findings of this study suggest that social capital promotes active volunteering. My study also shows that religious habitus and the role of the religious institutions have significant impact on the desire to volunteer.

Finally, the findings provide new ways of employing Bourdieu's theory of habitus and capital in higher education studies. Employing Bourdieu's theory to analyse the Malaysian higher education system has several merits. First, the results obtained in this study permit Bourdieu's theories to be viewed through a different cultural lens. Employing Bourdieu's theory of capital, I was able to identify how cultural capital works in an Asian context particularly in relation to the Malaysian higher education system. For example in Malaysia, there is a vast literature problematising inequalities in education especially between rural and urban areas but none of the research identifies how cultural capital plays a part in perpetuating these inequalities. In addition, the findings also add to the growing body of literature on the different kinds of capital and their value to individuals and families in an Asian context. Bourdieu's concept of capitals allowed me to identify the different types of capitals valued among Malaysian students and how the students make use of the different types of capital to engage in higher education. Second, Bourdieu's theory of field helps to explain how culture functions as a field of struggle among the different ethnic groups in Malaysia. It also provides an explanation for the perceptions students have of education and how the students devise strategies to obtain distinction in the field of higher education. Third, by utilizing Bourdieu's idea of habitus I was able to derive a link between students' practice and agency, and also what drives their engagement in extracurricular activities while at university. 


\subsection{Research limitations}

The first limitation in this study relates to the questions I asked in the survey. I was attempting to ascertain if Bourdieu's cultural capital theory applies to the Malaysian context. However, the items in the questionnaire were not designed to directly investigate Malaysian cultural capital. Because of this I was unable to identify specifically what constitutes Malaysian middle-class cultural capital. This may have a bearing on the results of the study especially in reference to their beliefs about what constitutes highbrow culture or the reasons why they do not socialise their children in highbrow cultural practices. For example, I could have asked the students if their parents kept paintings or art from Chinese painters or literary figures or if their parents possessed Chinese classical literature. Perhaps this would have provided more accurate answers about the Malaysian cultural capital in objectified form.

A further limitation concerns the results of the data collected. As the participants were all individuals who were/are actively involved in community work, clubs and voluntary activities, I am aware that the results cannot be extrapolated to fit the entire population. This might affect the results of the study, but nevertheless it highlights the importance of understanding the value these individuals place on community work and voluntary activities. It also gives insight into their educational decision-making processes and the types of learning activities they value while studying at university.

Another limitation is that this research does not track the participants' community service, clubs and voluntary experiences from a longitudinal perspective, which would track their progress from their foundation to degree years. Rather, this cross-sectional study examines the perspectives of two different groups of students. Findings from a longitudinal study would reveal further information about how students' perceptions are shaped or altered by their experiences of university activities. Furthermore, conducting a longitudinal study might reveal if these experiences did indeed have an impact on their career opportunities after graduation. 
Using Facebook as a method to gather data also has limitations as the participants could influence each other's interpretation or question the suitability of the photographs they uploaded, although equally, this may also be seen as strength of the study. One example of this was the comments made by one participant whose friend uploaded photographs of the food she had cooked while living away from home. She immediately questioned me if this was allowed and indicated that she, too, would like to upload photographs of food. However, some comments provided were very useful, as participants would remind their friends that including images of faces was a breach of ethics. They would then give useful suggestions about how to edit the pictures before re-uploading them. In some cases their friend's responses also reinforced the explanation given by a participant and either echoed the view or added their feelings about the activity, which was a valuable source of feedback.

In addition, the content of the photographs were also largely dependent upon the participants' interest levels and commitment to the project. Those who were more involved were producing a lot of valuable images for the research. The same set of students were influenced by the nature of the project and, to some, it showed how much they knew and cared about community work and voluntary activities. As a result some of the participants' voices were also more frequently used in the study as they were more involved and engaged in the project compared with their peers. Although I was still able to gather a substantial amount of data from the participants, the participants who were more involved generated a lot of important images, which they continued to upload after they had finished their semester. This also created a constraint as far as data analysis was concerned as I had to limit the number of images that could be used for the research, as it was impossible to work with such a huge volume of data. This could have implications for the data analysis as participants had to select the activities they felt were most beneficial or meaningful for them. This resulted in the loss of other data that could prove useful for this research. 


\subsection{Recommendation for further research}

It is recommended that further research be undertaken in the following areas: first, it is worthwhile to find out whether cultural capital or social capital are more important in maintaining the status quo for middle-class families in Malaysia. It would be interesting to explore how the Malaysian families generate or distribute social capital to advance their social status. This would contribute to the existing literature on social capital by examining Bourdieu's framework in a non-Western context. Further investigations in this area could be done to specifically examine how cultural, social and educational capital informs young people's decisions to participate in civic activities. Further research in this area in the Malaysian context would increase our knowledge about how social capital can be exploited to gain educational and economic resources. It is also worth studying whether families from different socioeconomic backgrounds employ similar strategies to advance their child's position within a field in the Malaysian context.

In addition, further studies on the cultural capital of Malaysian students and how their cultural capital shapes their perception of the purpose of university education are also warranted. Investigations in this area may reveal fascinating insight in order to better understand the importance of cultural capital in motivating students to engage in university activities. Future research into the importance of cultural capital and how this capital is used by families in Asian contexts would assist in the understanding of how it is accumulated and exploited, especially when it concerns attainment and success in the education system.

It is recommended that research be conducted to investigate whether there are differences between students' perceptions of, and their engagement in, university activities in other higher education institutions (HEIs) in Malaysia. It would be interesting to see how families from different socioeconomic or ethnic backgrounds perceive the role of education and the types of activities they choose to participate in. A similar study conducted in different university settings could provide more information with respect to this issue.

In addition, it would be useful to study and compare the students' perceptions and engagement in community service, clubs and voluntary work in public and private HEIs. This 
would add significantly to the understanding of cultural and social capital, and how it affects students studying in different institutions. It would be worth investigating the patterns of participation in civic activities especially in the Asian context as there are limited studies done which focus on this area of research. Further studies on this issue might provide information for educators and policy makers when designing the curriculum for university students.

Finally, the evidence found in this study indicates that further research on the patterns of participation in extracurricular activities could continue to add breadth and understanding on three areas of research: a) the connection between an individual's habitus, capital and their engagement in civic activities; b) how to engage students more in university activities and c) how to retain commitment among the students to continue with their service.

\subsection{Concluding statement}

This study has presented a contextualized view of cultural capital, habitus and social capital in relation to students' engagement in university activities in the Malaysian context of higher education. The data collected in this study comprised of students' voices, grounded in their personal narratives about how they perceive the role of education as a tool to facilitate career trajectories and how this belief then shapes their decision to engage in extracurricular activities within the university setting.

Parental educational capital is important in shaping students' perceptions about the importance of education. Also, as mentioned in Chapter Seven, parental educational capital may be useful to provide advice on what types of activities students should participate in, so that they can supplement their educational qualifications with the relevant skills required in the workforce. This study contributes to the growing body of literature on Asian students' cultural capital and educational outcomes and also provides insight into how Malaysian middle-class families draw on their cultural and social capital to create greater opportunities for their children's educational success. The findings support Bourdieu's (1977) view that cultural capital is an important resource that individuals draw from in order to maintain their position

within a society. Indeed, the findings in this study show that middle-class families are struggling to maintain their dominance in society, as they are no longer able to rely on their dominance as 
members of the upper classes to gain exclusive access to the educational institutions. Thus, they devise new strategies to create a path for their children to gain entry into well-paid, professional employment by supplementing educational qualification with relevant extracurricular experiences.

In addition, the findings also reveal that social capital is important for the students for two reasons: first, to obtain information from relatives, and also to gain knowledge and skills, which they require to perform well academically and non-academically in university. Second, social capital is important for the students, as this type of capital is a useful form of recruitment especially for future activities. Social capital is also crucial in sustaining interest in committing to clubs or voluntary organizations. This indicates the value of social relationships in facilitating student engagement in university. Taken together, the findings indicate that both cultural capital and social capital are important resources used by the students and their family members to achieve their goals in obtaining educational success. This thesis provides insight into student engagement, particularly in community service and voluntary activities in a private university in East Malaysia. These insights will have implications for educational practices especially when dealing with students' motivations and participation in university activities. By understanding what drives students' interest, both faculty and staff members can enhance student engagement in university life, which in turn provides greater gains beyond what can be taught in the classroom. 



\section{REFERENCES}

Abang Abdullah, A. A., Mohd. Ali, B., \& Mokhtar, A. (1994). Engineering education in rapidly industrialising Malaysia. Engineering, Science and Education Journal, 3(6), 291-296.

Abdul Aziz, R. (2012). New economic policy and the Malaysian multi-ethnic middle class. Asian Ethnicity, 13(1), 29-46.

Abdul Karim, N. S., \& Hasan, A. (2007). Reading habits and attitude in the digital age: Analysis of gender and academic program differences in Malaysia. The Electronic Library, 25(3), 285-298.

Aihara, A. (2009). Paradoxes of higher education reforms: Implications on the Malaysian middle class. IJAPS, 5(1), 81-113.

Albrecht, C. M. \& Albrecht, D. E. (2010). Social status, adolescent behaviour and educational attainment. Sociological Spectrum: Mid-South Sociological Association, 31(1), 114-137.

Andolina, M. W., Jenkins, K., Zukin, C., \& Keeter, S. (2003). Habits from home, lessons from school: Influences on youth civic engagement. Political Science and Politics,_36, 275-280.

Aronowitz, S. (2000). The knowledge factory: Dismantling the corporate university and creating true higher learning. Boston: Beacon Press.

Ary, D., Jacobs, L. C., Asghar, R., \& Chris, S. (2006). Introduction to research in education. Belmont, USA: Thomson Wadsworth.

Aschaffenburg, K., \& Maas, I. (1997). Cultural and educational careers: The dynamics of social reproduction. American Sociological Review, 62(4), 573-587.

Astin, A. W. (1977). Four critical years: Effects of college on beliefs, attitudes and knowledge. San Francisco: Jossey-Bass Publishers.

Astin, A. W., \& Sax, L. J. (1998). How undergraduates are affected by service participation. The Review of Higher Education, 21(2), 187-202.

Atkinson, W. (2011). From sociological fictions to social fictions: Some Bourdieusian reflections on the concepts of 'institutional habitus' and 'family habitus'. British Journal of Sociology of Education, 32(3), 331-347.

Atkinson, W. (2013). Some further (orthodox?) Bourdieusian reflections on the notions of 'institutional habitus' and 'family habitus': A reply to Burke, Emmerich, and Ingram. British Journal of Sociology of Education, 34(2), 183-189. 
Baker, D., \& Stevenson, D. (1986). Mother's strategies for children's school achievement. Sociology of Education, 59 (93), 156-166.

Baltar, F., \& Brunet, I. (2012). Social research 2.0: Virtual snowball sampling method using Facebook. Internet Research, 22(1), 57-74.

Banks, M. (2001). Visual methods in social research. London: Sage Publications.

Barbour, R. S. (2007). Doing focus groups. London: SAGE Publications.

Barker, D. P., \& Stevenson, D. L. (1986). Mother's strategies for children's school achievement: Managing the transition to high school. Sociology of Education, 59(3), 156-166.

Berg, B. L. (2004). Qualitative research methods for the social sciences. Boston: Pearson.

Berger, J. B., \& Milem, J. F. (2002). The impact of community service involvement on three measures of undergraduate self-concept. NASPA Journal, 40(1), 85-103.

Bourdieu, P. (1971). Systems of education and systems of thought. In M. K. D. Young (Ed.), Knowledge and control: New directions for sociology of education (pp. 189-207). London: Collier Macmillan.

Bourdieu, P. (1977). Cultural reproduction and social reproduction. In J. Karabel \& A. H. Halsey (Eds.), Power and ideology in education (pp. 487-511). New York: Oxford University Press.

Bourdieu, P. (1983). The field of cultural production, or: The economic world reversed. Poetics, 12(4), 311-356.

Bourdieu, P. (1984). Distinction: A social critique of the judgement of taste. London: Routledge \& Kegan Paul.

Bourdieu, P. (1986). The forms of capital. In J. G. Richardson (Ed.), Handbook of theory and research for the sociology of education (pp. 241-258). New York: Greenwood Press.

Bourdieu, P. (1990). The logic of practice. Stanford, CA: Stanford University Press.

Bourdieu, P., \& Passeron, J. C. (1977). Reproduction in education, society and culture. London: Sage Publications. 
Brickman-Bhutta, C. (2011). Not by the book: Facebook as sampling frame. Retrieved from http://www.thearda.com/workingpapers/download/Not\%20by\%20the\%20Book\%20\%20Bhutta.pdf.

Broh, B. A. (2002). Linking extracurricular programming to academic achievement: Who benefits and why? Sociology of Education, 75(1), 69-95.

Brooks, R. (2003). Young people's higher education choices: The role of family and friends. British Journal of Sociology of Education, 24(3), 283-297.

Brooks, R. (2007). Young people's extra-curricular activities: Critical social engagement. Journal of Social Policy, 36(3), 417-434.

Brooks, R., \& Everrett, G. (2009). Post-graduation reflections on the value of a degree. British Educational Research Journal, 35(3), 333-349.

Brooks, R., \& Waters, J. (2009). International higher education and the mobility of UK students. Journal of Research in International Education, 8(2), 191-209.

Brooks, R., \& Waters, J. (2010). Social networks and educational mobility: The experiences of UK students. Globalisation, Societies and Education, 8(1), 143-157.

Bryman, A. (2008). Social research methods. Oxford: Oxford University Press.

Burke, C. T., Emmerich, N., Ingram, N. (2012). Well founded social fictions: A defense of the concepts of institutional and familial habitus. British Journal of Sociology of Education, $34(2), 165-182$.

Burns, R. B. (2000). Introduction to research methods. London: SAGE Publications.

Butin, D. W. (2003). Of what use is it? Multiple conceptualizations of service learning within education. Teacher's College Record, 105(9), 1674-1692.

Byun, S. Y., Schofer, E., \& Kim, K. K. (2012). Revisiting the role of cultural capital in East Asian educational systems: The case of South Korea. Sociology of Education, 1-21.

Caputo, R. (2009). Religious capital and intergenerational transmission of volunteering as correlates of civic engagement. Non-profit and Voluntary Sector Quarterly, 38(6), 9831002.

Chang, P. F. (1999). Legends and history of Sarawak. Kuching: Lee Ming Press Co. 
Chaplin, E. (2004). My visual diary. In C. Knowles \& P. Sweetman (Eds.), Picturing the social landscape: Visual methods and the sociological imagination (pp. 35-48). London: Routledge.

Chow, S., \& Ho, M. (2007). The impact of filial piety and parental involvement on academic achievement motivation in Chinese secondary school students. Asian Journal of Counselling, 14(1), 91-124.

Clary, G. E., \& Synder, M. (1999). The motivations to volunteer: Theoretical and practical considerations. Current Directions in Psychological Science, 8(5), 156-159.

Clegg, S. (2011). Cultural capital and agency: Connecting critique and curriculum in higher education. British Journal of Sociology of Education, 32(1), 93-108.

Cohen, L., Manion, L., \& Morrison, K. (2007). Research methods in education. New York: Routledge.

Coleman, J. S. (1990). Foundations of social theory. Cambridge, Harvard University Press.

Coleman, J. S. (1998). Social capital in the creation of human capital. The American Journal of Sociology, 94, 95-210.

Collier, J. J. (1967). Visual anthropology: Photography as a research method. New York: Holt, Rhinehart and Winston.

Collier, M. (2001). Approaches to analysis in visual anthropology. In T. van Leeuwen, \& C. Jewitt (Eds.), Handbook of visual analysis (pp. 35-60). London: Sage.

Covay, E., \& Carbonaro, W. (2010). After the bell: Participation in extracurricular activities, classroom behaviour and academic achievement. Sociology of Education, 83(1), 20-45.

Creswell, J. W. (2003). Research design: Qualitative, quantitative and mixed method approaches. Thousand Oaks, California: Sage Publications.

Creswell, J. W. (2009). Research design: Qualitative, quantitative and mixed methods approach. ( $2^{\text {nd }}$ ed.)Thousand Oaks, California: SAGE Publications.

Creswell, J. W., \& Miller, D. L. (2010). Determining validity in qualitative inquiry. Theory into Practice, 39(3), 124-130.

Creswell, J. W., \& Plano- Clark, V. P. (2007). Designing and conducting mixed methods research. Thousand Oaks, California: Sage Publications. 
Croll, P. (2004). Families, social capital and educational outcomes. British Journal of Educational Studies , 52(4), 390-416.

Crozier, G., D. Reay, Clayton, J., Colliander, L., \& Grinstead, J. (2008). Different strokes for different folks: Diverse students in diverse institutions- experiences of higher education. Research Papers in Education, 23(2), 167-177.

Dalton, J. C., \& Petrie, A. M. (1997). The power of peer culture. The Educational Record, 78: 18-24.

De Graaf, N. D., De Graaf, P. M., \& Kraaykamp, G. (2000). Parental cultural capital and educational attainment in the Netherlands: A refinement of the cultural capital perspective. Sociology of Education, 73(2), 92-111.

De Graaf, P. M. (1986). The impact of financial and cultural resources on educational attainment in the Netherlands. Sociology of Education, 59(4), 237-246.

Denzin, N. K., \& Lincoln, Y. S. (2000). Introduction: The discipline and practice of Qualitative research. In N. K. Denzin \& Y. S. Lincoln. (Eds.), Strategies of Qualitative Inquiry (pp. 143). Thousand Oaks: California, Sage Publications.

Department of Statistics. (2010). Population distribution and basic demographic characteristics. Malaysia. Retrieved from http://www.statistics.gov.my/mycensus2010/images/stories/files/Taburan Penduduk dan Ciri-ciri Asas Demografi.pdf

Dika, S. L., \& Singh, K. (2002). Applications of social capital in educational literature: A critical synthesis. Review of Educational Research, 72(1), 31-60.

DiMaggio, P. (1979). On Pierre Bourdieu. American Journal of Sociology, 84(6), 1460-1474.

DiMaggio, P. (1982). Cultural capital and school success: The impact of status culture participation on the grades of high school students. American Sociological Review, 47(2), 189-201.

DiMaggio, P., \& Mohr, J. (1985). Cultural capital, educational attainment, and marital selection. American Journal of Sociology, 90(6), 1231-1261.

Dumais, S. A. (2002). Cultural capital, gender, and school success: The role of habitus. Sociology of Education, 75(1), 44-68.

Eccles, J. S. (1993). School and family effects on the ontogeny of children's interests, selfperceptions, and activity choice. In J. Jacobs (Ed.), Nebraska Symposium on Motivation: Vol. 40. Developmental perspectives on motivation (pp. 145-208). Lincoln: University of Nebraska Press. 
Egerton, M. (2002). Higher education and civic engagement. British Journal of Sociology, 53(4), 603-620.

Ellison, B. N., Steinfield, C., \& Lempe, C. (2007). The benefits of Facebook "friends": Social capital and college students' use of online social network sites. Journal of Computer-Mediated Communication, 12, 1143-1168.

Furstenberg, F. F. (2005). Banking on families: How families generate and distribute social capital. Journal of Marriage and Family, 67(4), 809-821.

Gilham, B. (2000). Case study research methods. London: Continuum.

Glanville, J. L., Sikkink, D., \& Hernandez, E. I. (2008). Religious involvement and educational outcomes: The role of social capital and extracurricular participation. The Sociological Quarterly, 49, 105-137.

Gould, S. B. (1970). Today's Academic Condition. New York: Colgate University Press.

Grant, B. M., \& Giddings, L. S. (2002). Making sense of methodologies: A paradigm framework for the novice researcher. Contemporary Nurse: A Journal for the Australian Nursing Profession, 13(1), 10-28.

Greene, J. C., Caracelli, V. J., \& Graham, W. F. (1989). Towards a conceptual framework for mixedmethod evaluation designs. Educational Evaluation and Policy Analysis, 11(3), 255-274.

Grenfell, M. (2009). Applying Bourdieu's field theory: The case of social capital and education. Education, Knowledge \& Economy, 3(1), 17-24.

Handy, F., Cnaan, R. A., Hustinx, L., Kang, C., Brudney, J. L., Haski-Leventhal, D., Holmes, K., Meijs, L. P. M., Pessi, A. B., Ranade, B., Yamauchi, N., and Zrinscak, S. (2010). A cross-cultural examination of student volunteering: Is it all about résumé building? Nonprofit and Voluntary Sector Quarterly, 39(3), 498-523.

Harker, R. K. (1984). On reproduction, habitus and education. British Journal of Sociology of Education, 5(2), 117-127.

Harker, R., Mahar C., \& Wilks, C. (1990). An introduction to the work of Pierre Bourdieu: The practice of theory. London: Macmillan.

Heckathorn, D. D. (1997). Respondent-driven sampling: A new approach to the study of hidden populations. Social Problems, 44(2), 174-198.

Helliwell, J. F. \& Putnam. R. D. (2007). Education and social capital. Eastern Economic Journal, 33(1), 1-19. 
Hergenrather, K. C., Rhodes S. D., \& Bardhoshi, G. (2009). Photo voice as community based participatory research: A qualitative review. American Journal of Health and Behaviour, 33(6), 686-698.

Hesse-Biber, S. N. (2010). Mixed methods research. New York: The Guilford Press.

Hodkinson, P., \& Sparkes, A. (1997). Careership: A sociological theory of career decision making. British Journal of Sociology of Education, 18(1), 29-44.

Holliday, R. (2004). Reflecting the self. In C. Knowles \& P. Sweetman (Eds.). Picturing the social landscape: Visual methods and the sociological imagination (pp. 49-64). London: Routledge.

Horvart, E. M. \& Antonio, A. L. (1999). Hey, those shoes are out of uniform: African American girls in an elite high school and the importance of habitus. Anthropology and Education Quarterly, 30(3), 317-342.

Hughes, H. \& Woldekidan, B. (1994). The Emergence of the Middle Class in ASEAN Countries. ASEAN Economic Bulletin, 11(2), 139-149.

Ingram, N. (2009). Working class boys, educational success and the misrecognition of working class culture. British Journal of Sociology of Education, 30(4), 421-434.

Jæger, M. M. (2009). Equal access but unequal outcomes: cultural capital and educational choice in a meritocratic society. Social Forces, 87(4), 1943-1971.

Jaeger, M. M. (2011). Does cultural capital really affect academic achievement? New evidence from combined sibling and panel data. Sociology of Education, 84(4), 281-298.

Jefferess, D. (2008). Global citizenship and the cultural politics of benevolence. Critical Literacy, 6(1), 27-36.

Jelani, J., \& Tan, K. G. (2012). Determinants of participation and expenditure patterns of private tuition received by primary school students in Penang, Malaysia: An exploratory study. Asia Pacific Journal of Education, 32(1), 35-51.

Johnson, B., \& Christensen, L. (2008). Educational research: Quantitative, qualitative and mixed approaches. Thousand Oaks, California: Sage Publications.

Johnson, R. B., \& Onwuegbuzie, A. J. (2004). Mixed methods research: A research paradigm whose time has come. American Educational Research Association, 33(7), 14-26.

Johnson, R. B., Onwuegbuzie, A. J., \& Turner, L. A. (2007). Towards a definition of mixed methods research. Journal of Mixed Methods Research, 1(112), 112-133. 
Jones, S. R., \& Hill, K. E. (2003). Understanding patterns of commitment: Student motivation for commnity service involvement. The Journal of Higher Education, 74(5),16-539.

Joonmo, S. \& N. Lin (2008). Social capital and civic action: A network based approach. Social Science Research, 37, 330-349.

Joseph, C. (2008). Ethnicities and education in Malaysia: Difference, inclusions and exclusions. In G. Wan (Ed.), The education of diverse student populations: A global perspective (pp. 183208). DOI: $10.1007 / 978-1-4020-8204-7 \_10$

Kalmijn, M., \& Kraaykamp, G. (1996). Race, cultural capital and schooling: An analysis of trends in the United States. Sociology of Education, 69, 22-34.

Kamogawa, A. (2003). Higher education reform: Challenges towards a knowledge society in Malaysia. African and Asian Studies, 2(4), 546-563.

Katsillis, J., \& Rubinson, R. (1990). Cultural capital, student achievement, and educational reproduction: The case of Greece. American Sociological Review, 55(2), 270-279.

Kaufman, J., \& Gabler, J. (2004). Cultural capital and the extracurricular activities of girls and boys in the college attainment process. Poetics, 32(2), 145-168.

Kok, J. K., \& Tan, J. H. (2011). Will I get a job after graduation? International Journal of Social Science and Humanity, 1(3), 160-166.

Kok, J. K., Cheah, P. K., \& Ang, S. M. (2011). The role of the university: Malaysian students' perceptions. IPEDR, 5, 94-98.

Kok, J., K., \& Cheah, P.K. (2011). The role of the university in fulfilling individual needs and promoting a better society. International Journal of Social Science and Humanity, 1(1), 711.

Lamont, M., \& Lareau, A. (1988). Cultural capital: Allusions, gaps and glissandos in recent theoretical developments. Sociological Theory, 6(2), 153-168.

Lareau, A. (1987). Social class differences in family-school relationships: The importance of cultural capital. Sociology of Education. 60, 73-85.

Lareau, A. (1989). Home advantage: Social class and paternal intervention in elementary education. New York: Falmer Press.

Lareau, A., \& Weininger, E. B. (2003). Cultural capital in educational research: A critical assessment. Theory and Society, 32, 567-606. 
Lee, H. G. (2006). Globalisation and ethnic integration in Malaysia. In S. S. Hock \& K. Kesavapany (Eds.), Malaysia: Recent trends and challenges (pp. 230-259). Singapore: Institute of Southeast Asian Studies.

Lee, M. N. N. (1999). Education in Malaysia: Towards Vision 2020. School Effectiveness and School Improvement, 10(1), 86-98.

Lee, M. N. N. (2004). Global trends, national policies and institutional responses: Restructuring higher education in Malaysia. Educational Research for Policy and Practices, 3(1), 31-46.

Lehmann, W. (2009). University as vocational education: Working class students' expectations for university. British Journal of Sociology of Education, 30(2), 137-149.

Leong, K. Y. (2008). Love it love it not: Parental attitudes regarding children's music learning in Kuala Lumpur. (Undergraduate dissertation, University of Sydney, Sydney, Australia). Retrieved from http://ses.library.usyd.edu.au/bitstream/2123/3993/1/Leong\%202008.pdf

Lewis, K., Kaufman, J., \& Gonzales, M., Wimmer, A., \& Christakis, N. (2008). Tastes, ties and time: A new social network dataset using Facebook.com. Social Networks, 30, 330-342.

Lichterman, P. (2008). Religion and the construction of civic identity. American Sociological Review, 78, 83-104.

Light, B., \& McGrath, K. (2010). Ethics and social networking sites: A disclosive analysis on Facebook. Information, Technology and People, 23(4), 290-311.

Lim, K. H. \& Wai, H. M. (2008). The end of academia?: From cogito ergo sum to consumo ergo sum. International Education Studies, 1(2), 32-40.

Lin, N. (1999). Building a network theory of social capital. Connections, 22(1), 28-51.

Lister, M., \& Wells, L. (2001). Seeing beyond belief: Cultural studies as an approach to analysing the visual. In T. van Leeuwen, \& C. Jewitt (Eds), Handbook of visual analysis (pp. 61-89). London: Sage Publications.

Majoribanks, K. (2002). Family background, individual and environmental influences on adolescents' aspirations. Educational Studies, 28(1), 33-46. 
Majoribanks, K. (2003). The family and schooling in Asian and Pacific countries. In J. P. Keeves and R. Watanabe (Eds.), The International Handbook of Educational Research in the AsiaPacific Region (pp. 43-56). Netherlands: Kluwer Academic Publishers.

Malaysian National Library (2006). The reading profile of Malaysians 2006. Unpublished research by the Malaysian National Library, Kuala Lumpur.

Malaysians still not reading enough, says Muhyiddin. (2009, April 19). The Star. Retrieved from http://thestar.com.my/news/story.asp?file=/2009/4/19/nation/3725792\&sec=nation

Marpsat, M., \& Razafindratsima, N. (2010). Survey methods for hard-to reach populations: Introduction to the special issue. Methodological Innovations Online, 5(2), 3-16.

Mason, J. (2002). Qualitative researching. London: Sage Publications.

Maton, K. (2008). Habitus. In M. Grenfell (Ed.), Pierre Bourdieu: Key concepts (pp. 49-65). Durham: Acumen.

Matthijs, K., \& Kraaykamp, G. (1996). Race, cultural capital and schooling: An analysis of trends in the United States. Sociology of Education, 69(1), 22-34.

Mayor's visit strengthens ties with Malaysian alumni. (2002). NZC News. Retrieved from http://www.nzcentre.biz/news/2002/h2/oct/oct-15.htm

McDonough, P. M., \& Antonio, A. L. (1996, April). Ethnic and racial differences in selectivity of college choice. Paper presented at the Annual Meeting of the American Educational Research Association, New York, NY.

McDonough, P., Antonio, A., \& Horvat, E. (1996, August). College choice as capital conversion and investment. Paper presented at the Annual Meeting of the American Sociological Association, New York, NY.

McFarland, D. A. \& Thomas, R. J. (2006). Bowling young: How youth voluntary associations influence adult political participation. American Sociological Review, 71, 401-425.

McNeal, R. B. (1999). Parental involvement as social capital: Differential effectiveness on science achievement, truancy and dropping out. Social Forces. 78(1), 1137-1164.

Md. Sidin, S., Hussin, S. R., \& Tan, H. S. (2003). An exploratory study of factors influencing the college choice decision of undergraduate students in Malaysia. Asia Pacific Management Review, 8(3), 259-280.

Merriam, S. B. (2002). Introduction to qualitative research. San Francisco: Jossey-Bass. 
Ministry of Higher Education. (2010) National Higher Education Action Plan 2007-2010. Retrieved from http://www.mohe.gov.my/educationmsia/index.php

Mitchell, C. (2008). Getting the picture and changing the picture: Visual methodologies and educational research in South Africa. South African Journal of Education, 28, 365-383.

Morrow, V. (2001). Young people's explanations and experiences of social exclusion: Retrieving Bourdieu's concept of social capital. International Journal of Sociology and Social Policy, 21(4), 37-63.

Morse, J. M., \& Niehaus, L. (2009). Mixed method design. California: Left Coast Press.

Moss, G. (2005). Cultural capital and graduate student achievement: A preliminary quantitative investigation. Electronic Journal of Sociology. Retrieved from http://www.sociology.org/content/2005/tier1/moss.html

Nash, R. (1990). Bourdieu on education and social and cultural reproduction. Journal of Sociology of Education, 11(4). 431-447.

Noble, J., \& Davies, P. (2009). Cultural capital as an explanation of variation in participation in higher education. British Journal of Sociology of Education, 30(5), 591-605.

Nora, A. (2004). The role of habitus and cultural capital in choosing a college, transitioning from high school to higher education, and persisting in college among minority and nonminority students. Journal of Hispanic Higher Education, 3(2), 180-208.

O'Donoghue, T. (1996). Malaysian Chinese students' perceptions of what is necessary for their academic success in Australia. Journal of Further and Higher Education, 20(2), 67-80.

Pandian, A. (1997). Literacy in postcolonial Malaysia. Journal of Adolescent \& Adult Literacy, $40(5), 402-404$.

Pandian, A. (2000, July). A study on readership behaviour among multi-ethnic, multi-lingual Malaysian students'. Paper presented at the $7^{\text {th }}$ International Literacy and Education Research Network (LERN) Conference on Learning, RMIT University, Melbourne. Retrieved from http://.ultibase.rmit.edu.au/Articles/aug01/pandian1.htm

Penrod, J., Preston, D. B., Cain, R. E. \& Starks, M. T. (2003). A discussion of chain referral as a method of sampling hard-to-reach populations. Journal of Transcultural Nursing, 14(2), 100-107.

Pink, S. (2003). Interdisciplinary agendas in visual research: Re-situating visual anthropology. Visual Studies, 18(2), 179-192. 
Pink, S. (2007). Doing visual ethnography. London, Sage Publications.

Pong, S. (1995). Access to education in Peninsular Malaysia: Ethnicity, social class and gender. Compare: A Journal of Comparative Education, 25(3), 239-252.

Pong, S. L., Hao, L., \& Gardner, E. (2005). The roles of parenting styles and social capital in the school performance of immigrant Asian and Hispanic adolescents. Social Science Quarterly, 86(4), 929-950.

Porritt, V. L. (1997). British colonial rule in Sarawak, 1946-1963. Kuala Lumpur: Oxford University Press.

Portes, A. (1998). Social capital: Its origins and applications in modern sociology. Annual Review of Sociology, 24, 1-24.

Putnam, R. D. (1993). The prosperous community: Social capital and community life. American. Prospect 13,35-42.

Pyvis, D., \& Chapman, A. (2007). Why university students choose an international education: A case study in Malaysia. International Journal of Educational Development, 27, 235-246.

Raslan, K. (2012). Continuing the tradition of mission schools. The Star Online. Retrieved from http://thestar.com.my/columnists/story.asp?file=/2012/4/3/columnists/ceritalah/11 $\underline{035175 \& \mathrm{sec}=\text { ceritalah }}$

Ream, R. K. \& Rumberger, R. W. (2008). Student engagement, peer social capital and school dropout among Mexican American and Non-Latino white students. Sociology of Education, 81(2), 109-139.

Reay, D. (1998). 'Always knowing' and 'never being sure': Familial and institutional habituses and higher education choice. Journal of Education Policy, 13(4), 519-529.

Reay, D. (2004). 'It's all becoming a habitus': Beyond the habitual use of habitus in educational research. British Journal of Sociology of Education, 25(4), 431-444.

Reay, D., David, M. E., \& Ball, S. (2005). Degrees of choice: Social class, race and gender in higher education. Staffordshire: Trentham Books.

Reay, D., Davies, J., David, M., \& Ball, M. (2001). Choices of degree or degrees of choice? Class, 'race' and the higher education choice process. Sociology of Education, 35(4), 855-874.

Robbins, D. (2005). The origins, early development and status of Bourdieu's concept of 'cultural capital'. The British Journal of Sociology, 56(1), 13-30. 
Rose, G. (2000). Practising photography: An archive, a study, some photographs and a researcher. Journal of Historical Geography, 26(4), 555-571.

Ryan, M. (2011). Productions of space: Civic participation of young people at university. British Educational Research Journal, 37(6), 1015-1031.

Ryan, R. L., Kaplan, R., \& Grese, R. (2001). Predicting volunteer commitment in environmental stewardship programmes. Journal of Environmental Planning and Management, 44(5), 629-648.

Saha, L. J. (2003). Cultural and social capital in Asian and Pacific countries. In J. P. Keeves \& R. Watanabe (Eds.), International Handbook of Educational research in the Asia-Pacific region (pp. 59-72). Dordrecht: Kluwer Academic Publishers.

Salganik, M. J., \& Heckathorn, D. D. (2004). Sampling and estimation in hidden populations using respondent driven sampling. Sociological Methodology, 34(1), 193-239.

Sato, M. (2005). Higher education reforms in Malaysia 1957-2003. NUCB Journal of Language Culture and Communication, 7(1), 73-88.

Saunders, G. E. (1971). Education in Sarawak. In E. L. French (Ed.), Melbourne studies in education. (pp. 44-88).Carlton, Melbourne University Press.

Sax, L. J. (2004). Citizenship development and the American college student. New Directions for Institutional Research, 122, 65-80.

Selvaratnam, V. (1988). Ethnicity, inequality, and higher education in Malaysia. Comparative Education Review, 32(2), 173-196.

Selwyn, N. (2009). Faceworking: Exploring students' education-related use of Facebook. Learning, Media and Technology, 34(2), 157-174.

Serow, R. C., \& Dreyden, J. I. (1990). Community service among college and university students: Individual and institutional relationships. Adolescence, 25(99), 553-566.

Shahabudin, S. H. (2007). Community service programmes in Universiti Kebangsaan Malaysia. 11th UNESCO-APEID Conference. Bangkok, Thailand: 1-7.

Sharom, A. (1980). Nation building and the university in developing countries: The case of Malaysia. Higher Education, 9(6), 721-741.

Shuker, L. (2012). 'It'll look good on your personal statement': Self marketing amongst university applicants in the United Kingdom. British Journal of Sociology, 1-20. DOI:10.1080/01425692.2012.740804

Sin, I. L. (2009). The aspiration for social distinction: Malaysian students in a British university. Studies in Higher Education, 34(3), 285-299. 
Singh, H. (2010). Ethnic conflict in Malaysia revisited. Commonwealth \& Comparative Politics, $39(1), 42-65$.

Singh, J. H., \& Mukherjee, H. (1993). Education and national integration in Malaysia: Stocktaking thirty years after independence. International Journal of Educational Development, 13(2), 89-102.

Singh, J. K. N., Schapper, J., \& Mayson, S. (2010). The impact of economic policy on reshaping higher education in Malaysia. Research and Development in Higher Education: Reshaping Higher Education, 33, 585-595.

Sirat, M. (2010). Strategic planning directions of Malaysia's higher education: University autonomy in the midst of political uncertainties. Higher Education, 59(4), 461-473.

Sivalingam, G. (2006). Privatization of higher education in Malaysia. Retrieved from http://forumonpublicpolicy.com/archive07/sivalingam.pdf.

Smith, P. (2001). Cultural theory: An introduction. Massachusetts: Blackwell Publishers.

Stake, R. E. (2008). Qualitative case studies. In N. K. Denzin \& Y. S. Lincoln (Eds.), Strategies of qualitative inquiry (pp. 119-149). Thousand Oaks, California: Sage Publications.

Stanton-Salazar, R. (2004). Social capital among working-class minority students. In M. A. Gibson, P. Gandara, \& J. P. Koyama (Eds.), U.S. Mexican youth, peers, and school achievement (pp. 18-37). MA: Teachers College Columbia University.

Stanton-Salazar, R. (2005). Adolescent peer networks as a context for social and emotional support. Youth and Society, 36(4), 379-416.

Stevenson, J., \& Clegg, S. (2011). Possible selves: Students orientating themselves towards the future through extracurricular activity. British Educational Research Journal, 37(2), 231246.

Stewart, D. W., Shamdasani, P. N., \& Rook, D. (2007). Focus groups: Theory and practice. Thousand Oaks, California: Sage Publications.

Strack, R. W., Magill, C., \& McDonagh, K. (2004). Engaging youth through Photovoice. Health Promotion Practice, 5(1), 49-58.

Strathdee, R. (2001). Changes in social capital and school-to-work transitions. Work, Employment \& Society, 15(2), 311-326.

Stuart, M., Lido, C., Morgan, J., Solomon, L., \& May, S. (2011). The impact of engagement with extracurricular activities on the student experience and graduate outcomes for widening participation populations. Active Learning in Higher Education, 12(3), 203-215. 
Sugimura, M. (2007). Universalization of primary education in the context of a multi-ethnic society: The case of Malaysia. Retrieved from http://www.ide.go.jp/Japanese/Publish/Download/Report/pdf/2005 0415 08.pdf.

Sullivan, A. (2001). Cultural capital and educational attainment. Sociology, 35(4), 839-912.

Sullivan, A. (2002). Bourdieu and education: How useful is Bourdieu's theory for researchers? The Netherlands' Journal of Social Sciences. 38(2), 144-166.

Swartz, D. (1997). Culture and power: The sociology of Pierre Bourdieu. London: The University of Chicago Press.

Swartz, D. (2002). The sociology of habit: The perspective of Pierre Bourdieu. The Occupational Therapy Journal of Research, 22, 61S-65S.

Tan, E. L. (2011, September 25). Credits mulled for students who volunteer. The Star Online. Retrieved from http://thestar.com.my/education/story.asp?file=/2011/9/25/education/9509023\&sec =education

The Malaysian Government's Official Portal. (n.d.). Secondary School Education. Retrieved from http://www.malaysia.gov.my/bm/relevant\%20topics/education\%20and\%20learning/ pages/educationmain.aspx

Thomas, L. (2002). Student retention in higher education: The role of institutional habitus. Journal of Education Policy, 17(4), 423-442.

Thomson, P. (2008). Field. In M. Grenfell. (Ed.). Pierre Bourdieu: Key concepts (pp. 67-81). Durham: Acumen Publishing.

Tzanakis, M. (2011). Bourdieu's social reproduction thesis and the role of cultural capital in educational attainment: A critical review of key empirical studies. Educate, 11, 76-90.

U.S. Department of State. (2012). Background note: Malaysia. Retrieved from http://www.state.gov/r/pa/ei/bgn/2777.htm.

Vail, K. (2001). Making schools value intellect. The Education Digest, 66(7), 22-28.

van Eijck, K. (1999). Socialization, education, and lifestyle: How social mobility increases the cultural heterogeneity of status groups. Poetics, 26, 309-328.

van Eijck, K., \& Knulst, W. (2005). No more need for snobbism: Highbrow cultural participation in a taste democracy. European Sociological Review, 21(5),513-528. 
Varsities with best outreach programme to get grants. (2010, December 1). The Star. Retrieved from

http://thestar.com.my/metro/story.asp?sec=nation\&file=/2010/12/1/nation/7533958

Vellymalay, S. K. N. (2011). A study of the relationship between Indians parents' education level and their involvement in their children's education. Kajian Malaysia, 29(2), 47-65.

Vellymalay, S. K. N. (2012). Parental involvement at home: Analyzing the influence of parents' socioeconomic status. Studies in Sociology of Science, 3(1), 1-6.

Villagran, M. (2011). Methodological diversity to reach patients along the margins, in the shadows, and on the cutting edge. Patient Education and Counselling, 82, 292-297.

Vryonides, M. (2007). Social and cultural capital in educational research: Issues of operationalisation and measurement. British Educational Research Journal, 33(6), 867885.

Walpole, M. (2003). Socioeconomic status and college: How SES affects college experiences and outcomes. The Review of Higher Education, 27(1), 45-73.

Wang, C. C. (1999). Photovoice: A participatory action research strategy applied to women's health. Journal of Women's Health, 8(2), 185-192.

Wang, C. C., Cash, J. L., \& Powers, I. S. (2000). Who knows the streets as well as the homeless? Promoting personal and community action through Photovoice. Health Promotion Practice, 1(1), 81-89.

Waters, J. L. (2006). Geographies of cultural capital: Education, international migration and family strategies between Hong Kong and Canada. Transactions of the Institute of British Geographers, 31(2), 179-192.

Waters, J. L. (2008). Education, migration and cultural capital in the Chinese diaspora. New York: Cambria Press.

Waters, J., \& Brooks, R. (2010). Accidental achievers? International education, class reproduction and privilege in the experiences of UK students overseas. British Journal of Sociology of Education, 31(2), 217-228.

Weininger, E. B. (2005). Pierre Bourdieu on social class and symbolic violence. In E. O. Wright, (Ed), Approaches to class analysis (pp. 116-165). Cambridge: Cambridge University Press.

White, A. M., \& Gager, C. T. (2007). Idle hands and empty pockets? Youth involvement in extracurricular activities, social capital and economic status. Youth and Society, 39(1), 75-111.

Wilkinson, D., \& Birmingham, P. (2003). Using research instruments: A guide for researchers. London: Routledge Farmer. 
Wilkinson, R., \& Yussof, I. (2005). Public and private provision of higher education in Malaysia: A comparative analysis. Higher Education, 50, 361-386.

Wollebaek, D., \& Selle, P. (2002). Does participation in voluntary associations contribute to social capital? The impact of intensity, scope, and type. Nonprofit and Voluntary Sector Quarterly, 31(1), 32-61.

World Directory of Minorities and Indigenous Peoples. (2005). Indigenous peoples and ethnic minorities in Sarawak. Retrieved from http://www.minorityrights.org/4540/malaysia/indigenous-peoples-and-ethnicminorities-in-sarawak.html

Wu, Yuxio. (2008). Cultural capital, the state and educational inequality in China, 1949-1996. Sociological Perspectives, 51(1), 201-227.

Wuthnow, R. (2002). Religious involvement and status bridging social capital. Journal for Scientific Study of Religion, 41(4), 669-684.

Yamamoto, Y., \& Brinton, M. C. (2010). Cultural capital in East Asian educational systems: The case of Japan. Sociology of Education, 83(1), 67-83.

Yin, R. K. (2003). Case study research: Design and methods. Thousand Oaks, California: Sage Publications.

Younis, J., McLellan, J. A., \& Yates, M. (1997). What we know about engendering civic identity. The American Behavioural Scientist, 40(5), 620-630.

Zainol Abidin, M. J., Pour-Mohammadi, M., \& Ooi, C. L. (2011). The reading habits of Malaysian Chinese university students. Journal of Studies in Education, 1(1), 1-13. 



\title{
APPENDICES
}

\author{
Appendix A: Research information sheet and consent letter \\ VICTORIA UNIVERSITY OF WELLINGTON \\ Te Whare Wananga o te Upoko o te Ika a Maui

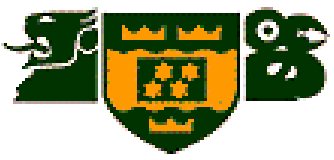

\section{Research Information Sheet}

\section{(To be given to the participants)}

Title of the project: The influence of cultural capital on students' perception of the purpose of university education: A study of student participation in community service, clubs and voluntary activities in a Malaysian university.

Dear

Researcher: Anita Jimmie: School of Education, Victoria University of Wellington

I am a doctoral student at Victoria University of Wellington in New Zealand. As part of this degree I am undertaking a research project leading to a thesis. The project I am undertaking is examining the influence of cultural capital on students' perception of the purpose of university education with emphasis on student participation in community services, clubs and voluntary activities in the university.

I would like to invite you to participate in this study and I highly appreciate your participation and cooperation.

If you agree to participate in this study, you will be asked to answer a questionnaire asking you specific questions on your perceptions of a university education and participation in university activities. You will also be requested to carry out a small Photo Diary project as part of the study. You will need to use your own cameras should you agree to participate in this photo diary project. You will be required to participate in this project for duration of four months (or one semester). You will also be interviewed in a focus group interview together with nine other students. Each interview will last around 1-2 hours and will involve 
discussions and activities in small groups. The interviews will be audio recorded to enable me to transcribe and analyze the data at a later stage in the research.

Participation is voluntary and all research findings reported will be on an anonymous basis and will thus not be associated with the names of participants. Any information that is obtained in connection with this study that can be identified with you will remain confidential to the researcher (and her supervisors). You will not be identified by name in any reports of the completed study. You will be sent a copy of your interview transcripts for verification, review and clarification.

The information from this research will be published in my $\mathrm{PhD}$ thesis and articles I hope to write or present at conferences. However, this will not compromise your privacy and confidentiality of information obtained during the focus group interviews. Your name will not be included in any write-up of the data. You can choose whether to be in this study or not. There is no penalty for not participating or for withdrawing from participating at any stage during the research.

If you are interested to participate in this research, please go through this information sheet carefully before signing the attached consent form. Should you have any queries, please do not hesitate to contact me at +640128900559 or email me at: anita.jimmie@vuw.ac.nz

You can also contact my supervisors, Dr. Joanna Kidman at \oanna.Kidman@vuw.ac.nz or Dr. Kathryn Sutherland at Kathryn.Sutherland@vuw.ac.nz for further information about the project. 


\section{VICTORIA UNIVERSITY OF WELLINGTON \\ Te Whare Wananga o te Upoko o te Ika a Maui}

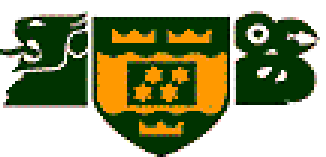

\section{Consent to participate in research:}

\section{Questionnaires}

Title of project: The influence of cultural capital on students' perception of the purpose of university education: A study of student participation in community service, clubs and voluntary activities in a Malaysian university.

I have been given information about this research project and I have understood an explanation of this research project. I have had an opportunity to ask questions

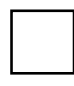
and have them answered to my satisfaction.

I understand that I may withdraw myself (or any information I have provided) from this project (before data collection and analysis is complete) without having to give reasons or without penalty of any sort.

I understand that any information I provide will be kept confidential to the researcher, the supervisor, the published results will not use my name, and that no

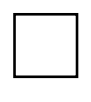
opinions will be attributed to me in any way that will identify me.

I understand that the tape recording of the focus group interviews will be electronically wiped at the end of the project unless my school indicates that it would like it returned.

I would like to receive feedback on the findings of this research.

I have given my consent to be involved in this project.

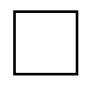

\section{Signed:}

Name of participant:

(please print clearly)

\section{Date:}

OR $\square \quad(\sqrt{ })$ I have emailed my consent to anita.jimmie@ vuw.ac.nz 


\section{VICTORIA UNIVERSITY OF WELLINGTON \\ Te Whare Wananga o te Upoko o te Ika a Maui}

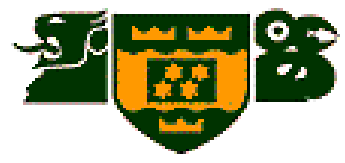

\section{Consent to participate in research:}

\section{Photo Diary Project}

Title of project: The influence of cultural capital on students' perception of the purpose of university education: A study of student participation in community service, clubs and voluntary activities in a Malaysian university.

I have been given information about this research project and I have understood an explanation of this research project. I have had an opportunity to ask questions

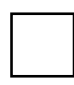
and have them answered to my satisfaction.

I understand that I may withdraw myself (or any information I have provided) from this project (before data collection and analysis is complete) without having to give reasons or without penalty of any sort.

I understand that any information I provide will be kept confidential to the researcher, the supervisor, the published results will not use my name, and that no

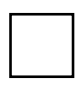
opinions will be attributed to me in any way that will identify me.

I understand that the tape recording of the focus group interviews will be electronically wiped at the end of the project unless my school indicates that it would like it returned.

I would like to receive feedback on the findings of this research.

I have given my consent to be involved in the this project.

Signed:

Name of participant:

(please print clearly)

Date:

OR

( $\sqrt{ })$ I have emailed my consent to anita.jimmie@ vuw.ac.nz 


\section{VICTORIA UNIVERSITY OF WELLINGTON \\ Te Whare Wananga o te Upoko o te Ika a Maui}

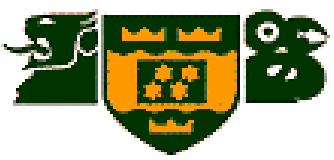

\section{Consent to participate in research:}

\section{Focus Group Interviews}

Title of project: The influence of cultural capital on students' perception of the purpose of university education: A study of student participation in community service, clubs and voluntary activities in a Malaysian university.

I have been given information about this research project and I have understood an explanation of this research project. I have had an opportunity to ask questions

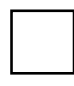
and have them answered to my satisfaction.

I understand that I may withdraw myself (or any information I have provided) from this project (before data collection and analysis is complete) without having to give reasons or without penalty of any sort.

I understand that any information I provide will be kept confidential to the researcher, the supervisor, the published results will not use my name, and that no

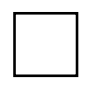
opinions will be attributed to me in any way that will identify me.

I understand that the tape recording of the focus group interviews will be electronically wiped at the end of the project.

I would like to receive feedback on the findings of this research.

I have given my consent to be involved in the this project.
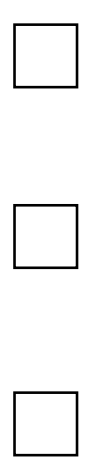


\section{VICTORIA UNIVERSITY OF WELLINGTON}

Te Whare Wananga o te Upoko o te Ika a Maui

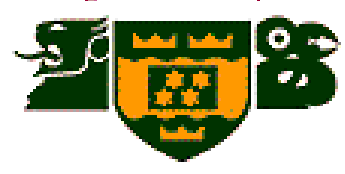

\section{Participants' demographics}

Name

Age

Nationality

Ethnicity

Sex

Year you graduated from high school

Religion

Highest qualification

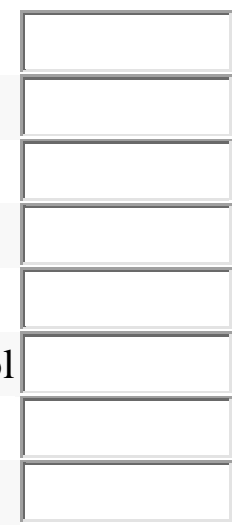

\section{Activities}

How often do you do these activities in your spare time?

\begin{tabular}{ll|l|l|} 
& Often & Sometimes & Rarely \\
Watch popular entertainment & $C$ & &
\end{tabular}


How often do you read books that are not connected to your college work?

Never

Less than Once a Month

Once a Month

2-3 Times a Month

O Once a Week

2-3 Times a Week

C Daily

State the titles and/or authors of any books you have read recently that are not connected with college work

Are you a member of the public library?
C Yes
(C)

\section{Family}

Which adults do you live with? Please select appropriate column
Mother
Father
Stepmother
Stepfather
Others (please specify)

Is your mother (or any other adult female you live with) employed?

Yes
No

Is your father (or any other adult male you live with) employed?
(C) Yes
No

Please provide some information about the jobs that your parents or caregivers do Father

Mother 
What kind of work do they do?

Father

Mother

Do they have their own business? Please select the appropriate answer.

Father Mother

Yes

No

Yes

No

Do they work full time or part time? Please select appropriate answer.

Father

No
Mother

No

What is the highest qualification that each of your parents has (or is studying for)? Please select appropriate answer.

Father (or male caregiver) Mother (or female caregiver)

No qualifications

SPM (Malaysian

Certificate of Education)

STPM (Malaysian

HigherSchoolCertificate)

Diploma

Vocational diploma

Degree

Postgraduate (Masters,

$\mathrm{PhD}$, etc)

Do your parents (adults you live with) get newspapers regularly (at least once a week)?

C Yes

Which newspapers do they get?

Do your parents (the adults you live with) listen to the radio?
C Yes
No

Which of the following have you heard your parents 9adults you live with) discuss? Often SometimesRarely Never

Art

Books

Science

$\begin{array}{cccc}0 & 0 & 0 & 0 \\ 0 & 0 & 0 & 0 \\ 0 & 0 & 0 & 0\end{array}$




\begin{tabular}{|c|c|c|c|}
\hline & Often & \multicolumn{2}{|c|}{ SometimesRarely } \\
\hline Music & $\mathrm{C}$ & $C$ & $\mathrm{C}$ \\
\hline Current affairs & $C$ & $\mathrm{C}$ & 0 \\
\hline Religion & $C$ & $\mathrm{C}$ & $C$ \\
\hline
\end{tabular}

Approximately how many books are in your home? Please select appropriate answer.
$0-25$
C 26-100
C 101-300
C 301-600
601 or more

Do your parents (adults you live with) do any of these activities in their spare time?

Watch popular entertainment on television

Listen to classical music

Go to art galleries or museums

Go to the cinema

Read novels Definitely yes Probably yes

Probably not Definitely not

Read non-fiction books

Go to the theater

Go to concerts

Play musical instruments

Go for evening or daytime classes

Attend church activities

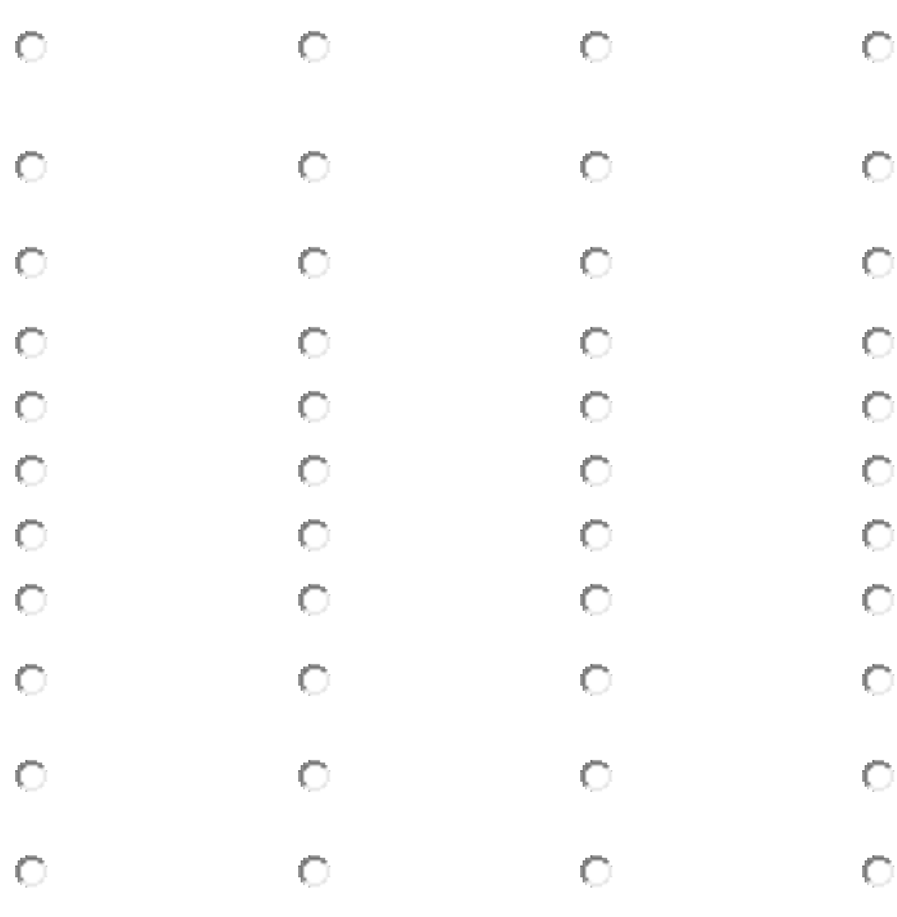

If your parents (adults you live with) listen to music, what kind of music do they listen to? 
Do you attend music classes? How frequently do you attend classes?

Do you play a musical instrument? Please choose appropriate answer.

$\Gamma$ Piano (Please state grade)

Г Guitar

$\Gamma$ Violin

Г Drums

$\ulcorner$ Others (Please specify)

Do you attend arts class? How frequently do you attend classes?

How often did you attend tuition classes in a week?

Once a week

Twice a week

Three times a week

More than four times a week

What subjects did you attend tuition classes for?

E English

$\ulcorner$ Bahasa Melayu

ए Mathematics

$\Gamma$ Accounting

$\ulcorner$ Additional Mathematics

$\Gamma$ Physics

$\Gamma$ Chemistry

$\Gamma$ Others (please specify) 


\section{Appendix C: Structured interview questions (First year foundation students)}

\section{Prompts for Interview Questions (Newly enrolled students)}

\section{Theme 1: Perception}

1. Why did you choose this university as your choice for study?

2. How did you come to take this course?

3. What do expect to get out of the course?

Theme 2: Participation in community service, clubs and voluntary activities

Pre-Service

1. Have you participated in any community service, clubs or voluntary activities in high school?

2. What kind of activities did you participate in?

3. What type of activities did you sign up for this semester?

4. Why did you decide to join the activities you chose?

Post-Service (to be asked after the period of study)

1. Could you describe your experience after participating in extracurricular activities?

2. What type of activities do you consider as valuable for you?

Theme 3: Questions arising from other areas of interest 


\section{Appendix D: Structured interview questions (Third year students)}

\section{Theme 1: Perception}

1. Has your expectations of the course changed since the first time you joined?

2. How do you feel about the whole experience of being in university?

3. Has the experience been beneficial? How? If answer is in the negative, why?

4. Has your experience in university changed in any way compared to the first day you enrolled?

5. Did you enjoy the experience you have had so far?

Theme 2: Participation and engagement in community Service, clubs or voluntary activities

\section{Pre- Service}

1. Have you ever participated in community service?

2. How often do you participate in community service activities/projects?

3. If so, what kind of activities did you do? How did you feel about your efforts in this activity?

\section{Post-Service}

4. Could you describe your experience after participating in extracurricular activities?

5. What type of activities do you consider as valuable for you?

6. In what ways do you think community service can enhance your education? (For example, how can it broaden your knowledge of diversity, career choices, or social awareness?)

\section{Theme 3: Questions arising from other areas of interest}




\section{Appendix E: Focus groups questions}

\section{Prompts for interview questions}

1. What do you think is the most important aspect of doing a community service project? Probe: How would you describe your experience? How has it helped/hindered your experience in university?

2. What are some of the issues in the community which concern you? How do you imagine yourself contributing to solving these issues while in university?

Probe: Could you explain what you mean? Can you share your thoughts?

3. Describe your community service experience. On a scale from 1-10 (10 being the highest), what would you rate the experience?

Probe: Why? What did you like best and what would you do differently?

4. a) What impact did the service project have on you, both individually and as part of the group?

b) Has your involvement with these activities influenced your university experience?

If it did, please share your thoughts and experience with us.

Probe: How did it help? Why do you say so? Can you note any changes?

5. What new information did you learn about your experience with community work?

Probe: What did you learn? How have you used this knowledge when participating in other university activities/in class? Two sub questions to try and elicit as much information as possible.

6. Two sub questions to try and elicit as much information as possible.

a) Now that you have been involved in the community, would you participate in volunteer work in the future? Why or why not?

b) For those who were not involved in any community service, clubs or voluntary activities, could you please share what type of activities you participated in during the period of one semester? (Hopefully this question can capture possible list of activities which are deemed important in their lives and how it contributes to their university experience, if any). 


\section{Appendix F: Focus group interview schedule}

1. The researcher will then hand out butcher paper to the group and ask them to divide the paper into sections. Each participant 'owns' a section of the paper, which they use to write their feelings/ responses to the questions asked during the session. Participants are asked to write down their names (or they can write aliases) if uncomfortable with revealing their name in each of their columns so a record of their statements can be kept. (For questions 1 \& 2)

E.g.

\begin{tabular}{|l|l|}
\hline Jane & Joyce \\
\hline Joe & \\
\hline & \\
\hline & \\
\hline
\end{tabular}

2. Once the second activity is over, participants will be given a conversation bubble, where they need to fill in the 'bubbles' with their opinion or responses to the question posed by the researcher. They can brainstorm, or exchange ideas, and write as many responses in the conversation bubble as they like. This will enable the researcher to gain insights into their interaction within the group and elicit as many responses as they are able to provide regarding the issue. (Questions 3, 4 \& 5)

E.g. 


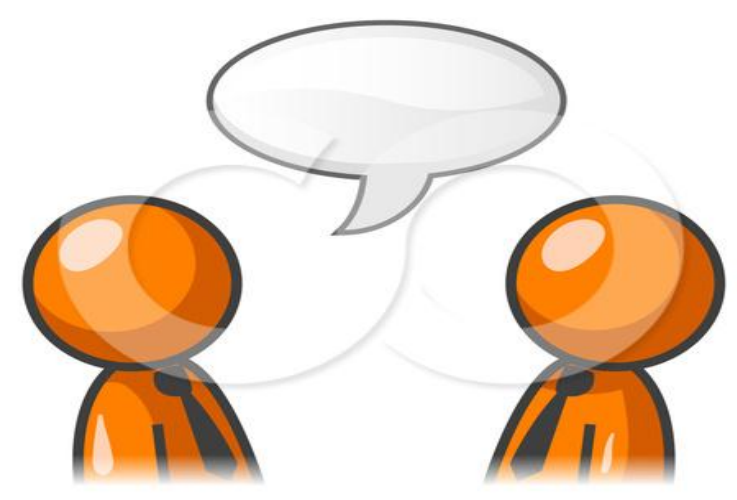

(ㅇ) Leo Blanchette * www.ClipartOf.com/17706

3. Students are given coloured papers or post it notes to record their responses. Students brainstorm and write their responses on a concept map (they can design their own and be as creative as they want or they can just come up with a simple concept map). (Note: Prepare magic markers, markers, different coloured A4 papers/sticky notes for participants to use). For Question 6.

E.g.

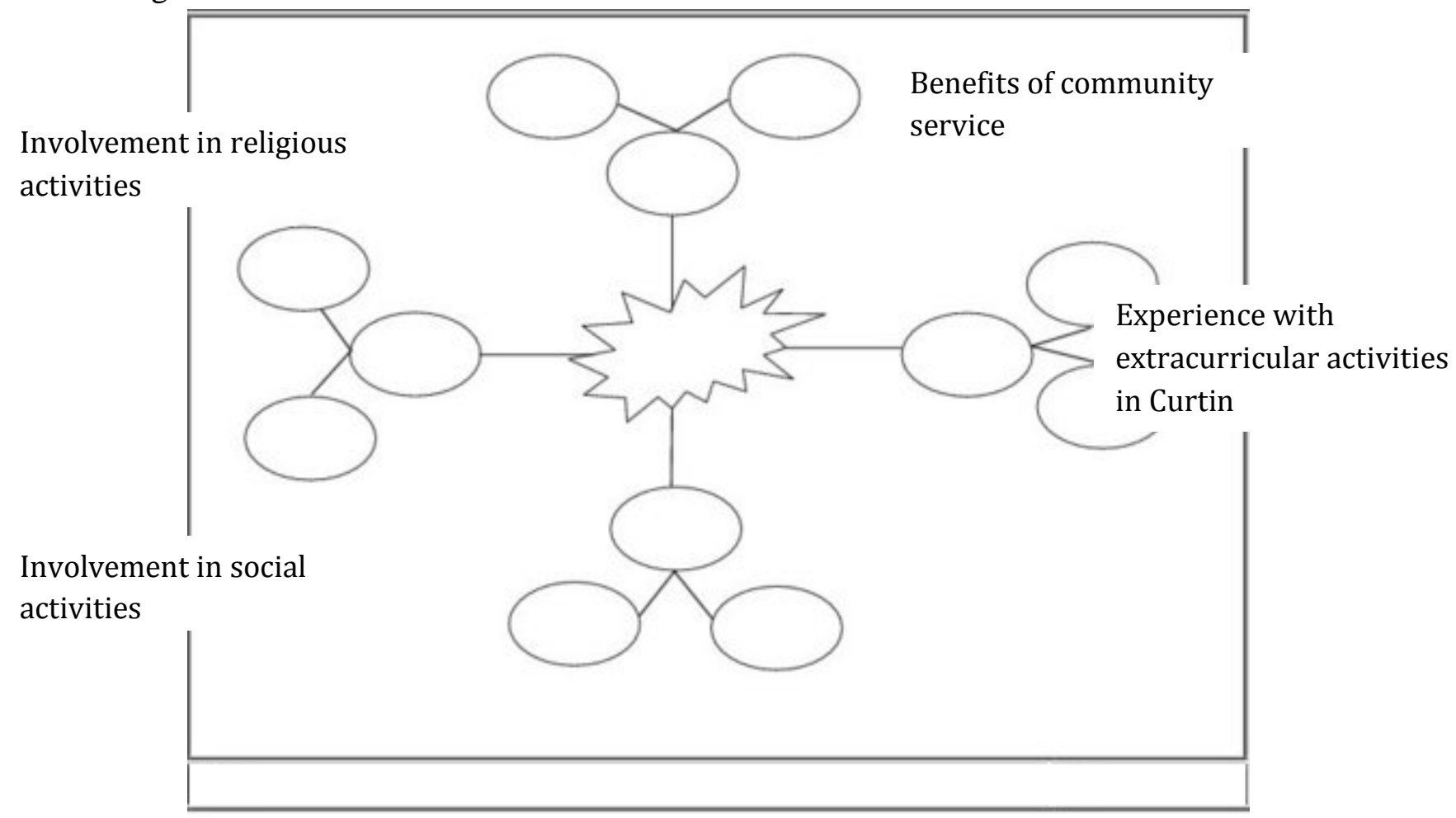




\section{Appendix G: Instruction sheet for photo diary project}

\section{VICTORIA UNIVERSITY OF WELLINGTON \\ Te Whare Wananga o te Upoko o te Ika a Maui

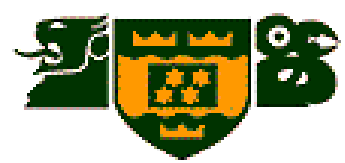

Thank you for volunteering to be a part of this research. Your participation and involvement is appreciated and will enable the researcher to obtain valuable data to be used in her $\mathrm{PhD}$ thesis.

Please note a few items of importance that must be discussed before we can embark on this project.

\section{Purpose:}

This Photo Diary project is done as part of the researcher's data collection method. It is aimed at identifying what kind of activities you participate in outside of the classroom environment, which you feel benefits your learning or adds on to the value of your learning experience in university. This project will look at your involvement in community work, clubs or voluntary activities which you will participate in during the period of one semester. In this project, I would like to invite you to become a researcher and contribute towards building the body of knowledge on community work, clubs and voluntary service in a Malaysian environment. This project serves to document, in your viewpoint, the activities which you judge will have a significant impact on your experience in university. It will also be a "lens" to enable me to understand how you view your world, the people around it, and the activities and interactions you consider as important in your university life.

\section{Materials:}

You will be asked to take photographs of the community work activities, clubs or volunteer activities you will participate in. You will have to use your own personal cameras to take photographs during these activities. You may use either a compact camera, a digital single lens reflex camera or your camera phones to record any activities you feel are significant or important to you. 


\section{Guidelines:}

1. Please ENSURE that the privacy of the individuals participating in the activities are protected.

2. DO NOT take photographs of people involved in the activities WITHOUT their permission.

3. Should you wish to include people in the photographs, please MAKE SURE they are not identifiable or recognizable in any way, shape or form. You may edit the photos you have taken should you realize the people in the photographs CAN BE IDENTIFIED. Please do NOT take pictures of any individual faces (both of adults and children) as this can be a breach of privacy.

4. Be as creative as you can when taking the photographs to ensure the individuals privacy and anonymity is protected.

5. Photographs that contain images of people used in the study will not be reproduced or displayed in the thesis or in any documents placed in any public domain (e.g. conference papers, journal articles). 